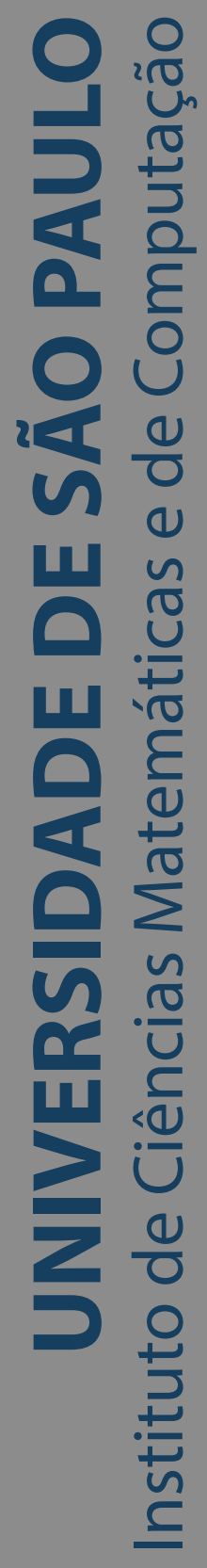

\title{
Detecção e análise de sinais EEG com aplicação em robótica
} educacional

\section{Adam Henrique Moreira Pinto}

Tese de Doutorado do Programa de Pós-Graduação em Ciências de Computação e Matemática Computacional (PPG-CCMC) 

Assinatura:

\title{
Adam Henrique Moreira Pinto
}

\section{Detecção e análise de sinais EEG com aplicação em robótica educacional}

\author{
Tese apresentada ao Instituto de Ciências \\ Matemáticas e de Computação - ICMC-USP, \\ como parte dos requisitos para obtenção do título \\ de Doutor em Ciências - Ciências de Computação e \\ Matemática Computacional. VERSÃO REVISADA \\ Área de Concentração: Ciências de Computação e \\ Matemática Computacional \\ Orientadora: Profa. Dra. Roseli Aparecida \\ Francelin Romero
}


Ficha catalográfica elaborada pela Biblioteca Prof. Achille Bassi e Seção Técnica de Informática, ICMC/USP, com os dados inseridos pelo(a) autor(a)

Moreira Pinto, Adam Henrique Detecção e análise de sinais EEG com aplicação em robótica educacional / Adam Henrique Moreira Pinto; orientadora Roseli Aparecida Francelin Romero. -São Carlos, 2020 .

$159 \mathrm{p}$.

Tese (Doutorado - Programa de Pós-Graduação em Ciências de Computação e Matemática Computacional) Instituto de Ciências Matemáticas e de Computação, Universidade de São Paulo, 2020 .

1. Interfaces Cérebro-Computador. 2. Interação Homem-Máquina. 3. Robótica Educacional. 4. ErrP. I. Francelin Romero, Roseli Aparecida, orient. II. Título. 


\section{Adam Henrique Moreira Pinto}

\section{EEG signal detection and analysis with application in educational robotics}

Thesis submitted to the Institute of Mathematics and Computer Sciences - ICMC-USP - in accordance with the requirements of the Computer and Mathematical Sciences Graduate Program, for the degree of Doctor in Science. FINAL VERSION

Concentration Area: Computer Science and Computational Mathematics

Advisor: Profa. Dra. Roseli Aparecida Francelin Romero

USP - São Carlos

February 2020 

Este trabalho é dedicado aqueles que modificam a sua maneira de pensar, para conseguir resolver os problemas causados pela forma como vemos o mundo. A Deus, a minha família (aos que se foram e aos que ainda estão) e a todos aqueles que passaram pelo meu caminho, contribuindo para eu me tornar quem eu sou hoje. 

Oito anos é muito tempo. Na minha jornada de vida, o maior que passei em algum lugar. Encerro mais um ciclo da minha vida sabendo que é impossível ser justo com todo esse tempo. Foram muitas pessoas que passaram por mim, muitas vidas que fizeram e ainda fazem diferença. Tanto que ainda nem sei como agradecer a todas elas. É uma imensa satisfação ter feito a diferença em tantas vidas, e ter a minha própria modificada por tanta gente. Aqui, terei que falar em grupos, e mesmo assim vou esquecer alguém, mas a todos o meu mais sincero muito obrigado.

Primeiramente e acima de tudo, agradeço a Deus, meu guia, minha força, minha esperança. É com Ele que converso todas as manhãs, que pergunto todas as minhas dúvidas e deposito toda a minha fé.

Á minha família, meus pais e irmãos Renata, Josué, Renan e Júnior. Eu tive um lar, eu tive paz, eu tive segurança, eu tive exemplo. Tem coisas que se aprende do berço, tem sacrifícios sem cobrança, tenho base para ser quem eu sou. Vovó Filomena, a senhora não conseguiu ver seu primeiro neto doutor, mas essa conquista é em sua homenagem.

À minha namorada Iara, um amor que era improvável e se tornou infinito. Essa conquista também é sua, por me aguentar nos piores momentos e ser forte quando eu não consegui ser. Você sabe, e nós sabemos que é recíproco.

Á minha orientadora, Roseli Romero, que me resgatou quando eu me perdi, que me cobrou quando eu quase desisti e que me apoiou e deu forças para eu conseguir. À todos os meus professores, que me ensinaram desde ler as primeiras letras até a resolver as equações mais complexas. Em especial, agradeço aos professores da Universidade de São Paulo, sempre dispostos a ajudar em qualquer dúvida. Houve sorrisos, houve bronca, houve churrasco e houve aprendizado.

Aos amigos do laboratório LAR/Biocom (Alface, Mega, Marcelão, Du, Champz, Nards, Zé, Doente, Cobertinha, Vitinho, Montanari, Mantovani, Barella, Saulo, Gean, David, Edésio, Daniel, Moises, Henrique, Forninho, Kamila, Chefe, Ever, Jeffinho, Gordillian, Valéria, Doug) que diariamente aguentaram minhas piadas ruins, meus socos na mesa, minhas perguntas idiotas. Foram muitas pausas para café, foram estudos em Computer Science, foram rodas de conversa no Seo Gera e no bandejão. Aprendi com grandes cientistas, convivi com grandes pessoas. Em especial, agradeço ao Daniel Tozadore, que formou comigo a dupla dinâmica, e juntos estamos tornando realidade os nossos sonhos do começo dessa jornada. 
Á todos aqueles que fizeram parte da minha segunda casa, o Warthog Robotics (Lang, Vareta, Bolacha, Joinha, Bacon, TT, Lukão, Lolo, Paks, X, Xitão, XXT, Leo, Fred, Faraó, Bahia, Apostolo, Nuno, Pedro, Diretor, Micuim, Pedrão, Estrela, Pedreiro, Nicão, Xandão, Torugo, Leo, Acra, Dom, Paula, Gi, Menininha, Willy, Pooh, Gemios, Bene, Dani, Gulol, Xurilo, Ana, Malu, Plínio, Mormaço, Mcloving, Arrombado, Henry, Gustavo, Megid, Pajé, Marco, Isis, Pedrin, Produça, Smith, Eta, Mega2 e mais tantos outros). Entre idas no turbo e decisões importantes como a quantidade de carros, crescemos, jogamos, vencemos. Somos bi-campeões latino-americanos, somos o maior grupo de robótica do país. Realizei alguns sonhos com essa turma, meu time será sempre o WR. E sempre me lembrarei que nada é de graça, provavelmente eu mereci.

À todo pessoal do IIN-ELLS, experiência fantástica que eu jamais vou esquecer. Me salvaram com a minha base de dados, me ensinaram muitas coisas, até o que fazer no caso de um assalto.

Aos grandes atletas que, junto comigo, mostraram muita Raça CAASO e foram o melhor time de futsal universitário. Aos grandes atletas que honraram meu Bulldogaum e mostraram a força do Flag em São Carlos. Aos atletas de sexta, de quarta, de segunda, que eram a minha válvula de escape durante todos esses anos. Tenho muitas conquistas, tenho muita história com vocês.

Conheci muita gente em vários cantos do mundo, com quem convivi mais ou menos tempo. Não me atrevo a tentar listar nem as cidades, porque numa conversa de corredor, numa discussão em competição, numa apresentação de um colega que muitas ideias surgem. São realmente muitas pessoas, a quem queria conseguir passar um a um e dar um abraço, um pão-de-queijo e dizer meu eterno muito obrigado.

E para mostrar que último não significa menos importante, tenho uma grande base da graduação que ainda é forte, com que fui em carnavais, em festivais, em congressos... São pessoas em quem eu confio, são pessoas pra quem eu sempre vou estender a mão, seja para pedir ou para oferecer ajuda, e sei que nunca vou conseguir agradecer o suficiente.

Agradeço também a FAPESP e a CAPES pelo apoio financeiro. 
"Cada letra, cada vírgula, cada pingo escrito, são o caminho que me trouxe a este ponto final."

(Próprio Autor) 



\section{RESUMO}

PINTO, A. H. M. Detecção e análise de sinais EEG com aplicação em robótica educacional. 2020. 159 p. Tese (Doutorado em Ciências - Ciências de Computação e Matemática Computacional) - Instituto de Ciências Matemáticas e de Computação, Universidade de São Paulo, São Carlos - SP, 2020.

Com a tecnologia, existem muitas formas de se aprimorar o aprendizado, mesmo fora da sala de aula. Sistemas educacionais têm sido bastante empregados para essa finalidade, inclusive com o uso de robôs, mas ainda pecam em alguns aspectos de interação com os humanos. As interfaces cérebro-computador (BCI) são sistemas que permitem a comunicação entre usuário e computador a partir de informações do cérebro, podendo dar mais robustez aos sistemas robóticos educacionais. As dificuldades dos alunos são claras durantes provas e outras atividades de avaliação, o problema são os erros durante os estudos para essas provas. Para ajudar neste ponto do aprendizado, foi utilizado um sinal evocado no cérebro relacionado à percepção do erro por um usuário, chamado de Error Related Potential (ErrP), que pode ser medido no EEG, uma forma não-invasiva de BCI. Porém, esses sistemas ainda pecam na qualidade do sinal obtido e na acurácia em encontrar esses momentos de erro. Neste trabalho, foi proposto um sistema de detecção do ErrP, passando pela filtragem, extração de características e classificação do sinal. O pré-processamento do sinal passou por filtros FIR e ICA para limpeza de ruídos e artefatos, foram criados vetores de características com as transformadas de Fourier e as famílias Haar e Daucechies de transformadas wavelets. Para classificação, foram comparadas redes neurais (MLP) e de aprendizado profundo (CNN). Os resultados demonstraram uma acurácia de 96\% quando o sinal foi aplicado na base criada, e de 77,23\% quando aplicada a toda a rede, mostrando ser promissora para utilização em sistemas educacionais. Além disso, mostrou que a diferença entre as famílias wavelets apresentadas neste trabalho foram pequenas, e que sua escolha pode ser feita considerando o tempo para processamento do sinal. Este trabalho serve como um módulo para um sistema educacional maior, que visa preencher algumas lacunas encontradas nos trabalhos disponíveis.

Palavras-chave: Interfaces Cérebro-Computador, Interação Homem-Máquina, Robótica Educacional, ErrP. 



\section{ABSTRACT}

PINTO, A. H. M. EEG signal detection and analysis with application in educational robotics. 2020. 159 p. Tese (Doutorado em Ciências - Ciências de Computação e Matemática Computacional) - Instituto de Ciências Matemáticas e de Computação, Universidade de São Paulo, São Carlos - SP, 2020.

With technology, there are many ways to improve learning, even outside the classroom. Educational systems have long been employed for this purpose, including the use of robots, but there are still a lack in some aspects of human interaction. Brain-computer interfaces (BCI) are systems that allow communication between user and computer from brain information, and can give more robustness to educational robotic systems. Students difficulties are clear during tests and other assessment activities, the problem is errors during the studies and preparation for these tests. To help with learning, a brain-evoked signal related to a user's perception of error, called Error Related Potential (ErrP), was used, which can be measured in EEG, a noninvasive form of BCI. However, these systems still lack the quality of the signal obtained and the accuracy of finding these Errp signals. In this work, a ErrP detection system was proposed, including filtering, feature extraction and signal classification. The preprocessing of the signal went through FIR and ICA filters for noise and artifact cleaning, feature vectors were created with the Fourier transforms and the Haar and Daubechies families of wavelet transforms. For classification, neural networks (MLP) and deep learning networks (CNN) were compared. The results showed an accuracy of $96 \%$ when the signal was applied to the base created, and 77,23\% when applied to the whole database, showing to be promising for use in educational systems. Moreover, it showed that the difference between the wavelet families presented in this work were small, and that their choice can be made considering the time for signal processing. This proposal works as a module for a larger education system, which aims to fill in some of the gaps found in the available work.

Keywords: Brain-Computer Interfaces (BCI), Human-Robot Interaction (HRI), Educational Robotics, Error Related Potentials . 



\section{LISTA DE ILUSTRAÇÕES}

Figura 1 - Arquitetura de um sistema BCI . . . . . . . . . . . . . . . . . 29

Figura 2 - Arquitetura geral do sistema proposto . . . . . . . . . . . 30

Figura 3 - O Neurônio não-linear. . . . . . . . . . . . . . . . . . . 65

Figura 4 - Arquitetura da Rede Neural MLP . . . . . . . . . . . . . . . 67

Figura 5 - Célula de memória da LSTM . . . . . . . . . . . . 70

Figura 6 - LSTM e GRU . . . . . . . . . . . . . . . 71

Figura 7 - Exemplo de uma rede convolucional para reconhecimento de dígitos . . . 71

Figura 8 - Exemplo de convolução em uma "imagem" usando um kernel 2x2 . . . . 72

Figura 9 - Exemplo do max-pooling, considerando uma região em quatro quadrantes . 73

Figura 10 - CNN proposta neste trabalho . . . . . . . . . . . . . . 74

Figura 11 - Primeiro experimento deste trabalho . . . . . . . . . . . . . . 76

Figura 12 - Arquitetura R-CASTLE . . . . . . . . . . . . . . . . . . . . 79

Figura 13 - Usuário participando do Jokempô . . . . . . . . . . . . . . . . . . . . 83

Figura 14 - Usuário participando do reconhecimento de emoções . . . . . . . . . . 83

Figura 15 - Arquitetura da parte de reconhecimento . . . . . . . . . . . . . 86

Figura 16 - Jogo Proposto nesta tese . . . . . . . . . . . . . . . . 87

Figura 17 - Tela do jogo criado para esta tese . . . . . . . . . . . . . . . 88

Figura 18 - Headset OpenBCI R \& D . . . . . . . . . . . . . . . . . . . . . . 92

Figura 19 - Headset ActiCAP . . . . . . . . . . . . . . . . . . . 93

Figura 20 - Processo de diminuição da impedância . . . . . . . . . . . . . . . . . . . 94

Figura 21 - Distribuição corpórea do robô NAO . . . . . . . . . . . . . . . . . . . 96

Figura 22 - Exemplo do dataset da literatura . . . . . . . . . . . . . . . . . . . 98

Figura 23 - Exemplo do dataset da literatura (jogo) . . . . . . . . . . . . . . . . . . 99

Figura 24 - Eletrodos escolhidos neste trabalho . . . . . . . . . . . . . 100

Figura 25 - Mudanças do jogo nos últimos 5 segundos . . . . . . . . . . . . . . 102

Figura 26 - Tela de encerramento . . . . . . . . . . . . . . . . . . . 103

Figura 27 - Momento de interação do robô NAO com um jogador . . . . . . . . . . . . 104

Figura 28 - Média da pontuação na escala Likert ～. . . . . . . . . . . . . . . 107

Figura 29 - Exemplo do sinal puro e no domínio de frequência . . . . . . . . . . . . 110

Figura 30 - Exemplo do sinal filtrado e no domínio de frequência . . . . . . . . . . . . 110

Figura 31 - Exemplo do resultado da clusterização da piscada de olho . . . . . . . . . . 111

Figura 32 - Dois exemplos de ondas das bases da internet . . . . . . . . . . . . 113

Figura 33 - Novas janelas com sinais de ErrP . . . . . . . . . . . . . . . . . 115 
Figura 34 - Novas janelas com sinais normais . . . . . . . . . . . . . . . . . . . . . . . . . 115

Figura 35 - Diferenças nos sinais de erros . . . . . . . . . . . . . . 117

Figura 36 - Exemplos de sinais obtidos do jogo proposto . . . . . . . . . . . . . 118

Figura 37 - Wavelet Daubechies aplicadas ao conjunto de dados. . . . . . . . . . . . . 120

Figura 38 - Estudante participando na etapa de jogo . . . . . . . . . . . . 122

Figura 39 - Software do OpenBCI . . . . . . . . . . . . . . . . 122

Figura 40 - Sinais durante a interação com o robô . . . . . . . . . . . . . . . . . . . . . . . . . . . . . . . . 123

Figura 41 - Separação dos lóbulos cerebrais. . . . . . . . . . . . . . . . . 143

Figura 42 - Sistema internacional de posicionamento 10-20 . . . . . . . . . . . 146

Figura 43 - Headset NeuroSky MindWave . . . . . . . . . . . . . . . . . . . . . . . . . . . . . . . . . . . . . . . .

Figura 44 - Headset EMOTIV Epoc . . . . . . . . . . . . . . . . . . . . . . . . . . . . . . . . . . . . . . . . . . . . . . . . . . .

Figura 45 - SVM Hiperplano separador . . . . . . . . . . . . . . 156 
Tabela 1 - Resultados de (TANAKA; GHOSH, 2011) . . . . . . . . . . . . . 39

Tabela 2 - Arquitetura das redes profundas utilizada neste trabalho . . . . . . . . . 73

Tabela 3 - Teste pareado de Wilcoxon para cada item dos dois grupos . . . . . . . 108

Tabela 4 - Porcentagem de emoções corretas . . . . . . . . . . . . . . . . 108

Tabela 5 - Média da energia relativa . . . . . . . . . . . . . . 112

Tabela 6 - Convergência utilizando a primeira janela . . . . . . . . . . . . . . . . . . . . . . . . . . .

Tabela 7 - Convergência utilizando a segunda janela . . . . . . . . . . . 116

Tabela 8 - Média da acurácia usando todos os métodos de extração . . . . . . . . 116

Tabela 9 - Média da acurácia dos classificadores . . . . . . . . . . . . . . . 119

Tabela 10 - Comparação de todos os extratores e classificadores . . . . . . . . . . . . 121

Tabela 11 - Resultado ruim com o capacete de pior qualidade . . . . . . . . . . . . 123

Tabela 12 - Uma comparação dos algoritmos mais utilizados em BCI . . . . . . . . . 159 



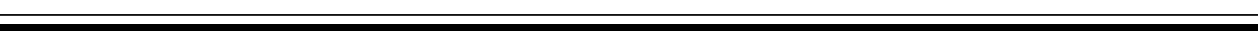

ANN Artificial Neural Networks

ANN Artificial Neural Network

BCI Brain-Computer Interface

BSS Blind Source Separation

CC Cross-Correlation

CNN Convolutional Neural Networks

CSP Common Spatial Patterns

DCT Discrete Cosine Transformation

DEA Distúrbio do Espectro Autista

DFT Discrete Fourier Transform

ECG Eletrocardiograma

EEG eletroencefalograma

EMG Eletromiograma

EOG Eletrooculograma

EP Evoked Potentials

ERD Event Related Desychronization

ERN Error Related Negativity

ERP Event-Related Potential

ERS Event Related Sychronization

FFT Fast Fourier Transform

FGW First Generation Wavelets

FIR Finite Impulse Response

HMM Hidden Markov Model

HRI Human Robot Interaction

HT Hilbert Transform

ICA Independent Component Analysis

IDE Integrated Development Environment

IIR Infinite Impulse Response

IQR Inter Quartile Range

KKT Karush-Kuhn-Tucker

kNN $\quad k$-Nearest Neighbors 
LDA Linear Discriminative Analysis

LSTM Long Short-Term Memory Network

LVQNN Learning Vector Quantization Neural Network

MAD Median Absolute Deviation

MLP Multi Layer Perceptron

PLV Phase Locking Value

PSD Power Spectral Density

PSD Power Spectral Density

QMF Quadrature Mirror Filters

R-CASTLE Robotic-Cognitive Adaptative System for Teaching and Learning

RBF Radial Basis Function

RNN Recorrent Neural Network

SDK Software Development Kit

SFS Sequential Feature Selection

SLT Statistical Learning Theory

SOA Stimulus-onset asynchrony

STEM Science, Technology, Engineering, and Mathematics

STFT Short Time Fourier Transform

SVM Support Vector Machines

SVM Support Vector Machines

TEA Transtorno do Espectro Autista

WoZ Wizard-of-Oz 


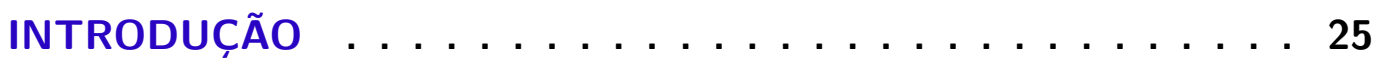

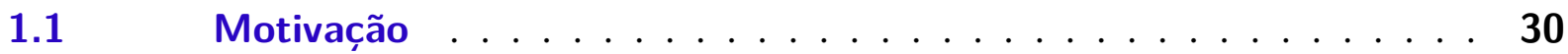

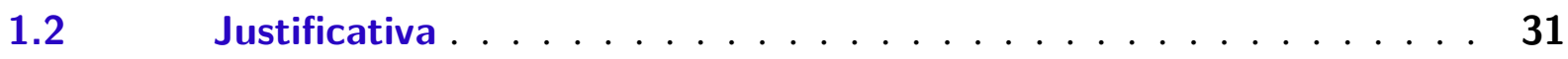

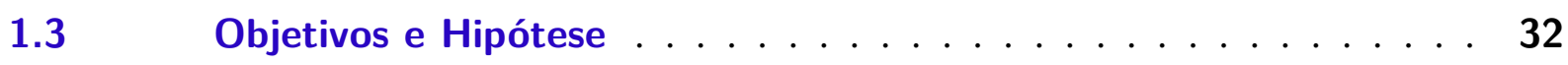

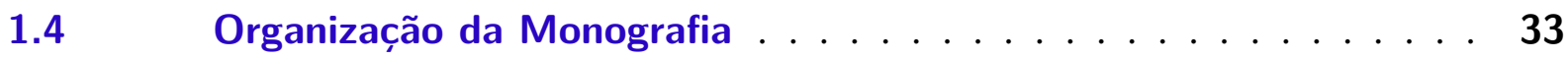

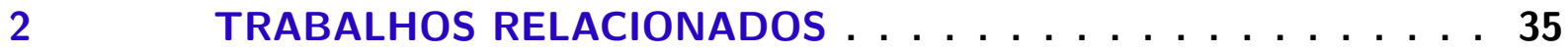

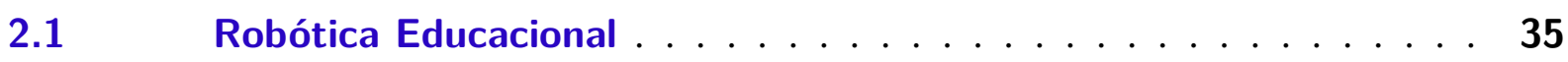

2.2 Trabalhos em Human-Robot Interaction (HRI) $\ldots \ldots \ldots . \ldots 37$

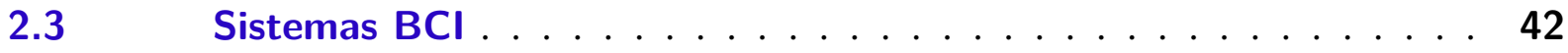

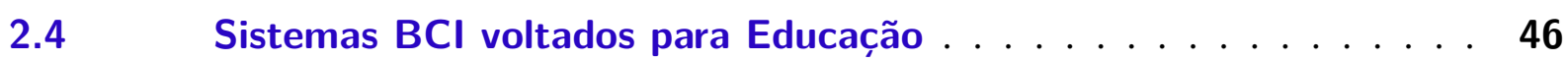

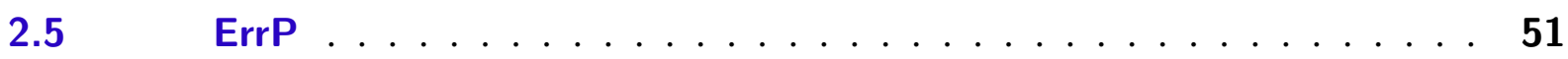

$2.6 \quad$ Considerações Finais $\ldots \ldots \ldots \ldots \ldots \ldots \ldots$

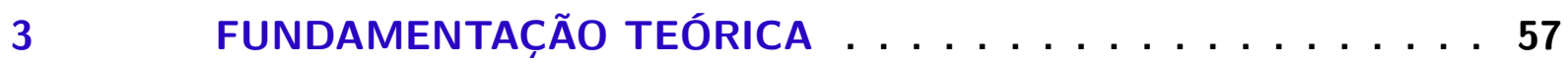

$3.1 \quad$ Filtragem Digital $\ldots \ldots \ldots \ldots \ldots \ldots \ldots$

3.1.1 Temporais . . . . . . . . . . . . . . . . . . . 57

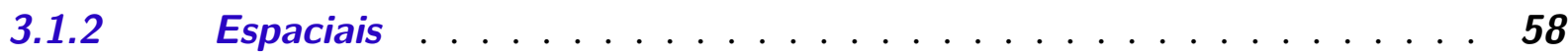

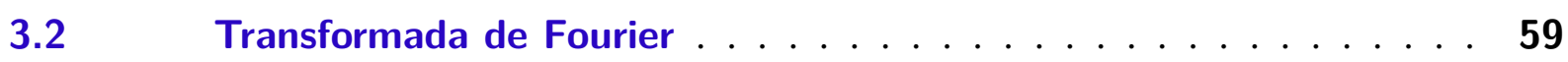

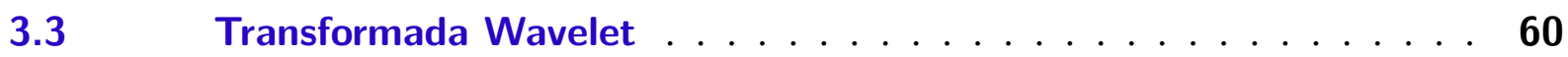

3.3.1 Transformada Haar . . . . . . . . . . . . . . . 61

3.3.2 Transformada de Daubechies . . . . . . . . . . . . . . 62

$3.4 \quad$ Independent Component Analysis - ICA . . . . . . . . . 62

$3.5 \quad$ Classificadores . . . . . . . . . . . . . . . . . . . . . 64

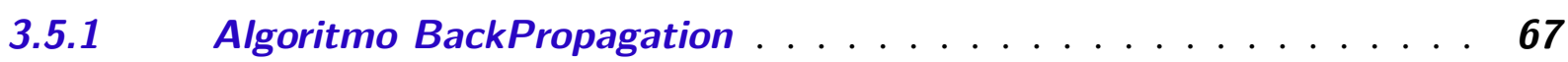

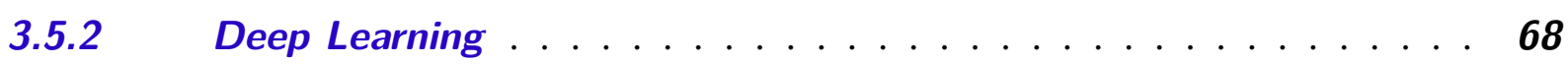

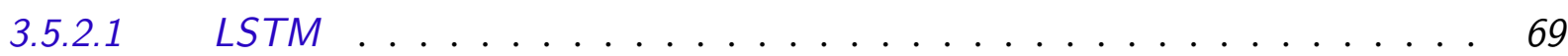

3.5.3 Convolutional Neuronal Networks - CNN . . . . . . . . . . . 71

3.5.3.1 Convoluções . . . . . . . . . . . . . . . . . . . . . 71

$3.6 \quad$ Considerações Finais $\ldots \ldots \ldots \ldots \ldots$

4 SISTEMA PARA DETECCุÃO E CLASSIFICAÇÃO DE SINAIS ERRP 75

4.1 Definindo os problemas dos sistemas educativos . . . . . . . 75

4.2 R-CASTLE - Sistema Adaptativo para Ensino e Aprendizado . . . 78 
4.2.1 Sistema Adaptativo do R-CASTLE . . . . . . . . . . . . . . 80

4.2.2 Integração do sistema proposto com o R-CASTLE . . . . . . . . . . 82

4.2.3 Inserindo emoções no sistema adaptativo . . . . . . . . . . . . . . 82

$4.3 \quad$ Arquitetura do sistema para reconhecimento de ErrP . . . . . . 85

4.3.1 Definindo o jogo . . . . . . . . . . . . . . . . 87

$4.4 \quad$ Considerações Finais . . . . . . . . . . . . . . . . . 88

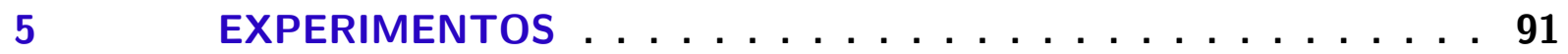

$5.1 \quad$ Materiais . . . . . . . . . . . . . . . . . 91

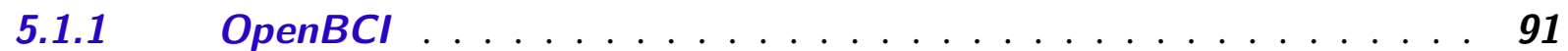

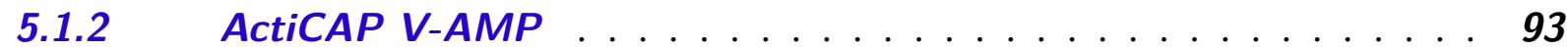

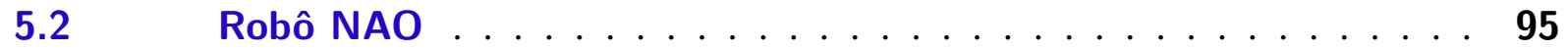

$5.3 \quad$ Experimentos com as bases de dados da literatura . . . . . . . . . 97

$5.4 \quad$ Experimentos com o jogo proposto . . . . . . . . . . . 100

5.4.1 Etapa de Calibração . . . . . . . . . . . . . . . . . . . . 100

5.4.2 Etapa real de jogo . . . . . . . . . . . . . . . . . . 101

$5.5 \quad$ Interação com o Robô NAO . . . . . . . . . . . . . . . . . 102

5.6 Considerações Finais . . . . . . . . . . . . 105

6 RESULTADOS E DISCUSSÃO . . . . . . . . . . . . . . 107

6.1 Reconhecimento de emoções - R-CASTLE . . . . . . . . . . . 107

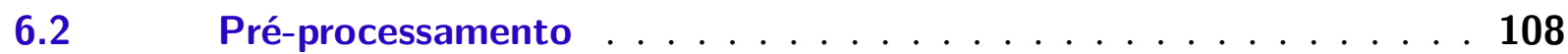

6.2.1 Piscar dos olhos . . . . . . . . . . . . . . . 109

$6.3 \quad$ Base da literatura . . . . . . . . . . . . . . . 112

$6.4 \quad$ Base criada . . . . . . . . . . . . . . . . 118

$6.5 \quad$ Considerações Finais . . . . . . . . . . . . . . . . 124

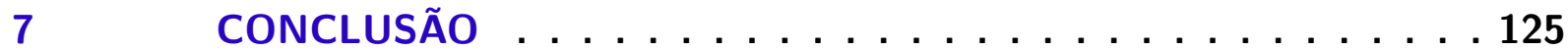

REFERÊNCIAS . . . . . . . . . . . . . . . . . 129

APÊNDICE A INFORMAC̣ÕES ADICIONAIS ......... 143

A.1 Anatomia do Cérebro . . . . . . . . . . . . . . 143

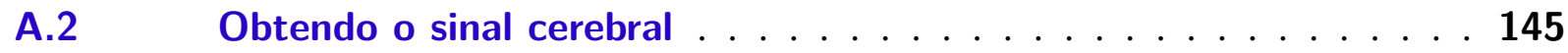

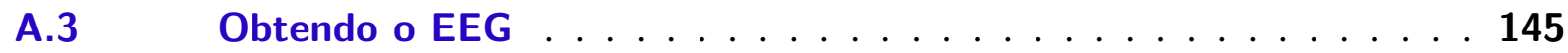

A.4 Dispositivos comerciais para captação do sinal EEG . . . . . . . . 147

A.4.1 NeuroSky MindWave . . . . . . . . . . . . . . . . . . . 147

A.4.2 EMOTIV Epoc . . . . . . . . . . . . . . . . . . 148

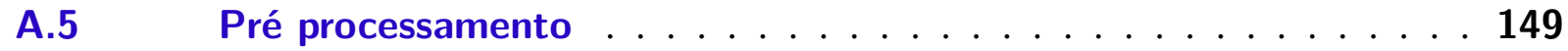

A.5.1 Filtros Temporais ................... 150 
A.5.2 Filtros Espaciais . . . . . . . . . . . . . . . . 150

A.5.3 Outras Soluções . . . . . . . . . . . . . . . . . . . 150

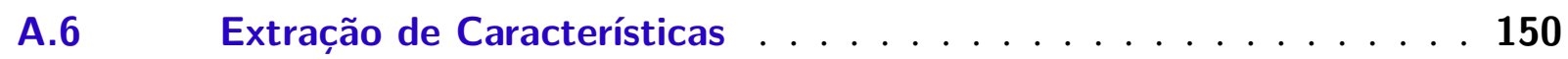

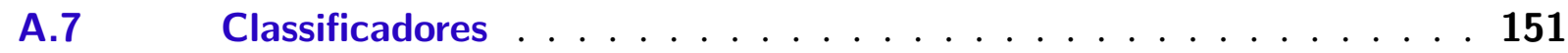

A.7.1 Conjuntos $K$ de Freeman . . . . . . . . . . . . . . . . 152

A.7.1.1 Aprendizado do KIII . . . . . . . . . . . . . . . . . . . . . . . . 154

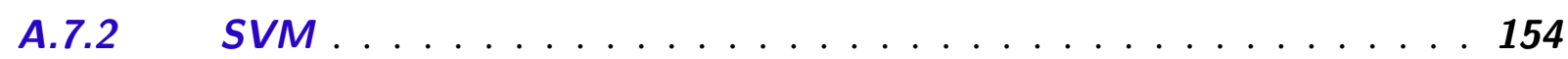

A.7.2.1 SVM Multiclasse . . . . . . . . . . . . . . . . . . . . . . 156

A.8 Construindo um sistema $\mathrm{BCl} \ldots \ldots$. . . . . . . . . . . . . . . 157

A.8.1 Os maiores problemas em classificação de $B C l s \ldots \ldots$. . . . . . 157 

Com o avanço tecnológico, diversas atividades passaram a ser feitas com a ajuda de dispositivos eletrônicos (como celulares e tablets), softwares específicos e até mesmo robôs (com diversas características, como os robôs fixos, humanoides, omnidirecionais e diferenciais). Cada um destes dispositivos tem uma forma diferente de interagir entre si e com os humanos, realizando desde as tarefas mais simples até as mais complexas, sendo encontrados em museus, laboratórios, fábricas e, de forma até mais comum hoje em dia, nas escolas com o papel de educador. Para uma boa aceitação dessas tecnologias, é importante que os sistemas tenham um comportamento mais natural possível para os humanos (BREAZEAL, 2004; GÁCSI et al., 2016), tanto para o tempo de resposta quanto às formas e variações de interação.

Assim como os humanos, esses sistemas precisam de informações do mundo para tomar decisões dos próximos passos. Para a maioria dos casos, estes dados são passados pelo próprio sujeito que interage com o sistema. Em alguns exemplos da literatura (que serão melhor discutidos no Capítulo 2), é utilizada a técnica do Wizard-of-Oz, onde o sistema é controlado por algum pesquisador humano, sem que seja do conhecimento dos participantes do estudo. Sistemas autônomos, entretanto, precisam receber, processar e tomar a decisão sem a intervenção humana (LUGER, 2008; JONES, 2015), usando para isso seus sensores (câmera, sonar, laser, bumpers) e atuadores (tela, LEDs, braços). Neste trabalho, o foco é em sistemas robóticos autônomos. Dedicado à compreensão, concepção e avaliação de sistemas robóticos para uso por ou com seres humanos, um dos campos emergentes com os avanços da robótica é a Human Robot Interaction (HRI).

A tarefa em HRI é entender e moldar as interações entre um ou mais seres humanos e um ou mais robôs (GOODRICH; SCHULTZ, 2007; WOLF et al., 2015). Interações entre seres humanos e robôs são inerentemente presentes em toda a robótica, mesmo para os robôs autônomos, afinal de contas, os robôs ainda são usados pelos seres humanos e estão fazendo o trabalho deles. Para Kelley (1984a), interação é um componente chave de um projeto de HRI 
válido. Como resultado, a avaliação das capacidades dos seres humanos e robôs, e a projeção as tecnologias e formação que produzem interações desejáveis são componentes essenciais da HRI. Esse trabalho é inerentemente interdisciplinar por natureza, exigindo contribuições da ciência cognitiva, linguística, psicologia, engenharia, matemática e ciência da computação; e também de engenharia de fatores humanos. Ainda segundo Goodrich e Schultz (2007), é possível dividir a tarefa da HRI em suas partes constituintes: Autonomia, Estrutura, Natureza da informação, Formato da tarefa e Adaptação do sistema.

Atualmente é comum o uso de robôs como alternativa ou auxílio para o ensino, e as técnicas de HRI tornam os robôs mais adaptativos e com uma comunicação mais próxima da esperado pelos humanos, melhorando o relacionamento do aluno com a máquina. A multidisciplinaridade da robótica permite um aprofundamento em diversos temas, sendo mais comum o seu uso em aulas práticas dos temas abordados em sala de aula. Na robótica educacional, são treinadas novas perspectivas para resolução de problemas usando lógica, criando um novo tipo de aprendizagem (OLIVEIRA, 2007). Sabe-se que o fator novidade contribui muito para a atenção dos alunos quando um robô é colocado em sala de aula. Esse fator deve ser contornado, considerando as interações de longo prazo (Long Term Interaction) (LEITE; MARTINHO; PAIVA, 2013), quando o usuário já se acostumou com a presença do robô, para entender seu real impacto na educação. Além da robótica educacional, existem outros métodos, como jogos sérios ${ }^{1}$, que focam na melhora de aprendizado do aluno fora da sala de aula. A maioria destes sistemas educacionais, entretanto, não trás para o aluno um feedback do foco de atenção no trabalho e principalmente de alguns erros, e não são capazes de se adaptar ao aluno. Neste trabalho, propõe-se um sistema para reconhecer essas informações e avisar ao aluno e professor sobre os erros cometidos, aprimorando a experiência do aluno com os métodos educacionais. Para isso, é importante que o sistema aja de forma natural e seja socialmente aceitável.

Estudos de proxêmica ${ }^{2}$ aplicado à robótica (RIOS-MARTINEZ; SPALANZANI; LAUGIER, 2015) mostram que o ser humano se sente mais confortável quando os robôs agem de forma mais natural. Apesar da grande quantidade de informação que os sensores até aqui mencionados conseguem captar, quando aplicados à educação, ainda é necessário obter uma interação mais próxima do real, segundo nossos estudos prévios (PINTO; TOZADORE; ROMERO, 2015; TOZADORE; PINTO; ROMERO, 2016). Por isso, nesta pesquisa, é proposta uma forma diferente de se obter informações: utilizando uma Interface Cérebro-Computador Brain-Computer Interface (BCI), abordagem que permite a obtenção de informações diretamente do cérebro ${ }^{3}$ da pessoa, para serem processados no computador. A captura dos dados cerebrais é feita de diversas maneiras, o que divide os trabalhos de BCI em:

1 São chamados jogos sérios aqueles que têm intuito maior do que apenas o entretenimento

2 A proxêmica descreve o espaço de indivíduos no meio social. Aplicada à robótica, discute o posicionamento socialmente aceitável de um robô em cada tipo de tarefa.

3 No Apêndice A.1 é discutido um pouco da anatomia do cérebro. 
- Invasiva: quando os eletrodos são implantados cirurgicamente e posicionados diretamente no cérebro, permitindo o registro de neurônios individuais;

- Semi-invasiva: eletrodos são posicionados na superfície do cérebro, também necessitando cirurgia, mas lendo populações de neurônios

- Não-invasiva: foco deste trabalho, faz a medição da atividade de populações de neurônios de forma externa ao corpo. Não necessita de intervenção cirúrgica.

O termo Brain-Computer Interface apareceu pela primeira vez na década de 1970, no trabalho de Vidal (1973), se referindo a obtenção dos sinais elétricos observáveis do cérebro, tratando essas informações para controlar um dispositivo externo. Vidal (1973) utiliza a BCI não invasiva, o que é mais comum na literatura (GRAIMANN; ALLISON; PFURTSCHELLER, 2011). Apesar de ter um sinal mais ruidoso do que as abordagens invasivas, devido à distância física do eletrodo para a fonte do sinal medido, a BCI não-invasiva dispensa a necessidade de equipes médicas, o que garante uma melhor disponibilidade de indivíduos para participação nas pesquisas.

Nestas abordagens, uma das técnicas para obtenção da informação cerebral é a eletroencefalografia, técnica que registra graficamente a diferença de potencial elétrico (ddp) desenvolvidas em populações de neurônios, que são obtidos através de eletrodos posicionados no escalpo. $\mathrm{O}$ sinal obtido pela eletroencefalografia é chamado eletroencefalograma (EEG) ${ }^{4}$. Os primeiros experimentos utilizando EEG, feitos com humanos, datam de 1929 (BERGER, 1929), mas a sua utilização em sistemas de BCI mais complexos (como imagética motora ${ }^{5}$ ou controle de cadeiras de rodas inteligentes) ficou desacreditada. Isso se deve às dificuldades de se extrair características do sinal, dado a grande quantidade de informação e ruído. Porém, a partir da década de 1990, a pesquisa cresceu rapidamente, surgindo inclusive competições envolvendo sistemas BCI não-invasivas, tentando encontrar sistemas mais precisos na interpretação dos sinais (SAJDA et al., 2003). Vários protótipos e aplicações foram propostos para estas competições, na sua maioria em áreas médicas (como em Rebsamen et al. (2007)) e realidade virtual (KREPKI et al., 2007).

Naturalmente, projetar um sistema BCI é uma tarefa que envolve conhecimentos multidisciplinares, como computação, processamento de sinais, psicologia e neurociência. Os sistemas aplicados costumam ser divididos em duas fases: um treinamento offline para calibração do sistema como um todo (se adaptando também as diferenças entre os indivíduos participantes) e uma fase online onde o reconhecimento das atividades e estados cerebrais são traduzidos para

4 A sigla EEG também é utilizada para eletroencefalografia. Como a bibliografia não deixa totalmente claro uma forma correta, será utilizado neste documento a eletroencefalografia como a técnica e o eletroencefalograma como o sinal obtido. A sigla EEG será sempre usada para indicar o eletroencefalograma.

5 Simulação mental do movimento de algum membro do corpo. 
comandos de máquina e execução de alguma tarefa. Essa fase, segundo Pfurtscheller, Flotzinger e Kalcher (1993) e demonstrada na Figura 1, pode ser ainda dividida em mais seis outras fases:

- Obtenção do sinal do cérebro: Consiste no uso de eletrodos para obter os sinais que refletem as atividades cerebrais (o resultado dessa obtenção é o EEG);

- Pré-processamento: Limpeza do sinal obtido, retirando possíveis ruídos causados pelo método não-invasivo de obtenção do sinal, buscando manter apenas as informações relevantes para a tarefa;

- Extração de características: Descrição do sinal limpo em características importantes para a tarefa;

- Classificação: Rotulação das características encontradas, indicando algum tipo de ação que o usuário quer fazer, como mexer o braço, por meio de um dispositivo eletrônico;

- Tradução para comando de máquina: Uma vez definido e rotulado um conjunto de características, um comando precisa ser associado à essa ação para sua execução no sistema;

- Feedback: O comando executado pela aplicação é analisado pelo usuário, que indica se a aplicação executou de acordo com o que era esperado. Um dos principais objetivos nas competições e pesquisas em BCI é aumentar a acurácia, que pode ser medida por este feedback.

Neste trabalho, o foco maior está nas etapas de extração de características e de classificação. Filtros temporais e espaciais são usados para extração do sinal e para limpeza de ruídos. Filtros passa-baixa e passa-banda retiram pedaços descartáveis do sinal, como um momento de alta amplitude que corresponda a um estímulo externo não esperado, e a Análise de Componentes Independentes (ICA) pode ser empregada para separar informações provenientes de dois sensores (mistura de sinal). É comum o uso da transformada rápida de fourier (FFT) em BCI (Nakayama; Inagaki, 2006), o que se estende principalmente pelo uso de sistemas comerciais que utilizam essa técnica como padrão. Alguns outros extratores, que podem descrever os dados em um domínio mais apropriado, acabam não sendo explorados da forma correta para algumas aplicações, principalmente relacionadas a educação. As características destacadas por esses extratores podem revelar comportamentos do cérebro que são importantes para se compreender as reações em momentos específicos, relacionados a certos estímulos. Alguns comportamentos do sinal são bem definidos e associados à situações já bem mapeadas e classificadas. Por exemplo, alguns desses sinais são nomeados com as letras P ou N (de Positivo ou Negativo) e o valor numérico correspondente ao milisegundo em que acontece após o estímulo. Um dos mais estudados é o P300, um pico positivo que acontece 300 milisegundos após um estímulo visual. Sistemas BCI 


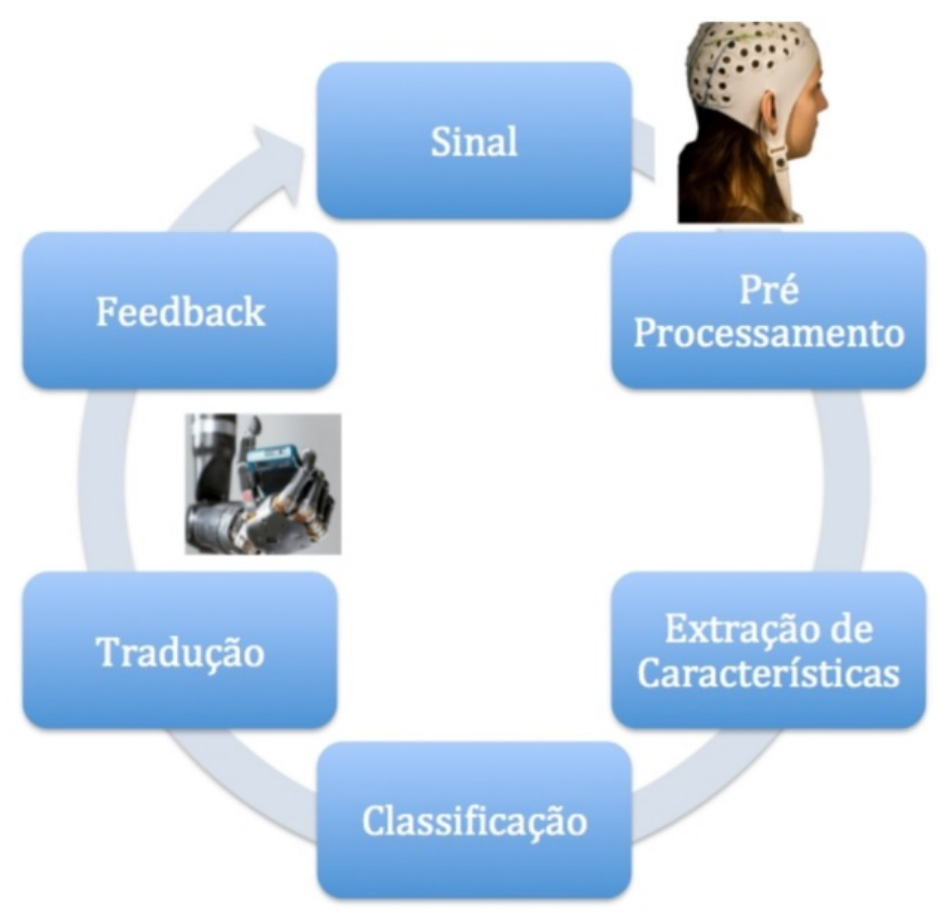

Figura 1 - Arquitetura geral de um sistema BCI online. A parte de tradução é exemplificada com a ação de um robô

Fonte: Elaborada pelo autor.

para reconhecimento de escrita usando letras na tela utilizam o P300 para reconhecer para qual letra o usuário está olhando.

Dentre os sinais mapeados, o de interesse nesta pesquisa foi o ErrP (Error Related Potential). Este sinal é um potencial evocado que gera um pico positivo, outro negativo, seguido por mais um pico positivo, iniciando 200 milisegundos após a percepção do estímulo, que é uma reação instantânea do cérebro sempre que o usuário comete algum tipo de erro durante alguma atividade. Como exemplo, podemos citar os bem definidos erros de Execução (Excecution Error) que ocorre quando a pessoa erra na execução de alguma atividade (como perder em um jogo eletrônico por causa da sua dificuldade) e o erro de resultado (Outcome Error) que pode ser exemplificado como um erro forçado, quando se tenta executar uma ação e o resultado é outro diferente. Considerando as comparações para se extratir a informação destes erros, pretende-se também comparar a acurácia na sua classificação. Neste trabalho, pretendemos comparar os resultados dos extratores Transformada de fourier e wavelet, utilizando MLP, um dos classificadores mais utilizados em BCI, e aprendizado profundo (Deep Learning), verificando se é possível melhorar a classificação de um sinal tão ruidoso. Considerando a dificuldade para encontrar bases de dados para testar o sistema proposto, foi criado um jogo para forçar o acontecimento dos erros dos usuários. Portanto, esta tese segue a arquitetura demonstrada na Figura 2, em que o jogo vai gerar uma base de dados que passará pelas etapas de filtragem, extração de características e classificação em momentos de erro ou não. 


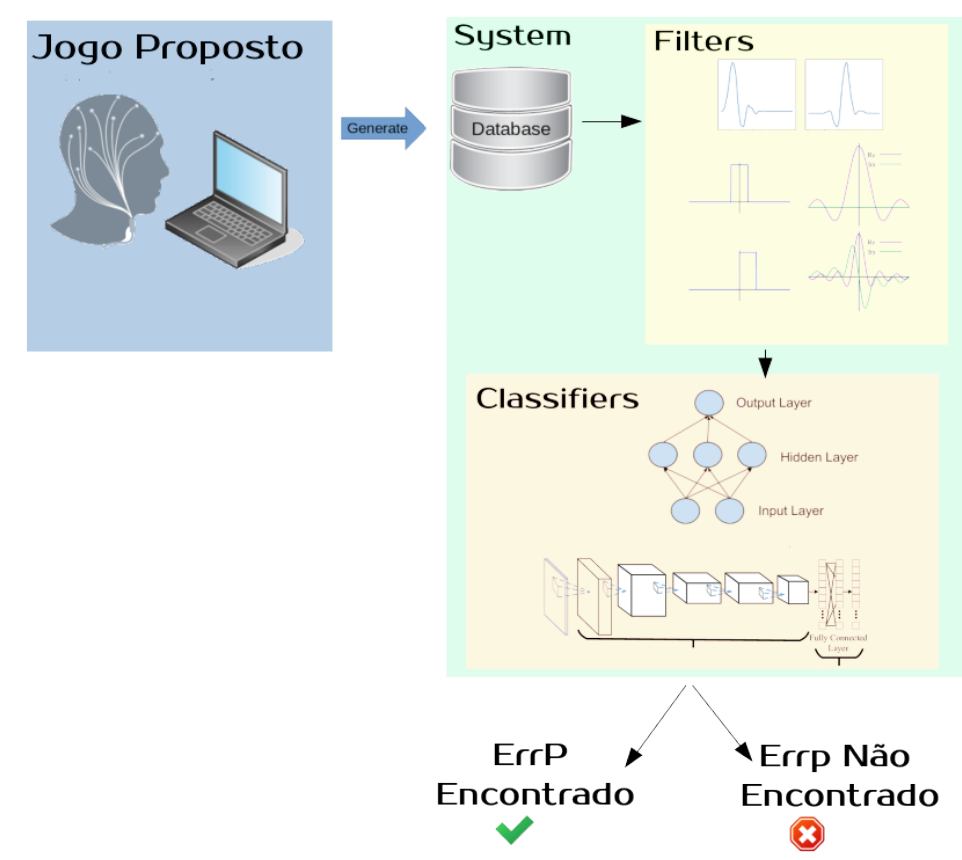

Figura 2 - Arquitetura proposta para esta tese: criação de uma base utilizando um jogo sério, e aplicação de filtragem e classificação dos sinais ErrP.

Fonte: Elaborada pelo autor.

\subsection{Motivação}

Em sala de aula o papel do professor é bem claro, ele direciona os estudos dos alunos, responde dúvidas e propõe conteúdos, materiais e avaliações. Quando se cria um sistema automático ou se coloca um robô autônomo em sala, boa parte dos alunos vai esperar a mesma estrutura. Além disso, o professor humano pode perceber mudanças de humor e comportamento dos alunos, e entender que algo além da matéria em si está atrapalhando o aprendizado. Neste trabalho, busca-se diminuir um pouco a distância entre o aluno e o professor, quando este é um sistema robótico. Para um resultado positivo nesta área, é preciso entender um pouco mais de robótica social e educacional.

A Robótica Social se caracteriza pelos comportamentos sociáveis que os robôs assumem interagindo com humanos e/ou outros robôs por meio de uma forma semelhante a dos humanos, como fala, visão e tato (SATAKE et al., 2009). A busca por respostas para esse aperfeiçoamento vem sendo realizada desde a metade do século passado (WALTER, 1950) até aplicações bem sucedidas nos dias de hoje, como a Robótica Assistiva (RABBITT; KAZDIN; SCASSELLATI, 2015). Tal fato chama a atenção de pesquisadores da robótica que trabalham para utilizar o potencial desta tecnologia contribuindo no processo educativo de crianças. Esta parte da robótica social leva o nome de Robótica Educacional, ou Pedagógica, e é caracterizada pela utilização da tecnologia como ferramenta no ensino, oferecendo situações e problemas nos quais os conhecimentos abstratos são abordados na prática, e o aluno passa por um processo de 
aprendizado mais completo, absorvendo e sendo capaz de aplicar o conhecimento (PLAZA et al., 2016). Mas sempre envolve a presença do professor.

Essa área tem como objetivo promover estudo de conceitos multidisciplinares, aplicando, por meio da robótica, as áreas da física, matemática, geografia, entre outras, introduzindo novos conceitos e tecnologias no ambiente educacional de forma mais prática. Existem motivações científicas e práticas para o desenvolvimento de robôs sociais. Tenta-se buscar inspiração no entendimento do comportamento social dos humanos, visando aprimorar o processo de aprendizagem dos robôs e aumentar a utilização destes no auxílio ao homem, em um número cada vez maior de tarefas. Neste contexto, alguns pesquisadores têm empregado robôs como ferramentas de ensino e em terapias com crianças com Transtorno do Espectro Autista (TEA) (ROBINS et al., 2004; BJÖRNE; BALKENIUS, 2005; BHARATHARAJ; KUMAR, 2013).

Como ferramentas de ensino, a robótica vêm sendo amplamente empregada, com resultados positivos. Tanto que existem kits comerciais como Lego e PETe, feitos com mecânica e programação simplificadas para crianças. Com a Olimpíada Brasileira de Robótica, escolas também começaram a empregar o uso de Arduíno, complementando o conhecimento dos alunos também em eletrônica. Mas quando se trata em o robô mediar uma aula, alguns cuidados precisam ser tomados. Com os estudos em robótica social, o comportamento que o robô emprega quando é o professor precisa ser o mais natural possível, de forma que seja confortável e bem aceito pelos alunos. O processamento de informações do cérebro com BCI ajudam ao robô a entender melhor o ambiente e a ter reações mais próximas do esperado pelo aluno.

O jogo e o experimento proposto neste trabalho busca gerar situações de diferentes estados mentais (frustração, medo, euforia, entre outros), que se assemelham a diferentes situações em sala de aula, já que foi difícil encontrar uma base que se adequasse a essas necessidades. Monitorando e classificando o ErrP, o sistema pôde perceber quando o aluno está tendo dificuldades em algum conteúdo, mesmo que seja enquanto estuda sozinho, utilizando um capacete neural. Com isso, o robô pode recomendar que o aluno procure outra fonte de estudo, pode avisar que o aluno está muito distraído, fortalecendo o estudo e a interação com o robô. Isso sem monitorar uma "atividade de avaliação", ou seja, uma prova ou um trabalho. Além do comportamento inteligente, estudos mostram que a forma do robô também é importante, uma vez que alunos, principalmente de menores idades, tendem a não aceitar que objetos (como carros e mesmo alguns animais) conduzam uma aula.

\subsection{Justificativa}

Os trabalhos encontrados em BCI carecem de estudos centrados no usuário, ou seja, que se preocupa com o público alvo, e o mesmo acontece com os trabalhos para robótica educacional (BENITTI, 2012). A possibilidade de interação, a autonomia do sistema e a resposta rápida do robô de acordo com as mudanças no estado mental podem aumentar a curiosidade 
do estudante, ajudando a manter o foco por um período mais longo e a deixá-lo confortável com os experimentos, colaborando com o aprendizado por exposição mais prolongada do conteúdo da aula. Percebendo-se também um notório decréscimo na área de Science, Technology, Engineering, and Mathematics (STEM) (Ciência, Tecnologia, Engenharia e Matemática), o conteúdo multidisciplinar, envolvendo programação, eletrônica e mecânica pode despertar o interesse nessas áreas do conhecimento, sendo um efeito secundário da aplicação do sistema.

Os trabalhos até então desenvolvidos com robôs no auxílio para educação infantil, embora com bons resultados, apresentam carência na autonomia do robô deixando boas oportunidades a serem trabalhadas. Os trabalhos utilizando BCI para educação geralmente utilizam as headsets de EEG comerciais (detalhadas do Capítulo 2) e não discutem a filtragem e extração de características, utilizando os sistemas na configuração padrão. As particularidades de cada pessoa podem afetar os resultados do sistema final. Assim, acredita-se que, com a observação de todos esses aspectos pode-se melhorar os resultados obtidos na literatura e também o aprendizado dos alunos.

Este trabalho pode ser implementado como um módulo de um sistema adaptativo para ensino e aprendizado, chamado R-CASTLE, que será melhor definido na Seção 4.2. Este módulo trabalharia para melhorar a etapa adaptativa do sistema, criando um feedback para aluno e professor e também para o robô. Com a percepção da dificuldade do aluno durante os estudos, o robô pode mudar o seu comportamento, selecionar novos conteúdos e ajudar o aluno durante os estudos, mesmo sem o auxílio do professor humano.

\subsection{Objetivos e Hipótese}

Este trabalho de doutorado teve como objetivo comparar a combinação de técnicas de filtragem e extração de características do sinal de EEG de forma reconhecer o ErrP enquanto os usuários jogavam um jogo sério criado para forçar a incidência de erros.

\section{Problemas de pesquisa}

Para explicitar como este projeto contribui para a ciência, foram propostos os seguintes problemas de pesquisa:

1. A utilização de novos algoritmos de classificação podem melhorar a acurácia de um sistema BCI aplicado à Educação?

2. Como as diferentes formas de filtragem e pré-processamento de sinais influenciam o sistema como um todo?

3. As bases de dados atuais são suficientes para extrair todas as informações necessárias para este trabalho? 
4. Qual a influência de um sinal específico como o ErrP na tomada de decisão de um robô?

\section{Hipótese}

A aplicação de redes neurais profundas (Deep Learning) como classificadores e técnicas de filtragem como as transformadas wavelets resultarão em um sistema de BCI aplicado à robótica educacional com melhor desempenho comparado aos sistemas disponíveis na literatura.

\section{Objetivos}

- Utilizar filtragens não-convencionais (wavelets) para a aplicação de BCI na educação, extraindo características mais relevantes à tarefa abordada;

- Aplicar Deep Learning para classificar o sinal do EEG e compará-lo em termos de acurácia e tempo de reposta com os algoritmos clássicos utilizados;

- Criar um módulo para um sistema educativo capaz de retornar um feedback para alunos e professores, melhorando e entendendo os momentos de erro do aluno durante o estudo através do ErrP;

- Criar uma base de dados com preocupação de avaliar situações comuns a sala de aula, como estresse.

\section{Contribuições desta tese}

- Criação de uma base de dados voltada para a educação considerando a aplicação da análise de sinal para aplicações em robótica

- Análise da utilização de Deep Learning para sinais ErrPs

- Análise do comportamento do sinal com o robô durante um questionário criado

- Comparações de extratores em aplicações educacionais

- Pré-processamento do sinal

\subsection{Organização da Monografia}

No Capítulo 2, são apresentados os trabalhos relacionados à esta pesquisa, considerando todas as áreas do projeto;

No Capítulo 3, é apresentada a fundamentação teórica, com as formulações matemáticas de todas as técnicas selecionadas para este trabalho, de filtragem, extração de características e classificação; 
No Capítulo 4, é discutido o sistema proposto, desde o primeiro experimento que foi utilizado para se entender todas as lacunas, passando pela apresentação do projeto R-CASTLE e, finalmente, discutindo mais detalhadamente a arquitetura proposta para reconhecimento do ErrP;

No Capítulo 5, são apresentados os materiais utilizados e os experimentos propostos para testar a arquitetura. São apresentados os experimentos que deram origem as bases da internet e todas as definições dos experimentos feitos para criação da base própria;

No Capítulo 6, são demonstrados os resultados e apresentadas as discussões sobre os experimentos propostos, passando por um experimento com um protótipo do R-CASTLE, experimentos com o pré-processamento, bases da literatura e com as bases criadas;

Por fim, o Capítulo 7 apresenta a conclusão, com a discussão das contribuições deste trabalho, limitações, dificuldades e trabalhos futuros. 


\section{TRABALHOS RELACIONADOS}

Este capítulo apresenta os trabalhos relacionados que forneceram a base científica para este projeto, bem como discussões sobre ética no uso desses sistemas e também o cenário brasileiro, importante pelas particularidades do país ${ }^{1}$. Primeiramente, são discutidos trabalhos sobre educação, robótica educacional e interação homem-robô, importantes quando se quer definir um sistema educacional. Esses trabalhos demonstraram as lacunas que precisam ser preenchidas com os sistemas propostos nesta tese. Também são descritos trabalhos com sistemas BCI em vários propósitos (imagética motora, médica, entre outros) e, por fim, os trabalhos que serviram de base para este sistema, que são os trabalhos de BCI aplicados na educação.

\subsection{Robótica Educacional}

Vygotsky (1993) afirmou, com relação ao desenvolvimento cognitivo, que o aprendizado pode ser reforçado com a associação de informações abstratas com objetos reais, sendo uma forma eficiente de memorização. De fato, a essência da memória humana está na capacidade de lembrar utilizando símbolos. O processo de cognição do homem, que o distingue dos animais, é ligado a formas abstratas, músicas e símbolos. Por isso, é comum processos de memorização utilizarem esses recursos, criando uma forma divertida de se aperfeiçoar o aprendizado.

O ambiente de robótica educacional é fundamentado pelas teorias de Jean Piaget, que foram revisadas por Seymour Papert, segundo Chella (2005). Para essa teoria, o centro do processo relacionado à cognição e aprendizado esta na participação ativa do estudante, que consegue ampliar seus conhecimentos por meio da construção e manipulação dos dados, objetos e símbolos abstratos significativos para o estudante e a comunidade a qual está inserido. Por isso a robótica pedagógica não tem um poder de aprendizado em si, pois não tem em si própria o poder de construção de conhecimento. A robótica, jogos e demais tecnologias educacionais

1 As dificuldades de acesso à tecnologia de ponta, a quantidade de regiões muito pobres do país influenciam no tipo de sistema que pode ser proposto. 
são ferramentas, fazendo parte do contexto de vida dos estudantes e servindo como simbologia para expansão do entendimento (PERRENOUD, 1999). As riquezas deste ambiente, entretanto, não estão sendo exploradas ao máximo (PRENSKY, 2005), então é necessário aprofundar os estudos sobre estes recursos, permitindo que as tecnologias sejam uma ferramenta para formação de novas habilidades, também entendidas como a capacidade de tomar atitudes de forma eficaz em qualquer tipo de situação, utilizando seus conhecimentos, mas não limitando-se a eles.

Pensando na exclusão digital, realidade em algumas regiões do Brasil, Thomaz et al. (2009) propuseram a implementação de um projeto envolvendo computadores e robôs na periferia de Natal - RN. O projeto foi desenvolvido durante 2 anos, envolvendo profissionais de todas as áreas de ensino, e contou com a participação de 24 estudantes da terceira e quarta séries do ensino fundamental. Os estudantes foram divididos em "grupos de trabalho", e eram guiados para completar tarefas que estimulavam o pensamento lógico, resolução de problemas e a construção de protótipos de robôs. As atividades eram interdisciplinares, e envolviam seguir manuais para a construção do robô e até a sua programação, para controle através do computador ou um comportamento autônomo. Foi utilizada uma ferramenta criada pelos pesquisadores, chamada de RoboEduc, para facilitar o aprendizado, já que era em português e abstraía alguns conceitos de programação de uma forma mais lúdica. Para avaliar os resultados, que foram baseados nas ideias de Perrenoud (1999), os estudantes participaram de 3 workshops, que envolviam os conhecimentos adquiridos durante o projeto, e os alunos foram avaliados tanto em grupo quanto individualmente. Para todo o grupo, foi comparada a melhora em pensamento lógico, habilidades computacionais e robótica, ao final de cada workshop, e foi possível perceber o crescimento em média em todos nestes conceitos, com a participação no projeto. Individualmente, os alunos foram comparados com os demais que não participaram do experimento com robótica, em provas de história, matemática, inglês (todas matérias abordadas nas atividades). Com exceção da matéria de história, os alunos que participaram do projeto tiveram um desempenho melhor nas provas, chegando a uma diferença (na média) de 2 pontos nas matérias de ciências e de matemática.

Também no contexto nacional, d'Abreu e Bastos (2013) fizeram uma discussão sobre os métodos tradicionais utilizados no ensino e as tecnologias disponíveis como ferramentas para a sala de aula. Após a inserção da matéria de robótica, os alunos de uma escola estadual de Campinas mostraram mais atenção para questões mais complicadas de exatas. Em um resumo de 30 anos de atuação do NIED (Núcleo de Informática Aplicada à Educação), instituto onde é pesquisado especificamente melhorias na educação, d'Abreu e Lourenço (2013) relatam a aceitação dos alunos pela robótica e uma melhora no aprendizado em escolas do ensino fundamental. Os experimentos utilizando kits robóticos, como o da MindStorms Lego Educational ${ }^{2}$, porém substituindo o bloco reprogramável por um Arduíno (placas eletrônicas de fácil programação). Esse bloco era conectado às peças de plástico do kit, que executam uma tarefa programada pelo

2 Discutido no Capítulo 4. 
usuário, mas não provê qualquer tipo de nova programação durante a execução da tarefa, sendo então considerado uma aplicação unidimensional. Mesmo com a pouca interação, a abordagem comprovou que os conhecimentos teóricos aprendido pelos alunos (crianças e adolescentes) foram eficientemente aprendidos, considerando a aula prática com o robô.

\subsection{Trabalhos em Human-Robot Interaction (HRI)}

Os trabalhos relacionados com HRI apresentam diversos focos de pesquisa. As pesquisas mais importantes para este projeto de Doutorado incluem: Relacionamento do robô com o homem em diversos ambientes, uso de sensores extras aos robôs para obtenção de mais informações e a aplicação da técnica Wizard of $O z$.

\section{Sensores extra aos robôs}

Para imitação de movimentos do braço de uma pessoa, Suay e Chernova (2011) utilizaram o sensor Kinect juntamente ao robô humanoide $\mathrm{NAO}^{3}$. Outros comandos mapeados com este dispositivo foram o controle de movimentação, a partir do mapeamento das posições de alguns membros do usuário. Utilizando a malha de pontos do Kinect e informações da câmera, o sistema permite, além do controle de movimento, comandos para ligar e desligar os motores e controle do foco de atenção do robô.

Já Veltrop (2012) utilizou vários sensores, entre eles o Kinect, para tele-operar o robô NAO. Estimando as posições espacias do corpo todo, e configurações de mão/punho (utilizando o controle Wiimote 4 e um head-mounted display que servia como visão para o usuário do robô. O sistema foi criado para servir de companhia pra os animais de estimação que ficavam sozinhos em casa, permitindo que o dono cuide remotamente.

Além da utilização do sensor Kinect, outros sensores podem ser utilizados para mapear os movimentos humanos. Por exemplo, Koenemann e Bennewitz (2012) utilizaram uma vestimenta de sensores inerciais para este fim, computando as junções do corpo e mapeando para as junções do robô em tempo-real. Com esse sistema o robô desempenhou uma imitação adequada, imitando movimentos inclusive das pernas sem cair no chão. Isso foi possível graças a um módulo de balanço, que ajustava o centro de massa de robô, compensando a diferença para a movimentação humana.

A partir de técnicas simples de matemática, Zuher e Romero (2012) tornaram o humanoide NAO capaz de receber comandos em tempo real para imitar os movimentos de braços e pernas de uma pessoa, caminhar, manipular objetos com suas mãos e realizar alguns comportamentos pré-definidos (levantar-se, sentar-se, acenar com a mão e desligar o robô), através

O robô NAO e o sensor Kinect são melhor discutidos no Capítulo 4.

4 Controle criado pela Nintendo para captação de movimentos utilizando três acelerômetros e um infra-vermelho. Foi descontinuado nas novas versões do console Wii. 
da interação com o Kinect. O sistema foi testado com usuários, e todos desempenharam as atividades propostas. Apenas a imitação de pernas não ficou perfeita, fazendo com que o robô caia algumas vezes no chão.

\section{Interação social}

Utilizando o robô humanoide Sony QRIO ${ }^{5}$, Tanaka, Cicourel e Movellan (2007) estudaram a interatividade entre o robô e crianças entre 1 e 3 anos para desenvolver e avaliar métodos educacionais e ajudar professores da educação infantil. Dividido em três fases, o experimento teve um total de 45 sessões, cada uma com duração média de 50 minutos. Na fase I, com um total de 27 sessões, o robô utilizava todo o seu repertório para interagir com as crianças, seguido pela fase II onde o robô passava a ter comportamentos altamente previsíveis, mesmo que interessantes, por mais 15 sessões. Nas três últimas sessões, o robô voltava a utilizar o repertório completo, configurando a fase III. Os comportamentos do robô envolviam fala, gestos e até assumir uma posição de dormir, quando sua bateria estava acabando (o que caracterizava o fim da sessão). Foi adotada uma progressão na interação, sendo que nas primeiras sessões o robô se limitava a saudações e, ao longo das sessões, passava a rir, tocar as crianças para chamar atenção e até dançar ao detectar alguma música. As sessões foram registradas por duas câmeras de vídeo e estudadas ao longo de dois anos para desenvolver métodos quantitativos para a análise dos comportamentos das crianças diante das fases de interação com o robô.

Uma das maiores preocupações dos autores foi encontrar uma maneira de avaliar a qualidade das interações, em questões de tempo que elas duravam e a resposta, positiva ou negativa, das crianças. Originalmente, utilizado para pesquisas de marketing, a Continuous Audience Response ${ }^{6}$ (FENWICK; RICE, 1991) foi útil para avaliar essas questões subjetivas. Cinco estudantes de graduação, que não sabiam o propósito da pesquisa, avaliaram e deram notas para as interações gravadas. Para obter uma amostragem independente, 15 sessões aleatórias eram escolhidas dentre as 45 possíveis e eram codificadas aleatoriamente frame-by-frame. Verificando as notas dadas e o comportamento dos alunos no vídeo, os pesquisadores perceberam que, com o passar do tempo, o robô passou a ser tratado mais como amigo do que como brinquedo pelos alunos, o que se deve ao fato da interação ser cada vez mais próxima da realidade das crianças. $\mathrm{O}$ estudo também constatou que as crianças mostravam um interesse inicial maior pelo robô, mas esse interesse era perdido ao longo das sessões, principalmente quando as ações passaram a ser previsíveis. A volta de comportamentos novos e o aumento contínuo de interação ajudavam a manter o interesse por mais tempo. Isso mostra que a tecnologia está próxima de alcançar uma socialização anônima aceitável por períodos de tempo prolongados, tendo um grande potencial em contextos educativos, ajudando aos professores à enriquecer o ambiente de aprendizado.

Tanaka e Ghosh (2011) colocaram o robô NAO como aluno, e não como professor,

5 Disponível em: http://www.sony.net/SonyInfo/News/Press_Archive/200312/03-060E/ .

6 Discutido melhor no Capítulo 4. 
invertendo o seu papel no ensino. O robô foi programado para participar de aulas de inglês com crianças japonesas na Universidade de Tsukuba, participando de todas as atividades com as crianças, como canto de cantigas em roda, respondendo perguntas sobre os animais e cores feitas pelo professor. $\mathrm{O}$ experimento foi feito em três dias, sendo que nos dois primeiros, o robô foi programado para responder corretamente todas as perguntas e no último dia ele deveria errar todas as perguntas feitas. Os pesquisadores monitoraram todas as interações e gravaram as aulas utilizando as próprias câmeras do NAO. No último dia, as crianças advertiam o robô a cada resposta errada, encontrando maneiras particulares de explicar o porquê de suas respostas estarem equivocadas, já que o professor não intervia nas interações entre as crianças e o robô. Os pesquisadores perceberam o aumento de interações por minuto ao longo do tempo, e também o aumento do número de respostas corretas dos alunos, individualmente e em grupo. Essa melhora no número de respostas corretas aconteceu proporcionalmente ao aumento da interação, mostrando que os processos cognitivos das crianças foram potencializados, conforme mostrado na Tabela 1. Os autores, que nesse trabalho se referem a interação como prestação de cuidados (care-giving instance), concluíram que a inserção do robô foi fundamental para o reforço do aprendizado. Porém, essa conclusão não se aplica à todas as interações, sendo necessários mais experimentos para comparação e conclusão.

Tabela 1 - Resultados de (TANAKA; GHOSH, 2011), sendo $\mathscr{I}$ a média de interações por minuto e $\mathscr{E}$ a média de interações por minuto resultantes em reforço de aprendizado.

\begin{tabular}{|c|c|c|}
\hline Ensaio & $\mathscr{I}$ & $\mathscr{E}$ \\
\hline Dia 1 & 0,38 & 0,25 \\
\hline Dia 2 & 0,67 & 0,27 \\
\hline Dia 3 & 0,77 & 0,63 \\
\hline
\end{tabular}

A melhora do aprendizado não é percebida apenas em crianças. O estudo de Verner et al. (2012) utilizou diversos robôs para aprimorar a experiência dos visitantes a um museu tecnológico. Os robôs foram programados para responder algumas perguntas específicas dos visitantes, explicar as seções do museus e interagir com os visitantes durante todo o passeio. Os pesquisadores perceberam que houve um aumento na quantidade de visitantes a partir da implantação dos robôs como guias, além de estimular o interesse destes visitantes, que foi medido pela quantidade de perguntas feitas por minuto. Ao final da visita, os participantes respondiam um questionário sobre o museu, mostrando uma melhora na memorização do que foi ensinado durante a visita pelo robô.

Em um estudo de interação social feito por Tapus et al. (2012), um experimento com quatro crianças com transtorno de espectro autista (TEA) foi proposto, comparando os níveis de interação com o robô NAO e com um humano. Duas dessas crianças não mostraram qualquer diferença no comportamento com a presença do robô, porém as outras duas prestaram mais atenção ao robô do que ao humano, sendo que uma delas mostrou uma grande interação com o robô. Em outro experimento, feito por Csala, Nemeth e Zainko (2012), crianças que são 
obrigadas a viver em pequenas salas estéreis de $2 \times 3$ metros devido a sua condição de saúde tiveram respostas bem positivas ao robô NAO. As crianças se animaram com a presença do robô e inclusive faziam alguns exercícios propostos pelo humanoide.

Estudando a comunicação e a interação de adolescentes com TAE, Kimberlee et al. (2013) compararam os níveis de interação entre os adolescentes em jogos com outros adolescentes com distúrbios diferentes, recrutados de escolas para pessoas com necessidades especiais. Durante três dias consecutivos, todos os adolescentes participaram de jogos, cada dia com uma forma diferentes: no primeiro com um robô humanoide, no segundo dia com uma Smart Board ${ }^{7}$ e no último dia com cartas. Os pesquisadores perceberam uma diminuição no comportamento individualista quando foram utilizados os dispositivos tecnológicos (robô e Smart Board), mostrando que o uso da tecnologia pode ajudar na melhora de comportamento e aprendizado desses alunos. $\mathrm{O}$ uso de robôs vêm sendo testado por muitos pesquisadores, com bons resultados de interação entre portadores de TAE e robôs (SHAMSUDDIN et al., 2012).

\section{Wizard of $\mathrm{Oz}$}

Proposta por Kelley (1984a), a técnica Wizard-of-Oz (WoZ) é comumente empregada em pesquisas de HRI pois permite uma interação convincente, com menor custo computacional. Baseado na obra literária "O Maravilhoso Mundo de Oz", onde um ilusionista tele-opera um avatar que todos conhecem como um poderoso feiticeiro na terra de Oz. A sua aplicação na Interação Homem-Máquina refere-se a uma pessoa (o pesquisador ou um parceiro) que opera remotamente algum dispositivo sem que o participante do experimento saiba. WoZ pode envolver qualquer quantidade de controle no espectro de autonomia, permitindo ao pesquisador a operação de membros, fala, navegação, gestos ou quaisquer outra atividade no repertório do dispositivo. O operador do dispositivo é, por questões de conveniência, o Mágico (Wizard) e o dispositivo controlado é o Oz. A utilização do WoZ é defendida pela incapacidade de interação autônoma dos robôs com as pessoas de maneira socialmente adequada e segura fisicamente (RIEK, 2012). Esse tipo de manipulação permite imaginar como a interação autônoma será no futuro e também testar aspectos preliminares da pesquisa que ainda não estão totalmente implementados, sendo parte de um design interativo de um processo maior.

Tradicionalmente não houve critérios explícitos para guiar as pesquisas na área de HRI, mas estes foram criados pela comunidade de Processamento de Linguagem Natural (PLN). Para realizar uma simulação de WoZ válida, os seguintes requisitos devem ser atendidos: Deve ser possível simular o sistema futuro de forma convincente, e ser possível especificar os futuros comportamentos do sistema, sempre respeitando as limitações humanas (FRASER; GILBERT, 1991).

É importante discutir o controle de vários aspectos sobre o comportamento do Mágico, pois alguns pesquisadores têm levantado questionamentos sobre os métodos a respeito desta

\footnotetext{
7 Uma lousa digital.
} 
técnica (WEISS, 2010). É preciso ter controle sobre o quão perfeito é o Mágico e como se controla variáveis como o erro, o tempo de resposta à um estímulo (em quanto tempo um computador conseguiria processar a mesma informação?) e quão grande é a interferência da presença do Mágico se comparado com o sistema autônomo esperado (é possível que o sistema obtenha as mesmas taxas do experimento com WoZ?) (FRASER; GILBERT, 1991). Weiss (2010) sugere que um robô controlado WoZ está servindo como uma ferramenta de interação humano-humano por meio de um robô, e não é de fato uma interação homem-robô.

Para contornar alguns desentendimentos Green, Huttenrauch e Eklundh (2004) sugerem uma metodologia para construção de um cenário WoZ em HRI:

- Instrução do usuário: a tarefa pretendida deve ser muito bem instruída ao usuário (O que o usuário deve fazer?);

- Hipótese de comportamento: se refere às expectativas do designer sobre os caminhos a serem escolhidos pelo usuário durante o experimento ( $\mathrm{O}$ que se espera que o usuário faça?);

- Comportamento do robô: dita, independentemente do nível de autonomia, as ações esperadas do robô para aquele cenário (O que o robô deve fazer?).

Tendo em vista as metodologias propostas e os problemas apontados, concluí-se que a interação é componente de um projeto válido, mas de forma alguma o WoZ deve ser considerado um ponto final de uma questão de pesquisa. Até porque é importante para os estudos WoZ levar em conta o ambiente e sua influência no robô e nos humanos, o quanto a autonomia do robô afeta o ambiente dos seres humanos e como simular esse modelo de ações do Mágico (STEINFELD; JENKINS; SCASSELLATI, 2009). O processo interativo de um sistema WoZ deve considerar que o Mágico, com a evolução da pesquisa, é eliminado gradativamente até a autonomia total do robô ser alcançada (KELLEY, 1984b).

Assim, tendo em vista experimentos centrados em um ou mais humanos e/ou robô, surgiram mais de um tipo de interações além do Wizard of WoZ. Existem também Wizard with $O z$ (método centrado no humano que utiliza a tecnologia real em um ambiente simulado), Wizard and $O z$ (método centrado no humano que utiliza a tecnologia real em um ambiente real), $O z$ with Wizard (método centrado no robô que inclui seres humanos, mas não se tiram métricas deles), $\mathrm{Oz}$ of Wizard (método centrado no robô no qual os seres humanos são simulados ou minimamente envolvidos) e Wizard or $O z$ (todos os aspectos do sistema são simulados).

Inclusive, as diferenças na percepção dos alunos com um robô tele-operado e autônomo são discutidas por Edwards et al. (2016), com uma abordagem de "professor como robô" (no caso do robô teleoperado) e do "robô como professor". 86 alunos de graduação, sendo 60 mulheres e 26 homens com idades entre 18 e 30 anos, foram divididos em 2 grupos: um para 
a abordagem autônoma e o outro grupo para a abordagem tele-operada. O robô utilizado foi o MantaroBot Classic, que conta com um monitor de 14" (onde era mostrado o rosto do professor ou uma animação) e uma base com rodas para movimentação. Apesar de ambas as abordagens serem consideradas "críveis", o robô tele-operado foi rotulado com maior credibilidade do que a abordagem autônoma. Este, entretanto, permitiu, segundo os próprios alunos, um aprendizado mais comportamental, ou seja, um jeito diferente de se agir e aprender. Detalhes importantes dessa abordagem, verificados também no trabalho de Hackman e Walker (1990), a voz, postura do corpo e mesmo atitudes como o sorriso são impactantes na interação entre os estudantes e seus professores, o que mostra a necessidade de mais estudos para utilização de robôs em sala de aula.

\subsection{Sistemas $\mathrm{BCl}$}

Existem diversas linhas de pesquisa utilizando sistemas BCI. Muitos laboratórios desenvolvem esses sistemas para permitir a comunicação e devolver capacidades motoras à pessoas que sofrem de severas incapacidades motoras (SCHALK et al., 2004). Esses estudos, nas últimas décadas, buscam traduzir os sinais cerebrais para informações, permitindo, apenas com a intenção de movimento ou "pensamento", o movimento de exoesqueletos, cadeiras de rodas, braços e pernas robóticos ou o envio de comandos para o computador, permitindo jogos, criação de partituras e até ajuda na hora de estudar.

O uso desse tipo de sistema envolve um tempo de adaptação, ou treinamento, para se conseguir obter os resultados esperados. Por isso, é interessante que algumas aplicações sejam testadas antes, inclusive com pessoas saudáveis, para se conhecer a acurácia do sistema proposto. É o caso do trabalho de Kanoh, Miyamoto e Yoshinobu (2011), onde cinco pessoas saudáveis controlavam um cursor na tela sem o uso de nenhum de seus músculos. Neste trabalho, foram utilizados dois computadores, um que recebia as informações do EEG e o segundo com o cursor que deveria ser movimentado. Ao lado desse cursor havia oito pequenos círculos com distância de $2 \mathrm{~cm}$ entre eles, que piscavam de forma aleatória mas com um Stimulus-onset asynchrony $(\mathrm{SOA})^{8}$ e duty-cycle $e^{9}$ fixos, e indicavam a direção para a qual o usuário queria mover o cursor. Quando o círculo para o qual o usuário estava olhando piscava, acontecia um ERP (o P300), que era reconhecido pelo primeiro computador, que também tinha a informação de qual círculo havia piscado e tomava a decisão de movimentar o cursor. Os eletrodos foram posicionados nas localizações $\mathrm{FCz}, \mathrm{Cz}, \mathrm{C} 1, \mathrm{C} 2, \mathrm{CPz}$, usando a orelha direita como referência e a esquerda como terra. O sinal era obtido no computador 2, amplificado e depois passava por um filtro passa-banda $(0.15 \sim 100 \mathrm{~Hz})$, para só então ser enviado para o primeiro computador. As respostas do EEG foram extraídas usando janelas de tempo (-100 500 ms). Essa informação extraída era corrigida usando o potencial médio entre $-100 \sim 0 \mathrm{~ms}$ e as amplitudes que excediam $\pm 50 \mu \mathrm{V}$

8 Tempo entre a ocorrência de um estímulo S1 e de um outro estímulo S2.

9 Duty-cycle é a fração de tempo em que um sistema, neste caso o piscar da bolinha, está ativo. 
eram consideradas artefatos, sendo descartadas e excluídas das análises. O classificador utilizado foi o Fisher's Linear Discriminative Analysis (LDA) - Análise Linear Discriminante, algoritmo que normalmente é utilizado para redução de dimensionalidade do espaço de dados.Todos os 5 participantes conseguiram mover o cursor e a acurácia, medida pela ocorrência de falsos e verdadeiros positivos, ficou na faixa dos $70 \%$. Um detalhe interessante, mas não muito comentado no artigo, é que o aumento do SOA de 600 para $800 \mathrm{~ms}$ melhorou a ocorrência dos verdadeiros positivos.

Os sistemas BCI são normalmente pouco flexíveis, o que significa que uma abordagem é normalmente específica para um tipo de obtenção de sinal, tratado com uma filtragem específica e aplicado em uma plataforma específica. Tentando melhorar esse cenário Schalk et al. (2004) propuseram o BCI2000, um sistema BCI de propósito geral. É importante perceber a discussão sobre a aquisição dos dados, onde diferentes toucas para captação do potencial elétrico dos neurônios precisam de diferentes tratamentos, como passar por filtros passa-banda ou ter o sinal amplificado para ser detectado. Outra importante discussão neste artigo é o módulo de processamento de sinal, no estágio de extração de características. Uma transformação linear nos dados de entrada é feita para calibração, convertendo o sinal para uma medida de microvolts. Em seguida, um filtro espacial (uma multiplicação matricial dos pesos com a saída do módulo de calibração) é utilizado para que o canal de saída seja uma combinação linear de todos os canais de entrada. Essa filtragem linear pode ser feita com Derivação Laplaciana ${ }^{10}$, ICA ou CSP. Por último, é possível utilizar um filtro temporal, como AR e FIR, permitindo encontrar os potenciais evocados. O sistema foi testado para várias aplicações diferentes e teve resultados comparáveis à literatura em todos eles.

Após a filtragem utilizando CSP, outra forma comum de se extraír características é utilizando as Wavelets, normalmente das famílias mais comuns. Porém, essa pode não ser a abordagem ótima. É o que Asensio-Cubero, Gan e Palaniappan (2012) discutiram, analisando eventos de imagética motora e as ocorrências de Event Related Desynchronisation e Event Related Synchronisation com famílias de Wavelets. Os autores utilizaram o dataset da IV Competição de BCI, que contém imaginação dos movimentos das mãos direita e esquerda, pés e língua de nove pessoas diferentes. Os dados foram gravados em $250 \mathrm{~Hz}$ de 22 canais posicionados pelo sistema 10-20 e depois foi aplicado um filtro elíptico passa-banda. Por avaliarem apenas o movimento da mão esquerda e língua, os canais escolhidos foram FC1, FC2, FC3, FC4, FCz, C1, C2, C3, C4, Cz, CP1, CP2, CP3, CP4 e CPz (totalizando 15 eletrodos). Foram comparadas as extrações de características utilizando wavelts da primeira geração (First Generation Wavelets (FGW)) - Haar, Daubechies e Coifflets - com uma abordagem do CSP com Wavelets da segunda geração, também conhecidas como wavelet lifting scheme. A abordagem apresentada teve um melhor desempenho se comparada com as Daubechies de alta ordem ou as Coifflets, mas foi comparável em desempenho com a Haar, normalmente descartada por ser muito simples para

10 Método operacional de resolução de problemas de valor inicial que permite levar a resolução de equações diferenciais à resolução de modo mais simples. 
problemas do mundo real, e utilizada apenas na teoria. $O$ tempo de convergência foi a vantagem do sistema CSP com Wavelets de segunda geração, já que como existe uma maior quantidade de características significativas, o sistema processou os dados em 54.9s contra 2311.2s da Wavelet Haar. Todos os dados foram classificados utilizando a LDA.

Entretanto, este trabalho é mais focado no tratamento dos sinais espontâneos, discutindo os domínios de suas características. Por exemplo, a tradução do movimento do cotovelo para um braço robótico, como no trabalho de Ghani et al. (2012), verificaram a intenção do movimento, e não os EPs. Três indivíduos saudáveis, com idades entre 18-24 anos, participaram deste estudo, que utiliza o sistema 10-20 de localização dos eletrodos. Os dados são inicialmente filtrados usando um filtro IIR Notch de frequência de $50 \mathrm{~Hz}$, removendo algumas falhas na aquisição do sinal. As característica no domínio e tempo podem ser utilizadas com sucesso para detectar movimentos do cotovelo. As características utilizadas foram: média, variância, assimetria, curtose, energia, Inter Quartile Range (IQR) e Median Absolute Deviation (MAD). Essas características foram plotadas em histogramas da movimentação do cotovelo direito e esquerdo, para se encontrar quais eram mais significativas para a tarefa, e foram escolhidos (para diminuir a complexidade do sistema): Curtose, IQR, MAD e média. Para reduzir a dimensionalidade, foi utilizado a Discrete Cosine Transformation (DCT) e o sistema foi classificado utilizando um classificador quadrático. Com uma acurácia de $73 \%$ na detecção correta do movimento (esquerda ou direita) os pesquisadores concluiram que o resultado satisfatório.

Lamti et al. (2013) propuseram o uso de uma interface para navegação de uma cadeira de rodas, utilizando o Gaze-based interfaces (Interfaces baseadas no olhar fixo) e BCI. Os pesquisadores utilizaram o ASL Eye Trac 6, sistema que faz o rastreamento do olhar, mapeando as coordenadas do local para onde o indivíduo está olhando, aliado com o neurosky headset para obter as informações de atenção e estado de relaxamento da pessoa. Cinco pessoas fizeram os testes, que consistia em olhar para uma tela com os comandos de movimento (frente, trás, direita, esquerda e parar). O sistema fazia o rastreamento do olho para encontrar o comando e, caso o nível de atenção estivesse acima de um threshold, executava a ação, que era sair de uma sala e chegar até uma outra, utilizando um caminho pré-determinado. Comparado a um sistema baseado apenas no olhar (como o Eletrooculograma (EOG)), a utilização da BCI fez com que o sistema ficasse mais estável, porém mais lento, pois a pessoa precisava se concentrar para ultrapassar o threshold estabelecido.

Para a robótica social, algumas informações são importantes na obtenção uma melhor aceitação dos participantes de uma atividade com robôs. E uma dessas situações importantes é o contato visual, quando o robô aparenta querer ouvir ou iniciar uma conversação com um humano. Para tentar reconhecer esse tipo de interação, Ehrlich et al. (2014) utilizaram o robô $i C u b$, que tentava reconhecer, através da BCI, a vontade de uma pessoa em conversar com ele. Aos participantes, era dito que eles podiam influenciar o comportamento do robô apenas pensando que estava com vontade de conversar. O robô ficava olhando para um monitor de computador, e 
através de um sinal sonoro, o humano sabia se deveria tentar influenciar o robô (pensar pra que o robô olhasse para ele) ou se deveria esperar que o robô iniciasse o contato (ou seja, se manter em estado normal, para servir de controle na comparação dos testes). Porém esse sistema era também um WoZ, pois o robô se virava em tempos aleatórios, e não era influenciado pelo pensamento do participante. A touca utilizada neste experimento foi a actiChamp, da BrainProducts, com 32 eletrodos e taxa de amostragem de $500 \mathrm{~Hz}$. O canal Cz era utilizado como referência na obtenção dos dados, e depois era reconstruído para remoção de artefatos, diminuindo a frequência para $250 \mathrm{~Hz}$. Ainda no pré-processamento, foi utilizado um filtro IIR passa-banda Butterworth Zero e manualmente retiravam informações conhecidas, como os picos que aconteciam nos avisos sonoros, finalizando com uma ICA. A extração de características era feita a partir de um filtro Chebyshev de segunda ordem, separando as seguintes ondas: Theta $(\theta)$, Alpha $(\alpha)$ baixa e alta, $\operatorname{Beta}(\beta)$ e Gamma $(\gamma)$, e a classificação utilizava uma SVM com um kernel de base radial (Radial Basis Function (RBF)). Comparando-se dois conceitos para medir a classificação (5-times-5-fold cross validation e Leave-1-out), o sistema, utilizado de forma offline para tentar rotular os dados obtidos durante o experimento com o robô, obteve $80.4 \%$ de acerto em definir a vontade de iniciar uma conversação por parte do humano.

Outra preocupação com sistemas BCI é a robustez com relação ao posicionamento dos eletrodos. Imaginando sistemas onde existe uma movimentação do indivíduo, existe a possibilidade de movimentação e de uma leve mudança na posição dos eletrodos. Oito voluntários executaram tarefas de imagética motora das mãos direita e esquerda 90 vezes, com eletrodos posicionados em 9 lugares diferentes no trabalho de Hwang, Im e Park (2013). Além dos eletrodos Fz, C3 e C4, usados como referências (pois grande parte das atividades cerebrias relacionadas a imagética motora são obtidas nesses eletrodos (PFURTSCHELLER et al., 2006)), seis outras posições foram criadas, em volta dos eletrodos C3 e C4 (C3a, C31, C3p, C4a, $\mathrm{C} 41$ e C4p). Novamente foi passado um filtro passa-banda, de forma a obter as ondas $\mu$ e $\beta$. Os melhores vetores de características foram selecionados utilizando o algoritmo de seleção sequencial de características (Sequential Feature Selection (SFS)) e a classificação foi feita utilizando LDA, com a acurácia medida utilizando o 5-times-5-fold cross validation. $\mathrm{O}$ trabalho compara a acurácia obtida após o uso de 3 técnicas: o PSD, o Phase Locking Value (PLV) e o Cross-Correlation (CC), e o CC teve uma acurácia superior as demais técnicas, provando ser menos afetado pelas pequenas alterações dos eletrodos.

Doenças neurodegenerativas causam dificuldades para comunicação e locomoção de alguns pacientes. Um dos casos é a esclerose lateral amiotrófica, onde 11 pacientes com paralisia severa foram treinados por seis anos para operar um dispositivo de comunicação, no trabalho de Neumann e Kubler (2003). Experimentos com pessoas nestas condições precisam de um cuidado maior, pois dependendo do sistema o tempo de treinamento pode ser elevado (no caso deste experimento foram 3 horas e 2 vezes por semana) e no início pode ser frustrante. É necessário um trabalho em conjunto com profissionais da saúde e da família, este último como um importante fator motivacional. O mesmo acontece na utilização de sistemas robóticos com 
crianças com Distúrbio do Espectro Autista (DEA) (BHARATHARAJ; KUMAR, 2013). Apesar dos poucos trabalhos na literatura, sistemas BCI podem ajudar as crianças a terem melhores respostas dos dispositivos robóticos, desde que se sintam confortáveis, e incrementar habilidades de aprendizado.

Foram usados sinais biomédicos para verificar melhoras na segurança de motoristas, especialmente nas rodovias, onde o tempo de viagem é maior, aumentando o risco de acidentes. Como a fadiga está relacionada à acidentes de carro, em Morales et al. (2015), foi criada uma plataformas vestível, utilizando EEG, sensores de pulso, microcontroladores, smartphones e um dispositivo de Gaze tracking, chamado BioTracker. Para captura do EEG, foi utilizado o Mindwave e o Arduíno UNO. Sozinhos, esses sensores não seriam suficientes para melhorar de maneira significativa a predição de acidentes. Juntos, entretanto, aumentam a quantidade de informações disponíveis para o sistema, melhorando a percepção de falhas.

\subsection{Sistemas $\mathrm{BCl}$ voltados para Educação}

Como mencionado, novos métodos de ensino, como jogos educativos e a robótica educacional, têm sido amplamente pesquisados e com resultados interessantes. Uma perspectiva que também ganhou força é o uso de sistemas BCI para aplicações educacionais, o que é foco deste trabalho. Pesquisas nesta área envolvem ajuda na leitura de textos longos, modelos de aulas extras para crianças e até ajuda para adultos, utilizando as informações extraídas do EEG para direcionar os estudos e aumentar a concentração. Os trabalhos estão aqui descritos em uma linha de complexidade.

A primeira discussão é o quanto o uso de vídeo-games pode influenciar nos estudos. Para tal, Andujar et al. (2011) propõem um experimento com 26 participantes com idades entre 19 e 25 anos, estudando sobre a história americana. Os grupos foram subdivididos em dois grupos, o primeiro utilizando o jogo (sete homens e seis mulheres) e o outro estudando com um livro (oito homens e cinco mulheres), sendo que todos indicaram conhecimento da língua em que estava escrito o texto e que poderiam ler sobre qualquer assunto. Os participantes de ambos os grupos utilizaram o Emotiv EPOC ${ }^{11}$ durante suas respectivas tarefas, após responderem um questionário para saber o conhecimento prévio sobre o tema. Os participantes tiveram 20 minutos para completar as tarefas e fizeram uma prova para avaliar o quanto aprenderam durante o experimento, enquanto o sistema capturava o nível de engajamento durante todo o processo. Estatisticamente, não foi comprovada diferença significativa entre os tipos de aprendizado e os testes demonstraram que as pessoas que estudaram com o texto tiveram maior nível de concentração, melhor desempenho no teste final e maior incremento no aprendizado se comparado com a prova feita no início do experimento. Isso mostra que apenas usar vídeo-games não é suficiente para se obter melhora no aprendizado. Um dado curioso apontado neste estudo é

11 Headset para obtenção do EEG, melhor discutido no Capítulo 4. 
que os afro-americanos tiveram um maior nível de concentração com o jogo, mas uma melhora nas respostas com a leitura do texto, já os asiáticos tiveram melhores resultados com os jogos. Logicamente, a quantidade de pessoas que participou do estudo é pequena para se fazer qualquer conclusão mais concreta.

Com a tecnologia, muitas pessoas têm acesso aos E-books e tablets, o que despertou e renovou o interesse pela leitura. Porém, quando é uma leitura obrigatória, alguns tópicos podem não ser interessantes, fazendo com que o leitor não detenha toda informação possível e perca atenção sobre a leitura. Atenção é um pré-requisito para se obter melhores resultados durante os estudos (REBOLLEDO-MENDEZ et al., 2010). No trabalho de Jimenez, Andujar e Gilbert (2012), o EPOC foi utilizado para medir o nível de atenção do participante durante a leitura de um texto pré-determinado. O sistema é calibrado dependendo de algumas variáveis (como humor e cansaço, que podem influenciar na resposta do sistema) e então o participante deve ler um texto por três minutos. Caso o seu nível de engajamento, medido pelo EEG, esteja abaixo de um threshold, o sistema automaticamente escolhia um vídeo relacionado com o texto, que ajuda o leitor a entender melhor o que estava sendo lido. Esse threshold, também estudado em Malik et al. (2012) é dado pela função Engagement $(E)=\frac{\beta}{\alpha+\theta}$ (considerando as formas de onda já discutidas) tendo o valor padrão definido em 0.549. A escala de "interesse" do vídeo era medida pelas notas obtidas em mídias sociais, como o Youtube. Por ser um trabalho em andamento, o sistema ainda não foi testado (ANDUJAR; GILBERT, 2013).

O uso de vídeos também foi discutido por Lee e Chin (2014). Primeiramente, 20 crianças de idades entre 4 e 6 anos assistiram a uma série de vídeos curtos, enquanto seu nível de atenção era medido através do EEG. Em seguida, foi desenvolvido um ambiente de aprendizado bastante lúdico, utilizando desenhos e muitas cores, para que as crianças respondessem algumas questões matemáticas, chamado Early Childhood Educator Assistant. Com o EPOC+, o nível de atenção era medido, e caso ficasse abaixo de um limiar, os vídeos que tiveram maiores níveis de atenção no primeiro experimento eram apresentados na tela, de forma a retomar o interesse da criança para o computador e, consequentemente, para o estudo. Para chegar a este limiar, o sistema verifica basicamente a ocorrência das ondas Alpha $(\alpha)$ e Beta $(\beta)$ que estão relacionadas aos níveis de atenção ou "relaxamento" do usuário. Sabe-se que essas ondas são melhor obtidas nos lóbulos occipital $(\alpha)$, frontal e parietal $(\beta)$, portanto um dos testes é diminuir a quantidade de eletrodos estudados, para diminuir a quantidade de informação e artefatos. Os eletrodos utilizados neste experimento foram: F7, F3, P7, O1, O2, P8, F4 e F8, ou seja, foram excluídos 6 eletrodos da configuração original do aparelho. Comparando-se o espectro de densidade de potência obtido por todos nos canais com e sem esses eletrodos descartados, percebeu-se que a quantidade de informação era muito próxima, ou seja, era possível inibir esses canais sem perda de rendimento do sistema para esta tarefa específica. 40 crianças foram convidadas para responder as perguntas matemáticas, sendo que 20 utilizaram o Early Childhood Educator Assistant e as outras 20 um método tradicional (caneta e papel). O nível de atenção foi medido para todas as crianças, e a utilização do sistema proposto teve uma média de atenção de $76.51 \%$, 
20,30\% a mais do que o sistema convencional. Além de aumentar a atenção das crianças para os estudos, também as ajudou a ter maior número de acertos, pois as crianças foram $24,75 \%$ melhores na média utilizando o sistema proposto.

Seguindo a mesma linha, o projeto BRAVO - BRAin Virtual Operator - (MARCHESI; RICCO, 2013) mediu o nível de atenção dos alunos durante o estudo, porém utilizando o equipamento Mindwave ${ }^{12}$, da NeuroSky. Um curso de história da arte utilizava modelos 3D com pontos onde o aluno clicaria para saber mais informações sobre o conteúdo, como a localização, o autor da arte, entre outros. Medindo a atenção do estudante durante o experimento, o sistema avalia a possibilidade de trazer conteúdo mais aprofundado sobre o tema, seguindo uma forma de avaliação conhecida como Testes Adaptativos Computadorizados - Computer Adaptative Test (CAT) - que seleciona conteúdo seguindo o nível de habilidade do estudante (REBOLLEDOMENDEZ et al., 2010). No caso da atenção do estudante diminuir, o sistema tenta reapresentar o conteúdo ou sugerir novos tópicos como alternativa. A aplicação deste sistema é ainda mais interessante, no ponto de vista educacional, se aplicado em grupos de alunos. Conectando os grupos remotamente, os alunos recebem um feedback quando algum dos colegas está com um nível muito baixo de atenção, como um pedido de ajuda, e o grupo pode retomar algum ponto que não foi entendido por todos que estão estudando. Professores podem acompanhar o desempenho e os níveis de atenção dos alunos, adaptando o conteúdo da aula de acordo com essa informação em tempo real. Os experimentos, feitos ainda com poucos alunos, são inconclusivos.

A estratégia de usar jogos é bem fundamentada na literatura. Estudos mostram que mais de $70 \%$ das crianças jogam com frequência (EOW; BAKI, 2009; JUNCO, 2012), utilizando redes sociais e despendendo muito tempo na internet, o que afeta negativamente os estudos. Para a criação de jogos educacionais, entretanto, deve existir o cuidado com uma série de fatores, como idade e gênero dos estudantes, experiências anteriores com jogos. O conteúdo, métodos e técnicas devem ser bem determinadas assim como sons, gráficos, controles e, principalmente, o feedback apropriado (PRENSKY, 2005). Yildirim e Varol (2013) defenderam que os jogos devem ser utilizados como reforços em algum tópico de ensino, ajudando a consolidar fundamentos e a repetição do conhecimento adquirido em um ambiente mais confortável. Um ponto importante levantado no artigo é que os estudos não consideram os diferentes níveis de stress e atenção de um aluno durante as aulas. $\mathrm{O}$ aluno pode chegar mais concentrado, relaxar na hora do almoço, ficar sonolento no início da tarde e voltar a se concentrar mais tarde, tudo sem influência direta do tipo de aula, mas sim apenas de sua própria rotina (YASUI, 2009). Usando o Neurosky Mindwave, os autores mediram os níveis de atenção e meditação de um aluno enquanto estudava usando um jogo educativo chamado Match Mind Match (MMM). Os altos níveis de meditação e atenção são importantes para o aprendizado pois quando um aluno se sente chateado, os níveis de cortisol em seu corpo ficam elevados, afetando a memória e o aprendizado. Segundo os autores, alguns dos jogos educacionais propostos na literatura são inadequados, ou por não proporcionarem um

12 Também discutida no Capitulo 4. 
feedback para alunos e professores da média de atenção e meditação ou por não se preocupar com a experiência do jogador. De toda forma, o MMM proposto não foi testado com alunos reais, então não é obtida nenhuma conclusão sobre a diferença do sistema proposto para os demais.

Em sua pesquisa, Verkijika e Wet (2015) convidaram 36 crianças de idades entre 10 e 16 anos, quase divididas igualmente em homens e mulheres, para utilizarem um jogo educacional desenvolvido pelos pesquisadores, a fim de medir os níveis de ansiedade com a matemática. $\mathrm{O}$ aprendizado de matemática é fortemente associado com emoções como a ansiedade (JANSEN et al., 2013; PRIMI et al., 2014) e sentimento como frustração e tédio tem um efeito adverso no aprendizado (SABOURIN; LESTER, 2014). Estudos mostram que 93\% dos cidadãos americanos sofrem com algum tipo de ansiedade matemática, o que afeta o desempenho dos alunos, e o mesmo acontece, até em maior escala, em países como a África do Sul. Apesar dos jogos mostrarem um enorme potencial para ajudar alunos com os estudos, ainda são necessários mais estudos empíricos para sustentar essa afirmação. Com relação às aplicações BCI, como comprovado pela pesquisa feita para este projeto de doutorado, ainda há muito o que ser testado. Os pesquisadores compararam uma escala utilizada na psicologia (Escala Fennema-Sherman de Ansiedade Matemática (FSMAS)) como os resultados obtidos pela interpretação do EEG, pois segundo os mesmos, os sistemas focam em testes após os jogos para avaliar o impacto no aprendizado do aluno, não discutindo o impacto dos jogos em outros componentes do aprendizado (como ansiedade, frustração, etc), experimentados pelos jogadores durante o jogo. Nesta abordagem, o jogador tinha um feedback do seu nível de ansiedade na tela do jogo, e sempre que seu nível de ansiedade ficava muito alto, um alerta aparecia na tela, pedindo para o jogador relaxar. O jogo consistia em vários níveis de dificuldade de contas matemáticas, com somas, subtrações, multiplicações e divisões. O usuário deveria clicar na resposta correta dentre quatro possíveis. O sistema não precisa da ajuda de especialistas para ser utilizado, permitindo que o usuário estude em casa, ou que seus pais e professores possam utilizar. Apesar de não especificar como são feitas as extrações de características, o sistema EPOC, na sua configuração padrão, utiliza a FFT. Os resultados demonstram que as informações da FSMAS e do BCI são similares, o que mostra seu grande potencial para ser utilizado no tratamento da ansiedade matemática.

Brennan et al. (2014) mediram a qualidade da informação captada utilizando essas toucas comerciais para tarefas mentais. Também utilizando o EPOC, quatro participantes saudáveis foram convidados a fazer tarefas em curtos períodos de tempo. O tempo de treinamento também foi curto: para cada participante, os comandos tinham de 3-15 períodos de treino de 8 segundos. Os sistema era treinado para reconhecer um estado "neutro" e outros quatro comandos: direita, esquerda, levantar e soltar. $\mathrm{O}$ treinamento para o estado neutro era feito com o participante relaxando, sem pensar em nada particular. Para os comandos de esquerda e direita, marcadores posicionados na esquerda e direita da tela e o usuário deveria olhar e focar nestes marcadores. Para treinar o comando de levantar, o participante deveria cerrar os seus dentes e para o comando de soltar ele deveria tocar seu pé esquerdo. Em seguida, o participante deveria repetir os comandos 
treinados 20 vezes ( 5 vezes para cada um) em no máximo 10 segundos, tendo 5 segundos de descanso entre uma requisição e outra, para mover um objeto virtual na tela do computador. Mesmo com o pouco tempo, o treinamento foi reconhecido pelo sistema, acertando em $81 \%$ das vezes. O comando "direita" foi o que melhor foi reconhecido durante o treinamento. Durante o experimento, entretanto, o sistema teve uma acurácia menor, ficando em $64 \%$ na média. $\mathrm{O}$ primeiro e o último participante não completaram a tarefa de soltar em nenhuma das 5 vezes em que foram solicitadas, porém todos os participantes conseguiram levantar o objeto nas 5 vezes. Um ponto importante apresentado pelo artigo é que algumas situações influenciaram no resultado final: a velocidade que a pessoa tinha para cumprir as tarefas, o pouco tempo de treinamento levando o autor a concluir que a indicação de engajamento medida pelo sistema pode ser ambígua, já que mesmo com todos os usuário totalmente focados na tarefa, a acurácia final foi considerada baixa. Existe, portanto, a necessidade de outras informações, como rastreamento do olhar ou sinais fisiológicos (como pressão sanguínea) para se obter informações mais completas. Outros projetos seguem a mesma premissa, utilizando mais informações além do BCI para obter um melhor resultado em sistemas para reabilitação (BERGAMASCO et al., 2011).

Essas aplicações BCI educacionais discutidas até agora são consideradas "Edutainment ${ }^{\prime \prime 13}$, porém existem aplicações consideradas mais sérias, usadas para tratamentos de distúrbios ou aplicados para educação em níveis superiores. Existem diversos tipos de "jogos sérios" aplicáveis à saúde, psicologia, terapia e até simulação militar, e sistemas BCI podem ser aplicados a todos tipos de jogos, com resultados significativos (KIM; BAE, 2014). Uma aplicação dos estudos em BCI é para o tratamento do Transtorno de Déficit de Atenção/Hiperatividade (TDA/H), distúrbio considerado comum durante a infância, que dificulta a concentração das crianças e, consequentemente, o aprendizado. Caso não seja tratado, pode causar problemas ainda mais graves na adolescência e na vida adulta, pois tente a se fazer acompanhar de outros transtornos, ou seja, exibe uma alta taxa de comorbidade (MEINZER et al., 2016).

No trabalho de Lim et al. (2012), 17 crianças (originalmente eram 20, porém 3 não completaram os experimentos) tiveram um tratamento intensivo de 8 semanas utilizando BCI e jogos, seguidos por outras 16 semanas com um tratamento de manutenção. A aquisição dos dados foi feita utilizando o Mindwave, com os eletrodos nas posições Fp1 e Fp2 do sistema 10-20. Artefatos como atividade ocular ${ }^{14}$ não são correlacionadas com condições de atenção e desatenção, por isso, foram facilmente excluídas do sistema. O sistema de treinamento é também um jogo onde se deve clicar em retângulos coloridos na tela. O retângulo é colorido de uma cor, mas em seu interior tem um nome de uma outra cor. O usuário deve clicar no retângulo em que a cor pedida está escrita. Essa calibração permitia um mapeamento individual do estado de atenção de cada uma das crianças. Durante o jogo, o nível de atenção da criança aumentava a velocidade de um avatar, e seu objetivo era completar um percurso no menor tempo possível. $\mathrm{O}$ espectro de potência era calculado para cada um dos canais separadamente, em seguida eram

13 Uma mistura de educacional e divertida (Education and Entertainment).

14 Artefatos fisiológicos e biológicos, como atividades muscular, ocular e respiração são comuns no EEG. 
segmentados em faixas de 2 segundos e computados utilizando uma FFT de 256 pontos e depois a diferença de potencial entre os canais era calculada. O sistema então selecionava características do sinal, maximizando a separação entre os estados de atenção e desatenção, de acordo com a informação teórica. Para medir os resultados do treinamento, os pais dos alunos participantes responderam um questionário dando notas para a desatenção e para o comportamento hiperativoimpulsivo dos alunos nas semanas 0, 4, 20 e 24. Baseado nessa escala, o treinamento intensivo de 8 semanas, com 3 tratamentos por semana, causou uma melhora estatisticamente significativa, tendo diminuído os sintomas de desatenção e hiperatividade. Porém, para o tratamento de manutenção, que era feito em menor escala, as crianças não tiveram uma melhora, mas também não regrediram para o quadro anterior. Os testes mostraram que existe correlação entre a melhora das crianças e as informações captadas pelo sistema.

\subsection{ErrP}

A percepção dos diferentes tipos de erros podem ajudar os sistemas a entender o que acontece durante uma atividade humana. Para isso, considera-se tanto o erro negativo (Error Related Negativity (ERN)) quanto o positivo (Pe) associado ao monitoramento de ações e detecção de erros. Para investigar a relação entre o processamento de erros e o auto-monitoramento consciente do comportamento, em (NIEUWENHUIS et al., 2001) foi feito um experimento que examinou se esses tipos de erros eram mensuráveis mesmo quando o usuário não percebia o erro. Neste trabalho, o tipo de erro positivo foi bem mais claro quando os usuário percebiam os erros cometidos. Independente de perceberem ou não os erros, o ERN era sempre considerável. Deste trabalho compreende-se que o erro positivo citado se refere ao ErrP. Com o crescimento de trabalhos sobre o assunto, a origem intra-cerebral dos potenciais evocados relacionados aos erros foi pesquisada em Brázdil et al. (2002). Neste experimento, foram estudados sete pacientes com patologias epiléticas, utilizando o paradigma oddball, registrando informações com reações motoras corretas e incorretas, verificando os lóbulos parietal, frontal e temporal. Os pesquisadores perceberam que o sinal aparece em vários pontos do cérebro, porém sendo mais longo (e mais fácil de ser analisado) nas regiões frontais.

Para a detecção automática de ErrPs, em (FERREZ; MILLAN, 2005) três voluntários deveriam mover um robô virtual de uma parte a outra em uma sala (para esquerda ou para a direita), enviando repetidos comandos até que o robô conseguisse chegar no alvo. Para cada vez que o robô recebia comandos, existia uma chance de $20 \%$ do robô tomar uma direção errada. Para os experimentos, foi utilizado o capacete Biosemic ActiveTwo, capturando 32 eletrodos seguindo o sistema 10-20. Os dados foram obtidos em $512 \mathrm{~Hz}$, e foi aplicado um filtro passabanda, ignorando a faixa entre 1-10Hz. Para classificação, foi feito um down sampling para $128 \mathrm{~Hz}$. Neste trabalho foi utilizado um classificador Gaussiano, verificando apenas os canais $\mathrm{Fz}$ e Cz, que são os que melhor indicam a existência do ErrP. Com essa configuração, o sistema foi capaz de acertar em $72 \%$ das vezes, reconhecendo os erros durante o experimento. 
Em um outro experimento, (FERREZ; MILLÁN, 2008) se perguntaram se o erro poderia ser medido também quando o erro era cometido pela interface, enquanto o sistema monitora as intenções do sujeito? Assim, foi criado um experimento para verificar se o feedback indica as respostas incorredas da interface em uma BCI simulada. Neste experimento, cinco voluntários saudáveis participaram de um experimento de interação humano-robô, utilizando-se uma janela curta para reconhecer os erros da interface. Seguindo configurações similares ao experimento anterior, o sistema foi capaz de reconhecer momentos corretos e de ErrP em 83,5\% e 79,2\% das vezes, respectivamente, usando um classificador construído com dados registrados até três meses antes.

Em um dos trabalhos melhor relacionados a esta tese, e útil também por disponibilizar uma base de dados, Chavarriaga e Millán (2010) descrevem um experimento em que os sujeitos deveriam movimentar um agente externo, no caso um quadrado verde, para uma posição específica da tela, definida por um quadrado vermelho. Durante essa intenção de movimentação, o sistema foi programado para, em momentos aleatórios, ir para a direção contrária à solicitada pelo usuário, gerando um erro forçado. Essa abordagem já se diferenciava das tradicionais, uma vez que o usuário não deveria dar comandos contínuos para o agente durante o experimento. Neste trabalho, foi demonstrada uma de reconhecimento do ErrP de 75.8\%, enquanto os momentos normais (sem a indução de erros) foram corretamente classificados em $63.2 \%$ das vezes. Esse resultado é a média de 6 participantes durante vários dias de coletas, que variavam ente 50 a 600 dias de diferença. Mais informações sobre aplicações, desafios e possibilidades do uso deste tipo de sinal podem ser visto em um survey destes mesmos autores Chavarriaga, Sobolewski e Millán (2014).

A percepção dos erros utilizando EEG com aplicações em jogos foi também utilizada em Spüler e Niethammer (2015). Neste trabalho, o usuário deveria mover uma bola para passar entre barras azuis que caiam da tela. Seguindo a ideia de Chavarriaga e Millán (2010), os pesquisadores criaram situações de erros forçados, porém adicionaram alguns graus diferentes de erro. Durante a atividade, a bolinha poderia aleatoriamente se mover para o lado oposto com um angulo de $45^{\circ}, 90^{\circ}$ ou $180^{\circ}$. Além disso, os pesquisadores compararam esse erro, que foi chamado de erro forçado, com erros causados pela dificuldade do jogo, em que o usuário não conseguia passar de fase quando a velocidade e a quantidade de barras ficasse maior. 10 sujeitos saudáveis (média de idade de 24.1 anos) participaram do experimento por mais de uma hora, gerando para cada uma média de 597 erros de dificuldade, 86 erros forçados e 475 exemplos sem erros. Tomados par a par, os resultados mostraram $75.5 \%$ de acerto em média para a comparaçao entre os dois tipos de erro. De forma semelhante, foram obtidos $74.1 \%$ classificando erro forçado contra o sinal sem erros e $66.0 \%$ na comparação entre erro de dificuldade e nenhum erro. Além disso, não foi encontrado nenhuma diferença significativa entre os diferentes graus de erro, diferentemente da comparação entre as médias dos erros de dificuldade e forçado, que apresentavam diferenças estatísticas em vários pontos do sinal. 
Os ErrPs são utilizados em sistemas de soletração para ajudar na classificação destes algoritmos. Porém poucos trabalhos conseguem estabelecer a boa utilização de técnicas baseadas nos ErrPs para adaptação destes algoritmos, em comparação a outros métodos supervisionados parciais. Para fazer essa comparação, Zeyl et al. (2016b) utilizaram um speller P-300 de duas fases com um subconjunto de testes online usando uma confiança medida de duas maneiras: com as resposta do ErrP; pontuações posteriores derivadas do p300 e; uma mescla das duas abordagens. Primeiro, foi avaliada a habilidade da adaptação parcialmente supervisionada e métodos de reciclagem para ajuste dos parâmetros, passo necessário para otimização online de SOA (Stimulus-onset assynchrony). Para os experimentos, 11 adultos saudáveis fizeram 3 sessões de soletração em dias separados. A adaptação dos métodos foi comparada, usando informações como a curva AUC e a quantidade de símbolos processados por minuto. Resultados usando os métodos supervisionados mostraram um aumento de $0.9 \%$ e 1,9\% na AUC (considerando a segunda e terceira sessão, respectivamente. Ambos os resultados passaram nos testes estatísticos) usando treinamentos do mesmo dia contra uso de treinamentos do dia anterior, o que suporta a adaptação do classificador em geral. Tanto usando AUC quanto a quantidade de símbolos soletrados, os resultados indicaram que o ErrP não é capaz de melhorar o desempenho do sistema. Em outro trabalho envolvendo sistemas de soletração, Cruz, Pires e Nunes (2017) utilizaram um duplo detector de ErrP, gerando duas respostas do sistema na tentativa de melhorar o resultado do sistema BCI ainda mais. Participaram do experimento nove pessoas saudáveis e um tetraplégico. A utilização do duplo detector permitiu uma melhor da 5\% na acurácia do sistema, ficando em 89.9\% e melhorando a acurácia para 2.92 símbolos por minuto.

Em seu trabalho Zeyl et al. (2016a) diz que o ErrP foi muito utilizado em BCIs visuais, tendo sucesso em algumas abordagens e sendo ruim para outras aplicações. Como normalmente os sistemas que usam as informações do ErrP são para melhora da acurácia, este trabalho utilizou o feedback de erro para melhor sistemas de BCI de audição, que comumente tem acurácias piores aos sistemas visuais. O sistema usa também o P300, porém é mais suscetível a ruídos e erros de interpretação por parte do sujeito. Foram convidados nove sujeitos saudáveis, que fizeram duas sessões com o sistema, em dois dias separados. Foi utilizada a área AUC para medir a acurácia do ErrP, atingindo 0.946. Esse resultado, além da melhora na velocidade em interpretação do erro quando comparada a confiança do próprio sistema BCI mostram que a utilização de ErrP permite melhora substancial no desempenho das BCI auditivas. O ErrP também foi utilizado como condição de controle de parada de um braço robótico (BHATTACHARYYA; KONAR; TIBAREWALA, 2017). Neste trabalho, a imagética motora era responsável pela movimentação do braço, usando a imaginação de diferentes membros do corpo para cada uma das atividades do braço e, quando o usuário percebia q o braço ultrapassava uma linha de atuação (ou seja, quando o usuário cometia um erro) o ErrP disparado parava o braço. Foram usados coeficientes Wavelets para extração de características e uma SVM para classificação. O ErrP foi detectado em $80 \%$ das vezes.

Em um survey sobre BCI aplicados para jogos, alguns dos grandes desafios da área foram 
apresentados. De acordo com Kerous, Skola e Liarokapis (2018), a pesquisa em jogos com BCI tem sido negligenciada, muito por conta da sensibilidade à ruídos, a dependência da colaboração e aceitação do usuário em participar do experimento, o alto valor da maioria dos sistemas para captura de sinal e também pelos artefatos presentes no sinal. A maioria dos trabalhos foca em potenciais evocados bastante conhecidos, como o P300 com o paradigma oddball e os Steadystate Visually Evoked Potential - SSVEP. As áreas de maior aplicabilidade dos jogos são as médicas, neurofeedback e principalmente imagética motora, sendo difícil encontrar pesquisas com aplicações voltadas à educação. O uso de ErrP não aparece neste survey, evidenciando que a técnica não foi até então utilizada para fornecer feedback das atividades em jogos.

Yousefi, Sereshkeh e Chau (2018) discutem que o uso ErrP para melhorar a classificação de sistemas de imagética motora, já que podem acusar erros na interpretação do usuário em tempo real, é bem estabelecido, mas não fica determinada a sua capacidade em outras atividades de BCI. Para confirmar a existência do ErrP em outras atividades, 20 adultos saudáveis participaram de duas sessões cada, cada uma delas com várias atividades mentais. Todas as atividades (aritmética, contagem, geração de palavras, rotação de figuras e se manter ocioso) deferiar ser feita para finalizar um alvo que aparecia em uma interface gráfica (cada atividade tinha seu próprio alvo). Para simulação dos erros, em $20 \%$ das vezes o usuário recebia algum feedback errôneo, além de ver sua pontuação para chegar no alvo também ser afetada. O experimento confirmou o acontecimento do ErrP com um pico negativo seguido por dois picos positivos em um espaço de aproximadamente 500ms. Com a utilização do feedback do ErrP, o sistema de reconhecimento das atividades teve uma melhora de $14 \%$, demonstrando que o uso do reconhecimento do ErrP maximiza a acurácia de sistemas BCI baseados em atividades cognitivas.

Kumar, Pirogova e Fang (2018) utilizaram um tipo específico de ErrP, chamado ErrP de obervação em seus trabalhos. Os 6 participantes do experimento tinham a tarefa de observar um cursor se movendo na tela, e este cursor deveria chegar at um alvo destacado na cena. Para tentar gerar os ErrPs, em alguns momentos esse cursor se movia para o lado oposto ao que estava esse objetivo, porém o usuário não tinha controle desse cursor. Utilizando uma LDA para classificação dos momentos com e sem erros, foi obtida uma acurácia de $81.43 \%$ com os momentos normais e uma acurácia $68.83 \%$ dos sinais com erro. Esse resultado ainda era melhor do que os obtidos utilizando um classificador gaussiano. Os pesquisadores ainda desenvolveram uma outra LDA, com parâmetros diferentes da que havia sido utilizado neste primeiro teste, porém obtiveram um resultado pior, passando a acertar $79.4 \%$ do sinais normais e $64.1 \%$ dos sinais com erros.

Como dito no Capítulo 1, uma das mais importantes aplicações de BCI é a reabilitação de pessoas com dificuldades de locomoção. Uma das maiores dificuldades das pessoas é as vezes não conseguir sequer pedir por alguma ajuda, ficando totalmente dependentes de ajuda. Para ajudar na comunicação, o ErrP foi utilizado para melhorar a acurácia de sistemas baseados em paradigmas conhecidos, com o oddball (BEVILACQUA; PERDIKIS; MILLAN, 2019). Poucos trabalhos exploram encontrar o ErrP em outras atividades de BCI, especialmente com o feedback 
sendo feito de forma online. Para testar essas condições, 10 indivíduos saudáveis executaram um série de atividades de imagética motora com tarefas de fala. Em alguns casos foi oferecido ao sujeito um feedback do sistema BCI e foi negado em outros casos. Os resultados $(78 \%$ de acurácia em e $74 \%$ de acurácia com o feedback) não demonstram diferença significativa entre ter ou não a informação do sistema nesta atividade.

A utilização desse tipo de sinal cresceu muito, uma vez que os resultados melhoraram consideravelmente com novas abordagens. Isso gerou interesse em entender melhor internamente no cérebro o acontecimento do ErrP, como a análise do ErrP em topografia cortical durante um sistema BCI com controle contínuo de erros (WILSON et al., 2019). O ErrP também foi utilizado em atividades de grande carga mental: controlador de tráfego aéreo (GOH et al., 2019). Apesar de ser ainda parcial, os resultados mostram que a utilização desse feedback pode ajudar sistemas de tomada de decisão, aprendendo com os acertos e erros do sujeito humano. Os experimentos foram feitos em um ambiente simulado, com várias decisões a serem tomadas de forma rápida, aumentando o estresse do operador e, consequentemente, a incidência do ErrP. Esses resultados evidenciam a importância de bons sistemas de reconhecimento de ErrP online.

\subsection{Considerações Finais}

Com os avanços da tecnologia, pesquisas envolvendo a interação entre homens e máquinas foram se tornando cada vez mais constantes. Esses trabalhos envolvem a repetição de movimentos, acompanhamentos de pessoas com dificuldades e também aplicações na educação. A robótica educacional se tornou uma realidade e se mostra bastante eficiente dentro de sala de aula, aumentando o interesse dos alunos por lógica, programação e trabalho em equipe.

Paralelamente, a tecnologia também permitiu a obtenção dos sinais cerebrais sem a necessidade de cirurgia, com técnicas como a eletroencefalografia. As pesquisas em sistemas BCI normalmente envolvem ajudar pessoas com doenças severas, que as impede de movimentar algum membro. Outra linha de pesquisa, importante para este trabalho, são as BCI aplicadas a educação. A pesquisa ainda precisa ser melhor fundamentada, pois muito pouco se foi provado nesta área, mas a literatura indica que é um caminho promissor para ajudar as pessoas a ter melhores desempenhos nos estudos, quando combinada com mais informações. 



\section{3}

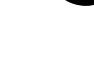

\section{FUNDAMENTAÇÃO TEÓRICA}

Neste capítulo, serão apresentados os vários métodos de Aprendizado de Máquina utilizados tanto na filtragem dos sinais EEG, quanto para classificação do ErrP. Os sinais EEG foram pré-processados utilizando as técnicas FIR, Butterworth e ICA e para extração de características dos sinais EEG foram comparadas as técnicas de fourier e wavelet. Por serem fundamentais para o pré-processamento, análise e classificação dos sinais EEG, estas técnicas são descritas em detalhes neste capítulo.

\subsection{Filtragem Digital}

Dentre a grande quantidade de dados gerados pela eletroencefalografia, torna-se complexo extrair e classificar características importantes para determinadas tarefas. Para ajudar na limpeza do sinal, diminuindo a presença de ruídos e artefatos, é comum a utilização de filtros digitais, que são divididos em filtros temporais e espaciais.

\subsubsection{Temporais}

O Finite Impulse Response (FIR) é um tipo de filtragem que tem uma resposta de fase linear, indicando que nenhuma distorção é produzida no sinal filtrado. Como é um filtro nãorecursivo, ou seja, não depende de uma entrada do próprio filtro, o FIR é sempre estável. Efeitos de precisão finita e erros de quantização são menos severos para esta abordagem e é recomendada sua utilização quando a distorção de fase desejada é pequena. Um filtro FIR genérico é dado por:

$$
y(n)=\sum_{i=0}^{P}\left(h_{i} x(n-i)\right)
$$

onde $y(n)$ é o sinal de saída, $P$ é a ordem do filtro, $h_{i}$ é o valor da resposta do impulso no i-ésimo instante usado como coeficiente e $x(n)$ é o sinal de entrada. 
Infinite Impulse Response (IIR) é um tipo de filtragem que necessita de menos coeficientes para atender uma mesma especificação (comparados ao FIR) e, correspondentemente, tem menor atraso. A utilização dos filtros IIR é recomendada para tarefas bem seletivas no domínio da frequência ou para conversão de filtros analógicos, já que estes podem ser facilmente convertidos em digitais utilizando o IIR. Um filtro IIR genérico é dado por:

$$
y(n)=\sum_{i=0}^{L}\left(h_{i} x(n-i)\right)-\sum_{k=1}^{K}\left(g_{i} y(n-k)\right)
$$

onde $y(n)$ é o sinal de saída, $L$ e $K$ são as ordens do filtro, $h_{i}$ e $g_{i}$ são os valores da resposta do impulso no i-ésimo instante usado como coeficiente e $x(n)$ é o sinal de entrada. O filtro depende das saídas passadas (recursividade), fazendo com que a duração da resposta seja infinita.

\subsubsection{Espaciais}

A Independent Component Analysis (ICA) se baseia na separação de informações a respeito dos dados de forma não-supervisionada. Em geral, o modelo ICA assume que o conjunto de sinais obtidos é uma combinação linear de fontes desconhecidas. A equação básica do modelo não prevê o ruído nos dados, o que não é realista nas aplicações para BCI, mas existem modelos mais complexos na literatura. O modelo, porém, prevê algumas restrições: é preciso assumir que as componentes independentes são estatisticamente independentes e precisam ter distribuições de probabilidade não-gaussianas. Sejam $n$ variáveis aleatórias observadas $x_{1}, \ldots, x_{n}$, significando os sinais misturados, capturadas pelos eletrodos. O sinal é modelado como uma combinação linear de $n$ variáveis aleatórias $s_{1}, \ldots, s_{n}$ tal que:

$$
x_{i}=\sum_{j=1}^{n}\left(a_{i j} s_{n}\right)
$$

onde $a_{i j}$ são os coeficientes de mistura. É comum na literatura o modelo matricial, denotando a matriz $A$ formada pelos coeficientes de mistura.

O Common Spatial Patterns (CSP) se baseia na decomposição do sinal em padrões espaciais, maximizando a variância do sinal para uma classe e minimizando para outra, ou seja, maximizando as diferenças entre as classes envolvidas. As desvantagens da CSP são a necessidade de uma densidade alta de eletrodos para captura de sinal e sua sensibilidade a artefatos. Este processo usa as covariâncias das classes, separando as principais características dos sinais. Seja $X_{1}$ de tamanho $\left(n, t_{1}\right)$ e $X_{2}$ de tamanho $\left(n, t_{2}\right)$ duas janelas de sinais multi-variados, com $n$ sendo o número de sinais e $t_{1}$ e $t_{2}$ a quantidade de exemplos. O CSP determina a máxima variância $w^{T}$ entre as janelas: 


$$
w=\operatorname{argmax}_{w} \frac{\left\|w X_{1}\right\|^{2}}{\left\|w X_{2}\right\|^{2}}
$$

computando então as matrizes de covariância:

$$
R_{x}=\frac{X_{x} X_{x}^{T}}{t_{x}}
$$

a resposta é obtida através da decomposição generalizada dos autovalores.

\subsection{Transformada de Fourier}

As transformações matemáticas são aplicadas aos sinais para se obter informações que não são facilmente identificáveis no sinal puro. A maioria dos sinais puros está no domínio de tempo, ou seja, o sinal é mensurável em função do tempo. Usualmente, os sinais são representados pela amplitude, gerando um gráfico de tempo-amplitude, mas nem sempre essa é a melhor forma de representar o sinal. Para os sinais biológicos, por exemplo, sintomas e condições patológicas ${ }^{1}$ podem ser mais óbvias no domínio de frequência do que no domínio de tempo. Existem muitas transformadas para serem estudadas: Transformada de Hilbert, de Radon, Distribuições de Wigner, entre outras. Todas elas possuem vantagens e desvantagens na sua área de atuação. Será discutida mais aprofundadamente a transformada de Fourier nesta pesquisa, dado os resultados da literatura com trabalhos utilizando esta técnica.

Batizada em homenagem ao matemático Jean Baptiste Joseph Fourier, a transformada de Fourier é a mais conhecida e utilizada, principalmente em aplicações das engenharias. Ela transforma o sinal do domínio de tempo para o domínio de frequência de forma reversível, ou seja, é possível retornar para o sinal original. Porém, apenas uma informação está disponível por vez, ou tempo ou frequência. Essa característica é particularmente importante para o EEG, devido ao fato do sinal ser não-estacionário ${ }^{2}$. A técnica consiste em decompor sinais periódicos em somas ponderadas de funções seno e cosseno.

Existem quatro tipos diferentes de transformadas da "família" Fourier, classificadas segundo alguns critérios dos sinais:

- Transformada de Fourier (FT): Sinal contínuo e aperiódico;

- Série de Fourier: Sinal contínuo e periódico;

- Transformada de Fourier de Tempo Discreto (DTFT): Sinal discreto e aperiódico;

Diagnósticos de doenças.

2 O sinal tem propriedades que se alteram em um período de tempo observável. 
- Transformada Discreta de Fourier (DFT): Sinal discreto e periódico.

Este trabalho será concentrado no caso geral de sinais contínuos e aperiódicos. A FT contínua de uma função $x(t)$ é definida por:

$$
X(\omega)=\int_{-\infty}^{+\infty} x(t) e^{-j \omega t} d t
$$

onde $e^{-j \omega t}=\cos \omega t-j \sin \omega t$ são exponenciais complexos e $\omega$ é a frequência angular relacionada com a frequência linear $f$ por $\omega=2 \pi f$. Como a função é reversível, a FT inversa é dada por:

$$
x(t)=\frac{1}{2 \pi} \int_{-\infty}^{+\infty} X(\omega) e^{-j \omega t} d \omega
$$

Sinais digitais têm comprimento finito e são obtidos em uma dada frequência de amostragem, o que gera problemas para a FT. Uma vez que existe um número finito de pontos, com base na FT, pode-se fazer essa discretização de $x$, definindo as DFT como sendo a soma finita de exponenciais complexas. Assim temos as funções:

$$
\begin{gathered}
X(k)=\sum_{n=0}^{N-1} x(n) e^{-j 2 \pi k n / N} \\
x(n)=\frac{1}{N} \sum_{n=0}^{N-1} X(k) e^{-j 2 \pi k n / N}
\end{gathered}
$$

Porém na prática, devido a redundância embutida pelos coeficientes complexos, o algoritimo mais utilizado para o processamento de sinais é a Transformada rápida de Fourier (FFT Fast Fourier Transform), fazendo com que a complexidade do algoritmo caia de $N^{2}$ para $N \log N$ operações.

\subsection{Transformada Wavelet}

Se a Transformada de Fourier decompõe o sinal em senos e cosenos, $i$. e. as funções localizadas no chamado espaço Fourier, as transformadas Wavelets usam funções que são localizadas tanto no espaço real quanto no Fourier. Em 1909, Alfréd Haar publicou sua tese Zur Theorie der orthogonalen Funktionensysteme, onde introduzia o que depois seria reconhecido como o sistema wavelet fundamental (STANKOVIĆ; FALKOWSKI, 2003). Depois da Fourier 
janelada, as Wavelets são o passo lógico seguinte, sendo porém essa janela de tamanho variável. A definição de uma transformada Wavelet para um sinal contínuo é dada por:

$$
F(a, b)=\int f(t) \Psi_{a, b}(t) d t
$$

sendo os parâmetros $a$ e $b$ variantes em $\Re$. Essas informações correspondem às informações de escala e tempo. A função $\Psi_{a, b}$ é denominada Wavelet e é definida como:

$$
\begin{gathered}
\Psi_{a, b}=\frac{1}{\sqrt{a}} \Psi\left(\frac{t-b}{a}\right) \\
F_{m, n}(a, b)=a_{0}^{\frac{-m}{2}} \int f(t) \Psi\left(a_{0}^{-m} t-n b_{0}\right)
\end{gathered}
$$

A Wavelet mãe, cuja dilatação e translação influenciam o comportamento da função, deve satisfazer a seguinte propriedade:

$$
\int \Psi(t) d t=0
$$

\subsubsection{Transformada Haar}

Uma família particular de funções lineares podem ser usadas como base para representar qualquer função de energia finita dada no sistema Haar. A base ortogonal foi definida por Haar sobre o domínio $[0,1]$, ou seja, $h_{0}(x), h_{1}(x), \ldots, h_{n}(x)$ tal que, para qualquer função contínua sobre o intervalo definido, a série da equação 3.14 converge a $f(x)$ de forma uniforme. A Wavelet mãe é definida como a equação 3.15 .

$$
\begin{gathered}
f(t)=\sum_{j, k} a_{j, k} \psi_{j, k}(t) \\
\Psi_{j, k}(x)=2^{j / 2} \Psi\left(2^{j} t-k\right)
\end{gathered}
$$

onde $n=2^{j}+k, k \in\left[0,2^{j}\right], x \in\left[k 2^{-j},(k+1) 2-1\right.$. A equação 3.14 é a expressão sintética para a função no domínio do tempo. Assim, uma versão da construção de Haar é definida por:

$$
h(x)=\left\{\begin{array}{cc}
1, & x \in[0,0.5] \\
-1, & x \in[0.5,1] \\
0, & \text { caso contrario }
\end{array}\right\}
$$

Devido a ortogonalidade das funções bases, os coeficientes de escala com produtos internos ou projeções, considerando essas funções base são determinados por:

$$
a_{j, k}=\left\langle\psi_{j, k}(t), f(t)\right\rangle
$$


Finalmente, as projeções para o espaço de Hilbert tem a forma integral:

$$
\left\langle\psi_{j, k}, f(t)\right\rangle=\int_{-\infty}^{\infty} \psi_{j, k}^{*}(t) f(t) \mathrm{d} x
$$

\subsubsection{Transformada de Daubechies}

Outra transformada muito utilizada para análises de sinais é a Daubechies (Vonesch; Blu; Unser, 2007). Considerando que a função $\phi_{r}(x)$ em $L^{2}(\Re)$ tem a propriedade que $\phi_{r}(x-k) \mid k \in Z$ é uma base sequencial ortonormal em $L^{2}(\Re)$, sendo $j$ o índice de escala, $k$ o índice de translação e $r$ o índice de filtragem, definimos a equação:

$$
\phi_{r, j, k}(x)=2^{\frac{j}{2}} \phi_{r}\left(2^{j} x-k\right), j, k \in Z
$$

A tendência $f_{j}$ na escala de uma função onde $f \in L^{2}(\mathfrak{R})$ é definida como a equação 3.20 e os detalhes de flutuações são definidos pela equação 3.21. A análise dos detalhes em cada escala precisa da definição de uma base ortonormal $\Psi_{r}(x)$ com propriedades similares das já definidas anteriormente.

$$
\begin{gathered}
f_{j}(x)=\sum_{k}\left\langle f, \phi_{r, j, k}\right\rangle \phi_{r, j, k}(x) \\
d_{j}(x)=f_{j+1}(x)-f_{j}(x)
\end{gathered}
$$

Foram portanto definidas as funções Wavelet pai (função scaling - $\left.\phi_{r}(x)\right)$ e mãe $\left(\Psi_{r}(x)\right)$, que são as funções mais importantes para a análise dessa base de wavelets. As famílias de Wavelets são geradas a partir da pai ou da mãe, mudando-se a escala e a translação no tempo. A base de Dauchebies segue as seguintes propriedades: $\Psi_{r}$ tem o intervalo de suporte compacto $[0,2 \mathrm{r}+1]$ e $\int_{-\infty}^{\infty} \psi_{r}(x) d x=\cdots=\int_{-\infty}^{\infty} x^{r} \phi_{r}(x) d x=0$.

A propriedade do suporte compacto permite a localização no domínio espacial, o que é importante para os trabalhos com BCI. Assim, as Wavelets mãe determinam os detalhes de um sinal e os coeficientes da Wavelet pai armazenam as informações de tendência. Essas Wavelets são implementadas através de filtros Quadrature Mirror Filters (QMF) com sua convolução implementada através de filtros passa-baixa e passa-alta. Comparadas as Wavelets Haar, as Daubechies preservam mais informações do sinais por apresentarem uma melhor concentração de energia.

\subsection{Independent Component Analysis - ICA}

Muito usada principalmente para problemas multi-canais, a ICA separa o sinal $x(n)=$ $\left[x_{1}(n), x_{2}(n), \ldots, x_{k}(n)\right]^{T}$ que está misturando em várias fontes $s(n)=\left[s_{1}(n), s_{2}(n), \ldots, s_{w}(n)\right]^{T}$. 
A ICA, portanto, define uma matriz quadrática $M$ pxp, sendo $p$ o número de fontes, que define o peso em que cada uma dessas fontes esta presente no sinal adquirido pelo EEG seguindo a equação 3.22. Essa matriz retorna a proporção em que cada um dos componentes independentes está ligado a cada uma das fontes. Neste trabalho, assume-se que o número de fontes é a quantidade de eletrodos utilizados. Essa separação do sinal seguiu as premissas definidas para o ICA infomax, além de usar uma variante aprimorada pela transformada Wavelet.

$$
x(n)=M s(n)
$$

A implementação utilizada identifica os componentes usando dois thresholds básicos: o mMSE e a curtose. O índice mMSE é baseado no conceito de entropia dos exemplos, ou seja, é um índice para quantificar a regularidade e complexidade dos dados obtidos. Para observar, dado o w-ésimo componente estimado, considerando que existam $N_{s}$ pontos $\left(\left\{\hat{S}_{w}(n): 1 \leq n \leq N_{s}\right\}\right)$ o seguinte vetor de características é formado pela equação 3.23. $\hat{S}_{w} 0(i)$, dado pela equação 3.24 , é a baseline para generalização do vetor e $m$ é o tamanho máximo de épocas.

$$
\begin{gathered}
\hat{S}_{i}^{m}=\left\{\hat{S}_{w}(i), \hat{S}_{w}(i+1), \ldots, \hat{S}_{w}(i+m-1)\right\}-\hat{S}_{w} 0(i) \text { para }\left(i=1, \ldots, N_{s}-m+1\right) \\
\hat{S}_{w} 0(i)=\frac{1}{m} \sum_{j=0}^{m-1} S_{p}(i+j)
\end{gathered}
$$

Considerando que o número máximo $(\mathrm{N})$ de pontos pode ultrapassar os 45000 para cada uma das instâncias, foram setadas janelas de 10 segundos de sinal (por volta de 5000 pontos). Para definição dos componentes, é necessário o cálculo das distâncias entre os vetores, dada pela equação 3.25. É possível também computar o grau de similaridade entre vetores. Esse cálculo é feito pela equação 3.26, onde $r$ é a inclinação da função sigmoide, ou seja, representa a tolerância. O valor setado para $r$ foi de 0.3 .

$$
\begin{gathered}
d_{i j}^{m}=d\left[\hat{S}_{i}^{m}, \hat{S}_{j}^{m}\right]=\max _{h \in(0, m-1)}\left|\hat{S}_{w}(i+h)-\hat{S}_{w} 0(i)-\left(\hat{S}_{w}(j+h)-\hat{S}_{w} 0(j)\right)\right| \\
D_{i j}^{m}=f\left(d_{i j}^{m}, r\right)=\frac{1}{1+\exp \left[\left(d_{i j}^{m}-0.5\right) / r\right]^{\prime}}
\end{gathered}
$$

Finalmente, o índice mMSE é definido por:

$$
\begin{gathered}
m M S E(m, r)=\lim _{N s \rightarrow \infty}\left(\ln B_{r}^{m}-\ln A_{r}^{m}\right) \\
m M S E\left(m, r, N_{s}\right)=-\ln \left(A_{r}^{m} / B_{r}^{m}\right)
\end{gathered}
$$


Sendo A e B funções utilizadas para contar as $m$ e $m+1$ correspondências com a tolerância.

$$
\begin{aligned}
A_{r}^{m}(i) & =\frac{1}{N s-m-1} \sum_{j=i, j \neq i}^{N_{s}-m} D_{i j}^{m}+1 \\
B_{r}^{m}(i) & =\frac{1}{N s-m-1} \sum_{j=i, j \neq i}^{N_{s}-m} D_{i j}^{m} \\
A_{r}^{m} & =\frac{1}{N_{s}-m} \sum_{i=1}^{N_{s}-m} A_{r}^{m}(i) \\
B_{r}^{m} & =\frac{1}{N_{s}-m} \sum_{i=1}^{N_{s}-m} B_{r}^{m}(i)
\end{aligned}
$$

Além do mMSE, foi utilizado também o índice de curtose, definido como acumulador de quarta-ordem, usado para definir a variabilidade dos dados e medir a forma da onda de acordo com uma distribuição Gaussiana. Considerando $m_{w c}$ como o c-ésimo momento central e $m_{w 1}$ a média desse centro, a curtose é definida pelas seguintes equações:

$$
\begin{gathered}
\text { curtose }_{w}=m_{w} 4-3 m_{w} 2^{2} \\
m_{w c}=E\left\{\left(\hat{S}_{w}-m_{w} 1\right)^{c}\right\}
\end{gathered}
$$

Ao final, para auxiliar na classificação do sinal, foi utilizada a ICA aprimorada com uso de Wavelets, definidas pelas equações:

$$
\begin{gathered}
W(a, b)=\frac{1}{\sqrt{a}} \int \hat{S} w(n) \Psi_{a, b}(n) d n \\
\Psi_{a, b}=\Psi\left(\frac{n-b}{a}\right)
\end{gathered}
$$

\subsection{Classificadores}

Inspiradas no funcionamento do cérebro humano, a proposta das Redes Neurais Artificias (Artificial Neural Networks (ANN)) é manter um processamento paralelo e independente dos neurônios, sendo similar ao comportamento biológico. Isso permite uma maior estabilidade para a rede, ou seja, se um pequeno número de neurônios for danificado, a rede ainda opera, com pouca perda de desempenho. O neurônio, que é base o sistema nervoso (KANDEL; SCHWARTZ; 


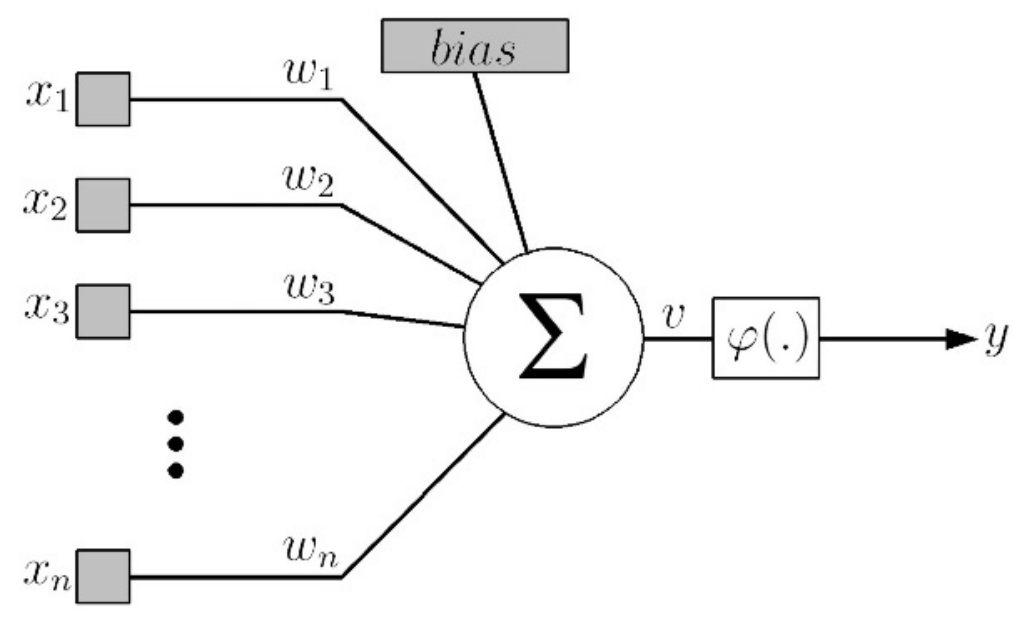

Figura 3 - O Neurônio não-linear.

Fonte: Haykin (2008).

JESSELL, 1997), possui funções de receber, processar e transmitir informações (MACHADO, 2000) e o modelo matemático deve traduzir essas funções para o mundo computacional

O primeiro modelo de um neurônio foi proposto por McCulloch e Pitts, ficando restrito a representação matemática do neurônio biológico e não considerava o que ocorria no restante do cérebro. Mostrado na Figura 3, o neurônio é composto pelas entradas (representando os dendritos) que são os estímulos recebidos e são ponderados pelos pesos (sinapses). A saída é obtida após um somatório de todas essas entradas multiplicada pelos pesos. As equações do modelo matemático são definidas por:

$$
\begin{gathered}
\sum_{i=1}^{n}\left(x_{i} w_{i}\right) \geq \theta \\
v=\left(\sum_{i=1}^{n} x_{i} w_{i}\right)+\text { bias } \\
y=\varphi(v)
\end{gathered}
$$

onde $n$ representa a quantidade de entradas $(x), w$ os pesos associados as sinapses (quando $w$ é positivo a sinapse é excitatória, sendo inibitória em caso negativo) e $\theta$ representa o limiar de ativação. Matematicamente, a equação 3.37 é o produto escalar do vetor de pesos $w$ com o vetor de entradas $x$. $v$ é o somatório das entradas ponderadas pelos pesos acrescido do termo bias (equação 3.38). $\varphi($.$) é a função de ativação do neurônio e y$ a sua saída (equação 3.39). 
A função sigmóide logística (equação 3.40) e a tangente hiperbólica (equação 3.41) são as mais utilizadas como função de ativação, sendo que a principal vantagem dessa escolha, segundo Haykin (2008), está na sua garantia da derivação, o que permite a construção de algoritmos que dependem dessa derivada para o cálculo do gradiente, como é o caso do algoritmo backpropagation (subseção 3.5.1).

$$
\begin{gathered}
\varphi(v)=(1+\exp (-a v))^{-1} \\
\varphi(v)=\tanh (v)
\end{gathered}
$$

Devido às limitações, novas modelagens mais eficientes surgiram com outras propostas, como o modelo não-linear perceptron (Figura 3). O modelo foi bastante utilizado, mas logo foi desacreditado por não resolver um problema simples: separar as respostas do XOR. Isso acontece porque o perceptron é um modelo de uma única camada, ou seja, um único hiperplano que separa o espaço de dados, não sendo capaz de resolver esse problema de classificação. Para resolver esse problema, foram propostas as Multi Layer Perceptron (MLP) ${ }^{3}$, uma generalização do modelo de uma única camada. Com mais camadas é possível traçar mais hiperplanos e assim resolver todo problema que seja linearmente separável. Sua arquitetura está apresentada na Figura 4, e mostra a organização por camadas da rede. A primeira camada, chamada camada de entrada, é apenas um canal de transmissão para a próxima camada. O sinal é propagado através da rede (pelas camadas $1=0,1, \ldots, \mathrm{L})$, sofrendo a ponderação do peso sináptico de cada camada $\left(w_{i j}\right)$. A soma de todas as entradas $\left(y_{j}\right)$ ponderadas é chamada de campo local induzido $(v)$ e é representada pela equação (3.42).

$$
v_{j}^{l}=\left(\sum_{i=1}^{m} w_{j i}^{l} y_{i}^{l-1}\right)+\text { bias }_{j}^{l}
$$

O sinal de saída do neurônio $\left(N_{i}^{l}\right)$ é computado pela função de ativação $\varphi($.$) (equação (3.43)).$

$$
y_{j}^{l}=\varphi\left(v_{j}^{l}\right)
$$

Mas as MLPs carecem com o problema de ajuste de pesos nas camadas ocultas. Para resolver esse problema, os pesquisadores Rummelhart, Hintno e Willians propuseram, em 1986, o algoritmo de retropropagação do erro (backpropagation), baseados no trabalho de Bryson e Ho em 1969. 


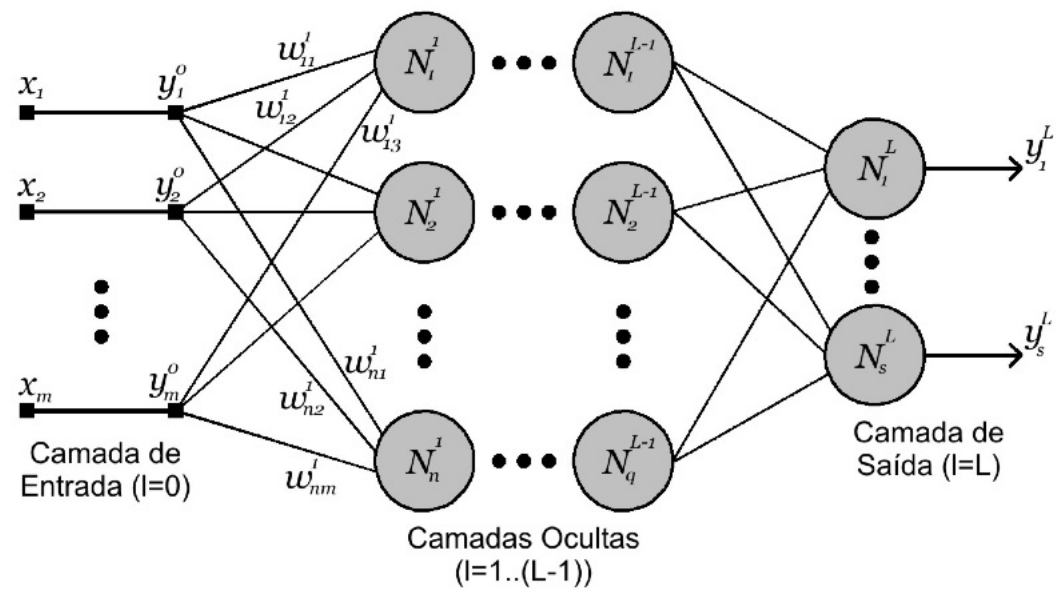

Figura 4 - Arquitetura da Rede Neural MLP.

Fonte: Haykin (2008).

\subsubsection{Algoritmo BackPropagation}

Tanto pelo seu papel histórico, em reiniciar as pesquisas com as ANN quanto pelo seu poder computacional, o algoritmo backpropagation é um dos mais importantes desenvolvidos para as redes neurais. Este algoritmo utiliza a regra delta generalizada, um método de aprendizado, que com a aplicação do gradiente descendente da superfície do erro, minimiza o erro propagado em todas as camadas da rede, permitindo a convergência do algoritmo.

O erro obtido na camada de saída (comparação da resposta da rede com o resultado esperado) é causado por uma sequência de erros nas camadas anteriores. Neste algoritmo, o erro é retro-propagado para o ajuste dos pesos individuais de cada neurônio nas camadas. Assim, a utilização da rede se dá em duas fases: a fase feed foward, onde o sinal passa pelas camadas, obtendo-se a saída e calculando o erro e a fase backward, onde esse erro é usado para o ajuste da rede. Por se utilizar de um "resultado esperado", a MLP é um algoritmo de aprendizado supervisionado, onde uma base de treinamento corretamente rotulada é utilizada para treinar a rede. Uma vez treinada, a rede passa a fazer apenas a fase feed foward.

A equação 3.44 apresenta a entrada da rede. A saída dos neurônios da camada $l=1$ é gerada pelas equações 3.42 e 3.43 respectivamente. Camada a camada, esse procedimento é executado até que o sinal atinja a camada de saída $l=L$ gerando o vetor $Y^{L}(p)$. Esse vetor é comparado ao vetor contendo os valores de saída desejados $D(p)$ para o padrão $p$ apresentado (equação 3.45) obtendo assim, o erro $e_{j}$ para cada neurônio $j$ da camada de saída $L$ :

$$
\begin{gathered}
y_{j}^{0}=x_{j} \\
e_{j}(p)=d_{j}(p)-y_{j}^{L}(p)
\end{gathered}
$$


O erro quadrático total apresentado pela rede para o padrão de entrada $p$ é definido por $E(p)$ (Equação 3.46) e o erro médio quadrático para todos os padrões é definido pela Equação (3.47). Os pesos $w$ da rede são ajustados pela Equação 3.46. Para tal, camada a camada, o erro é retropropagado calculando-se os gradientes $\delta$ para cada neurônio (Equação 3.48). Os gradientes para os neurônios das camadas ocultas são calculados pela Equação 3.49. Após o cálculo do gradiente, o ajuste dos pesos é feito pela Equação (3.50) no qual $\eta$ representa o coeficiente de aprendizagem.

$$
\begin{gathered}
E(p)=\frac{1}{2} \sum_{j \in L} e_{j}^{2}(p) \\
E_{\text {med }}=\frac{1}{P} \sum_{p=1}^{P} E(p) \\
\delta_{j}^{l}=e_{j}^{L} \varphi_{j}^{\prime}\left(v_{j}^{L}\right) \\
\delta_{j}^{l}=\varphi_{j}^{\prime}\left(v_{j}^{l}\right) \sum_{k} \delta_{k}^{l+1} w_{k j}^{l+1} \\
w_{j i}^{l}(t+1)=w_{j i}^{l}(t)+\eta \delta_{j}^{l} y_{i}^{l-1}
\end{gathered}
$$

Para este trabalho, foi definido o uso de MLPs com duas configurações: 2 camadas escondidas com a mesma quantidade de neurônios e com a quantidade de neurônios diminuindo a cada nova camada escondida (piramidal). Foram utilizados diversos números de neurônios nas camadas escondidas, e os resultados apresentados se referem as melhores respostas dentro dessas arquiteturas. A quantidade de neurônios na camada de entrada foi definido pelo tamanho dos vetores de características gerados em cada uma das implementações (os valores estão definidos no Capítulo 6) e dois neurônios na camada de saída.

\subsubsection{Deep Learning}

Para comparação com as redes neurais, foi proposta a utilização de algoritmos de aprendizado profundo. A ideia principal destes algoritmos é a utilização da informação sequencial, e.g., processamento de video, linguagem ou sinais. Para certos tipos de redes, como no caso das redes recorrentes (Recorrent Neural Network (RNN)), a saída e a entrada são dependentes, o que implica na eficiências em muitas tarefas. As RNN terão a resposta caso seja necessária uma predição, saber uma próxima sequência ou ação (GHAEMMAGHAMI, 2017). Assim, a razão para explorar as arquiteturas profundas é a sua capacidade de aprender como processar as informações espaço-temporal, informação importante no caso do EEG. Alguns pontos importante sobre as RNNs são (RIBEIRO; MANCHO, 2002): 
- Reconhecimento e Classificação de sequências: a rede produz um padrão de saída particular uma vez que toda a sequência de entrada é demonstrada;

- Reprodução e Predição de sequências: a rede pode inferir uma sequência inteira mesmo a acessando apenas parcialmente;

- Associação temporal: a rede produz uma saída em resposta a uma sequência de entrada específica. Esta característica foi a mais importante para os resultados com os vetores de características do EEG utilizados.

Um dos tipos mais comuns de RNN é a LSTM, que foi a escolhida para ser utilizada nesta tese.

\subsubsection{LSTM}

A Long Short-Term Memory Network (LSTM) (HOCHREITER; SCHMIDHUBER, 1997) é um tipo especial de RNN capaz de lembrar de valores em estados arbitrários, aprendendo mesmo com dependências de longa interação. Em alguns casos é necessária ter uma memória de longo-termo para ser possível fazer uma boa predição. A LSTM é adequada para classificar e prever séries temporais, característica importante para as aplicações BCI. Apesar de ter sido criada em 1997 por Hochreiter and Schimdhuber, passou a ser realmente utilizada com certa relevância nos últimos anos, quando passou a demonstrar boa acurácia para várias aplicações.

A LSTM é composta por uma célula de memória (Figura 5) e três portões (gates), chamados de gates de entrada, saída ou inferência e de esquecimento. As células são responsáveis por manter a informação por longos períodos de tempo, e a manipulação dessas informações é feita pelos gates (RIBEIRO; MANCHO, 2002):

- Entrada: é feita a adição de informações úteis. Essas informações são reguladas usando uma função que filtra os valores a serem lembrados. Portanto, neste gate é definida as informações que serão armazenadas

- Saída: extrai as informações úteis do estado da célula, para serem apresentadas como uma saída. Portanto este gate é tido como a definição de como aplicar cada uma dessas informações

- Esquecimento: Remove as informações que não são mais úteis, evitando que os estados internos da células cresçam desenfreadamente, alimentando a conexão auto-recorrente, de acordo com a sua saída

O gate de esquecimento (Equação 3.51) representa o caminho da informação até o estado da célula. Então, o gate de entrada (Equação 3.52) e os valores candidatos, definidos pela Equação 3.53 decidem qual das novas informações será de fato armazenada naquela célula. $\mathrm{O}$ antigo estado da célula é então atualizado através da Equação 3.54. Finalmente, o gate de saída 
(Equação 3.55) com o estado da célula decidem, através de tanh, o que vai para a saída, como definido da equação 3.56

$$
\begin{aligned}
& f_{t}=\sigma\left(W_{f} \cdot\left[h_{t-1}, x_{t}\right]+b_{f}\right) \\
& i_{t}=\sigma\left(W_{i} \cdot\left[h_{t-1}, x_{t}\right]+b_{i}\right) \\
& \hat{C}_{t}=\tanh \left(W_{C} \cdot\left[h_{t-1}, x_{t}\right]+b_{C}\right) \\
& C_{t}=f_{t} \odot C_{t-1}+i_{t} \odot \hat{C}_{t} \\
& o_{t}=\sigma\left(W_{o} \cdot\left[h_{t-1}, x_{t}\right]+b_{o}\right) \\
& h_{t}=o_{t} \odot \tanh \left(C_{t}\right)
\end{aligned}
$$

Os parâmetros $W$ denotam as matrizes de pesos, os termos $b$ representam os vetores de bias, $\sigma$ é a função sigmoide. Sabendo que $i$ é o gate de entrada, $f$ o gate de esquecimento, $o$ o de saída e $C$ representa o estado da célula, todos esses parâmetros têm o mesmo tamanho que a célula do vetor de ativação da saída $h_{t}$. $\odot$ é o produto dos vetores (SAK; SENIOR; BEAUFAYS, 2014). Na Figura 6, é demonstrada a LSTM juntamente com a GRU.

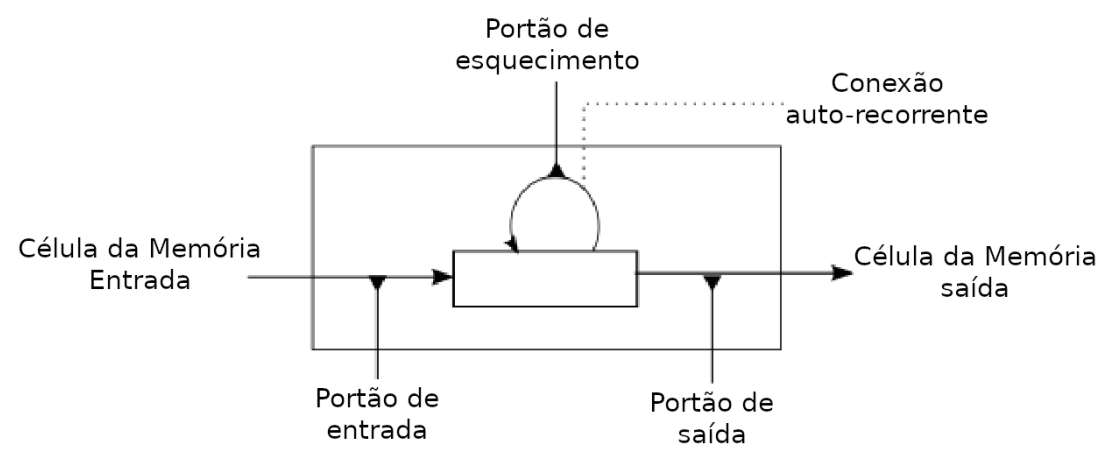

Figura 5 - Célula de memória da LSTM

Fonte: Adaptada de Ghaemmaghami (2017). 


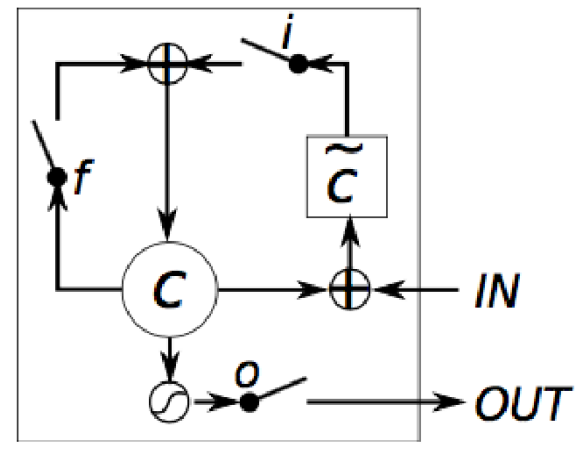

(a) Long Short-Term Memory

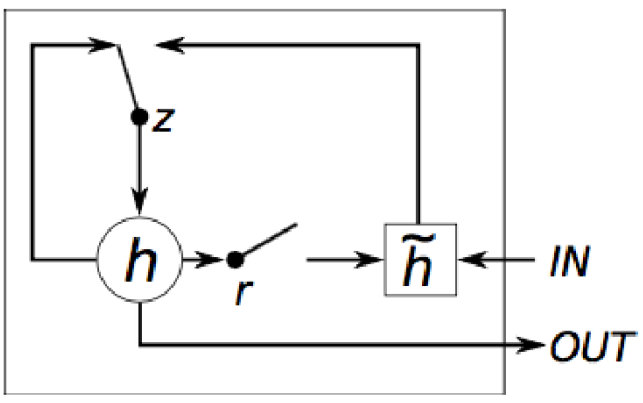

(b) Gated Recurrent Unit

Figura 6 - LSTM e GRU

Fonte: Chung et al. (2014).

\subsubsection{Convolutional Neuronal Networks - CNN}

As CNNs são utilizadas em larga escala em tarefas de reconhecimento, pois as características de aprendizado dessa rede permite uma boa acurácia em várias pesquisas, sendo interessante para aplicação nesta tese. A Figura 7 apresenta um exemplo de rede utilizada para reconhecimento de dígitos escritos a mão. As CNNs podem apresentar camadas de convolução, subamostras e redes completamente conectadas, max-pooling e softmax. A CNN contém alguns parâmetros principais, que são chamados de hiper-parâmetros: $\mathrm{O}$ tamanho do filtro, o chamado kernel da camada convolutiva; e o número de mapas de características, constituído de um conjunto de $\mathrm{K}$ filtros requeridos na camada de convolução.

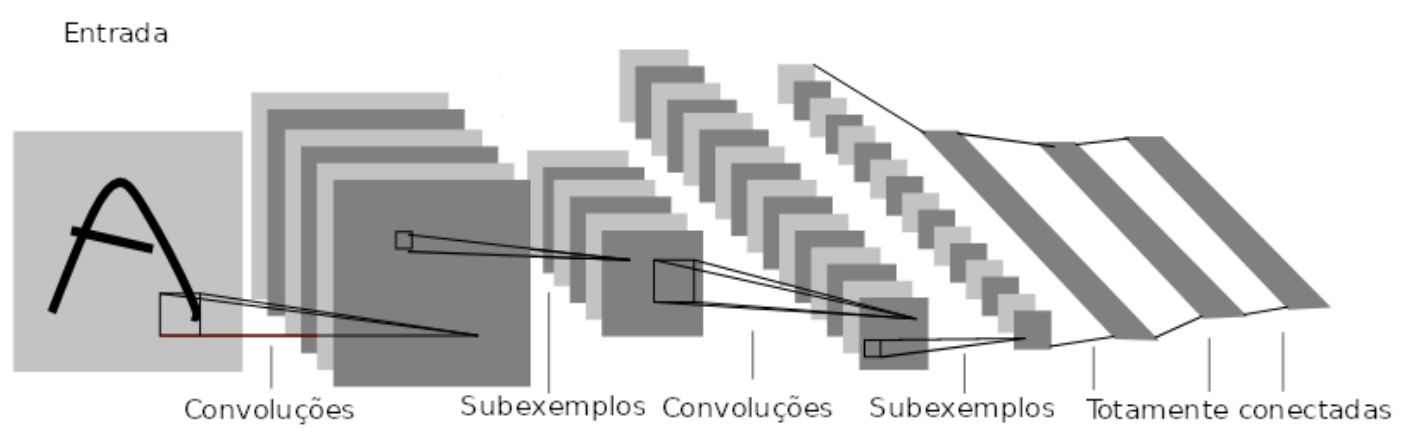

Figura 7 - Exemplo de uma rede convolucional para reconhecimento de dígitos

Fonte: Adaptada de LeCun et al. (1998).

\subsubsection{Convoluções}

As convoluções tem inspiração na estrutura na qual estão estruturados os neurônios do cérebro humano. A convolução age como uma operação que, partindo de duas funções, gera 
uma terceira. A cada aplicação da convolução, uma região é alterada, gerando um outro exemplo (chamado de mapa de características, que representa as informações do dado original). Esses dados são alterados utilizando o kernel. Em algumas situações, em principal para aplicações em imagens, esse processo pode causar muita perda de informação, atrapalhando a resposta da rede. Neste caso é utilizado o processo de padding, em que informações são adicionadas antes da operação de convolução, buscando manter a dimensionalidade da informação original. Os resultados dessas convoluções podem gerar mapas de características representativas o suficiente para classificar uma informação. Para que isso aconteça, é necessário utilizar algoritmos de aprendizado para treinar os valores do kernel. A Figura 8 indica o uso do kernel.
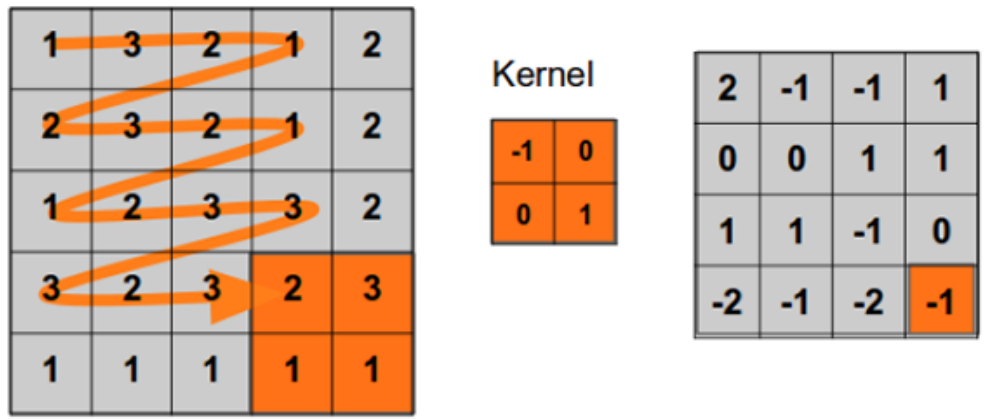

Figura 8 - Exemplo de convolução em uma "imagem" usando um kernel 2x2

Fonte: Rocha (2015).

Outra operação importante para a rede é o processo de pooling, que tem como objetivo diminuir a sensibilidade da rede com relação à pequenas alterações nos dados originais. Assim, o processo diminui a dimensionalidade da entrada por um fator constante, eliminando redundâncias da rede e combinando várias características em uma única região. Essa etapa diminui a variâncias e reduz a quantidade de parâmetros, sendo também importante para seleção de características. Dentre as diferentes operações de pooling, a mais utilizada é o MaxPooling, exemplificada na Figura 9.

A operação de maxPooling retira o maior elemento (máximo valor de ativação) de uma determinada região da matriz. Isso implica que a derivada de saída $z_{i}$, com relação a uma entrada $x_{j}$ assume 0 ou 1 dependendo se esse valor foi escolhido. Considerando a quantidade de camadas, a derivada escolhida pode atrapalhar o processo de treino, sendo caro computacionalmente. A Equação 3.57 define o maxpooling.

$$
z_{i}=\max _{j}\left\{x_{j}\right\}
$$

Também utilizada em outros contextos, a softmax auxilia na interpretação da saída de uma rede como uma distribuição de probabilidades discreta da entrada de pertencer a uma das classes de interesse. Na função softmax existe um vetor de parâmetros para cada classe, sendo 


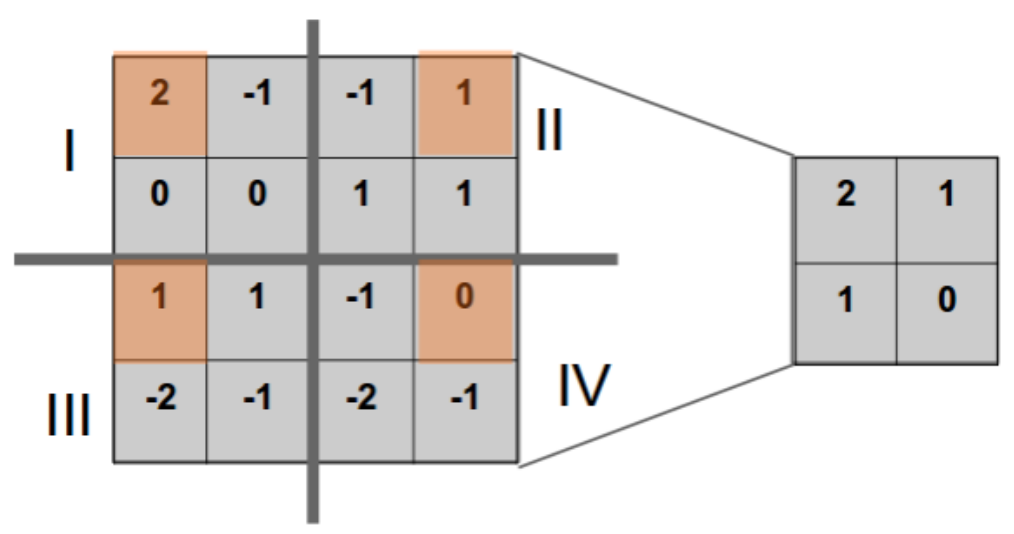

Figura 9 - Exemplo do max-pooling, considerando uma região em quatro quadrantes

Fonte: Rocha (2015).

Tabela 2 - Arquitetura das redes profundas utilizada neste trabalho

\begin{tabular}{llll} 
Operação & Tam. Kernel & Saída & Ativação \\
\hline Entrada & - & 2048,2 & - \\
Conv & 100 & 2948,32 & ReLu \\
MaxPooling & 5 & 409,32 & - \\
\hline Conv & 5 & 409,64 & ReLu \\
MaxPooling & 5 & 81,64 & - \\
\hline LSTM & - & 100 & Tanh \\
Dense & - & 1 & Sigmoide
\end{tabular}

possível computar a similaridade dos dados de entrada com cada um desses vetores (equação 3.58). Ao invés da distância euclidiana, aplicações utilizam a entropia cruzada como medida do erro (equação 3.59).

$$
\begin{gathered}
\hat{y}_{j}=\frac{e^{-z j}}{\sum_{i} e^{-z i}} z i=w_{i} x \\
\frac{\partial E r r}{\partial w_{i}}=\left(\hat{y}_{i}-y_{i}\right) x \\
y=\max (0, x)
\end{gathered}
$$

Como função de ativação, foi utilizada a função ReLU, dada pela equação 3.60, que adiciona a não linearidade à rede, o que condiz com os problemas mais complexos aos quais a rede será exposta. A Tabela 2 descreve a arquitetura utilizada neste trabalho e a Figura $10 \mathrm{o}$ processo de classificação dos sinais utilizando a CNN com LSTM. 


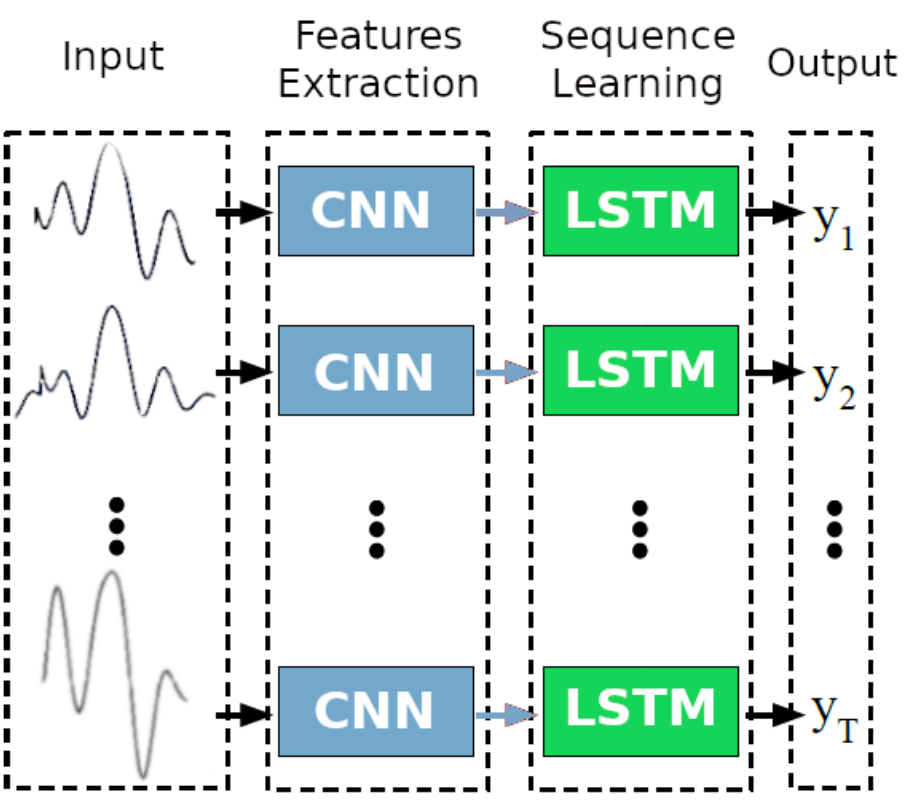

Figura 10 - Processo de classificação do sinal EEG abordado neste trabalho

Fonte: Elaborada pelo autor.

\subsection{Considerações Finais}

Neste capítulo foram apresentados matematicamente todos os métodos a serem utilizados nesta tese. Essa fundamentação é importante para se entender as escolhas de métodos feitos para esta tese, que serão aplicados em diversos pontos do sistema para detecção de ErrPs. No próximo capítulo, será apresentado o sistema educacional proposto, tanto para geração de base de dados quanto para obtenção do Error Related Potencial. 


\section{SISTEMA PARA DETECÇÃO E CLASSIFICAÇÃO DE SINAIS ERRP}

Este capítulo apresenta um sistema para detecção e classificação de sinais Errp. Como o sistema proposto faz parte de um projeto maior denominado R-CASTLE, que é um sistema adaptativo criado para auxílio na educação, primeiramente, apresenta-se o R-CASTLE, seguido pelas contribuições desta tese, que diretamente colaboram com o desenvolvimento do mesmo. Descreve-se o primeiro experimento realizado, que serviu de base para definir as premissas desta tese. Em seguida, é proposta a arquitetura do sistema de reconhecimento de ErrP, que é constituída por um módulo de pré-processamento, um módulo de filtragem e um módulo de classificação.

\subsection{Definindo os problemas dos sistemas educativos}

Em um experimento inicial, o objetivo foi verificar se, a partir do uso de dispositivos simples como câmeras, era possível perceber sinais de falta de atenção do aluno, para se entender o problema de pesquisa proposto. Para tal, o ambiente desenvolvido em Pinto, Tozadore e Romero (2015) foi utilizado com a aplicação do robô humanoide NAO como professor. Este experimento teve duas etapas: na primeira, os alunos participaram de forma isolada e na segunda os alunos participaram em pequenos grupos de no máximo 3 alunos. Os experimentos foram feitos em uma sala de aula, com o robô em uma mesa grande no centro da sala e os alunos posicionados em cadeiras em volta desta mesa. Uma câmera foi posicionada aos pés do robô, focalizando o rosto da criança e uma segunda câmera estava posicionada atrás dos alunos. Devido a pouca iluminação, foram necessários usar refletores para ajudar no reconhecimento dos objetos, e microfones foram posicionados próximo às crianças, para que respondessem às solicitações do robô. A Figura 11 mostra esse primeiro experimento.

Para a primeira etapa foram escolhidos 4 alunos com idades entre 10 e 13 anos, sendo 


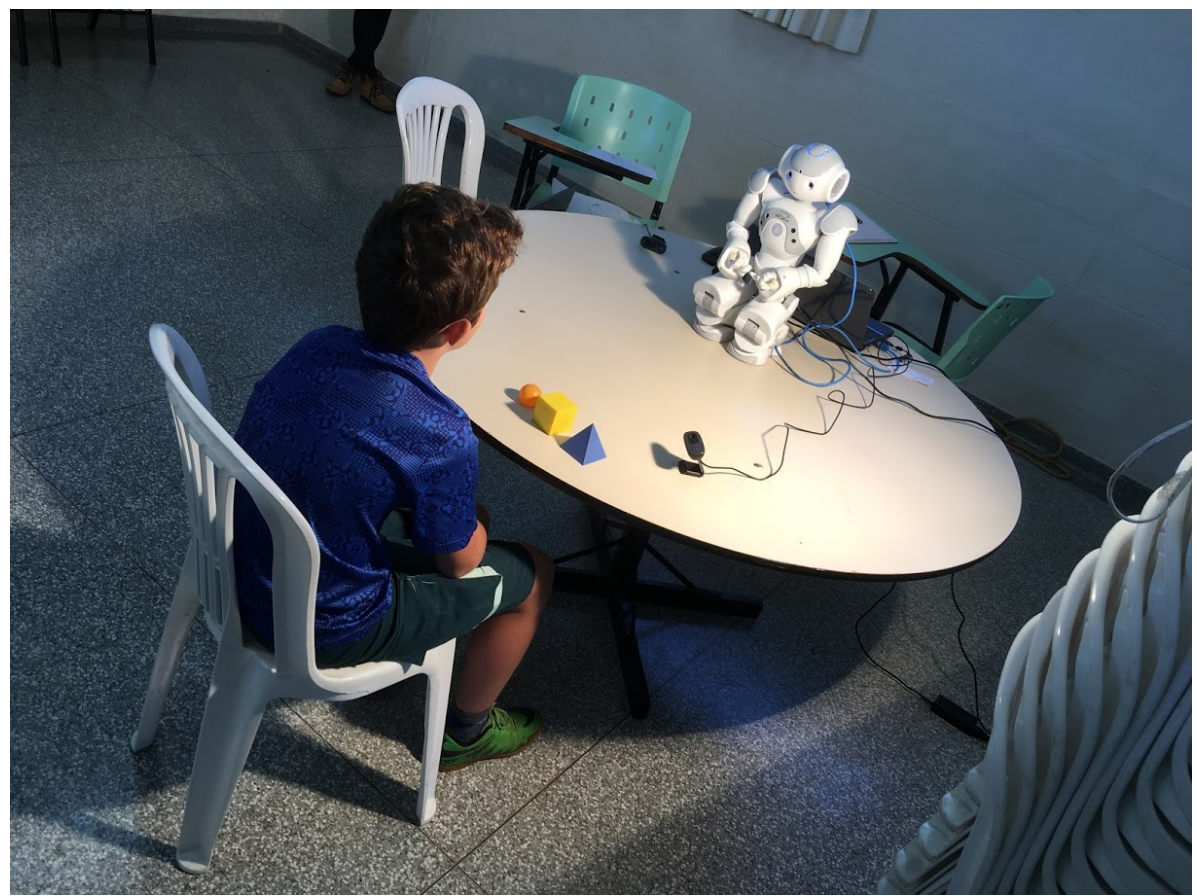

Figura 11 - Primeiro experimento feito para este trabalho, visando medir as reações dos alunos com a presença do robô

Fonte: Elaborada pelo autor.

que 2 participavam de trabalhos com robótica na escola, e os outros 2 nunca tinham participado com atividades utilizando um robô. Para a segunda etapa, foram feitos experimentos com 3 grupos, recrutando alunos que se declarassem como amigos ${ }^{1}$. As reações das crianças foram gravadas para comparar as diferenças entre todos os casos apresentados durante a interação a longo prazo com o robô. As crianças responderam questionários pré e pós a atividade, deram notas utilizando a escala Likert e ainda foram entrevistados ao final do experimento.

Algum padrões foram percebidos durante a atividade. Os alunos que nunca tinham trabalhado com robótica são mais participativos no início, e ficam por mais tempo concentrados nos movimentos do robô. Apesar da robótica humanoide ser diferente dos kits robóticos aos quais estavam acostumados, os alunos com experiência em robótica perderam o interesse mais rapidamente, pois o comportamento repetitivo do robô acabava sendo frustrante. Os dois alunos com experiência, em média, mostraram sinais de desatenção aos 4 minutos de atividade (que durava em torno de 10 minutos), olhando para os lados ou não ouvindo o que o robô dizia, enquanto os outros alunos começavam a mostrar esses sinais após os 6 minutos de atividade. Apesar de não ser estatisticamente significativa, essa diferença mostra que a presença do robô, por si só, não é suficiente para manter a atenção da criança. Não houve diferença estatisticamente significativa no resultado das provas, tendo uma pequena melhora para os alunos que prestaram atenção por mais tempo e todos os alunos disseram que o robô precisava ser aprimorado.

1 Pedir para os alunos formar grupos entre amigos é importante para medir o quanto a interação entre o grupo pode desfocar o aluno da tarefa de estudo, principalmente sem a presença de um professor real. 
Já os grupos com amigos tiveram um desempenho pior (20,76\%) nas provas. Em grupos, os alunos perdiam o foco o tempo todo, conversando entre si e muitas vezes não chegavam em acordo quanto a resposta a ser dada para o robô. Outro problema claro era a falta de feedback quando aos momentos de erros e dificuldades dos alunos, que queriam fazer mais perguntas para o robô, enquanto este não estava preparado para responder. Em um dos grupos, uma das alunas se isolou e não participou da atividade, pois não entendia seus erros. Apesar de não aparentar desatenção, nem olhar para os lados, a estudante não estava confortável com o experimento.

Alguns alunos se assustam quando o robô se movimenta sozinho. Isso também afeta a interação aluno-robô e, consequentemente, o resultado final da atividade. Apesar de darem notas mais altas na escala Likert, os próprios alunos demonstraram não ter entendido tudo o que o robô perguntou e também apresentaram bastante frustração. Recrutar os alunos em grupos de amigos favoreceu a interação entre os alunos, mas causou desconcentração da atividade com o robô. A única informação proveniente do experimento é que o uso de mais câmeras ajudou os pesquisadores a perceberem os momentos de perda de atenção, mas são necessárias ferramentas de processamento dessas imagens para servir de feedback em tempo real para o sistema.

A quantidade de dados ainda tinha sido pequena para se ter base estatística para conclusões, mas os resultados apontam que existem muitas variáveis a serem discutidas para a implementação de um sistema educacional. O robô precisa ter uma grande quantidade de movimentos, deve ser capaz de entender os alunos, reagir aos estímulos e devolver informações sobre a atividade, ou sua presença será mais frustrante do que benéfica para o aprendizado. Os resultados do Continuous Audience Response confirmaram a baixa qualidade de interação quando os alunos já tinham experiência com a robótica e principalmente quando estavam em grupo. $\mathrm{O}$ sistema pode ficar mais robusto se esse tipo de informação for tratada juntamente com o sinal do EEG, verificando as regiões ativas do cérebro e sinais de erros ou desatenção, sendo capaz de entender as emoções do aluno e níveis de engajamento com o trabalho, podendo selecionar atividades que condizem com o estado do aluno no momento do experimento, apresentando os pontos em que o aluno teve maior dificuldade.

Neste experimento, foi possível observar algumas lacunas que delinearam as pesquisas a seguir. A informação de atenção precisa ser ligada a outros fatores, como principalmente a frustração dos alunos durante as atividades. Sempre que se relacionam com sistemas nãohumanos, como jogos educacionais e robôs, os alunos tem dificuldade em obter um feedback que os guie para melhorar seus estudos. Destes experimentos, alguns pontos principais foram definidos:

- A importância de se entender o sinal do EEG, e como disponibilizar um bom feedback para o estudante;

- A necessidade de bases de dados focadas em educação, que ajude o sistema a ser testado com relação aos principais problemas a serem atacados; 
- A importância de moldar o comportamento do robô, utilizando HRI para manter interesse e foco dos alunos durante as atividades com agentes não-humanos.

Para tentar resolver o maior número de problemas possível, foi definido, junto a outros pesquisadores do nosso laboratório (Laboratório de Aprendizado de Robôs - LAR/ICMC), um sistema maior chamado Robotic-Cognitive Adaptative System for Teaching and Learning (RCASTLE). Este é um sistema educacional adaptativo que considera todas as lacunas levantadas nos experimentos anteriores. Assim, a classificação de sinais utilizando EEG proposta neste trabalho é um dos módulos deste sistema educacional, auxiliando no feedback para alunos e professores, além de verificar os níveis de atenção.

\subsection{R-CASTLE - Sistema Adaptativo para Ensino e Apren- dizado}

Considerando a revisão bibliográfica feita nesta tese, grande parte das aplicações para educação usando tecnologia são criadas em contextos específicos, relacionados a uma certa faixa de idade, ou a certos conceitos muito bem definidos. Com isso, as aplicações disponíveis não são generalistas e são difíceis de serem utilizadas ou adaptadas para novos conteúdos. Quando se trata da utilização de robôs nas escolas, é necessário contratar professores específicos ou passar por longos treinamentos para utilizar a tecnologia, o que distancia o usuário final da melhor experiência possível. Existem muitos kits robóticos com várias abordagens, porém os robôs considerados em estado-da-arte para a educação não disponibilizam uma plataforma amigável para utilização pelos professores. Neste trabalho, foi considerado apenas o robô NAO como dispositivo para o sistema.

Pensando neste problema, e unindo trabalhos de vários pesquisadores do grupo, foi criado o sistema R-CASTLE (TOZADORE et al., 2019) que tenta modularizar as fases importantes da interação, encapsulando algoritmos, cálculos e detalhes técnicos do robô e oferecendo uma interface intuitiva, na qual o professor pode programar o conteúdo a ser dado com auxílio do robô. Essa arquitetura, demonstrada na Figura 12, permite a utilização de comportamentos open-source pré-programados (como processamento de voz, reconhecimento de face e objetos) de robôs, unidos com movimentações corpóreas e outras atitudes mais próximas das humanas e regasta conteúdos já utilizados anteriormente para montar uma atividade. Pessoas que nunca programaram podem apenas adicionar novos conteúdos e selecionar comportamentos para a montagem de seu conteúdo de forma simples através da interface criada.

Alguns trabalhos prévios foram feitos para verificar a viabilidade do sistema. Em um experimento (TOZADORE et al., 2017), foi comparada a eficiência do aprendizado dos nomes de animais em inglês com crianças, usando o robô NAO e um tablet para estudar. Foram testadas a qualidade da interação e as respostas a um questionário, além de entrevistas com as crianças 


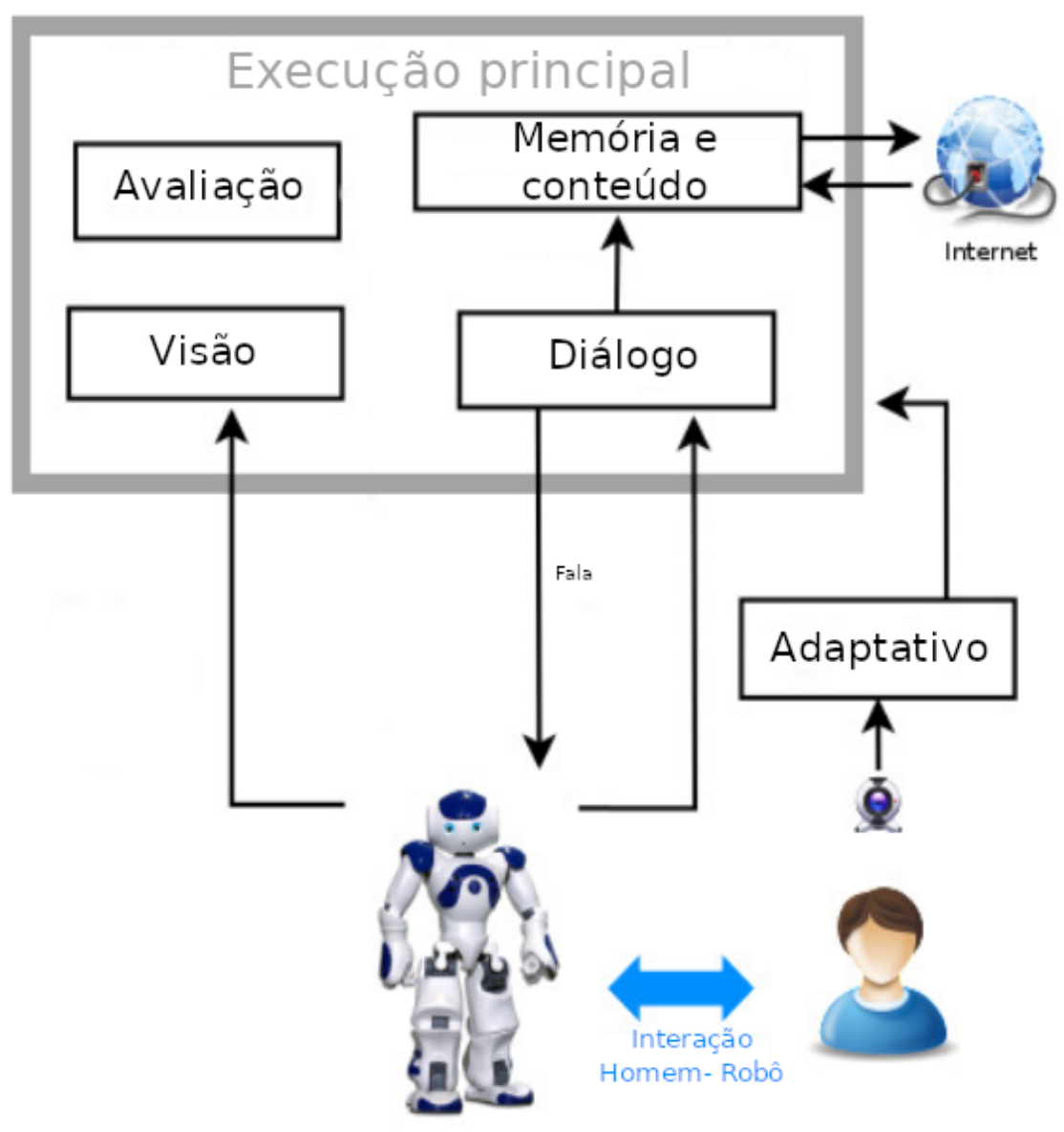

Figura 12 - Arquitetura do R-CASTLE, mostrando os módulos disponíveis durante a interação.

Fonte: Adaptada de Tozadore et al. (2019).

após o experimento. Apesar do NAO ter sido considerado mais divertido, as crianças tiveram melhores resultados com o tablet, uma vez que o áudio e a possibilidade de usar legendas ajudou no entendimento dos nomes. Esse resultado foi contrário ao que se previa, imaginando que o robô mais atrativo traria melhores resultados. Em outro trabalho (TOZADORE et al., 2017), foi discutida a percepção dos alunos quando o robô é tele-operado, comparado ao robô autônomo. Excluindo-se casos em que o robô teve problemas de internet (fazendo com que a interação fosse muito ruim) não houve uma diferença significativa no aproveitamento dos alunos. Porém, ao saber que o robô era tele-operado, os alunos diminuíram as notas de inteligência dadas ao robô. Esses experimentos, feitos com 104 alunos, mostraram a necessidade de melhorar os recursos de comunicação do robô, garantindo uma mensagem eficiente, e também demonstraram que a utilização do robô autônomo não atrapalhava a interação, quando era bem executada.

Os módulos que constituem o R-CASTLE são:

- Visão: Responsável por reconhecer e classificar objetos anteriormente treinados, utilizando 
as câmeras disponíveis.

- Diálogo: Permite uma comunicação mais fluida e próxima a humana. Consiste em reconhecer a fala, processar a sentença e responder no menor tempo possível. Foram usados pacotes disponíveis para o robô NAO, pacotes da linguagem Python e a API do Google.

- Memória: Permite a adaptação de novos conteúdos. Caso algum termo seja reconhecido pelo módulo de diálogo e não exista na base de dados, o sistema busca informações na internet.

- Avaliação: Responsável por gerar informações sobre a qualidade da interação e informar para o criador da atividade. Apresenta para o professor as dificuldades do sistema e do aluno com aula proposta. É neste ponto que o sistema proposto nesta tese pode ser utilizado para melhorar as informações obtidas.

O módulo de visão utiliza um ensemble de classificadores clássicos, com diferentes abordagens de KNN, MLP e SVMs. A abordagem aprimora trabalhos anteriores do grupo, como (PINTO et al., 2014) e (TOZADORE; PINTO; ROMERO, 2016), utilizando de mais técnicas para comparar tanto a acurácia quanto o tempo para classificação das imagens. A base da dados inclui várias figuras geométricas vistas da mão do robô e muitos dados com vários tipos de ruídos, como variação do fundo da imagem, outros objetos na imagem e diferentes distâncias do objeto para a câmera do robô. Em geral, o uso do ensemble tem tido melhores resultados do que o uso dos algoritmos isolados.

O módulo de diálogo ainda precisa ser aprimorado, uma vez que segue uma linha de pesquisa por si só. Outra importante barreira para o robô é a linguagem, uma vez que a maioria das ferramentas disponíveis estão em inglês, e o robô deve conversar em português com os alunos. Apesar dos pacotes de text to speech do robô NAO serem suficientes para se entender o português, a voz ainda é bastante robotizada, e isso atrapalha a comunicação natural. O uso da API contorna alguns problemas para reconhecimento das sentenças, mas depende da internet, o que também afeta o tempo de processamento. Porém, o robô tem tido uma boa acurácia para entender os substantivos e procurar informações na internet. Com isso, em momentos que precisa chamar a atenção da criança, o robô pode procurar por alguma preferência que ele saiba da criança, como comida ou esporte favorito, conversar com ela sobre este assunto antes de retomar as aulas.

\subsubsection{Sistema Adaptativo do R-CASTLE}

Como já mencionado neste trabalho, uma boa parte da aceitação, principalmente de crianças mais novas, à tecnologia é a boa comunicação. Sendo fluida e concisa, a atenção do estudante será mantida por mais tempo, o que melhora a probabilidade de aprendizado. Para que isso seja possível em ambientes robóticos, a adaptação é uma importante chave, que entende 
as pequenas mudanças de comportamento e atenção e se modifica para garantir a qualidade da interação.

Nos trabalhos relacionados percebemos que o robô pode assumir diferentes papeis durante a interação (como por exemplo os experimentos com o robô assumindo o papel de aluno junto com as crianças muito pequenas no experimento de (TANAKA; CICOUREL; MOVELLAN, 2007)), podendo melhorar os resultados do aprendizado. Pensando nisso, o R-CASTLE tem um módulo específico de adaptação, que molda o comportamento do robô tendo como base indicadores captados do usuário. O módulo usa uma média de três grandes grupos de interesse: atenção, comunicação e aprendizado:

- Atenção: Utiliza informações como a postura do aluno e o foco de visão. A atenção pode ser medida utilizando o EEG

- Comunicação: Analisa a quantidade de palavras ditas pelo usuário, assim como as suas emoções. É muito relacionada a qualidade de interação

- Aprendizado: Verifica a quantidade de respostas certas e erradas do estudante e o tempo que ele leva para responder. $\mathrm{O}$ sistema proposto também pode ser utilizado nesta etapa

Pesos devem ser associados a cada um destes grupos, de acordo com a sua influência no comportamento final do robô. Esses indicativos servem tanto para alimentar o módulo de avaliação, que serve como um feedback para o professor e aluno, quanto para definir os próximos comportamentos a serem executados pelo robô. Atualmente, é utilizada uma escala de 1 a 5 , que define a influência de dois tipos independentes de comportamentos. Por exemplo, quando a atenção do aluno apresenta uma queda, o robô pode atuar de forma mais interativa e demonstrar mais comportamentos que voltem a chamar a atenção do estudante. Por outro lado, quando o aluno está completamente focado, o robô passa a se preocupar mais com o conteúdo da matéria em si. O robô deverá alternar entres esses dois comportamentos para manter a criança com o melhor desempenho possível.

Com relação ao sistema adaptativo, foi primeiramente testada a tarefa de reconhecimento do desvio de olhar. Essa tarefa exige cuidado, pois existem pequenos desvios quando as pessoas estão pensando em uma resposta, mas não necessariamente indicam a falta de atenção. Apesar de ser uma tarefa simples, o processamento utilizando a biblioteca da OpenCV exigiu que fosse executado em um computador diferente do que tratava a aplicação principal. Disparado juntamente com a classificação de emoções, a classificação de desvio utilizou o algoritmo de Haar Cascade, e definiu número de vizinhos (parâmetro do algoritmo) e tempo para contar um desvio de atenção. Após vários testes, foi determinado que o tempo para início da contagem de desvio deveria ser entre 0,6 e 0,7 segundos com o mínimo de vizinhos igual a 9. Estes foram os que obtiveram a melhor acurácia para detecção de desvio de atenção. 


\subsubsection{Integração do sistema proposto com o $R$-CASTLE}

Como descrito, o sistema adaptativo do R-CASTLE depende de informações do nível de atenção do aluno e também oferece um feedback para acompanhar a melhora do aluno durante as interações com a ferramenta educacional. Esse tipo de informação, para ser retirada da postura, câmeras e demais dispositivos é custosa e tem uma acurácia razoável, mas ainda longe de alguns métodos. Os sistemas BCI extraem a informação diretamente do cérebro, sendo portanto mais precisa, porém com o ônus da necessidade do dispositivo para captura de sinais. Nas etapas de teste do protótipo, o sistema BCI proposto nesta tese pode ser utilizado como um ground truth, considerando que a medida de atenção do aluno segue uma proposta consolidada, testada e com menor influência de fatores externos.

Além da atenção, a quantidade de erros do aluno durante as atividades oferece um indicativo de dificuldade em algum tema específico. Apesar das dificuldades ficarem claras em atividades como uma prova, é importante que o aluno e o sistema tenham o acompanhamento dos erros. A detecção do ErrP durante os estudos pode ajudar o sistema a saber que precisa encontrar outras maneiras de abordar um conteúdo, e as emoções do aluno podem indicar a melhor forma de abordar esse assunto. Um dos problemas do uso de tecnologia para educação está justamente nessa adaptação, mais fácil para humanos, porém complicada quando se utiliza um robô no auxílio de atividades educacionais.

Por se tratar de uma idade em que muita coisa ainda é novidade para os alunos, a arquitetura proposta nesta tese experimenta criar um ambiente competitivo, que consiga manter o foco de atenção do aluno na atividade proposta, e assim verificar que as demais técnicas aplicadas ao R-CASTLE concordam com as informações coletadas pelos eletrodos. Essa informação também pode ser enviada como feedback, após as atividades. Como visto nos trabalhos para educação, no Capítulo 2, essa informação pode ser utilizada inclusive como forma de chamar atenção, parando a atividade e pedindo para que o aluno atinja um determinado grau de atenção antes de continuar. As atividades e resultados com relação ao uso de BCI estão melhores definidos nos Capítulos 5 e 6. Na próxima seção, será apresentada uma outra contribuição ao sistema R-CASTLE realizada nesta tese.

\subsubsection{Inserindo emoções no sistema adaptativo}

Emoções são uma parte importante da interação, e os robôs, para serem bem aceitos, devem conseguir tanto reconhecer quanto demonstrar emoções. O comportamento e a aparência do robô devem ser compatíveis com o seu papel durante a interação, porém sempre tomando cuidado com o vale da estranheza (uncanny valley). Para o reconhecimento de emoções, duas arquiteturas CNN foram utilizadas: Inception (SZEGEDY et al., 2017) e Mobile Net (HOWARD et al., 2017), utilizando a framework Keras. Através de bases de dados disponíveis na internet e outros criados em nosso laboratório, o reconhecimento das emoções foi considerado satisfatório, e aplicado em diversos outros robôs nossos, como a Pepper, da SoftBank, e a robô LARa, 


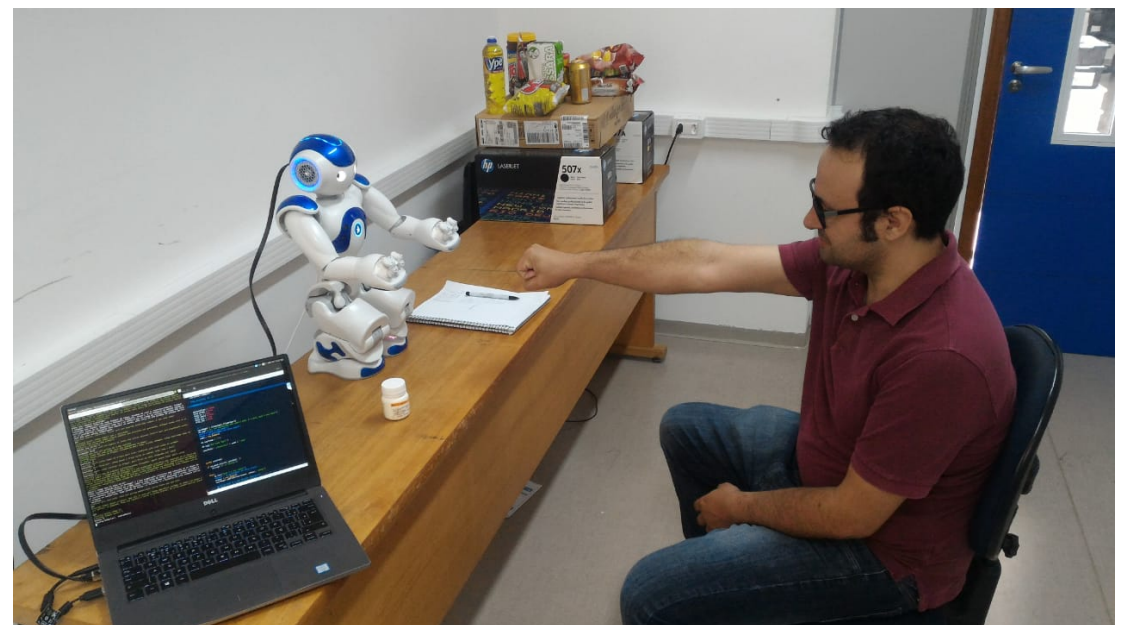

Figura 13 - Participação de um usuário na comparação do Robô NAO e da Robô LARa. O usuário participa de um jogo de Pedra, Papel ou Tesoura

Fonte: Elaborada pelo autor.

criada para a categoria @ Home de competição da Robocup. Estes outros robôs, bem como suas aplicações e competições, estão fora do escopo deste trabalho.

Além de reconhecer as emoções humanas, é esperado para uma melhor interação que o robô consiga demonstrar emoções de forma correta. A demonstração de emoções, o poder de persuasão e o reconhecimento das emoções humanas foram testadas e comparadas em (PINTO et al., 2018b). Neste experimento, colocamos o robô NAO utilizando todos os seus atuadores (som, luz, braços) para realizar uma série de atividades comparadas as mesmas atividades com a robô LARa, que tinha apenas um display para demonstração de braços e emoções, e sons demonstrados através do notebook da robô.

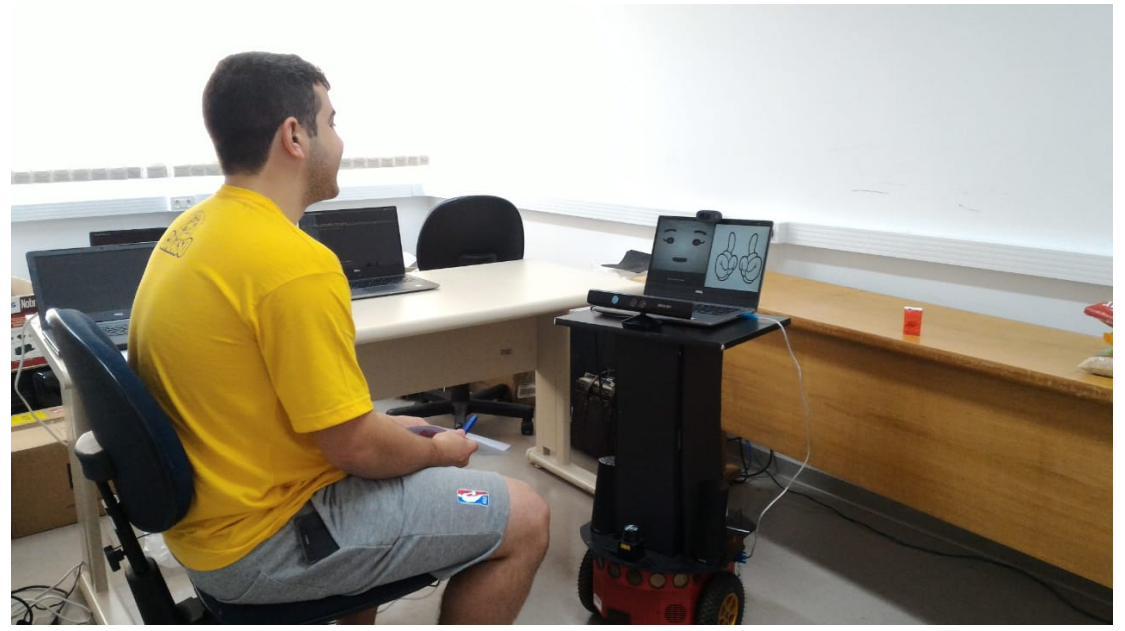

Figura 14 - Participação de um usuário na comparação do Robô NAO e da Robô LARa. Aqui o usuário sorri para o robô, demonstrando a emoção de felicidade

Fonte: Elaborada pelo autor. 
entre 19 e 37 anos $(M=24.5$ e DP = 5.316) todos alunos da Universidade de São Paulo, foram convidados para participar das atividades com os robôs (cada participante iria fazer a atividade apenas com um dos robôs). $70 \%$ dos participantes indicaram ter alto conhecimento de tecnologia e $35 \%$ responderam já ter familiaridade com os robôs. Os grupos, divididos igualmente entre os robôs, deveriam fazer exatamente as mesmas atividades, que eram compreendidas em duas atividades de sugestões dos robôs, uma atividade de relaxamento e outras duas atividades de jogos (Pedra, papel ou tesoura [também conhecido como Jokenpô] e Atores). Os robôs eram operados por WoZ, um pesquisador ficava na sala junto com o participante enquanto o outro assistia a interação por uma câmera de video, tomando as decisões pelo robô sempre que necessário.

Os robôs iniciavam o experimento com um protocolo de saudação, se apresentando e pedindo informações como o nome do usuário, esporte, comida e banda musical favoritos. Este protocolo utiliza os demais módulos do R-CASTLE para encontrar informações sobre os interesses do usuário. Em seguida, começava as atividades definidas para o experimento, que eram:

1. Remédio: primeira atividade de sugestão, o robô dizia perceber algum problema de saúde com o usuário e o recomendava para tomar um remédio, que estava em cima da mesa. $\mathrm{O}$ robô deveria insistir pelo menos uma vez caso a pessoa se negasse a tomar o remédio

2. Prateleira: segunda atividade de sugestão, o robô solicitava que a pessoa reorganizasse alguns itens comprados que estavam em cima da mesa em uma prateleira ao lado. A pessoa organizava da forma que desejasse, porém o robô sempre teria alguma sugestão para melhorar a organização dos objetos, que a pessoa poderia ou não aceitar. O robô não insistia no caso desta sugestão

3. Relaxamento: única atividade deste tipo, o robô sugeria alguns exercícios de alongamento para a pessoa fazer. No caso do robô NAO, os exercícios eram de fato realizados pelo robô, enquanto no caso da LARa eram apresentadas imagens com os exercícios que deveriam ser feitos

4. Jokenpô: primeiro jogo, o robô solicitava jogarem o jogo clássico de pedra, pepel ou tesoura, como visto na Figura 13. Para agir da forma mais natural possível, o operador do robô tomava a decisão do que o robô deveria mostrar muito antes do usuário

5. Atores: segundo jogo, se tratava da principal atividade deste experimento. Envolvia o robô tentar reconhecer as emoções dos humanos e os humanos reconhecerem as emoções do robô. A LARa demonstrava suas emoções através do display com seu rosto enquanto o NAO tinha que utilizar outros tipos de movimentos. Essa atividade pode ser vista na Figura 14.

Para avaliar a interação, após os testes, os usuários deveriam responder um questionário com sete perguntas seguindo a escala Likert. Nesta abordagem, perguntas positivas e negativas 
são mescladas, para se entender se o usuário está realmente prestando atenção em tudo que está sendo perguntado. O usuário deveria dar uma nota de 1 a 7 , sendo 1 "nem um pouco" e 7 sendo "totalmente" para as seguintes perguntas:

I1 Quanto você é familiarizado com robôs?

I2 Quando você gostou das atividades propostas?

I3 Você sentiu algum relacionamento com o robô?

I4 Quanto você achou que o robô influenciou suas decisões?

I5 Quanto você acha que a forma do robô é problemática para estas atividades?

I6 Quanto você considera os robôs importante para suporte doméstico?

I7 Quanto você considera que robôs personalizáveis são importantes para estas atividades?

Considerando o experimento inicial, foi definida a arquitetura para este trabalho: um sistema para detecção e classificação dos erros dos alunos, para gerar um melhor feedback e moldar o comportamento do robô. A partir das informações do EEG, é possível entender a atenção do aluno e os momentos do ErrP, ajudando um sistema educacional à adaptar as atividades. Essa arquitetura é um módulo do sistema R-CASTLE, nutrindo informações para melhores respostas de HRI, a partir de informações de atenção e erros do aluno. Assim, o sistema pode aprimorar o aprendizado mesmo sem a presença de um professor humano.

\subsection{Arquitetura do sistema para reconhecimento de ErrP}

Existem duas importantes lacunas nos trabalhos com BCI aplicados a educação vistas no Capítulo 1 e também vistas no primeiro experimento que devem ser discutidas. A maioria dos trabalhos utiliza os headsets comerciais, e discutem o resultado sem propor outras formas de tratamento e classificação desta informação. Computacionalmente, é importante testar os filtros na etapa de pré-processamento, as possíveis diferenças entre os extratores de características para entender se o domínio aplicado corresponde ao adequado para essa tarefa específica. É importante considerar os ruídos que o sinal apresenta, principalmente quando o sistema é aplicado em ambientes não controlados, como salas de aula.

Além disso, boa parte dos trabalhos utiliza LDA para classificação, sendo possível que outros algoritmos de classificação tenham um desempenho melhor. Os algoritmos clássicos em tarefas de classificação supervisionada, como MLP, precisam ser testados para esse espaço de dados. Outro emergente classificador são as redes convolucionais Convolutional Neural Networks $(\mathrm{CNN})$, muito utilizadas na área de reconhecimento de padrões, que podem ter um desempenho melhor, dado o grande volume de dados com as leituras do EEG. É importante considerar a forma 
como cada uma das redes trabalha com o espaço de dados, sendo a abordagem de aprendizagem profunda uma abordagem interessante para esta aplicação.

Considerando as aplicações educacionais, muitas informações podem gerar ruídos e interferirem nos estudos dos alunos. Em ambientes não controlados, várias situações podem tirar a concentração do aluno, fazendo com que ele cometa mais erros. Além disso, o conteúdo da aula também precisa ser exposto de forma interativa. Um bom feedback pode ajudar o professor a compreender os pontos em que os alunos estão com dificuldades e a melhorar a forma de dar aula. Dessa forma, a base de dados deve levar em consideração esses outros ruídos existentes nas aplicações finais, que podem atrapalhar a acurácia dos algoritmos de classificação.

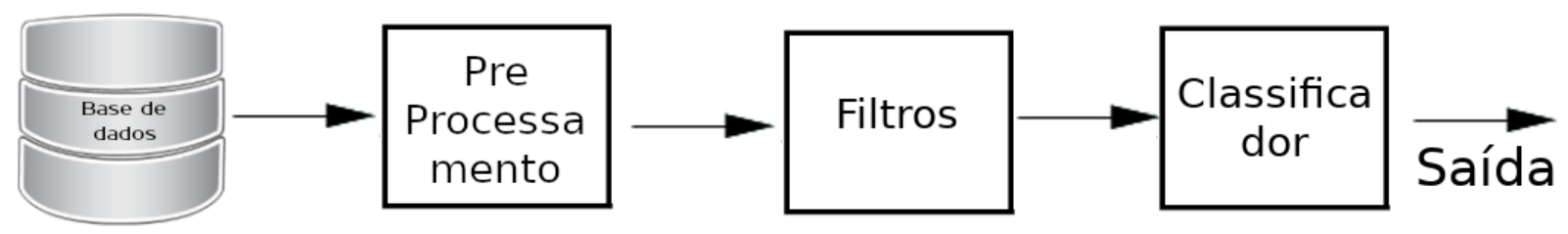

Figura 15 - Arquitetura proposta neste trabalho, considerando a etapa de processamento do ErrP

Fonte: Elaborada pelo autor.

A Figura 15 apresenta a arquitetura proposta para este trabalho. Na etapa de préprocessamento, foram utilizados os filtros clássicos para limpeza do sinal, como os filtros passa-banda Butterworth, para atenuação do sinal, e também a remoção de informações de piscar de olhos (manualmente e utilizando uma heurística). Os artefatos, principalmente em ambientes não controlados, devem ter uma atenção especial. Para a etapa de filtragem, a proposta deste trabalho é aplicar, para um sistema de educação, soluções mais utilizadas em trabalhos relacionados a imagética motora. Como explicitado, os filtros utilizados por padrão podem não ser o melhor para representar as informações do sinal. Para isso, foram comparadas as transformadas de Fourier com as Wavelets. Assim, é possível discutir o sinal tanto no domínio de frequência quanto de tempo, podendo ter uma melhora na leitura do sinal. Por fim, para a etapa de classificação, comparar algoritmos de classificação, uma vez que a alta densidade de informações e ruídos podem impactar na acurácia desses algoritmos.

Com a análise das bases de dados disponíveis (discutidas no Capítulo 5), o sinal recebido já estava pré-processado, ou mesmo envolvia captação de eletrodos que não estavam definidos para esta tese, como o EEG. Nessas bases, o ambiente era controlado, e não reproduziam todas as situações que foram definidas para este trabalho. Portanto, foi definido que seria criada uma base própria, construída seguindo algumas premissas para a educação, o que não foi encontrado nas bases disponíveis. Foi proposto um jogo sério, com elementos de competição, e uma interação com um robô humanoide para gerar todas as informações consideradas importantes para serem analisadas. A Figura 16 demonstra essa arquitetura para a criação da base. 


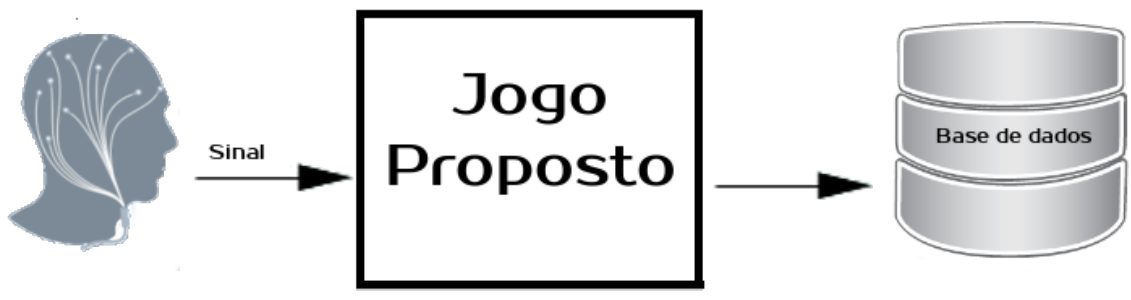

Figura 16 - Criação da base de dados própria

Fonte: Elaborada pelo autor.

\subsubsection{Definindo o jogo}

Para testar a incidência de ErrP em uma base de dados conhecida, foi desenvolvido um jogo utilizando PyGame para gerar erros forçados dos usuários. Seguindo uma linha parecida com a que foi vista em (SPÜLER; NIETHAMMER, 2015), o jogo deveria ser desafiador e interessante para participação das pessoas. Porém, foram observados os aspectos de frustração e instigação durante a execução do jogo, que seriam mais interessantes para melhorar a base de dados para ser utilizada neste trabalho. $\mathrm{O}$ jogo foi criando com a ajuda de especialistas em game design, que deram dicas com relação a cores, sons e outros pontos para que o jogo ficasse o mais completo possível para a apresentação.

O jogo tem uma proposta e objetivo simples: com as setas do teclado, mover um zumbi que deveria comer a maior quantidade de cérebros possível antes de acabar o tempo. O zumbi tinha uma animação de abrir e fechar a boca, que acontecia o tempo todo (mesmo que o zumbi ficasse parado). Os cérebros apareciam de forma randômica na tela e nenhum outro obstáculo foi implementado. O jogo tinha uma tela inicial, onde o usuário deveria escrever o seu nome, a tela do jogo propriamente dita e uma tela final de vitória ou de derrota. Artes foram criadas para todas as telas:

- Uma inscrição "Brain Rush", como foi intitulado o jogo, na tela inicial

- Um cemitério com uma casa ao fundo, utilizado com background do jogo principal (Figura 17)

- Vários zumbis com a inscrição "You Win! Go bite the world"como tela de vitória e uma lápide com as inscrições "You didn't make it"como tela de derrota

Além das artes, foi composta uma música para a tela inicial (rock para servir de empolgação para os alunos) e foi escolhida outra música, mais aterrorizante, para a tela de jogo. Foram incluídos sons para quando o zumbi comia um cérebro, gritos e sons de erro característicos de sistemas operacionais (utilizados nos momentos de erros forçados), risadas para a tela de vitória e um grito de dor para a tela de derrota. Os sons criam uma melhor imersão ao jogo, além de 


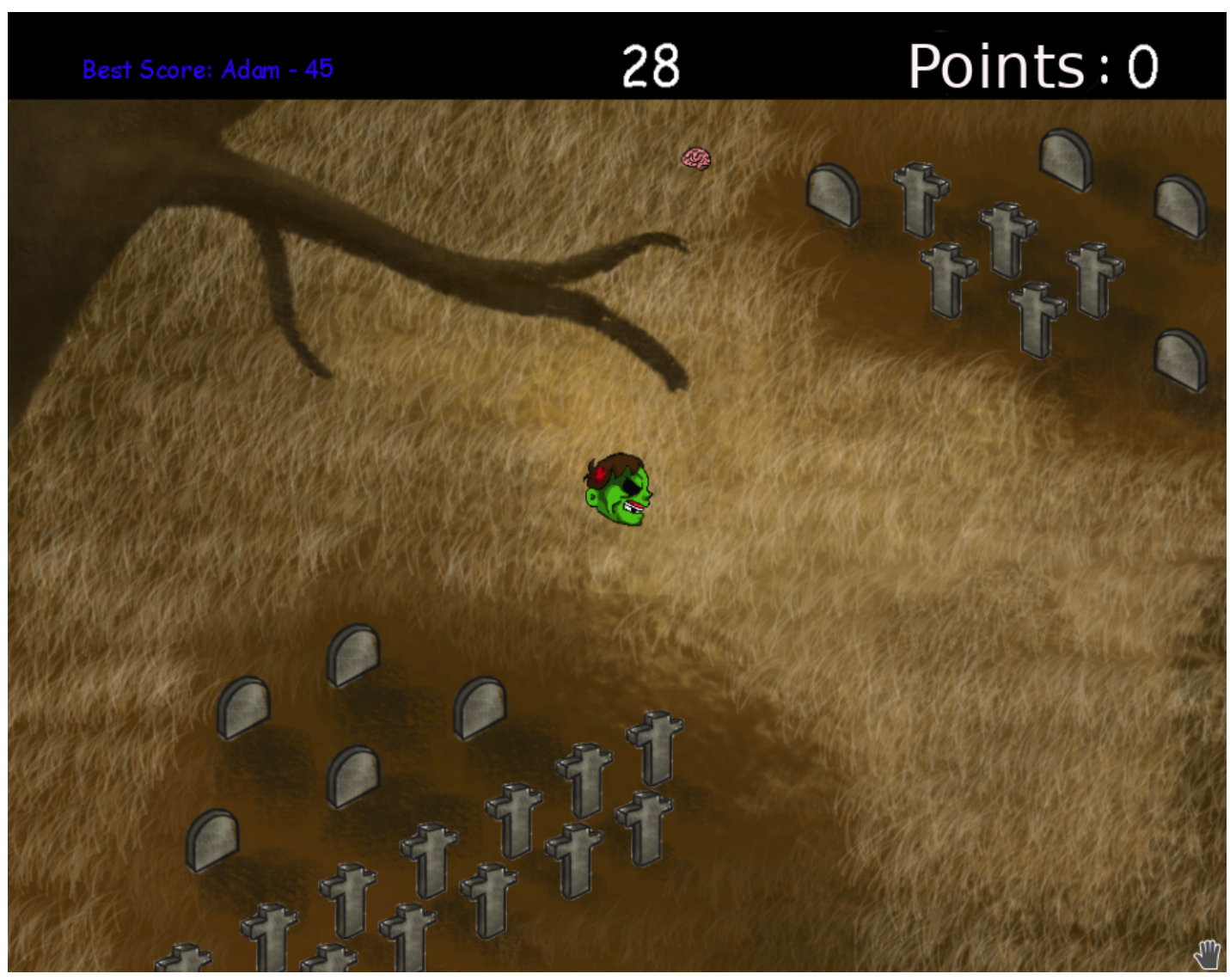

Figura 17 - Tela do jogo criado para esta tese

Fonte: Elaborada pelo autor.

também ser um comportamento esperado pelas pessoas acostumadas com jogos eletrônicos, e não são considerados artefatos por estarem em uma frequência diferente do ErrP, sendo facilmente descartadas durante o pré-processamento.

\subsection{Considerações Finais}

Neste capítulo foi apresentada a arquitetura utilizada nesta tese. Foram explicados os primeiros experimentos desenvolvidos, que mostraram as lacunas presentes na área e a partir dele foram definidas as metas para as pesquisas do laboratório. Para atender a todos os problemas apresentados, o sistema R-CASTLE foi desenvolvido, envolvendo pesquisas de vários integrantes do grupo de trabalho. Esse sistema é uma ferramente para ajudar os professores que não tenham conhecimentos em programação à montar atividades com os robôs, de acordo com os recursos (sensores e atuadores) disponíveis.

Além de professores, esse sistema é pensado em ajudar os alunos, gerando feedbacks das atividades educacionais e atenção, permitindo que a experiência de aprendizado seja melhor aproveitada. Neste sentido, o sistema de detecção de erros é um módulo importante do RCASTLE, aprimorando as capacidades de HRI do sistema. Foram apresentados os primeiros 
resultados do protótipo desse sistema e definido os parâmetros para os experimentos a serem realizados para validar a proposta deste trabalho.

No próximo capítulo, serão mostrados os experimentos definidos, o jogo que foi desenhado para criar uma base de dados própria, levando em consideração a necessidade de se manter a atenção do usuário, criar um ambiente imersivo e forçar o acontecimento de erros para detecção e classificação. 

Neste capítulo, são apresentados os dispositivos utilizados neste trabalho, abordando suas diferenças e características. Devido às diferenças de hardware, é interessante entender os tipos diferentes de capacetes para serem aplicados no trabalho. Além disso, apresentamos o robô NAO, utilizado em alguns testes. Por fim, foram definidos os experimentos para comparação dos algoritmos propostos, mostrando algumas informações da literatura e também a forma como foi aplicado o jogo proposto. a partir dessas definições foram selecionados os participantes, a sequência dos experimentos e os recursos para se obter os sinais a serem utilizados no sistema proposto nesta tese.

\subsection{Materiais}

Os sistemas BCI utilizam, na sua maioria, o EEG, que é uma abordagem não-invasiva para obter os potenciais elétricos do cérebro. Existem alguns dispositivos, chamados de touca ou headset, que são muito utilizados nas pesquisas pelo seu baixo preço e pela facilidade de uso. Junto com alguns destes dispositivos, são disponibilizados softwares para pré-tratamento do sinal, que mostram de forma rápida para o usuário os espectros de potência e medições relacionadas a atenção e meditação. Esses softwares foram descartados nesta implementação. Informações sobre os capacetes disponíveis comercialmente podem ser vistas no Apêndice A.4. Nas próximas subseções, serão discutidos os dispositivos utilizados neste trabalho.

\subsubsection{OpenBCI}

Uma outra opção de dispositivo para obtenção do EEG é o kit R\& D, da OpenBCI, desenhado para ser expansível e, ao mesmo tempo, de fácil acesso para quem não possui experiência com hardware. Este kit consiste de uma placa eletrônica com um microcontrolador PIC e um bluetooth RFDuíno para comunicação com o computador e 16 eletrodos (existe uma versão da placa que suporta apenas 8 eletrodos), que podem ser posicionados de acordo com a 


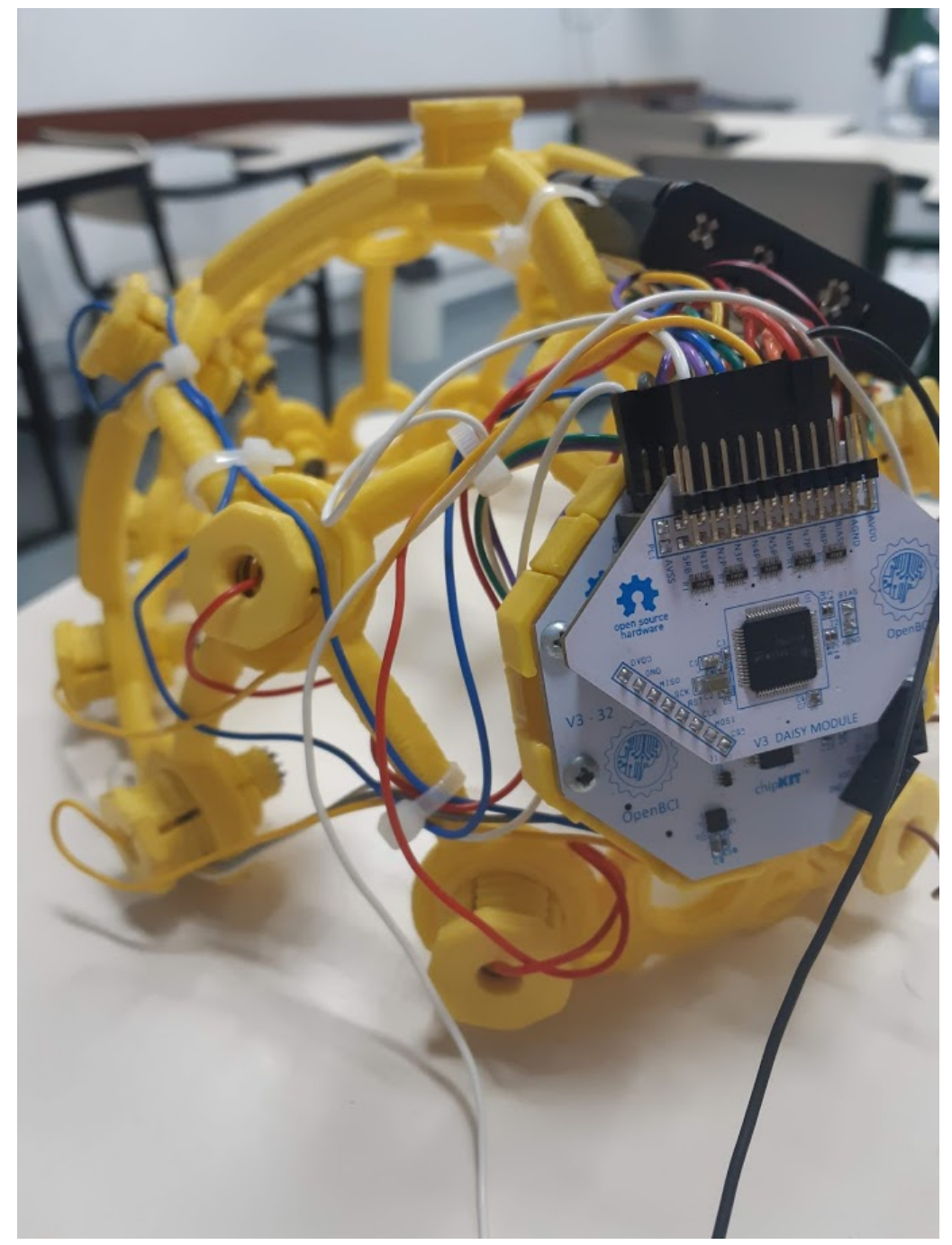

Figura 18 - Headset OpenBCI R \& D.

Fonte: Elaborada pelo autor.

necessidade do pesquisador. O diferencial deste kit é a possibilidade de expandi-lo para mais canais, sendo possível reprogramar o seu microcontrolador ou adicionar um Arduíno. O kit possuí também um acelerômetro, entrada para cartão SD (permitindo salvar os dados em caso de problema na comunicação wireless) e uma taxa de amostragem de até $16 \mathrm{kHz}$, o que é suficiente para medir o EEG, o Eletromiograma $(E M G)^{1}$ e o Eletrocardiograma $(E C G)^{2}$. O kit pode ser visto na Figura 18.

É possível encontrar gratuitamente algumas bibliotecas específicas para o OpenBCI reconhecer o Arduíno, além de sistemas em Python e Java para testar da forma mais fácil e rápida possível o sistema. A SDK em Java permite verificar a conexão do equipamento, ligar e desligar canais específicos, realizar o teste de impedância, ligar e desligar um modo de simulação e interface com outras ferramentas. Por disponibilizar o sinal puro, é possível integrar o sistema

1 Monitoramento da atividade elétrica nas células musculares.

2 Monitoramento da atividade elétrica do coração. 
com o MATLAB e com diversas toolboxes disponíveis para tratar o sinal do EEG. São elas:

- EEGLAB: ferramenta que processa o sinal contínuo e os ERP (Potenciais relacionados à eventos) utilizando várias técnicas como ICA, análise de tempo/frequência entre outros métodos, e inclui a remoção de artefatos;

- BCILAB: ferramenta para design, protótipo, teste e experimentação de sistemas BCI;

- ERPLAB: Ferramenta focada na análise dos ERPs, provendo visualização, análise e processamento robustos.

\subsubsection{ActiCAP V-AMP}

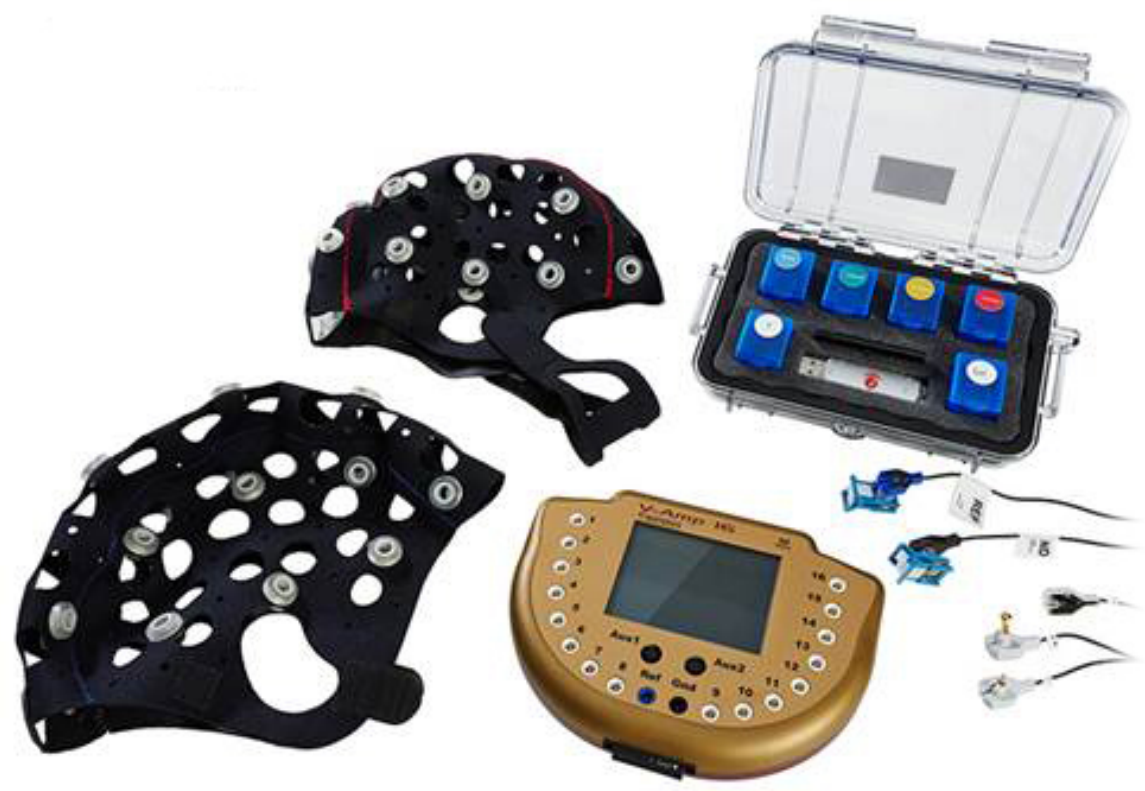

Figura 19 - Touca ActiCap e amplificador V-AMP, utilizados nesta tese. Fonte: Site BrainProducts ${ }^{3}$.

Produzido pela Brain Products, o actiCAP (Figura 19) é uma touca que facilita o posicionamento dos eletrodos, contando com o amplificador V-AMP. Com diversas configurações, a versão utilizada nesta tese conta com 16 eletrodos curvados e mais 2 plugs auriculares para os canais de referência (eletrodo azul) e terra (eletrodo preto). O capacete utilizado utiliza o "mecanismo twist", que ajusta a profundidade do eletrodo com relação à touca, o posicionando mais próximo do couro cabeludo com facilidade. Para melhorar a aquisição do sinal, é necessário o uso de gel condutor, além de ser recomendado usar álcool para limpar áreas como a testa e as orelhas, que podem estar oleosas. O processo de utilização deve seguir os seguintes passos: medição da impedância, monitoramento e teste do sinal. Essa sequência de passos precisa ser instruída por profissionais, mas uma vez aprendida pode ser executado por leigos.

3 Disponível em: https://www.brainproducts.com/ . 
Além da touca e do amplificador, o produto acompanha o ImpBox, usado para determinar as impedâncias de cada eletrodo. Com o tipo de eletrodo utilizado nesta implementação, é suficiente que a impedância seja medida em intervalos. No ImpBox, esses intervalos variam de $10 \mathrm{kOhm}$ a $300 \mathrm{kOhm}$. O chicote com os eletrodos é ligado ao ImpBox (que usa mesma porta de 40 pinos do V-AMP) e um LED fica verde quando os eletrodos estão na faixa correta. A comunicação é feita através de um cabo flat. A impedância deve ser diminuída para a faixa esperada, mantendo os canais de referência e terra na faixa de $10 \mathrm{kOhms}$. Neste trabalho, os eletrodos foram mantidos na faixa dos $100 \mathrm{kOhms}$. Durante a diminuição da impedância, os eletrodos apresentavam LEDs que variavam de vermelho a verde. Essa coloração pode ser vista na Figura 20.

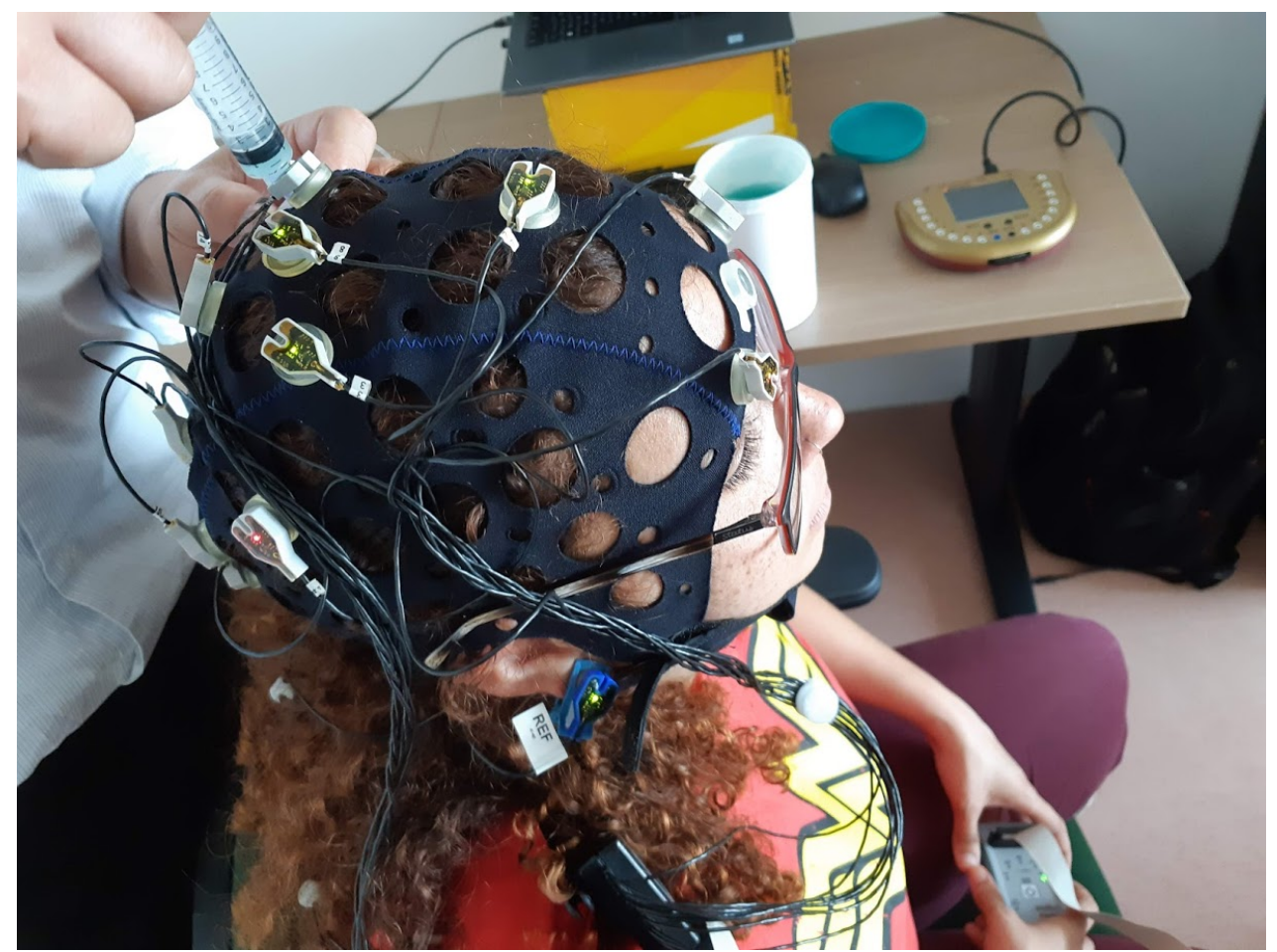

Figura 20 - Processo de diminuição da impedância utilizando gel condutor. Na imagem, três eletrodos estão com a coloração verde, sinalizando que a impedância está na faixa esperada. O mesmo acontece para o eletrodo de referência. A participante do experimento está com o ImpBox nas mãos.

Fonte: Elaborada pelo autor.

A transferência dos dados é feita via USB (assim como a alimentação do amplificador), a frequência varia de 0 a $320 \mathrm{~Hz}$ (Modo de alta velocidade) e as taxas de amostragem vão de 100 a $20000 H z$. O V-AMP é compatível apenas com sistemas Windows, porém os dados capturados podem ser interpretados por outros softwares. Nesta abordagem, utilizamos os OpenVibe, software gratuito, disponível também para Linux, para design e teste de BCIs. O software pode ser usado para aquisição, filtragem, processamento, classificação e visualização dos dados tanto em tempo-real quanto offline, podendo inclusive analisar batchs com grandes quantidades de sinais. Nesta tese foram utilizados os seguintes módulos: 
- Visualização: utilizado principalmente na etapa de calibração, permite ao pesquisador verificar o sinal adquirido após o processo de diminuição de impedância. O usuário seguia uma rotina de exercícios (piscar rapidamente os olhos, respirar fundo, mexer os olhos para os lados). Esses dados eram imediatamente descartados uma vez que o pesquisador estivesse satisfeito com o resultado.

- Aquisição: responsável por capturar os dados vindos do amplificador. Este módulo simplesmente deixava os dados disponíveis no ambiente do OpenVibe.

- Escrita dos dados puros (Raw): este método não fazia qualquer processamento no sinal adquirido, escrevendo em um arquivo CSV exatamente a informação vinda do amplificador.

- Filtro Butterworth: este módulo aplicava um filtro passa-banda, deixando o sinal apenas na faixa esperada pelo pesquisador. Ele não executava nenhuma outra alteração no sinal capturado.

- Escrita dos dados tratados: exatamente da mesma forma do escrita pura, este módulo escrevia os dados apos passarem pela filtragem de sinal em um arquivo CSV.

- Transformada Wavelet: criado para comparação, este módulo desempenhava a transformada wavelet Haar conforme definido pelo OpenVibe, sendo permitida a decomposição apenas em 3 canais. Este sinal também era salvo em um arquivo CSV, com a diferença da transformada ser feita imediatamente após a aquisição dos dados.

A configuração descrita neste capítulo foi utilizada em todos os experimentos feitos utilizando o V-AMP.

\subsection{Robô NAO}

A robótica educacional pode ser aplicada em várias áreas do conhecimento, com diversos níveis de aprofundamento. Alguns kits priorizam a mecânica e programação, sendo mais simples de montar e também mais restritos. É o caso dos kits da $\mathrm{LEGO}^{4}$ e $\mathrm{PETe}^{5}$, amplamente utilizados para pesquisas de robótica educacional. Outros kits priorizam o aprendizado eletrônico, fornecendo uma base mecânica, mas utilizando a placa reconfigurável Arduíno ${ }^{6}$ ou esperando que o estudante construa sua própria placa eletrônica. Por fim, alguns robôs são programados pelos pesquisadores e levados à sala de aula com algum propósito específico. Esses robôs, apesar de comerciais, costumam ter um preço mais elevado, o que impossibilita algumas escolas de adquiri-los, e por isso, não estão ao alcance dos estudantes. Neste trabalho, utilizamos o robô NAO para nossos testes.

4 Disponível em: http://shop.lego.com/en-US/LEGO-MINDSTORMS-EV3-31313 .

5 Disponível em: http://loja.pete.com.br/kit/kit-alpha-mecatronica .

6 Disponível em: https://www.arduino.cc/ . 
Criado pela empresa Aldebaran Robotics ${ }^{7}$, o humanoide NAO é um robô de propósito geral que contém uma grande gama de sensores, atuadores e programação inteligente. O robô tem $60 \mathrm{~cm}$ altura, $5 \mathrm{~kg}$ de peso, 25 graus de liberdade, 2 câmeras, microfone, sintetizador de voz, sensores táteis na cabeça, mãos e pernas, giroscópio, entre outros sensores, conforme mostrado na Figura 21. Em questões de software, ele suporta as principais linguagens de programação: C++, Python, Java e Matlab (ALDEBARAN, 2014). O robô tem sido utilizado em mais de 600 universidades e laboratórios de pesquisa espalhados pelo mundo, e aparece em muitas pesquisas em robótica educacional

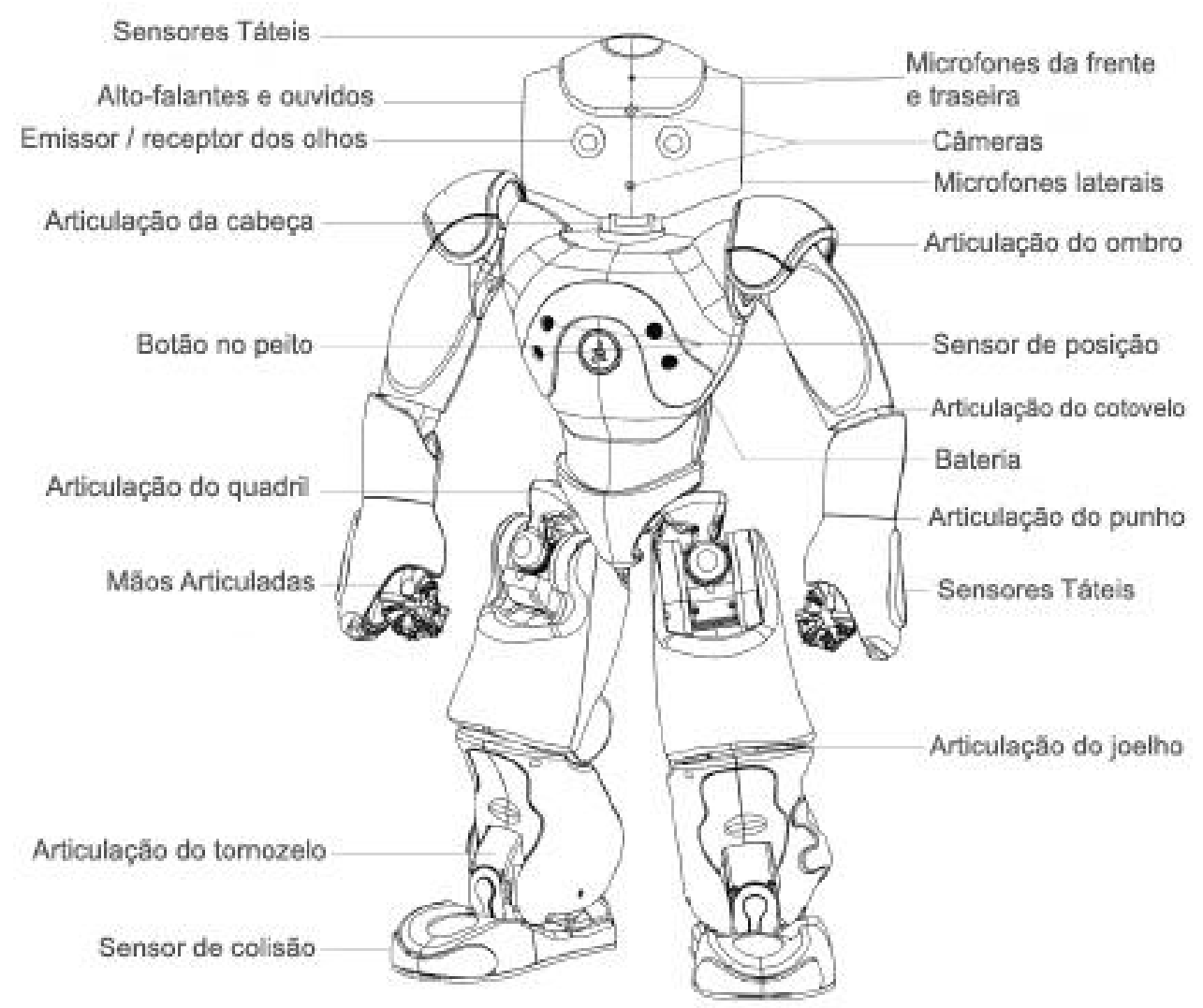

Figura 21 - Distribuição corpórea do robô NAO.

Fonte: Adaptada de Aldebaran (2014).

Na compra do robô, são disponibilizados três softwares:

- Monitor: permite monitorar as câmeras, tirar fotos e fazer vídeos;

- Webots for NAO: permite testar implementações em um ambiente simulado 3D;

- Coregraphe: permite criar novos comportamentos em uma programação por blocos ou movimentar os atuadores para gravar novos posicionamentos.

7 Disponível em: https://www.ald.softbankrobotics.com/en . 
O Choregraphe (POT et al., 2009) é um software para programação intuitiva do robô. Não é necessário que o usuário tenha conhecimento de programação, pois o programa utiliza um conceito "Drag and Drop", sistema igual ao usado pela LEGO, onde basta colocar a "caixa" que representa a funcionalidade desejada, arrastá-la e ligá-la com as demais e o robô passa a executar essa nova função. A ordem de execução segue a ordem em que as caixas são conectadas, portanto, uma caixa só será executada quando a caixa antecessora for finalizada. Isso permite a criação de muitos comportamentos, de mais básicos aos mais complexos, incluindo leitura dos sensores, espera por eventos (apertar um dos sensores táteis da cabeça, por exemplo), estruturas de repetição, entre outros.

Toda a interação Homem-Robô é programada no Choregraphe, como as falas, os movimentos de seu corpo, a coloração dos Leds. Por meio de bibliotecas padrão proprietárias da Aldebaran e de uma Software Development Kit (SDK), todos esses comportamentos salvos no robô podem ser acessados diretamente por programas escritos em qualquer linguagem, mas a Aldebaran recomenda o uso de $\mathrm{C}++$. A framework $\mathrm{C}++$ permite a escrita de código em tempo real, e o uso da SDK permite a criação e a interpretação de código pelo robô, incluindo algoritmos de aprendizado de máquina e comportamentos autônomos.

Para compilar os códigos para o robô é recomendado pela própria Aldebaran a utilização do CMake (um sistema multiplataforma para realizar geração automatizada), juntamente com a framework qiBuild. O qiBuild gerencia as dependências entre os projetos e suporta o cross-compilation, permitindo a boa interpretação do código pelo NAO. A Aldebaran recomenda a utilização da Integrated Development Environment (IDE) - Ambiente de Programação) do QTCreator, pois algumas funções do QT estão inseridas no robô, tornando mais fácil a implementação de um novo módulo.

\subsection{Experimentos com as bases de dados da literatura}

Nas próximas seções são apresentados os experimentos propostos para validar esta Tese. Uma vez definido o papel que o sistema teria para completar o R-CASTLE, e sabendo que o erro era uma informação valiosa para medir a capacidade de aprendizado do aluno, foram definidos os seguintes passos: $O$ primeiro teste foi feito com uma base de dados encontrada na internet e discutido na Seção 5.3. Em segundo, foi desenvolvido um jogo em Python para forçar o acontecimento do ErrP, e criar um ambiente de competição e atenção do aluno, que é apresentado na Seção 4.3.1. A Seção 5.5 discute a interação com o robô humanoide e a Seção 5.6 apresenta as considerações finais deste capítulo.

A princípio, houve muita dificuldade em encontrar bases de dados em que fosse possível aplicar os algoritmos propostos, pois a maioria era muito específica (como as bases de dados da BCI Competition) e com diferentes objetivos do que esta pesquisa. Ou ainda, bases de dados que eram fechadas cujos pesquisadores responsáveis não estavam disponíveis. Em pesquisa, 
entretanto, foi encontrado o Projeto BNCI Horizon 2020, que tem como finalidade ajudar novos pesquisadores e disponibilizar bases de dados de diferentes pesquisas, criando elos entre os pesquisadores da área.

Dentre as bases de dados disponíveis, duas tinham como principal tema o ErrP. Na primeira base (CHAVARRIAGA; MILLÁN, 2010), seis indivíduos saudáveis (Média de idade 27,83 D.P. 2,23) deveriam monitorar as ações de um agente, porém sem a possibilidade de alterar seus movimentos. Neste experimento, o usuário deveria olhar fixo para o centro do monitor, enquanto um agente (representado por um quadrado verde) se movimenta horizontalmente. Existe uma área de 20 locais demarcados nessa linha central horizontal em que o agente deve parar. A direção para o alvo é denotada pelas cores azul (quando o agente deve ir para a esquerda) e vermelha (quando o agente deve se mover para a direita).

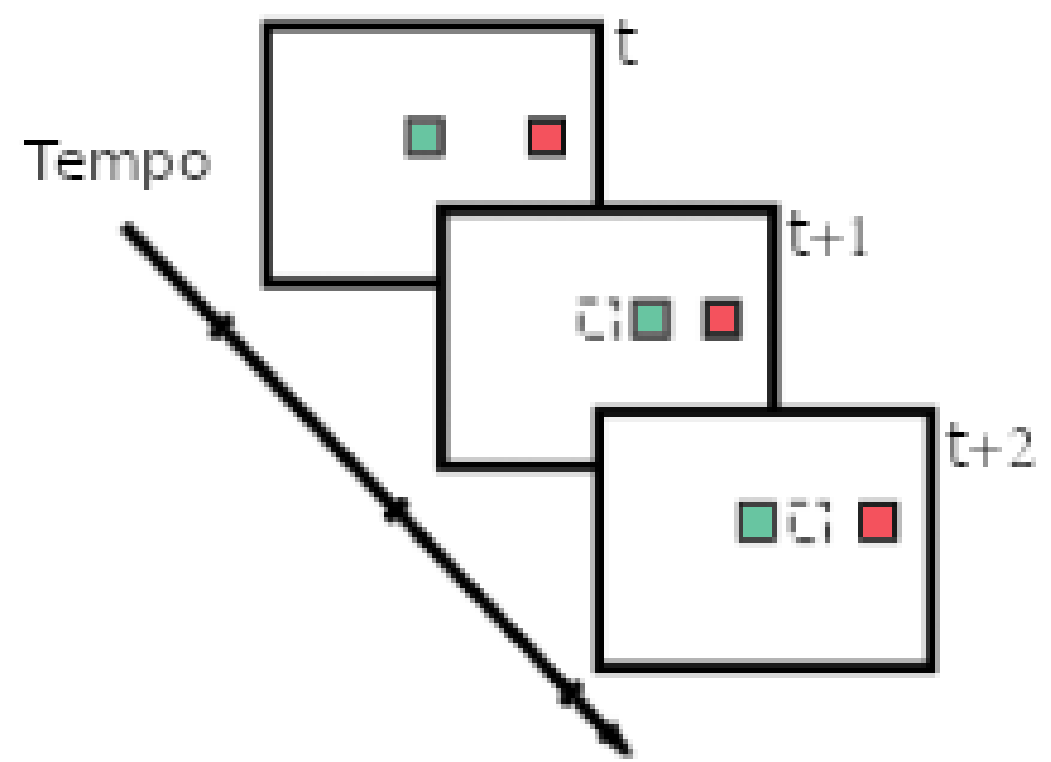

Figura 22 - Exemplo do dataset. Quadrado verde representa o cursos em movimento, o vermelho indica o alvo. O quadrado pontilhado indica a posição do cursor no tempo anterior. Exemplo de movimentação correta $(t+1)$ e errada $(t+2)$

$\mathrm{f}$

Fonte: Adaptada de Chavarriaga e Millán (2010).

Para gerar o ErrP, em todas as movimentações do agente existe uma probabilidade de $20 \%$ de se movimentar para o lado contrário do alvo. Os indivíduos fizeram seções de 3 minutos (aproximadamente 50 posicionamentos por seção), sendo que a distância entre a primeira e a última seção variou para cada indivíduo. O primeiro teve uma distância de 51 dias, o segundo de 52 até o último que teve uma distância de 643 dias. O EEG foi gravado a $512 \mathrm{~Hz}$ utilizando o Biosemi Active Two System. Foram gravados 64 canais seguindo o sistema 10/20 e um sinal foi adicionado ao canal para indicar a posição do alvo e o movimento do agente. Além dessa marcação em hardware, foi adicionado o marcador onde os eventos 5 e 10 são movimentações corretas e 6 e 9 demarcam movimentações errôneas. 
Analisando as bases de dados anteriores, fica claro que existem diferentes tipos de sinais de erro, demonstrando diferentes formas de onda de acordo com o tipo de erro reconhecido. Essa é uma ferramenta poderosa para os sistemas BCI de adaptarem e corrigirem problemas após a realização de tarefas. Porém, poucos trabalhos exploram o ErrP durante tarefas de feedback contínuo. Assim, assume-se que existem muitas variantes do ErrP, sendo este um termo genérico para se referir a todas as possíveis respostas ao perceber um erro. No trabalho de Spüler e Niethammer (2015), um outro jogo foi definido para testar esses tipos diferentes de ErrP.
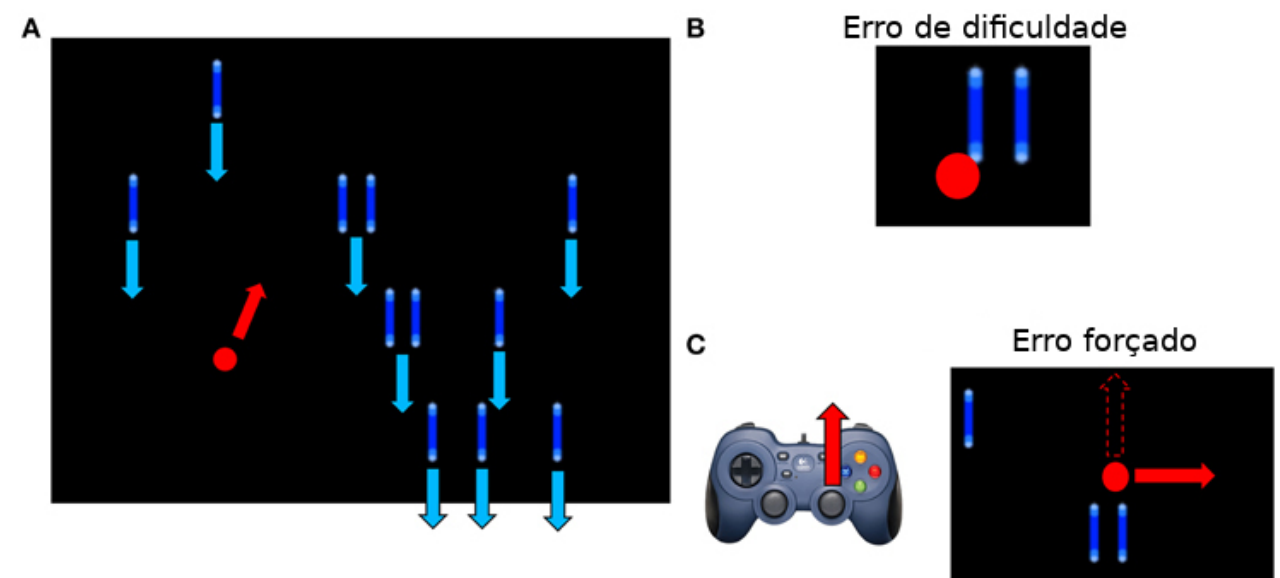

Figura 23 - Exemplo do funcionamento do jogo, com os erros de dificuldade e erros forçados. Em A é demonstrada a tela do jogo. B indica um erro de dificuldade (não conseguir desviar das barras azuis) e $\mathrm{C}$ mostra o controle recebendo um comando e a bola vermelha executando outra função, configurando um erro forçado

Fonte: Adaptada de Spüler e Niethammer (2015).

No jogo, similar ao proposto por Milekovic et al. (2012), o usuário deveria movimentar uma bola vermelha pelo cenário, de forma a passar pelas barras azuis sem se chocar. Ao contrário da proposta de Chavarriaga e Millán (2010), neste jogo o usuário realmente comandava o agente, e a dificuldade do jogo era progressiva (as barras azuis iam aumentando de quantidade e velocidade, de forma a ser desafiador). No caso de algum choque, o jogo continuava por um segundo, e depois parava. Esse delay foi introduzido para garantir que o jogador reconhecesse que tinha colidido, gerando o erro de dificuldade, e não que o jogo simplesmente parasse e reiniciasse. Além do erro de dificuldade, para garantir a percepção de outros erros, foram adicionados erros forçados, onde o agente virtual reagiria em um ângulo diferente do apresentado pelo sujeito, de forma aleatória entre 45, 90 e 180 graus. O erro durava por dois segundos e o tempo entre dois erros forçados variava entre cinco e oito segundos.

Para esta base de dados, 10 indivíduos saudáveis (Média de idade: 24,1 D.P. 1,1) foram recrutados, e utilizaram o BrainProducts ActiCap System, porém com o amplificador USBamp. 28 eletrodos foram posicionados no escalpo (Fpz, AFz, F3, Fz, F4, F8, FC3, FCz, FC4, T7, C3, $\mathrm{Cz}, \mathrm{C} 4, \mathrm{~T} 8, \mathrm{CP} 3, \mathrm{CPz}, \mathrm{CP} 4, \mathrm{P} 7, \mathrm{P} 3, \mathrm{Pz}, \mathrm{P} 4, \mathrm{P} 8, \mathrm{PO} 7, \mathrm{POz}, \mathrm{PO} 8, \mathrm{O} 1, \mathrm{Oz}$ e O2) e outros três foram posicionados embaixo do olho e próximo ao nariz para a leitura do EOG. Os dados foram salvos a $512 \mathrm{~Hz}$, sendo adicionado um filtro de $50 \mathrm{~Hz}$ parar evitar ruído da rede elétrica. Uma 
porta paralela do computador era utilizada para repassar a informação sobre os acontecimentos dos erros durante o jogo. A base de dados foi segmentada em diferentes exemplos de 1 segundo: momentos com os erros de dificuldade; momentos com o erro forçado; e momento em que nenhum erro foi apontado. Para cada um dos sujeitos, foram salvos 1 hora de dados de EEG, tendo aproximadamente 597 erros forçados $( \pm 22), 86$ erros de dificuldade $( \pm 30)$ e 475 momentos normais $( \pm 39)$. Para redução dos artefatos relacionados aos olhos, uma regressão baseada em EOG foi utilizada.

\subsection{Experimentos com o jogo proposto}

Após a criação do jogo de zumbis proposto, os experimentos foram conduzidos em 2 etapas: uma etapa de calibração e outra com o jogo real. Ambas as etapas tinham regras específicas, a primeira usada para entender o comportamento do cérebro sem a indução de erros, e tinha duração bem definida. A segunda era mais caótica, com a indução dos erros e com a competição. Essas etapas serão melhor definidas nas subseções 5.4.1 e 5.4.2. Os eletrodos selecionados para a captação do sinal são demonstrados na figura 24.

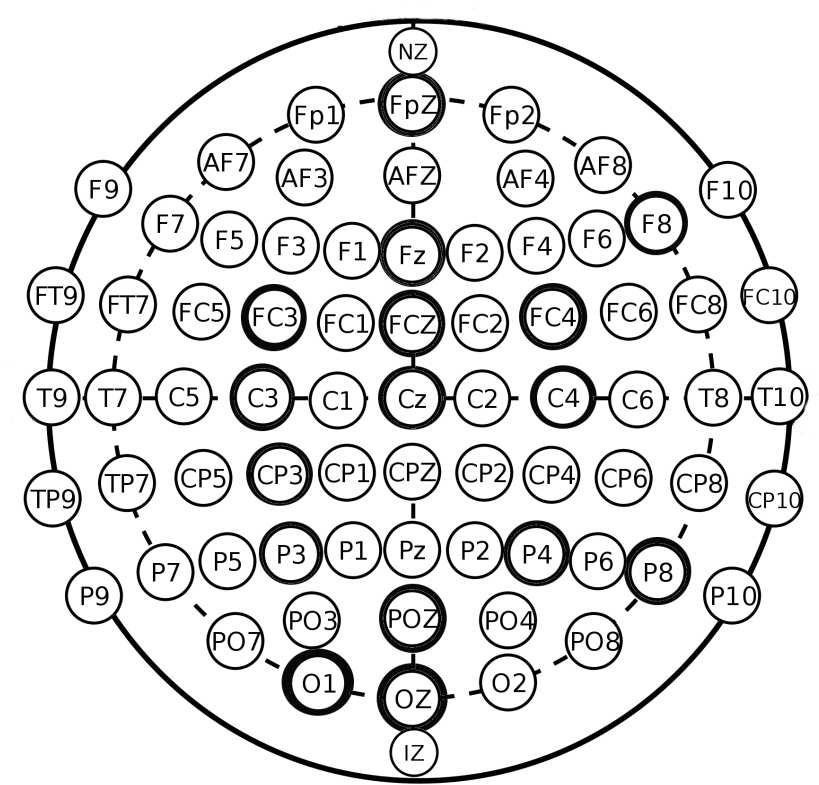

Figura 24 - Posicionamento dos eletrodos para os experimentos com o jogo proposto, seguindo o sistema internacional 10-20

Fonte: Adaptada de Klem et al. (1999).

\subsubsection{Etapa de Calibração}

Na etapa de calibração, o usuário era convidado a participar do jogo sem que tivesse muitas explicações. O jogador, após colocar o capacete e verificar que a aquisição de dados 
estava correta, era posicionado a frente do computador (o pesquisador o posicionava, evitando muita movimentação), digitava o seu nome e depois utilizava as setas para jogar. Essa etapa era feita duas vezes, e os participantes eram instruídos que se tratava apenas de entender como funcionava o jogo. Nesta etapa, o usuário tinha 20 segundos para pegar o máximo de cérebros possível, e o relógio nunca parava de decrescer. Na tela de jogo, existia apenas um relógio com contagem regressiva e um contador de pontos, referentes aos cérebros apanhados.

$\mathrm{Na}$ primeira tentativa, os usuários normalmente conseguiam poucos pontos. Mesmo um jogo simples sem muita explicação causava desconforto, pois 20 segundos foi pouco tempo para acostumar com o jogo. Para a segunda tentativa da etapa de calibração era acrescentado na tela um scoreboard com a pontuação da primeira rodada. O pesquisador instigava os participantes a terem uma pontuação melhor do que da primeira para continuar o jogo. Após as duas tentativas na etapa de calibração, o usuário veria a tela de vitória, convidando a continuar participando do experimento. Apesar de seguir as mesmas características de jogo, na segunda rodada foi acrescentada a necessidade de ser melhor que na primeira. Isso foi uma tentativa de gerar uma tensão e consequentemente melhorar a atenção do usuário para o jogo, ambas informações importantes para a análise dos dados ao final do experimento. Em todas as etapas do jogo (calibração e real) existia uma contagem regressiva nos últimos 5 segundos, com o relógio ficando vermelho e uma voz macabra, também com a intenção de aumentar a tensão do jogador. Na Figura 25 é apresentada a tela da contagem regressiva do experimento.

\subsubsection{Etapa real de jogo}

Para a etapa real de jogo, as regras sofriam pequenas alterações. O relógio foi setado para 30 segundos e existia um acréscimo de 3 segundos para cada cérebro que o usuário conseguisse capturar. A tela de jogo era basicamente a mesma, mas agora o scoreboard indicava um outro nome e uma pontuação. $\mathrm{O}$ pesquisador instruiu os usuários das mudanças de regras e avisou que, para ir a uma suposta (e inexistente) fase três do jogo, era necessário superar essa pontuação, estabelecendo um novo recorde. Os usuários não foram avisados sobre os erros forçados, o que os fazia acreditar que a tarefa de vencer a pontuação era algo bastante fácil. Com a inclusão do erros, entretanto, essa tarefa era impossível de ser alcançada. O pesquisador não deveria ter mais nenhuma outra interação com o jogador, mesmo que este reclamasse dos constantes problemas e erros apresentados. O jogo foi programado para progressivamente aumentar a incidência dos erros, fazendo com que ficasse impossível continuar o jogo após um período de tempo. A Figura 26 apresenta um jogador assistindo à mensagem de erro após não atingir a pontuação máxima.

Após essa primeira falha, o jogador era convidado a participar mais uma vez do experimento. Desta vez, era explicado que o erros eram propositais, e que iriam ocorrer exatamente para frustrar o jogador. Mesmo sendo avisado, o usuário não sabia qual tipo de erro e nem quando ele iria acontecer, deixando-o tenso, o que era a intenção desta fase do experimento. Ter que melhorar uma pontuação, sabendo que erros sem seu controle iriam ocorrer, simulava uma 


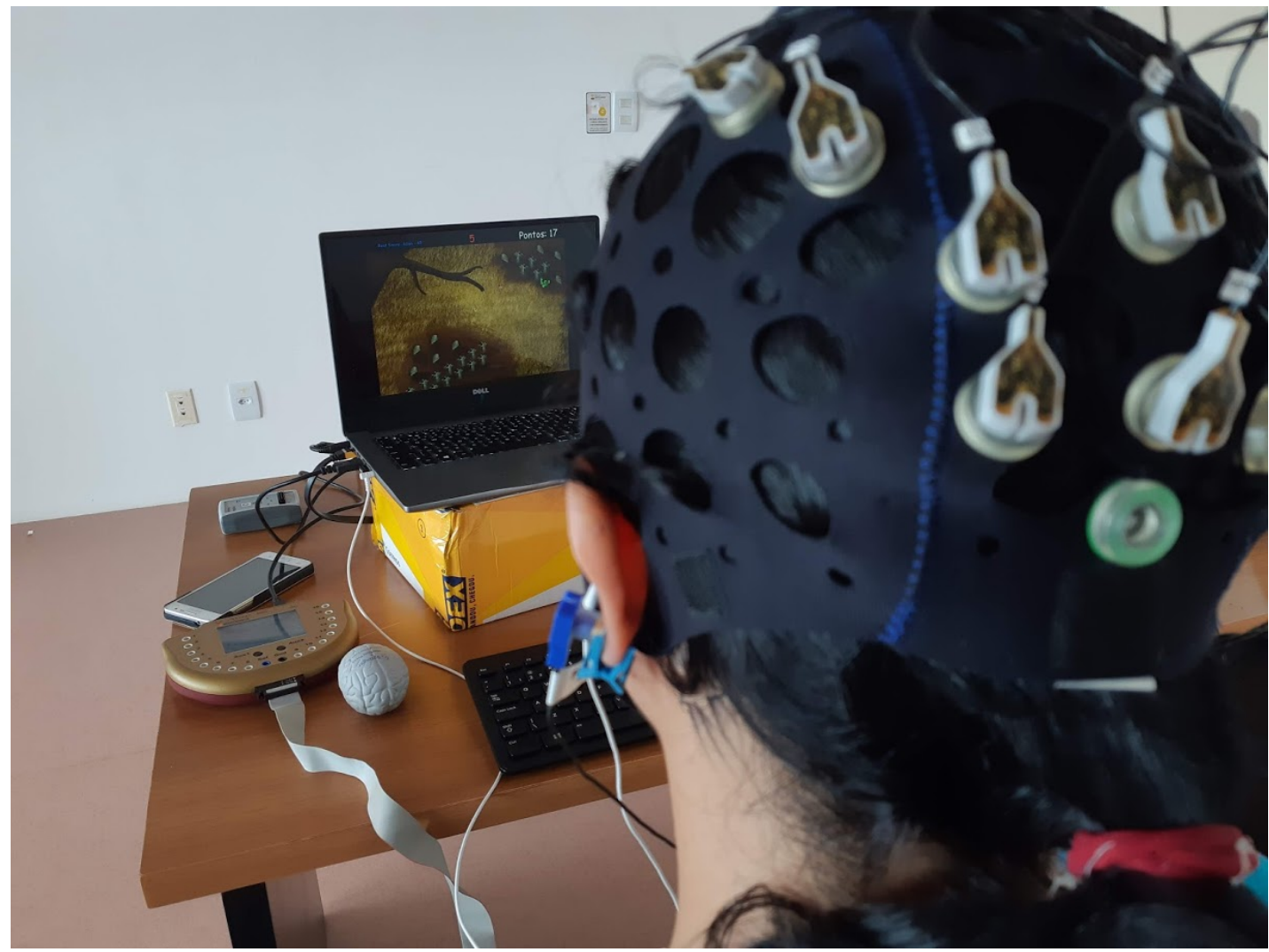

Figura 25 - Usuário durante os últimos 5 segundos de jogo, o relógio muda de cor, acompanhado de uma contagem regressiva sonora

Fonte: Elaborada pelo autor.

necessidade maior de atenção ao jogo, e esse dado era usado para se comparar a forma como o cérebro se comportava em outras situações de estresse, como na hora de resolver provas, por exemplo.

\subsection{Interação com o Robô NAO}

Apesar da frustração do jogador, o pesquisador avisava que ele não tinha conseguido chegar a fase três do jogo. Mesmo assim, o usuário era convidado a fazer um outro experimento, interagir com o robô NAO. Para esta etapa, toda a explicação era feita pelo robô, e o pesquisador novamente deveria intervir apenas em casos de falhas. O robô já estava posicionado exatamente ao lado do computador, gerando o mínimo de movimentação necessária para que o usuário pudesse ficar de frente ao NAO e iniciar a interação.

O robô NAO se levantava, cumprimentava e pegava algumas informações, como o nome da pessoa que estava a sua frente, seguindo a proposta de interação definida no Capítulo 4.1. Depois dessa etapa de cumprimentos e algumas brincadeiras, o robô voltava a ficar sentado para continuar a interação. A movimentação do robô foi limitada para evitar quedas, barulhos ou outros ruídos ao sinal do EEG. Nesta atividade, o robô se apresentava como um novo aluno 


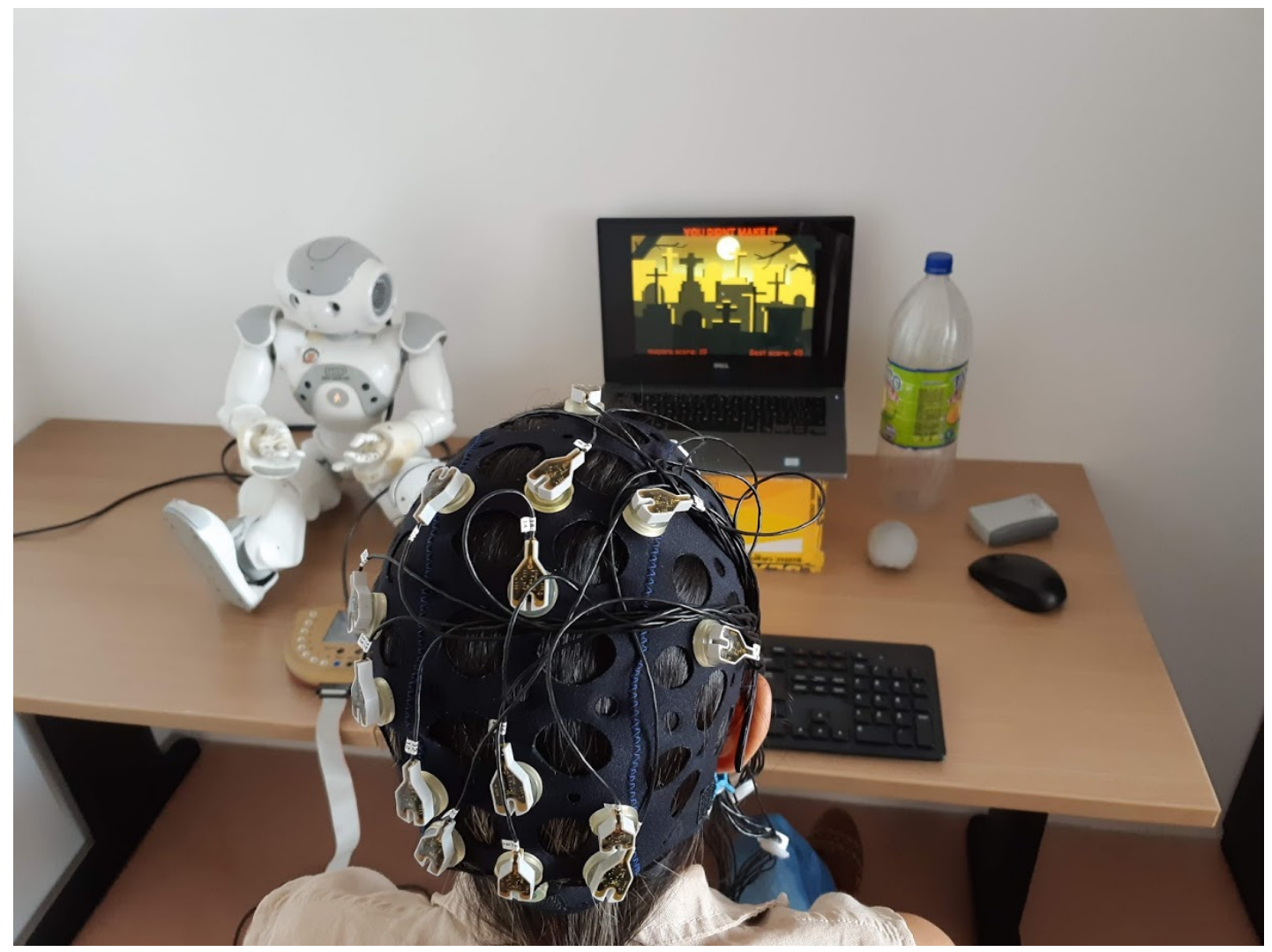

Figura 26 - Jogador assiste a tela de encerramento, indicando a sua pontuação e a que deveria ser alcançada para a próxima fase

Fonte: Elaborada pelo autor.

da faculdade, que precisava de ajuda para compreender informações relacionadas ao cérebro e também a inteligencia artificial.

Assim, o robô fazia algumas perguntas e daria quatro alterativas para a pessoa responder. Porém, ele pedia que as pessoas respeitassem duas condições: responder a todas as perguntas feitas e apertar a letra "b" quando tivesse certeza da resposta e a letra "c" caso estivesse em dúvidas. Como era impossível saber o exato momento em que as pessoas iriam pensar na resposta dentro da interação, foram incluídas essas letras para servirem de marcadores na aplicação final, sendo que no exato momento em que o botão era pressionado, uma informação numérica correspondente a letra era inserida em uma coluna específica do CSV. Na Figura 27 é possível ver o momento de interação, estando na tela do computador algumas instruções do jogo e as ondas captadas. Os dados foram salvos em $512 \mathrm{~Hz}$, seguindo as especificações definidas no Capítulo 5.1.2.

As questões foram divididas em fáceis e difíceis, considerando o conhecimento dos participantes. As questões fáceis eram sobre informações do cérebro humano, como: "quais são os lóbulos cerebrais?"; "Como é considerada a captação do sinal cerebral utilizando EEG?" entre outras. Por serem profissionais da área da saúde, e também por já terem estudado matérias como anatomia e processamento de sinais bio-médicos, todos os participantes eram capazes de 


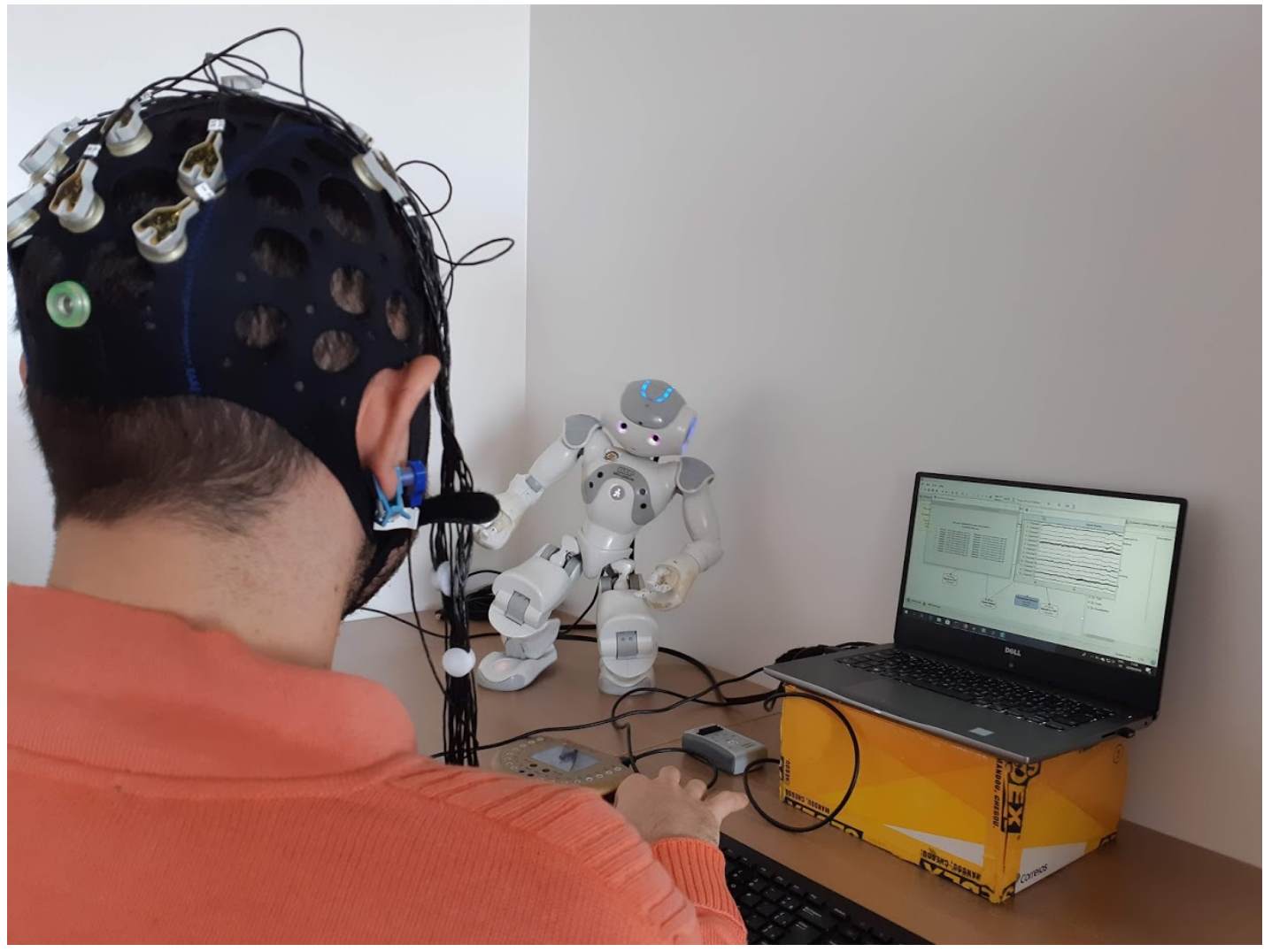

Figura 27 - Momento de interação do robô NAO com um jogador

Fonte: Elaborada pelo autor.

responder facilmente a estas questões. Porém, o mesmo não acontecia para as questões difíceis, que envolviam entender conceitos de programação avançada e aprendizado de máquina. Assim, era esperado que o comportamento do cérebro fosse normal na primeira fase do experimento com as resposta que os alunos já sabiam e depois um comportamento de erros, quando o aluno não tivesse certeza das respostas.

O robô, após a pergunta, dava alternativas de resposta, que poderiam ser repetidas quantas vezes fossem necessárias. Ao ouvir as respostas, o robô tinha 3 comportamentos possíveis:

- Comportamento 1: O robô ouve a resposta e age da forma esperada pelo aluno: responde que a alternativa está correta caso o aluno tenha acertado ou explica que está incorreta, caso contrário

- Comportamento 2: O robô ouve a resposta e age de forma contrária à esperada: responde que a alternativa está correta caso o aluno tenha errado e responde que está errada caso o aluno acerte

- Comportamento 3: O robô ouve a resposta mas age como se estivesse confuso. Por exemplo, o robô entende que a resposta foi "letra b" quando o usuário na verdade respondeu 
"letra d". O robô sempre "entendia" a resposta errada no grupo de questões fáceis e sempre entendia a resposta correta no grupo de questões difíceis.

As questões e os comportamentos eram escolhidos automaticamente pelo robô de forma aleatória. A única garantia é que todos os três comportamentos deveriam acontecer e as questões do grupo fácil deveriam ser feitas antes de iniciar as perguntas difíceis, não havendo mesclagem entre os grupos. A montagem desta interação também foi para forçar o acontecimento do ErrP durante a etapa de questões difíceis.

\subsection{Considerações Finais}

Neste capítulo, foram apresentados os experimentos feitos tanto para algumas bases de dados disponíveis online (usadas nos primeiros testes) e também a geração de uma base de dados própria, seguindo as premissas educacionais escolhidas para servirem de teste. Para o jogo criado, foram utilizados vários elementos não vistos nos demais trabalhos na literatura, como a instigação de tensão, que buscam melhorar a experiência de jogo e aproximar de outras situações do cotidiano de estudantes. A interação com o robô também foi ajustada para ser mais atraente para os alunos, mesmo aqueles que já tem contato com a robótica anteriormente, tentando evitar a dispersão dos mesmos durante os experimentos. A abordagem utilizando feedback BCI pode garantir a melhora nas interações, ajustando os comportamentos do sistema conforme as medições do EEG, podendo, quando bem treinada, servir de termômetro em tempo real para as atitudes do robô, e ajudar a propor novas atividades que mantenham o foco de atenção. 

CAPÍTULO

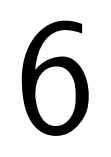

RESULTADOS E DISCUSSÃO

Neste capítulo, serão apresentados e discutidos os resultados das análises feitas nas bases de dados da literatura bem como as feitas na base da dados própria. Primeiramente, serão discutidos os resultados de um experimento de reconhecimento de emoções usando um protótipo do R-CASTLE. Depois, serão apresentados os resultados do pré-processamento dos sinal puro obtido, seguido dos resultados do sistema aplicado as bases de dados da literatura. Por último, serão discutidos os resultados, considerando a base criada com o jogo proposto nesta tese.

\subsection{Reconhecimento de emoções - R-CASTLE}

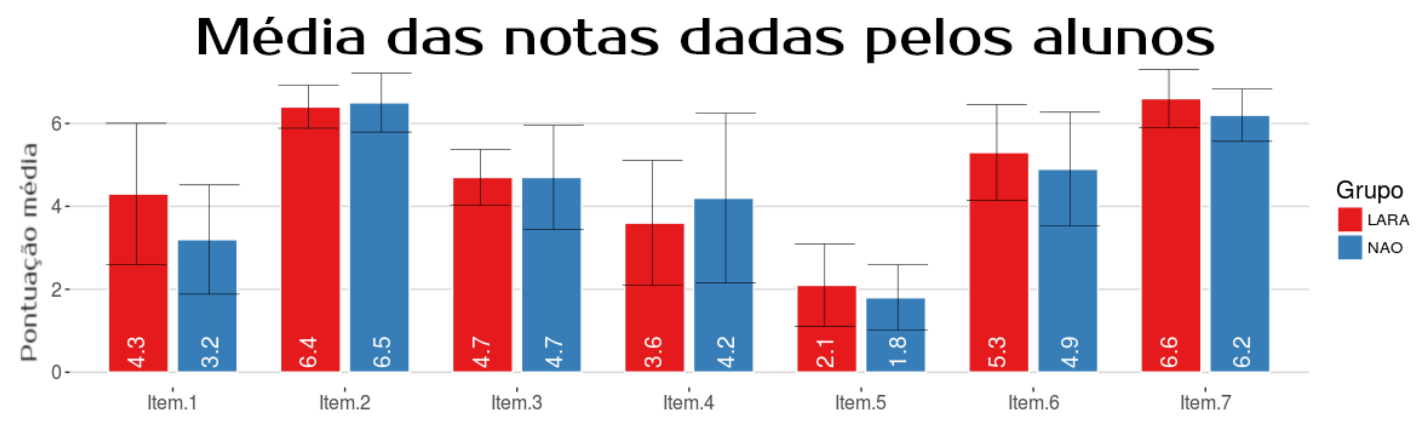

Figura 28 - Resultados das médias de pontuação dadas pelos usuários de cada grupo na escala Likert

Fonte: Elaborada pelo autor.

Os experimentos descritos na Seção 4.2.3 demonstraram que nossa hipótese inicial de que o robô NAO seria muito melhor aceito não se confirmava. Ambos os robôs NAO e LARa foram bem aceitos (Item I3 da pontuação dada pelos participantes, descritos na Subseção 4.2.3) e foram considerados divertidos (Item I2), não sendo encontrada diferença estatística entre um grupo e outro. A média das respostas pode ser vista na Figura 28 e a análise estatística pode ser vista na Tabela 3. No Item I4 é possível ver uma pequena vantagem do robô NAO na 
influência do comportamento, o que era confirmado pelas respostas das pessoas nos testes. $30 \%$ dos participantes não aceitaram nenhuma sugestão da robô nos dois comportamentos, enquanto todos os participantes com o NAO acataram a pelo menos uma das três sugestões (duas vezes sobre o remédio e uma sobre o posicionamento dos itens da prateleira).

Tabela 3 - Teste pareado de Wilcoxon para cada item dos dois grupos

\begin{tabular}{c|ccccccc} 
Items & 1 & 2 & 3 & 4 & 5 & 6 & 7 \\
\hline$W$ & 31 & 57 & 54 & 58.5 & 42 & 42 & 32 \\
p-value & 0.1524 & 0.5794 & 0.7788 & 0.5392 & 0.5472 & 0.561 & 0.1421
\end{tabular}

A robô LARa teve uma desvantagem quando os usuários foram perguntados sobre a forma (item I5) e no jogo do Jokenpô, porém na atividade de reconhecimento de emoções por parte dos usuários, o rosto robótico teve melhor desempenho. Mesmo com algumas emoções mais difíceis de se demonstrar usando somente a face, os usuários tiveram mais facilidade para classificar corretamente com a robô doméstica do que com o robô NAO. Esse resultado confirmou a hipótese de que o reconhecimento dos usuários seria mais fácil para comportamentos mais próximos do conhecido por eles. Alguns movimentos do NAO eram confusos e dificultaram o entendimento de qual expressão era demonstrada, feita atraés do movimento dos braços e posicionamento do corpo. A apresentação das emoções foi feita de forma aleatória em ambos os robôs. A Tabela 4 mostra as porcentagens de acerto para cada um dos robôs.

Tabela 4 - Porcentagem de emoções corretamente classificadas pelos participantes, por robô

\begin{tabular}{lcc}
\hline Emoção & LARa & NAO \\
\hline Felicidade & $\mathbf{1 0 0 . 0 0 \%}$ & $70.00 \%$ \\
Tristeza & $80.00 \%$ & $\mathbf{1 0 0 . 0 0 \%}$ \\
Raiva & $\mathbf{8 0 . 0 0 \%}$ & $50.00 \%$ \\
Medo & $\mathbf{5 0 . 0 0 \%}$ & $30.00 \%$ \\
Desgosto & $\mathbf{5 0 . 0 0 \%}$ & $10.00 \%$ \\
Suspresa & $\mathbf{8 0 . 0 0 \%}$ & $70.00 \%$ \\
\hline Média & $73.33 \%$ & $55.00 \%$ \\
\hline
\end{tabular}

Apesar da hipótese de aparência do robô ter sido refutada nestes testes, a relação entre a qualidade de interação e os recursos disponíveis do sistema foram perceptíveis, para as diversas tarefas feitas com ambos os robô. Isso mostra a dificuldade de fazer sistemas que sejam bem aceitos, considerando todas as formas de interação. O desenho do R-CASTLE deve levar em consideração esse tipo de resultado, pois quando aplicado à educação, a qualidade de interação com os alunos é muito importante para a melhora do aprendizado.

\subsection{Pré-processamento}

As bases da internet já tem a característica de estarem pré-processadas, ou utilizarem outras medições para facilitar a remoção de artefatos como piscar de olhos e batida do coração. 
Essas bases de dados não disponibilizam o dado puro, este disponível nas medições feitas pelo próprio pesquisador. Portanto, para as próximas subseções, serão discutidas apenas os algoritmos utilizados para pré-processamento do sinal puro feito na base de dados própria.

\subsubsection{Piscar dos olhos}

Um dos artefatos mais bem conhecidos do EEG, o piscar de olhos é bem definido e segue algumas propriedades: a influência do sinal é atenuada de acordo com a distância do eletrodo para os olhos, a atividade desse artefato propaga de forma simétrica pelos eixos anterior e posterior e a faixa em que acontece varia entre $4 \mathrm{~Hz}$ e $7 \mathrm{~Hz}$. A princípio, parecia um sinal simples de ser reconhecido e removido, mas não foi o que aconteceu de fato. Apesar de ser uma informação bem-definida (um P200 após o estímulo), outros eventos relacionados aos olhos aconteciam durante o jogo. Enquanto na maioria dos trabalhos relacionados ao piscar de olhos as tarefas dos participantes é simples, nesta base de dados eles deveriam movimentar os olhos o tempo todo em busca da nova posição do cérebro. Por isso, situações como a onda $\lambda$ (potencial occipital positivo baseado na mudança do estímulo visual ocorrendo 300ms após piscar) e o potencial cerebral causado pela cópia de eficiência, que representa um processo de antecipação da mudança no estímulo visual do movimento ocular podiam acontecer.

Como o sinal do EEG é ruidoso, não-estacionário, não-linear e com descontinuidades temporais, uma das respostas para melhorar a condição é passar o sinal por uma transformada. Para tentar limpar o sinal, foi utilizada a transformada de Hilbert - Hilbert Transform (HT) mantendo o sinal no mesmo domínio, mas mudando a fase (FREEMAN et al., 2003; FREEMAN, 2004). Essa informação adicionada é um propriedade que pode guiar as próximas etapas de filtragem e classificação. A transformada de Hilbert de uma função $f(x)$ é a função $\breve{u}(x)$ dada por:

$$
H\{f(x)\}=\check{u}(x)=\frac{1}{\pi} \int_{-\infty}^{\infty} \frac{f(u)}{u-x} d u
$$

A Figura 29(a) mostra o resultado do sinal de um canal após a transformada.

A aplicação da Discrete Fourier Transform (DFT) neste sinal vai apresentá-lo no domínio da frequência, já que estava sendo demonstrado pelo domínio do tempo. Apesar de não ser o melhor para filtragem de características do sinal, a DFT é uma boa ferramenta para análise dos artefatos. A Figura 29(b) mostra o mesmo canal da Figura 29(a), após ser aplicada a DFT.

Neste ponto, é possível aplicar um filtro para separar as frequências em que o sinal esperado realmente ocorre, ou seja, na frequência entre as ondas $\Delta(0.5-4 \mathrm{~Hz})$ e $\Theta(4-8 \mathrm{~Hz}) . \mathrm{O}$ filtro aplicado foi o FIR, de ordem 1000. Os filtros FIR são sempre estáveis e com fase linear, o que gera um atraso no tempo. As Figuras 30(a) e 30(b) demonstram o sinal resultante do filtro e também a análise no domínio da frequência desse sinal. É possível perceber uma diferença 


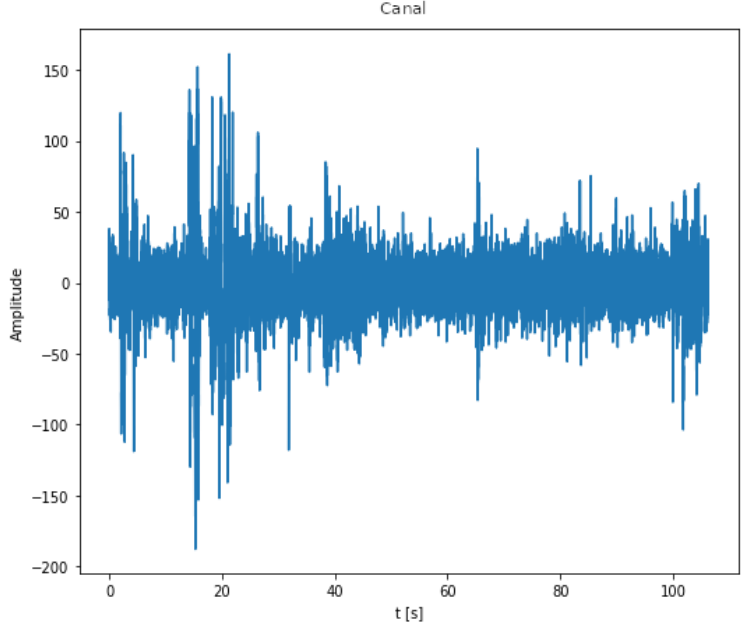

(a)

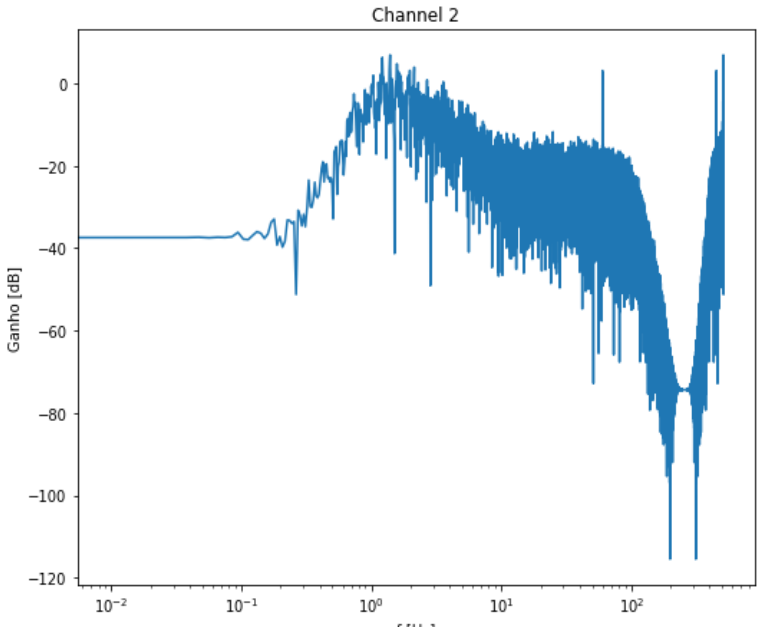

(b)

Figura 29 - Exemplo do sinal puro (a) após o uso da HT e (b) em seu domínio de frequência

Fonte: Elaborada pelo autor.

grande entre a primeira e a segunda imagem em frequência, mostrando que o sinal foi atenuado com o filtro.

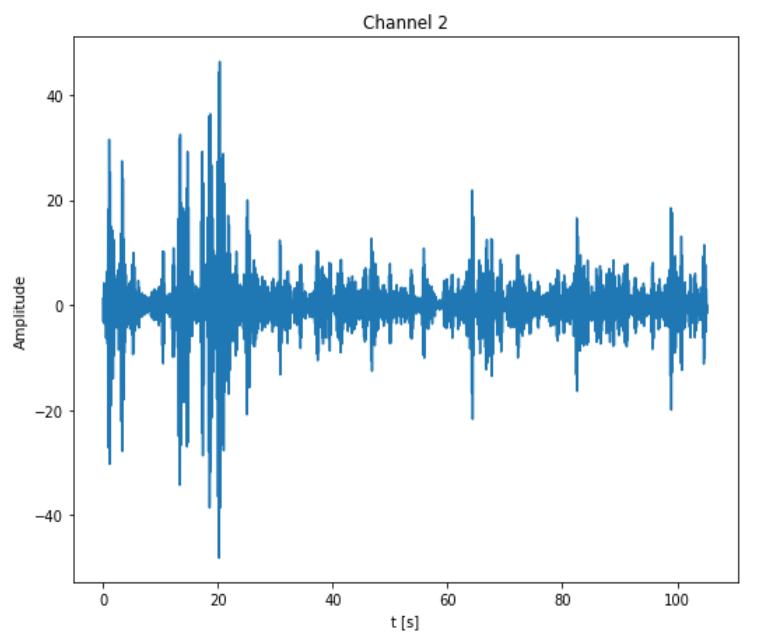

(a)

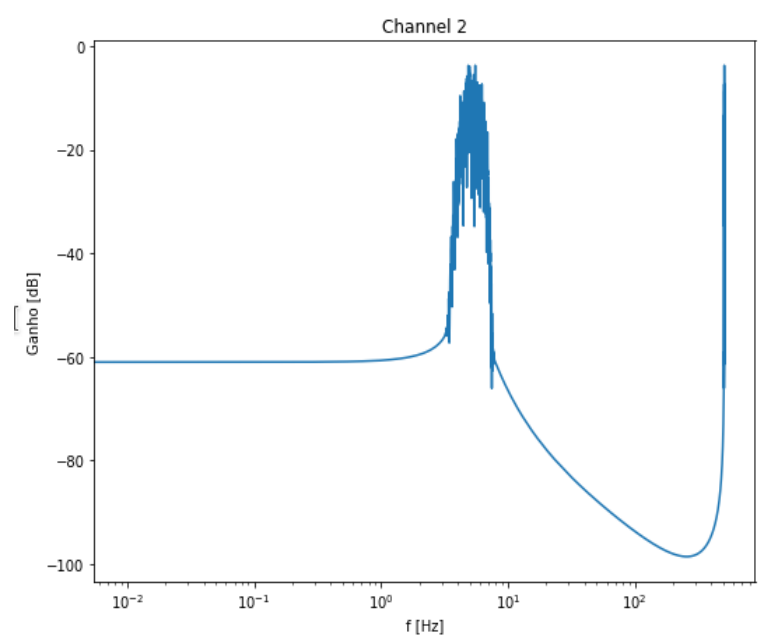

(b)

Figura 30 - Exemplo do sinal filtrado (a) após a HT e (b) em seu domínio de frequência Fonte: Elaborada pelo autor.

Por fim, é possível fazer o agrupamento dos prováveis locais que indiquem a piscada do olho. Uma das soluções é a utilização do KMeans (Figura 31), tentando clusterizar a informação importante do sinal, que deveria representar o piscar dos olhos, para essa faixa. Essa informação não é precisa, uma vez que a pessoa tende a diminuir a frequência com que pisca os olhos enquanto está concentrada, o que também dificulta o reconhecimento automático dessas informações. 


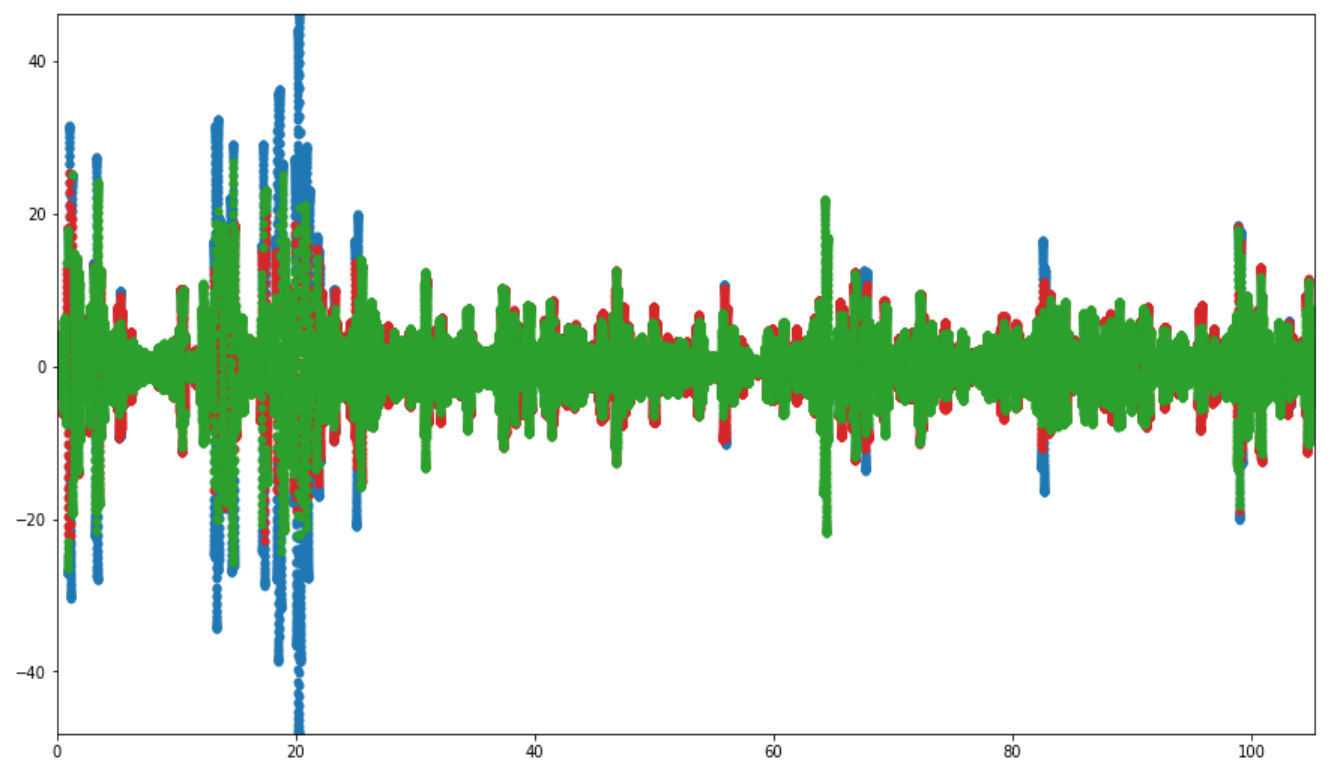

Figura 31 - Exemplo do resultado da clusterização da piscada de olho

Fonte: Elaborada pelo autor.

Com essas informações, utilizamos alguns algoritmos clássicos para tentar validar a implementação utilizada. Para tal, utilizamos a base de dados EEG Eye State Data Set, base pública disponível na UC Irvine Machine Learning Repository. Essa base já contém exemplos de piscar de olhos rotulados. Os resultados, porém, foram abaixo do esperado, ficando todos baixo de $60 \%$ de acurácia. Os melhores resultados foram do KNN com acurácia de 0.55120 (com K=5) e de uma MLP com acuárica de 0.55126 (utilizando 100 neurônios na única camada escondida). Os resultados muito próximos e ruins mostraram que não foi uma boa abordagem, considerando a base bastante ruidosa (o mesmo processo, feito na base limpa e com momentos bem definidos de piscar de olhos, teve melhores resultados). Por serem melhor encontrados no lóbulo frontal, foram utilizados para esta análise os eletrodos posicionados em Fpz e F8.

Portanto, uma melhor abordagem é a utilização de ICA para a separação dos sinais. Para separação de sinais multi-canais em componentes distintos espacial e temporalmente, a ICA é uma poderosa ferramenta muito utilizada em BCI (MAKEIG et al., 1996). Assim, o algoritmo ICA Infomax (BELL; SEJNOWSKI, 1995) foi utilizado para separação dos componentes independentes, que ajudaram a classificar os componentes em atividade neural ou artefato. Para aplicação da ICA, assume-se que o sinal é composto por combinações lineares de informações, advindos de fontes estatisticamente independentes. Além disso, assume-se que o número de fontes independentes é igual ou menor que o número de sinais observados. Em uma janela de 10 segundos, é comum ter entre 3 e 4 piscadas.

Porém, os artefatos relacionados ao piscar de olhos podem ser alocados em mais de um componente independente, fazendo com que a classificação continue tendo baixa acurácia. 
Tabela 5 - Média da energia relativa em toda a base de dados para o melhor e o pior caso.

\begin{tabular}{lcccccccc}
\hline Indivíduo & 1 & 2 & 3 & 4 & 5 & 6 & 7 & 8 \\
\hline $\mathrm{FPz}$ & $0.87 \pm 0.153$ & $0.87 \pm 0.161$ & $0.86 \pm 0.054$ & $0.87 \pm 0.218$ & $0.88 \pm 0.228$ & $0.87 \pm 0.161$ & $0.87 \pm 0.153$ & $0.87 \pm 0.161$ \\
\hline $\mathrm{Cz}$ & $0.84 \pm 0.166$ & $0.84 \pm 0.267$ & $0.84 \pm 0.101$ & $0.85 \pm 0.237$ & $0.84 \pm 0.261$ & $0.84 \pm 0.166$ & $0.84 \pm 0.218$ & $0.85 \pm 0.126$ \\
\hline
\end{tabular}

Isso acontece pois as redes cerebrais têm muita sobreposição, especialmente em potenciais relacionados a eventos (ERP). Então, foi proposta uma combinação de ICA com transformada wavelet (MAHAJAN; MORSHED, 2014), que automaticamente identifica os componentes utilizando dois thresholds: kurtosis e nMSE. Os processos matemáticos para utilização dessa ICA estão definidos no Capítulo 4

Assim, o sinal já filtrado e mantido entre a faixa desejada (frequência $\Delta$ e $\Theta$ ) foi analisado em janelas de 5 segundos. Foi selecionado o maior pico entre 50 e $100 \mu \mathrm{V}$. A definição dessas épocas foi feita, em um primeiro instante, para encontrar características do sinal, então a presença do piscar de olhos foi verificada para montagem da base de dados. Para a análise foi utilizado o periodograma de Welch, utilizando a janela de Hamming (padrão na implementação do python) para estimar o Power Spectral Density (PSD). O tamanho da janela e o número de DFT foram definidos em $512 \mathrm{~Hz}$ e foi feita uma média dos valores estimados para PSD nas bandas $\Delta$ e $\Theta$. Esses valores foram comparados separadamente entre cada um dos canais. A energia relativa para a frequência delta nos eletrodos FpZ (mais próximo) e Oz (mais afastado) são demonstrados na Tabela 5.

As características do piscar de olhos é um rápido pico positivo, acompanhado de um pico negativo, sendo logo depois atenuado, porém passando várias vezes pelo marco 0 da amplitude. A ICA definida neste trabalho teve boa acurácia em reconhecer o comportamento da onda, porém, durante boa parte do experimento, vários outros movimentos dos olhos também causavam artefatos, fazendo com que a acurácia final ficasse consideravelmente abaixo da obtida em bases de dados exclusivas de piscar de olhos. A movimentação, assim como o próprio piscar, se propaga pelo cérebro, aumentando a dificuldade em fazer a limpeza deste sinal. A adição de outros eletrodos, específicos para a movimentação ocular (EOG), ajudariam a guiar os momentos exatos de movimentação e piscar, facilitando a limpeza do sinal. Porém, para este trabalho, pela frequência em que acontece o ErrP, esses artefatos não foram tão influentes no resultado final.

\subsection{Base da literatura}

O objetivo inicial, utilizando as bases de dados de (CHAVARRIAGA; MILLÁN, 2010; SPÜLER; NIETHAMMER, 2015) era comparar a eficiência na extração de características utilizando duas técnicas: a FFT, algoritmo bastante utilizado nas soluções default dos headsets disponíveis no mercado e uma transformada wavelet Haar. A FT, propriamente dita, não é adequada para sinais não-estacionários, por isso é utilizada é a Short Time Fourier Transform (STFT), que melhora a informação espacial analisando o sinal em janelas de tamanhos invariantes. 
A transformada wavelet, por sua vez, decompõe o sinal, trazendo informações de tempo e frequência de forma simultânea, permitindo a análise do sinal considerando ambas informações. Além dessas duas informações, comparar também algoritmos de classificação, utilizando tanto a MLP, bastante aplicada nas pesquisas de BCI, quanto a CNN. Todas as definições matemáticas das técnicas descritas podem ser encontradas no Capítulo 4.
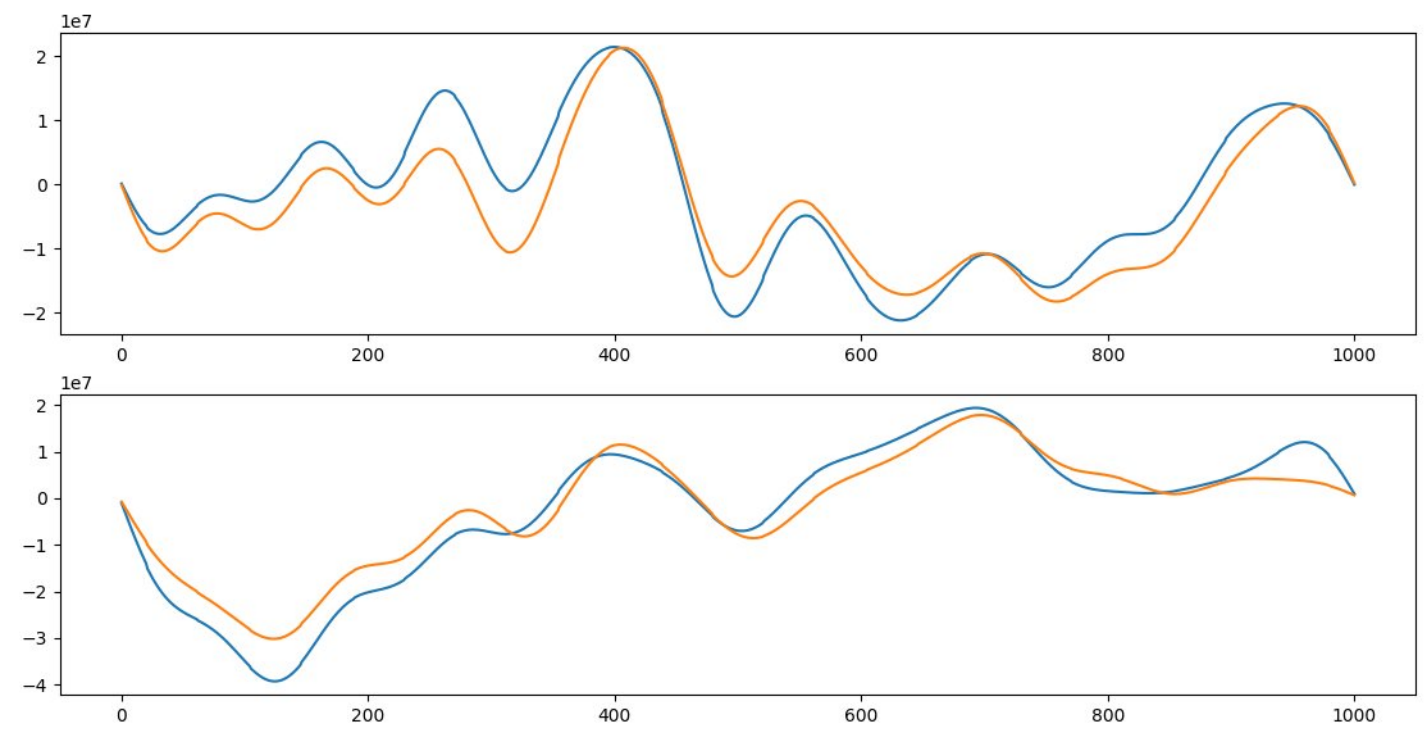

Figura 32 - Dois exemplos de janelas usadas inicialmente neste trabalho. A imagem de cima mostra a ocorrência de um ErrP e a de baixo mostra o comportamento normal do cérebro, sem erros. $\mathrm{O}$ canal FCz é representado pela linha azul, enquanto o canal $\mathrm{Cz}$ é representado pela laranja

Fonte: Elaborada pelo autor.

O sinal lido das bases passou por um filtro passa-banda, para eliminação de artefatos e limpeza do sinal. O filtro IIR Butterworth fase zero foi setado para rejeitar sinais abaixo de 0.5 $\mathrm{Hz}$ e acima de $100 \mathrm{~Hz}$. A remoção do piscar de olhos foi feita utilizando a informação contida no EOG. Um ponto importante é que no dataset está muito bem definido os momentos em que era iniciado os 2 segundos de erro, facilitando o recorte dos momentos de maior interesse para a criação dos conjuntos de treinamento.

A passagem do sinal pela transformada wavelet seguiu a metodologia indicada na literatura. Um vez que, pelo teorema de Nyquist, frequências só podem ser representadas até a metade da frequência de amostragem, pudemos desmembrar as faixas de frequência. Foram gerados 8 níveis de decomposição de alguns ritmos de interesse, permitindo uma melhor extração de informações. Após a decomposição, a quantidade de informação do sinal está dividida nas várias escalas, permitindo uma representação fiel do sinal, pois é possível reconstruir o sinal original a partir das escalas geradas. Os testes feitos neste trabalho utilizaram tanto as informações de todas as escalas quanto a informação apenas da última.

Seguindo as definições da base de dados, primeiramente foram feitos os testes analisando 
Tabela 6 - Convergência utilizando a primeira janela. 832 exemplos de treinamento e 208 exemplos para teste (melhores configurações de topologias)

\begin{tabular}{ccccc}
\hline Topologia & Conv (iterações) & Resposta Inicial & Acurácia & Melhora \\
\hline \multirow{3}{*}{$3000 / 3000$} & 90 & $58.653 \%$ & $65.865 \%$ & $7.212 \%$ \\
& NC & $57.692 \%$ & $58.173 \%$ & $0.481 \%$ \\
& NC & $61.057 \%$ & $62.019 \%$ & $0.962 \%$ \\
\hline \multirow{3}{*}{$1000 / 1000$} & NC & $57.211 \%$ & $61.057 \%$ & $3.846 \%$ \\
& NC & $54.326 \%$ & $62.019 \%$ & $7.693 \%$ \\
\multirow{3}{*}{$500 / 500$} & NC & $58.653 \%$ & $54.326 \%$ & $-4.327 \%$ \\
\hline \multirow{3}{*}{$100 / 100$} & NC & $62.500 \%$ & $54.326 \%$ & $-8.174 \%$ \\
& NC & $51.923 \%$ & $58.653 \%$ & $6.730 \%$ \\
& NC & $53.846 \%$ & $62.980 \%$ & $9.134 \%$ \\
\hline & NC & $64.423 \%$ & 60.576 & $-3.847 \%$ \\
& 347 & $39.423 \%$ & $61.538 \%$ & $\mathbf{2 2 . 1 1 5 \%}$ \\
& NC & $47.115 \%$ & $57.211 \%$ & $10.096 \%$ \\
\hline
\end{tabular}

uma janela de 1 segundo do sinal. Assim, foram gerados 1040 segmentos com 4097 pontos cada, sendo inicialmente separados em 832 segmentos para treinamento e 208 para testes. Exemplos destes segmentos podem ser vistos na Figura 32. Para a classificação foi utilizada uma Rede Neural Artificial MultiLayer Perceptron (MLP) com o algoritmo Resilient Backpropagation (R-PROP) utilizando a tangente hiperbólica como função de ativação.

Mesmo com várias tentativas diferentes de topologia de rede, ela quase não convergia. Foi percebido que existiam dois problemas: essa abordagem criou um grande desbalanceamento no conjunto de treinamento, tendo uma incidência muito maior de exemplos mais parecidos com "normais" (aqui considerados os dados em que não ocorriam nenhum dos tipos de ErrP), o que prejudicava a convergência da rede. Como visto na Figura 32, apenas um pequeno pedaço (200ms a 500ms imagem superior) representa o ErrP o que atrapalhava o reconhecimento da rede.

O segundo problema foi oriundo do tipo da janela, pois a seleção automática dos pontos em que ocorriam os ErrP causava um tipo de overlap, dificultando a convergência da rede. A Tabela 6 mostra os resultados com essas janelas, considerando que, quando a rede demorava muito para zerar o erro ou acabava entrando em um mínimo local, o treinamento foi encerrado manualmente e feito a acurácia com os pesos após esse tempo. Considerando essa resposta para a transformada wavelet, não foram feitos os testes para a transformada de Fourier nesta fase do processo.

Para contornar esse problema, foi criada uma nova janela, selecionando manualmente os exemplos em que era perceptível a ocorrência do ErrP. Assim, os dados foram novamente divididos em 36 segmentos com 2048 pontos para treinamento e 10 para teste para cada indivíduo. Dessa forma o tempo de convergência caiu e também houve uma perceptível melhora na acurácia, aproximando-se dos resultados da literatura, relacionando apenas ao próprio indivíduo. Porém, 

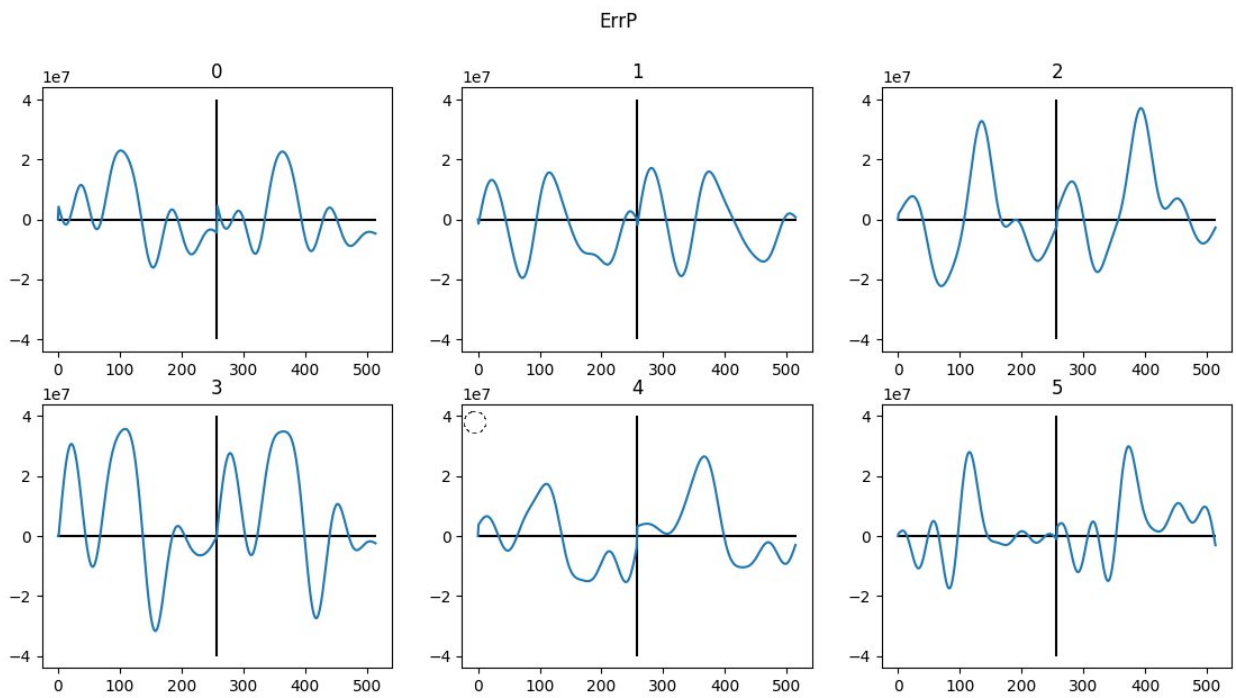

Figura 33 - Sinais de erros, considerando uma janela menor, selecionada manualmente. É possível reconhecer mais de um tipo de erro

Fonte: Elaborada pelo autor.
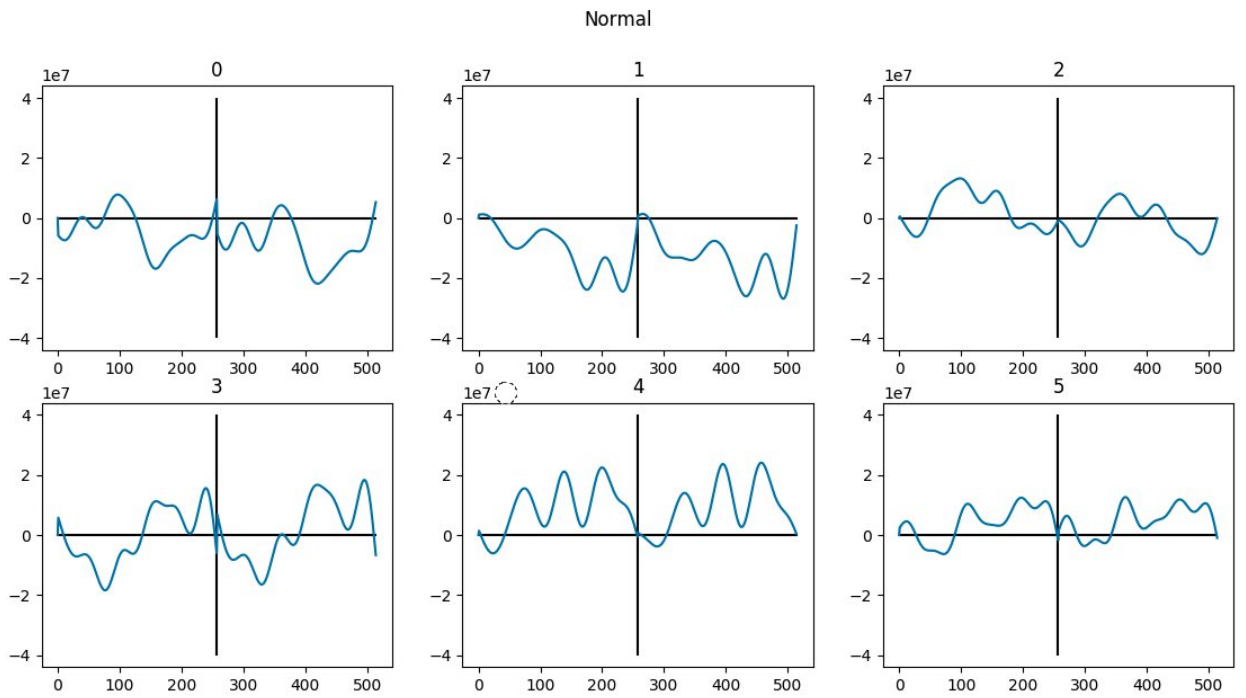

Figura 34 - Sinais normais (sem nenhuma ocorrência de ErrP) considerando a janela menor. Esses dados foram selecionados manualmente

Fonte: Elaborada pelo autor.

ao utilizar esses pesos para todos o dataset a acuácia voltou a cair. A Tabela 7 exemplifica esses resultados e exemplos desta nova janela podem ser vistos nas Figuras 33 e 34.

Uma vez que os dados foram mais consistentes com o esperado, com a rede neural convergindo, foram feitas as baterias de testes utilizando toda a estrutura descrita. Para comparação, foram utilizados as seguintes configurações:

- Haar Completa: Usando todas as 8 camadas (decomposições) da Transformada de Haar, resultando em um vetor de 4097 pontos; 
Tabela 7 - Convergência considerando a segunda janela: 36 exemplos para treinamento e 10 para teste para cada indivíduo (melhores configurações de topologias)

\begin{tabular}{ccccc}
\hline Topologia & Conv & Resposta Inicial & Acurácia & Melhora \\
\hline \multirow{3}{*}{ MLP 5000/5000 } & 40 & $60 \%$ & $70 \%$ & $10 \%$ \\
& 30 & $50 \%$ & $90 \%$ & $40 \%$ \\
& NC & $60 \%$ & $70 \%$ & $10 \%$ \\
\hline \multirow{3}{*}{ MLP 1000/1000 } & 23 & $70 \%$ & $70 \%$ & $0 \%$ \\
& 20 & $80 \%$ & $90 \%$ & $10 \%$ \\
& 21 & $60 \%$ & $90 \%$ & $30 \%$ \\
\hline \multirow{3}{*}{ MLP 500/500 } & 27 & $10 \%$ & $\mathbf{1 0 0 \%}$ & $\mathbf{9 0 \%}$ \\
& 25 & $60 \%$ & $80 \%$ & $20 \%$ \\
& 24 & $40 \%$ & $80 \%$ & $40 \%$ \\
\hline \multirow{3}{*}{ MLP 100/100 } & 37 & $60 \%$ & $90 \%$ & $30 \%$ \\
& 36 & $40 \%$ & $\mathbf{1 0 0 \%}$ & $60 \%$ \\
& 35 & $60 \%$ & $60 \%$ & $0 \%$ \\
\hline
\end{tabular}

Tabela 8 - Média da acurácia usando todos os métodos de extração de características, utilizando 36 exemplos de treinamento e 10 para teste por indivíduo

\begin{tabular}{lcccc}
\hline Topologia & Haar Final & Haar Completa & FFT & RFFT \\
\hline MLP 3000/3000 & $76.33 \%$ & $76.00 \%$ & $66.50 \%$ & $70.00 \%$ \\
\hline MLP 1000/1000 & $74.66 \%$ & $79.00 \%$ & $63.50 \%$ & $\mathbf{7 3 . 3 3}$ \\
\hline MLP 500/500 & $75.00 \%$ & $75.00 \%$ & $69.00 \%$ & $69.66 \%$ \\
\hline MLP 100/100 & $72.33 \%$ & $75.66 \%$ & $62.50 \%$ & $63.33 \%$ \\
\hline CNN + LSTM & $\mathbf{7 9 . 3 0 \%}$ & $\mathbf{8 0 . 5 0 \%}$ & $\mathbf{7 2 . 3 3 \%}$ & $70.00 \%$ \\
\hline MÉDIA & $75.52 \%$ & $77.23 \%$ & $66.76 \%$ & $69.26 \%$ \\
\hline
\end{tabular}

- Haar Final: Usando apenas a última camada da Transformada de Haar, resultando em um vetor de 512 pontos;

- FFT: Usando ambos os lados da Transformada de Fourier (com redundância), resultando em um vetor com 513 pontos;

- RFFT: Usando apenas um lado da Transformada de Fourier, resultando em um vetor com 259 pontos

As médias do desempenho dos extratores de características e dos classificadores podem ser vistas na Tabela 8.

Durante a fase de seleção manual, foram encontrados basicamente os dois tipos de erro (Execução e Dificuldade, como pode ser visto na Figura 35) e ambos foram utilizados no conjunto de treinamento. Os erros são visivelmente diferentes na sua forma de onda onde o primeiro acontece com uma menor amplitude e menos espaçado no tempo, enquanto o erro de dificuldade tem maior amplitude e dura mais tempo. Além disso, o erro de execução é praticamente restrito ao eletrodo $\mathrm{Cz}$, enquanto o de dificuldade acontece espalhado em ambos. É importante saber que o tipo de erro influencia na forma de onda, para melhoria dos sistemas BCI. Interessantemente, 
apesar de serem significativamente diferentes em forma, a intensidade do erro não influência no sinal, segundo estudos dos criadores do dataset.
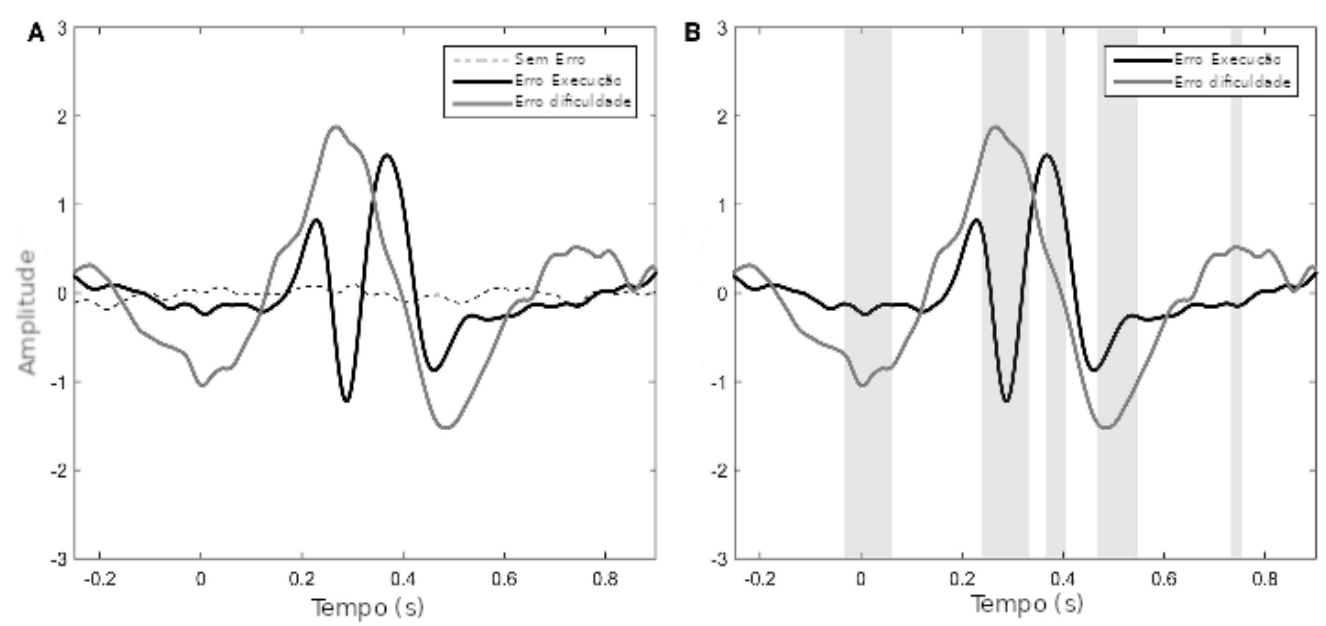

Figura 35 - Diferenças entre os erros da base de dados. As barras cinzas significam pontos em que o sinal é significativamente diferente

Fonte: Adaptada de Spüler e Niethammer (2015).

Enquanto a literatura relata acurácias de 75-90\%, nos nossos testes em escala reduzida alcançamos $100 \%$ de acurácia em alguns testes. Isso mostrou que a escolha correta das janelas para o conjunto de treinamento influencia diretamente no resultado da classificação, porém o resultado caiu muito quando comparada à todo dataset. Isso mostra que uma boa acurácia depende ainda de um trabalho manual de seleção dessas janelas, o que é inviável em aplicações reais.

Para testar a influência da topologia da rede, executamos a classificação com os pesos aleatórios e comparamos com a classificação após a convergência. Separamos a rede sempre em duas camadas escondidas, com os neurônios divididos igualmente entre elas, gerando testes com 200, 1000, 2000 e 10000 neurônios nessas camadas. Com as janelas reduzidas, as topologias menores tiveram um aumento em média de $30 \%$ entre as duas classificações, enquanto as com mais neurônios tiveram um aumento em média de 15,30\%. Já com o dataset completo, as diferenças foram de $4.90 \%$ com menos neurônios e $3.37 \%$ para as topologias com mais neurônios.

Existem algumas pesquisas que buscam encontrar a melhor técnica para a extração de características, porém esse tipo de decisão depende muito do tipo de dado que está sendo analisado. A transformada de Fourier é mais apropriada para certos tipos de onda e tem tido sua velocidade melhorada quando comparada a outros tipos de métodos, principalmente em aplicações de tempo real. Os resultados deste trabalho não levaram em conta uma implementação mais elaborada da transformada, que pode ser construída para melhorar a acurácia obtida, mas demonstra que a transformada de Haar foi mais rápida, mais simples e teve comportamento melhor em um 
ambiente controlado. Para os criadores do dataset, não existiu diferença significativa quando foram extraídas características temporais e espaciais.

Com os resultados próximos aos da literatura, era necessário buscar alternativas para classificação. Assim, além da MLP já descrita, foi implementado também um algoritmos de Deep Learning, passando o sinal após já ter sido extraídas as características pelos extratores definidos. O ponto mais importante de se utilizar a CNN foi enviar para treinamento os dados das camadas da Haar e FFT, considerando seu overlap. Quando dividimos o sinal em camadas, ou quando utilizamos a redundância do sinal, essas informações em posições diferentes acontecem na mesma unidade de tempo, informação essa que era desconsiderada pela MLP. Com a aplicação da CNN levando essa informação em consideração, os resultados foram melhores, com um ganho de $8,76 \%$.

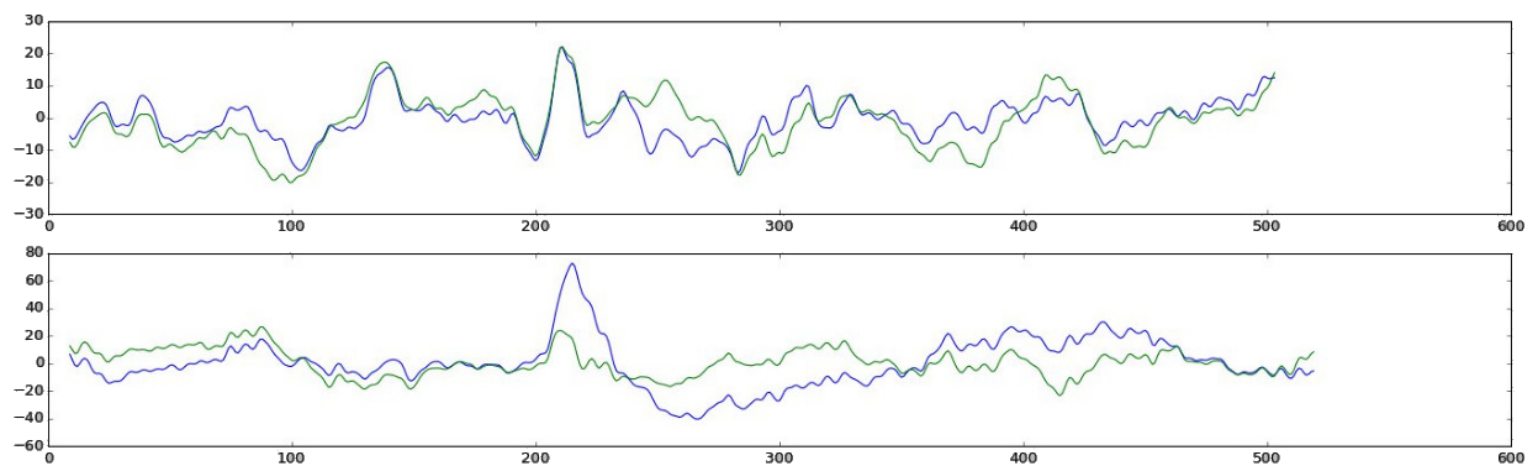

Figura 36 - Dois exemplos de sinais obtidos da case criada com o jogo. A imagem de cima mostra a ocorrência do ErrP (entre 190 e $210 \mathrm{~ms}$ ) e a de baixo mostra um momento normal. O canal FZ é representado pela linha azul, enquanto o canal $\mathrm{Cz}$ é representando pela linha verde.

Fonte: Elaborada pelo autor.

\subsection{Base criada}

Para os experimentos, 8 voluntários (5 homens e 3 mulheres) com idades entre 20 e 34 anos (M. = 25,75, D.P. = 5,192) foram convidados a participar de todas as interações: calibração, jogo do zumbi e interação com o robô. Todos os indivíduos foram voluntários na participação do experimento, e nenhum deles tinha histórico de problemas sensoriomotor, oftalmológico ou auditivo. Os usuários convidados não foram informados dos objetivos da pesquisa, tinham todos um nível próximo de conhecimento em robótica e sinais biomédicos (todos são alunos de neuroengenharia, em diferentes etapas) ${ }^{1}$

Os participantes foram levados individualmente para uma sala isolada, aonde existia o mínimo de barulho ou qualquer outro distúrbio possível. Dentro desta sala, havia somente um computador, o robô, um fone de ouvido, o capacete neural, o indivíduo e o pesquisador. Antes 
Tabela 9 - Média dos resultados de classificação considerando todos os métodos utilizados

\begin{tabular}{lcccc}
\hline Topologia & Haar Final & Haar Completa & FFT & RFFT \\
\hline MLP 3000/3000 & $79.16 \%$ & $77.60 \%$ & $63.33 \%$ & $73.33 \%$ \\
\hline MLP 1000/1000 & $73.33 \%$ & $79.16 \%$ & $67.16 \%$ & $\mathbf{7 5 . 0 0}$ \\
\hline MLP 500/500 & $77.60 \%$ & $79.16 \%$ & 70.00 & $69.16 \%$ \\
\hline MLP 100/100 & $69.16 \%$ & $82.50 \%$ & $63.33 \%$ & $60.00 \%$ \\
\hline CNN + LSTM & $\mathbf{9 4 . 1 6}$ & $\mathbf{9 2 . 5 0}$ & NA & NA \\
\hline MÉDIA & $78.68 \%$ & $82.18 \%$ & $65.95 \%$ & $69.37 \%$ \\
\hline
\end{tabular}

de cada experimento, a touca utilizada era lavada e esterilizada com álcool, assim como a testa e orelhas do participante, para evitar a resistência da pele. O experimento era feito todo de uma vez, e todo o processo levava em média 40 minutos, desde a colocação da touca até o encerramento e liberação do voluntário. Destes 40 minutos, as gravações eram divididas em 5 etapas: 2 etapas de calibração, 2 etapas do jogo real e 1 etapa da interação com o robô. Em média, o tempo total de gravação, juntando todas as etapas, era de 8 minutos.

A princípio, pelo que pode ser notado na Figura 36, a característica do sinal é muito mais ruidosa do que a das bases da internet (Figura 32). Por isso a justificativa de maior trabalho para filtragem do sinal, demonstrado na Seção 6.2. Com o total conhecimento do que aconteceu durante as etapas da geração da base de dados, e com as informações adicionadas, os momentos dos erros foram separados para serem classificados. Em um trecho de 1 minuto de jogo $( \pm 31000$ pontos observados), havia uma média de 10 erros forçados. Cada um desses erros podia ser observados dentro de 1 segundo de sinal ( \pm 520 pontos), estando mais precisamente em uma pequena faixa desse sinal ( \pm 200 pontos). Portanto, a base precisou ser balanceada, pois a quantidade de momentos do sinal normal (sem erros) era muito maior do que a quantidade de erros forçados.

Seguindo a mesma metodologia utilizada nos testes com as bases da internet, foram comparadas as técnicas de extração de características e de classificação do sinal. Para este trabalho, tentou-se buscar as janelas de sinais ErrP e Normal de forma automática, dentro dos segundos em que aconteciam cada um dos erros. Essa seleção, porém, ainda não teve um bom resultado, e as janelas tiveram de ser reorganizadas manualmente. É um processo custoso e inviável para aplicações em tempo real. O primeiro teste, cujos resultados são apresentados na Tabela 9 demonstram a força que a informação temporal teve para esta aplicação.

Enquanto a transformada de Fourier teve uma queda nos resultados com esta base, as Wavelets tiveram uma pequena melhora quando comparadas ao experimento anterior, considerando somente as classificações utilizando MLP. Essa implementação ainda não considerava o uso da ICA aprimorada com Wavelets para limpeza de sinal, então ainda existia muito ruído, fazendo com que a implementação considerando apenas o domínio da frequência fosse bastante prejudicada. Considerando a baixa classificação com essa extração de características, a utilização das redes profundas foi descartada neste caso. A variação entre as topologias de MLP se mostrou 
estatisticamente insignificante, já que foram testadas diversas variações de tamanhos das camadas escondidas, mantendo os resultados muito próximos (a acurácia entre as topologias variou em média $3,36 \%$ ).

Os resultados utilizando a CNN, entretanto, foram surpreendentes, uma vez que a acurácia teve uma melhora realmente alta. Foi considerado que este resultado se deu por meio do maior número de exemplos da base de dados, que contém uma quantidade maior de janelas de erro, se comparada as anteriores, sendo esses momentos bem definidos no dataset. A CNN, portanto, pareceu mostrar uma capacidade maior de generalizar a informação, sendo um resultado bastante importante para esta pesquisa, porém perigoso. Mesmo que existem trabalhos que reportem altas acurácias ((LI; CICHOCKI, 2014; PUTTEN et al., 2017)) e até 100\% (JINGWEI; YIN; WEIDONG, 2015) de acurácia com reconhecimento, foram necessários mais testes para comprovar os valores que haviam sido encontrados.

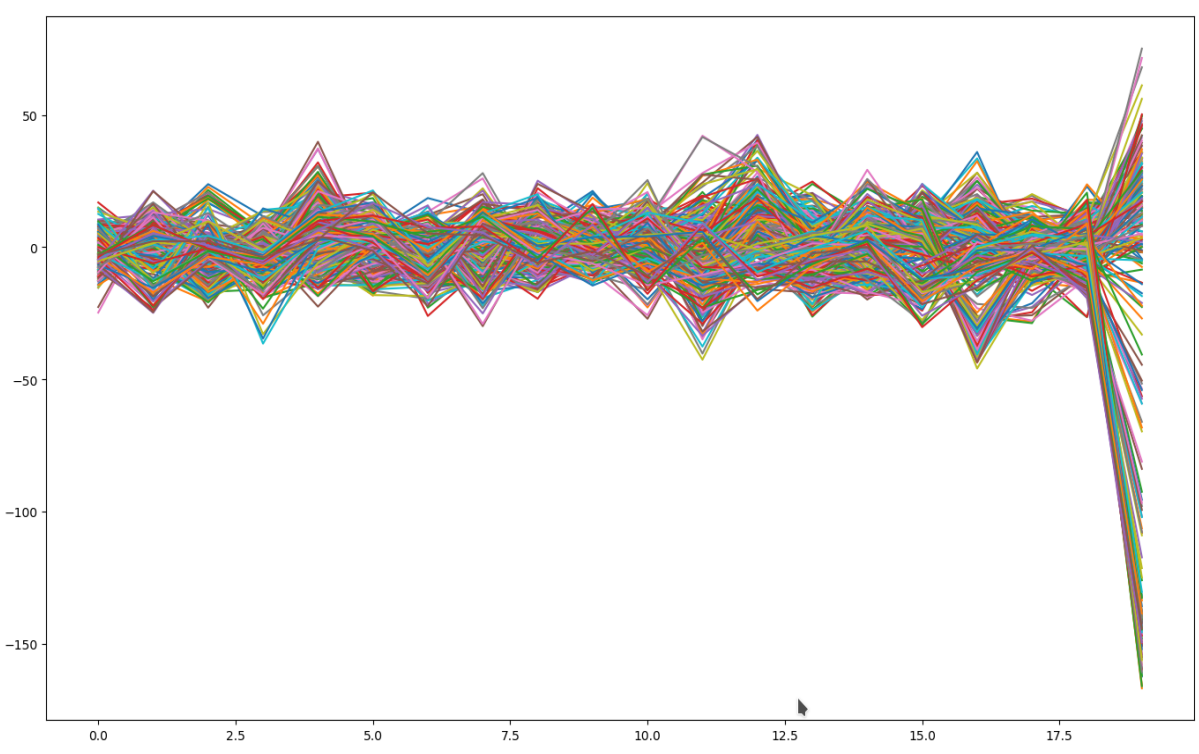

Figura 37 - Wavelet Daubechies aplicadas ao conjunto de dados.

Fonte: Elaborada pelo autor.

Para este novo teste, primeiramente foi feito todo o trabalho de filtragem de sinal, utilizando a ICA aprimorada. Esse processamento, apesar de demorado, melhorou o sinal obtido, sendo possível portanto melhorar os resultados da metodologia proposta. Além disso, para comparação com os dados anteriores, foi utilizada uma nova família de Wavelets, a Daubechies, já definida no Seção 3.3.2. Ela foi selecionada considerando o bom desempenho que essa transformada tem tido na literatura e a diferença em tempo para a geração das informações, quando aplicadas a grandes espaços de dados. A Figura 37 demostra a aplicação da transformada no conjunto de dados e a Tabela 10 mostra os resultados das técnicas.

Os resultados mostraram o que era esperado. Com a melhora da base de dados, os métodos encontraram melhores vetores de características, melhorando assim o resultado. Porém, 
Tabela 10 - Comparação de todos os extratores e classificadores utilizados neste trabalho

\begin{tabular}{lcccccc}
\hline Filtro/ Classificador & $\begin{array}{c}\text { Verdadeiro } \\
\text { Positivo }\end{array}$ & $\begin{array}{c}\text { Verdadeiro } \\
\text { Negativo }\end{array}$ & Accuracia & Precisão & Recall & F1 Score \\
\hline $\mathrm{db} 2 / \mathrm{MLP}$ & 0.800 & 0.850 & 0.825 & 0.800 & 0.842 & 0.820 \\
$\mathrm{db} 2 / \mathrm{CNN}$ & 0.900 & 0.900 & 0.900 & 0.900 & 0.900 & 0.900 \\
\hline $\mathrm{db} 4 / \mathrm{MLP}$ & 0.900 & 0.850 & 0.875 & 0.900 & 0.857 & 0.878 \\
$\mathrm{db} 4 / \mathrm{CNN}$ & 0.925 & 1.000 & $\mathbf{0 . 9 6 2}$ & 0.920 & $\mathbf{1 . 0 0 0}$ & $\mathbf{0 . 9 6 1}$ \\
\hline Haar Complete/MLP & 0.875 & 0.775 & 0.825 & 0.875 & 0.795 & 0.837 \\
Haar Complete/CNN & 0.875 & 0.975 & 0.925 & 0.875 & 0.972 & 0.921 \\
\hline Haar Final /MLP & 0.825 & 0.700 & 0.761 & 0.825 & 0.733 & 0.776 \\
Haar Final/CNN & 0.925 & 0.975 & 0.950 & $\mathbf{0 . 9 2 5}$ & 0.973 & 0.948 \\
\hline FFT/MLP & 0.725 & 0.675 & 0.700 & 0.725 & 0.690 & 0.707 \\
FFT/CNN & 0.775 & 0.720 & 0.750 & 0.775 & 0.738 & 0.756 \\
\hline
\end{tabular}

houve uma diferença na utilização da transformada completa e apenas a última camada de Haar, que inverteram os resultados. Até este teste, a utilização de todas as camadas era a que gerava melhores resultados, o que condiz com o esperado. Verificando-se então outras informações, como precisão e recall, essa mudança é ainda mais complicada que a utilização apenas de uma camada da transformada teve a melhor precisão, que indica que ela, em média, foi a que mais acertou o ErrP (o recall, indica o reconhecimento do sinal normal). Outra importante conclusão é que as transformadas Wavelets escolhidas tiveram uma performance muito próxima em acurácia, o que indica que a escolha pode ser feita levando em consideração o tempo para o cálculo do vetor de características. Apesar de lidar, na maior parte do tempo, com janelas pequenas e, consequentemente, ter pouco custo computacional, essa escolha é importante para sistemas que precisam responder em tempo real. Em média as Haar precisou de 1,1888s para processar os sinais de 1 sujeito, enquanto a Daubechies 2 levou 1.47s e a Daubechies $41.68 \mathrm{~s}$ em média.

A preocupação é que esses resultados indicavam um provável overfitting, uma vez que várias variáveis foram controladas, mantendo o experimento com uma baixa diferença de idade e escolaridade. Para verificar esses resultados, o sistema foi aplicado com as crianças nas escolas. Por se tratar de um capacete diferente e também de informações diferentes, este teste iria verificar a real capacidade da base em generalizar as informações dos erros. A Figura 38 demonstra uma das crianças fazendo o experimento com o jogo. O capacete rígido e grande foi desconsiderado, pois os eletrodos não ficavam posicionados corretamente nos pontos definidos para os testes.

Os testes com as crianças indicaram uma grande diminuição na capacidade de reconhecer o ErrP do sistema proposto, como demonstrado na Tabela 11. Apesar de poder indicar que o sistema não conseguiu generalizar o reconhecimento do sinal, o fator hardware é algo que deve ser levado em consideração. A diferença de capacidade de captação dos dois equipamentos é grande, a começar com a utilização de eletrodo seco, e a comunicação via bluetooth, que insere um ruído no sinal. Junto com o headset é disponibilizado um software que faz a limpeza do sinal, porém perde-se grande parte do que foi aplicado neste trabalho, utilizando uma solução 


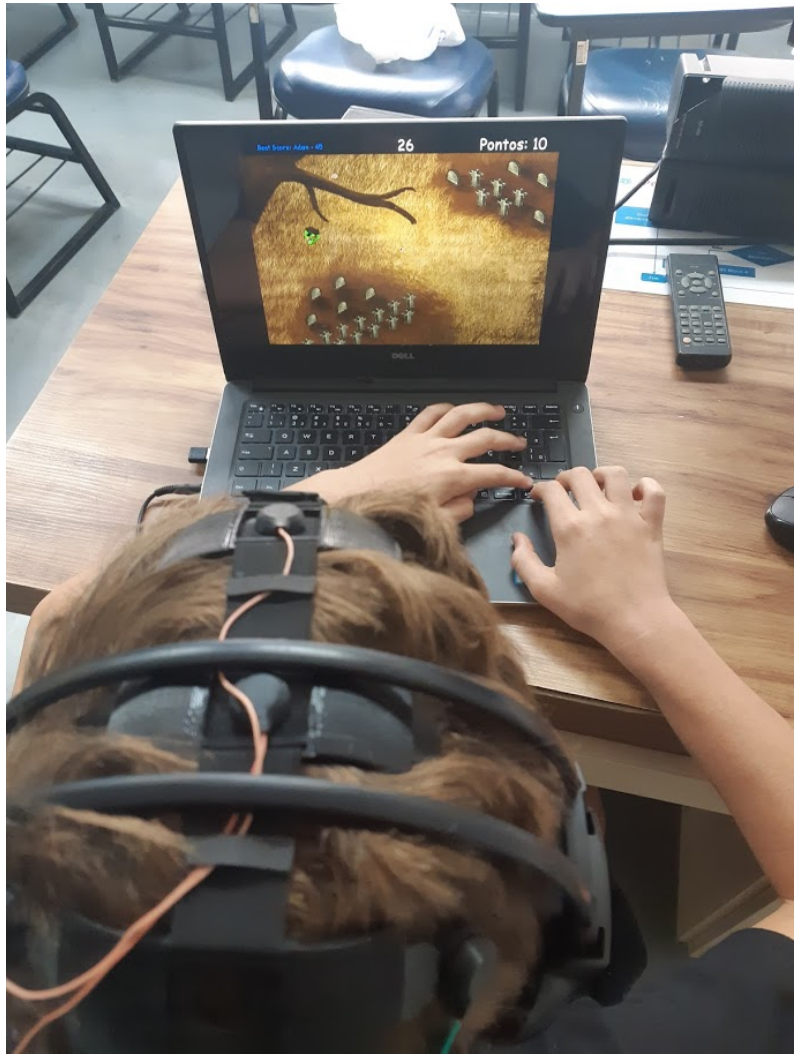

Figura 38 - Estudante participando na etapa de jogo

Fonte: Elaborada pelo autor.

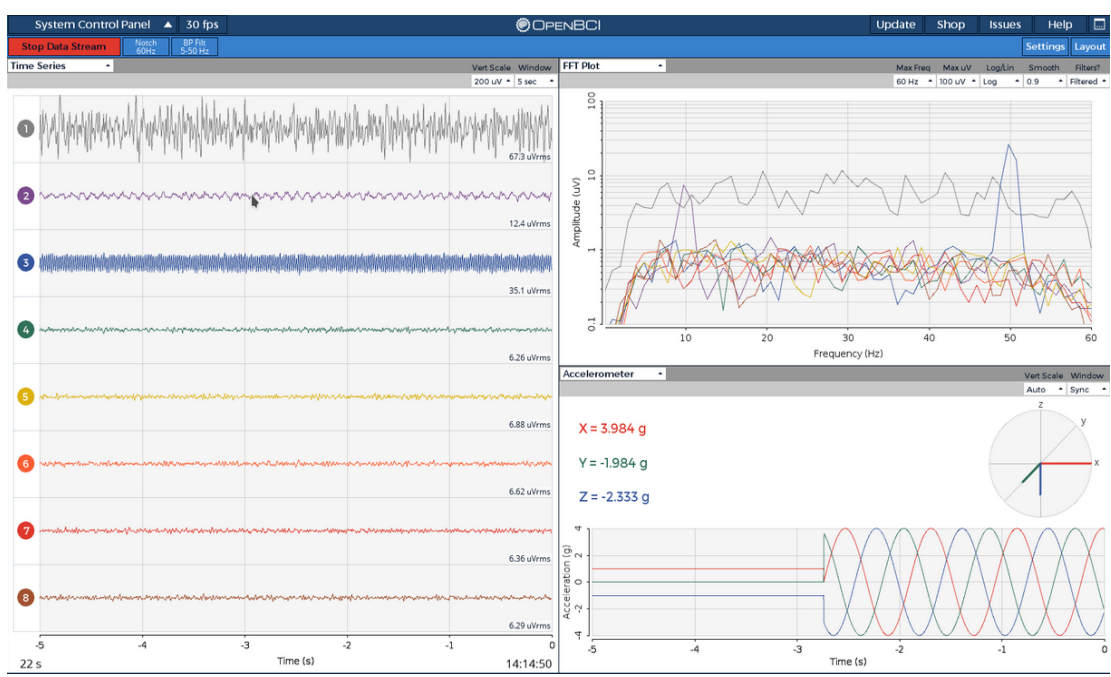

Figura 39 - Software disponível com o headset OpenBCI

Fonte: Elaborada pelo autor.

padrão. A Figura 39 mostra a tela do computador durante uma coleta de dados, sendo perceptível a quantidade de ruídos presentes no sinal, demonstrados pelas diferenças nos picos dos sinais. Apesar de serem resultados razoáveis se comparados a literatura, ainda se perde muito da solução apresentada até aqui. Os resultados entretanto, são melhores quando se aplica apenas aos alunos, 
Tabela 11 - Resultado ruim com o capacete de pior qualidade

\begin{tabular}{lc}
\hline Filtro/Classificador & Acurácia \\
\hline $\mathrm{db} 2$ / MLP & 0.538 \\
$\mathrm{db} 2$ / CNN & 0.667 \\
\hline $\mathrm{db} 4$ / MLP & 0.558 \\
$\mathrm{db} 4$ / CNN & 0.71 \\
\hline Haar Com / MLP & 0.55 \\
Haar Com / CNN & 0.667 \\
\hline Haar Final / MLP & 0.538 \\
Haar Final / CNN & 0.653 \\
\hline FFT / MLP & 0.474 \\
FFT / CNN & 0.525 \\
\hline
\end{tabular}

mas ainda muito abaixo dos resultados obtidos nas aplicações com a touca melhor.

Como último experimento, foi analisada a capacidade de se reconhecer as informações durante o teste com o robô NAO. Em se tratando da mesma base de dados dos demais testes, em geral, os resultados são similares aos resultados do resto da base criada com o jogo. Isso, se considerado os momentos de interação em que a pessoa sabia a resposta. Independente do comportamento apresentado pelo robô, o ErrP emergia sempre que a pessoa tinha certeza da resposta, sendo diferente apenas a sua intensidade (como os casos já descritos de erros de execução e dificuldade). A base de dados, neste caso, era menor, pois muitas amostras foram comprometidas com erros dos sujeitos. Porém, nos casos em que os usuários tentaram adivinhar a resposta correta, um novo padrão surgiu. Diferente do ErrP, o comportamento deste padrão não foi bem classificado. Analisando as informações da literatura, entende-se que se trata de um sinal utilizado para detecção de mentiras, e é um comportamento diferente do esperado para esta aplicação. A diferença do sinal pode ser vista na Figura 40.

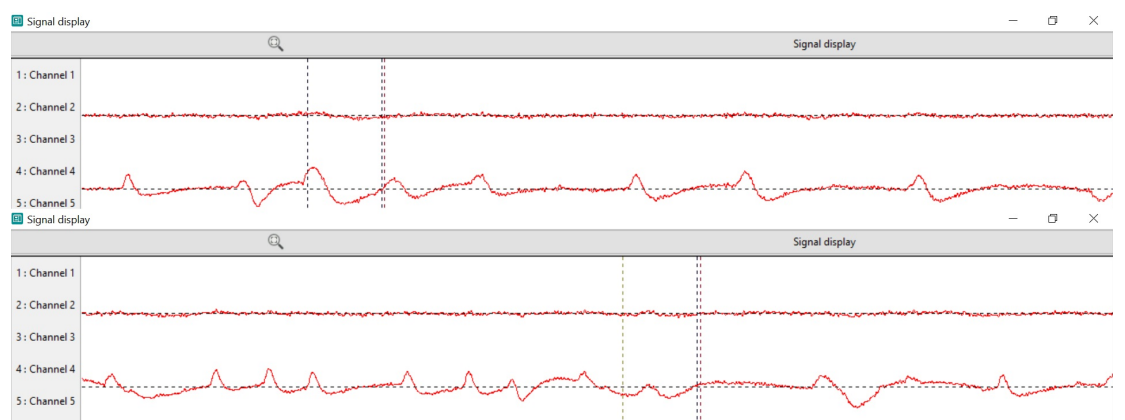

Figura 40 - Diferentes sinais obtidos durante o teste com o robô em momentos quem que o sujeito sabia a resposta e o robô respondeu errado (parte superior da imagem) e em um momento de adivinhação (parte inferior)

Fonte: Elaborada pelo autor. 


\subsection{Considerações Finais}

Neste capítulo, foram apresentados e discutidos os resultados desta tese de doutorado. Primeiro, um experimento relacionado ao R-CASTLE, como contribuição ao sistema educacional, comparando o reconhecimento de emoções em dois tipos de robôs diferentes e analisando a resposta das pessoas à algumas tarefas. A qualidade de interação discutida nesse experimento é importante quando se espera melhorar o feedback para o aluno e, principalmente, os níveis de aprendizado. Reconhecer e ser capaz de demonstrar emoções pode ajudar a melhorar essa qualidade de interação, e o sistema teve um bom resultado.

Em seguida, foram demonstrados os resultados com o sistema de reconhecimento de erros, que pode ser aplicado em outro módulo do R-CASTLE. Primeiramente discutiu-se o pré-processamento e a capacidade de limpar o sinal da base obtida pelo jogo proposto. Foi necessário bastante esforço para alcançar um bom resultado nessa limpeza de sinal. Quando o sistema foi aplicado as bases da internet, percebeu-se uma dificuldade em abordar o problema, passando por momentos em que as redes sequer convergiam até conseguir uma classificação melhor. Apesar de serem limpas, perde-se um pouco do controle das informações nas bases da internet. É interessante analisar esse resultado buscando uma melhor generalização da solução proposta.

O sistema foi então aplicado à base criada com o jogo proposto. Os resultados demonstraram que a filtragem ajudou no resultado final, melhorando a acurácia das soluções escolhidas. A CNN teve uma alta acurácia, comparável às melhores soluções da literatura, chegando aos $96 \%$ em uma das aplicações. Porém, esse resultado não foi o mesmo quando aplicado à uma base diferente. O sistema, mesmo no pior caso, ainda teve uma acurácia comparável à literatura, comprovando que a arquitetura proposta neste trabalho é factível. 
Neste trabalho foi apresentado um sistema de detecção e classificação do Error Related Potential, potencial evocado quando um usuário percebe que cometeu um erro durante uma tarefa. Os resultados mostraram a importância de se fazer uma boa filtragem durante o préprocessamento do sinal, onde foi possível eliminar grande parte de ruídos do sinal puro obtido na rede, permitindo uma melhora na acurácia do sistema. Também foram conduzidos testes com bases de dados da internet, já pré-processadas ou com informações adicionais que ajudavam a eliminar alguns ruídos. Após a seleção de janelas corretas, diminuindo a quantidade de informação redundante, foram obtidos resultados que se aproximavam da literatura, tendo uma média de acerto de $80.5 \%$ na melhor aplicação. As diferenças nas classificações confirmaram que a escolha de um bom extrator de características é muito importante para um bom desempenho do sistema, sendo talvez até mais importante que a escolha do classificador em si. A rede teve uma boa capacidade de generalizar as informações mas era necessário fazer testes com uma base de dados própria.

Criada para gerar diferentes sensações no usuário, de forma a se aproximar de situações durante estudos e provas, foi proposto um jogo para criação da base de dados. Vale ressaltar que, a base de dados foi criada junto ao Instituto Internacional de Neurociência Edmond e Lily Safra, ao qual deixamos o nosso agradecimento, fornecendo equipamento, o capacete V-amp, e também um grupo de participantes licenciados para a realização do experimento. Como não dispunhamos do sensor EOG, aumentou-se o número de ruídos, o que ajudou a testar melhor o sistema criado. O sistema novamente precisou de que as janelas fossem selecionadas manualmente, e após vários testes e readaptações do sistema, foi possível atingir $96 \%$ de acurácia no melhor caso, utilizando a transformada wavelet junto com uma classificação com CNN. A informação temporal, ignorada pela MLP, ajudou na melhor classificação dos dados, mesmo considerando os vetores de características criados pelos extratores. Os resultados confirmam as vantagens das wavelets para extração deste tipo de sinal e mostra que existe pouca diferença na acurácia entre uma implementação mais simples e mais complexa da transformada. A utilização da ferramenta 
mais simples, apesar de perder um pouco na classificação correta, pode ser melhor aplicada quando a informação precisa ser processada em tempo real.

Esta pesquisa é parte de um sistema educacional maior chamado R-CASTLE. A partir dos primeiros experimentos, demonstrando frustração e a dificuldade dos alunos, esse sistema foi proposto para preencher algumas lacunas presentes na maioria dos trabalhos de robótica educacional. Os testes mostram que é necessário um cuidado ao se propor uma aplicação educacional. Mesmo que a presença do robô seja uma novidade que interessa às crianças em um primeiro momento, a manutenção desse interesse é bastante complicado. Com esse sistema de detecção de erros, o aluno pode ter um feedback durante o período de estudos, e não somente em atividades de avaliação. Essas informações podem ajudar a moldar o comportamento do robô, se adaptando a necessidade do estudante. A demora para a resposta, os erros cometidos pelo robô e a repetição muito grande de movimentos leva à frustração, causando o efeito contrário ao esperado com atividades de auxílio educacional e prejudicando o aprendizado.

Aliado ao fato de sistemas BCI conseguirem classificar os níveis de atenção do aluno com facilidade, esse sistema auxilia a comunicação Homem-Robô, a tornando mais dinâmica e próxima do real, melhorando a aceitação do aluno e os níveis de aprendizado. A robótica é uma importante ferramenta para ajudar no aprendizado, e vem sendo utilizada com sucesso na sala de aula, principalmente por trazer aos alunos uma noção prática e divertida de conceitos aplicados. Além disso, com o oferecimento crescente de ferramentas, facilitação do acesso ao robô e existência de competições, os alunos são convidados a experimentar o trabalho em equipe, a diferença entre as simulações e a aplicação no mundo real entre outras informações que ajudam no crescimento pessoal de cada aluno. E também, aprendem conceitos que não são diretamente ligados com o currículo escolar, como mecânica, eletrônica e lógica de programação, podendo aplicar e ver o resultado do conhecimento, aprendendo a ter uma visão mais ampla e crítica da área STEM (Science, Technology, Engineering and Mathematics).

Durante este doutorado, alguns artigos foram publicados. Os seguintes trabalhos são diretamente relacionados à esta tese e já foram publicados:

- "Variation in a Humanoid Robot Behavior to Analyse Interaction Quality in Pedagogical Sessions with Children" (TOZADORE; PINTO; ROMERO, 2016);

- "Tablets and Humanoid Robots as Engaging Platforms for Teaching Languages" (TOZADORE et al., 2017);

- "Wizard of Oz vs Autonomous: childrens perception changes according to robots operation condition" (TOZADORE et al., 2017);

- "Users perception variance in emotional embodied robots for domestic tasks" (PINTO et al., 2018b); 
- "Comparing features extraction and classification methods to recognize ErrP signals" (PINTO et al., 2018a);

- "A Serious Game to build a Database for ErrP Signal Recognition" (PINTO et al., 2019);

- "Project R-CASTLE: Robotic-Cognitive Adaptive System for Teaching and LEarning" (TOZADORE et al., 2019).

Além destes já publicados, temos um journal em processo de revisão e outro sendo finalizado para publicação. Outros trabalhos foram realizados durante o período e foram publicados:

- "Robótica humanoide no grupo Biocom/LAR da USP de São Carlos" (PINTO et al., 2015);

- "Addressing Escorting by Behavior Combining Using Multiple Differential Drive Robots" (BATISTA; PINTO; ROMERO, 2015);

- "A Question Game for Children Aiming the Geometrical Figures Learning by Using a Humanoid Robot" (PINTO; TOZADORE; ROMERO, 2015);

- "Reconhecimento de Figuras Geométricas 3D utilizando Redes Neurais em um Robô Humanoide para aplicação na Educação" (TRIDICO; PINTO; ROMERO, 2016);

- "Modelling a Solenoid's Valve Movement" (DEMARCHI et al., 2017);

- "A Review on Locomotion Systems for RoboCup Rescue League Robots" (OLIVEIRA et al., 2017);

• "Uma introdução à interação humano-robô para cuidados com idosos" (ROMERO et al., 2017);

- "Uma análise quantitativa e qualitativa de aprendizado a longo prazo de crianças em idade pré-escolar" (LOURENÇO et al., 2018);

- "LARa: a robotic framework for human-robot interaction on indoor environments" (RANIERI et al., 2018);

- "Um estudo de Interação a longo prazo com aulas de matemática usando robôs" (TELLES; PINTO; ROMERO, 2019).

Uma das maiores limitações do trabalho está na perda de acurácia com a mudança do tipo de hardware aplicado. Para isso, é importante aumentar a base de dados considerando-se outros equipamentos, uma vez que o sistema deve funcionar para qualquer configuração de dispositivo. Uma vez que existem trabalhos buscando criar dispositivos mais acessíveis para leitura do EEG, o trabalho proposto deve ser capaz de processar e filtrar respostas mesmo de eletrodos secos e mais ruidosos, expandindo sua possibilidade de aplicação. Outros algoritmos 
de filtragem de sinais podem sem empregados para melhorar a resposta do sistema, deixando-o capaz de generalizar a informação obtida.

Outra limitação é a quantidade de extratores de características aplicados. Uma vez que fica claro que o procedimento escolhido é importante na resposta do sistema, outras possibilidades e variações podem ser empregadas para aprimorar o sistema. É importante salientar que os sistemas BCI são muito sensíveis ao tipo de aplicação, sendo que alguns algoritmos com resultados ruins em uma aplicação podem ter uma resposta melhor em outros casos. Pontos como a quantidade de dados, velocidade de resposta do sistema, domínio de aplicação e espaço físico em que a aplicação será feita são importantes para a definição do melhor algoritmo. Aliado a isso, em trabalhos futuros, pretende-se melhorar a seleção automática das janelas, diminuindo o trabalho manual para selecionar os conjuntos de treinamento e testes do ErrP. Considerando a rede melhor treinada e com uma boa taxa de acerto, essa seleção tende a ser menos custosa, para dados nunca antes vistos.

Outros trabalhos futuros envolvem a integração com o R-CASTLE, utilizando o sistema proposto nesta tese para medir os estados mentais do aluno e alterar os pesos do módulo de adaptação do sistema educacional. Junto com os demais trabalhos, esse sistema deve conseguir extrair informações para ajudar o robô a se adaptar as condições de estudo do aluno, melhorando a comunicação homem-robô em tempo-real. O sistema proposto também pode fazer parte de um aplicativo de celular, que oriente os estudos dos alunos sem a presença de qualquer tipo de professor, usando-se poucos eletrodos. Conforme perceba que o usuário percebe muitos erros, o sistema pode buscar alternativas de conteúdos automaticamente, melhorando o dinamismo da aplicação.

Porém, fazem parte das dificuldades deste trabalho, o acesso à capacetes e toucas para o EEG, já que mesmo as mais baratas tem um alto valor e são de difícil aquisição. Essa dificuldade se estende também ao uso de robôs, considerando uma maior quantidade de sensores e atuadores e também uma melhor aparência para ser bem aceito em sala de aula. Isso dificulta a utilização deste tipo de tecnologia em larga escala no Brasil e também as pesquisas, que exigem ao pesquisador recursos para fazer todos os experimentos. Outra dificuldade com o trabalho foi a aprovação do comitê de ética, que demorou muito tempo para ser concedida, exigindo inclusive que o pesquisador encontrasse outros institutos para concluir a pesquisa. Foram mais de dois anos, no caso desta pesquisa, para se obter uma resposta positiva. 


\section{REFERÊNCIAS}

ALDEBARAN. 2014. Available in: http://trends.directindustry.com/products/this-pint-sizedrobot-plays-soccer-but-youl-never-guess-what-else-it-can-do/. Citado na página 96.

ANDUJAR, M.; EKANDEM, J.; ALVAREZ, I.; JAMES, M.; GILBERT, J. Are educational video games all they're cracked up to be?: A physiological approach for measuring engagement in educational video games vs. conventional learning techniques. In: Proceedings of World Conference on E-Learning in Corporate, Government, Healthcare, and Higher Education. [S.1.: s.n.], 2011. p. 539-544. Citado nas páginas 46 e 148.

ANDUJAR, M.; GILBERT, J. E. Let's learn!: enhancing user's engagement levels through passive brain-computer interfaces. In: ACM. CHI'13 Extended Abstracts on Human Factors in Computing Systems. [S.1.], 2013. p. 703-708. Citado na página 47.

ASENSIO-CUBERO, J.; GAN, J. Q.; PALANIAPPAN, R. Extracting common spatial patterns based on wavelet lifting for brain computer interface design. In: IEEE. Computer Science and Electronic Engineering Conference (CEEC), 2012 4th. [S.1.], 2012. p. 160-163. Citado na página 43.

BATISTA, M. R.; PINTO, A. H. M.; ROMERO, R. A. F. Addressing escorting by behavior combining using multiple differential drive robots. In: IEEE. 2015 12th Latin American Robotics Symposium and 2015 3rd Brazilian Symposium on Robotics (LARS-SBR). [S.1.], 2015. p. 187-191. Citado na página 127.

BELL, A. J.; SEJNOWSKI, T. J. An information-maximization approach to blind separation and blind deconvolution. Neural Computation, v. 7, n. 6, p. 1129-1159, 1995. Disponível em: $<$ https://doi.org/10.1162/neco.1995.7.6.1129>. Citado na página 111.

BENITTI, F. B. V. Exploring the educational potential of robotics in schools: A systematic review. Computers \& Education, Elsevier, v. 58, n. 3, p. 978-988, 2012. Citado na página 31.

BERGAMASCO, M.; FRISOLI, A.; FONTANA, M.; LOCONSOLE, C.; LEONARDIS, D.; TRONCOSSI, M.; FOUMASHI, M. M.; PARENTI-CASTELLI, V. Preliminary results of bravo project: brain computer interfaces for robotic enhanced action in visuo-motor tasks. In: IEEE. 2011 IEEE International Conference on Rehabilitation Robotics. [S.1.], 2011. p. 1-7. Citado na página 50 .

BERGER, H. Uber das elektroenkephalogramm des menschen. Archiv fur Psychiatrie und Nervenkrankheiten, p. 87:527-570, 1929. Citado na página 27.

BEVILACQUA, M.; PERDIKIS, S.; MILLAN, J. D. R. On error-related potentials during sensorimotor-based brain-computer interface: Explorations with a pseudo-online brain-controlled speller. IEEE Open Journal of Engineering in Medicine and Biology, IEEE, 2019. Citado na página 54. 
BHARATHARAJ, J.; KUMAR, S. S. Considerations in autism therapy using robotics. In: IEEE. Computing, Communications and Networking Technologies (ICCCNT), 2013 Fourth International Conference on. [S.1.], 2013. p. 1-5. Citado nas páginas 31 e 46.

BHATTACHARYYA, S.; KONAR, A.; TIBAREWALA, D. Motor imagery and error related potential induced position control of a robotic arm. IEEE/CAA Journal of Automatica Sinica, IEEE, v. 4, n. 4, p. 639-650, 2017. Citado na página 53.

BJÖRNE, P.; BALKENIUS, C. A model of attentional impairments in autism: First steps toward a computational theory. Cognitive Systems Research, Elsevier, v. 6, n. 3, p. 193-204, 2005. Citado na página 31 .

BLANZ, V.; SCHÖLKOPF, B.; BÜLTHOFF, H.; BURGES, C.; VAPNIK, V.; VETTER, T. Comparison of view-based object recognition algorithms using realistic 3d models. In: SPRINGER. International Conference on Artificial Neural Networks. [S.1.], 1996. p. 251-256. Citado na página 154.

BOGACZ, R.; MARKOWSKA-KACZMAR, U.; KOZIK, A. Blinking artefact recognition in eeg signal using artificial neural network. In: Proc. of 4 th Conference on Neural Networks and Their Applications, Zakopane (Poland). [S.l.: s.n.], 1999. Citado na página 150.

BRÁZDIL, M.; ROMAN, R.; FALKENSTEIN, M.; DANIEL, P.; JURÁK, P.; REKTOR, I. Error processing-evidence from intracerebral erp recordings. Experimental Brain Research, Springer, v. 146, n. 4, p. 460-466, 2002. Citado na página 51.

BREAZEAL, C. L. Designing sociable robots. [S.1.]: MIT press, 2004. Citado na página 25.

BREIMAN, L. et al. Arcing classifier (with discussion and a rejoinder by the author). The annals of statistics, Institute of Mathematical Statistics, v. 26, n. 3, p. 801-849, 1998. Citado nas páginas 157,158 e 159.

BRENNAN, C. P.; MCCULLAGH, G.; LIGHTBODY, G.; GALWAY, L.; TRAINOR, D. Quantifying brain activity for task engagement. IEEE International Conference on Bioinformatics and Biomedicine - 2-5 November - Belfast, United Kingdon, Belfast, United Kingdon, 2014. Citado na página 49.

CHAVARRIAGA, R.; MILLÁN, J. d. R. Learning from eeg error-related potentials in noninvasive brain-computer interfaces. IEEE transactions on neural systems and rehabilitation engineering, IEEE, v. 18, n. 4, p. 381-388, 2010. Citado nas páginas 52, 98, 99 e 112.

CHAVARRIAGA, R.; SOBOLEWSKI, A.; MILLÁN, J. d. R. Errare machinale est: the use of error-related potentials in brain-machine interfaces. Frontiers in neuroscience, Frontiers, v. 8, p. 208, 2014. Citado na página 52.

CHELlA, M. T. Ambiente de robótica educacional com Logo. [s.n.], 2005. Disponível em: $<$ www.Nied.unicamp.br/ siros/doc/artigo_sbc2002_wie_final.pdf>. Citado na página 35.

CHUNG, J.; GULCEHRE, C.; CHO, K.; BENGIO, Y. Empirical evaluation of gated recurrent neural networks on sequence modeling. arXiv preprint arXiv:1412.3555, 2014. Citado na página 71.

CRUZ, A.; PIRES, G.; NUNES, U. J. Double errp detection for automatic error correction in an erp-based bci speller. IEEE Transactions on Neural Systems and Rehabilitation Engineering, IEEE, v. 26, n. 1, p. 26-36, 2017. Citado na página 53. 
CSALA, E.; NEMETH, G.; ZAINKO, C. Application of the nao humanoid robot in the treatment of marrow-transplanted children. International Conference on Cognitive Infocommunications (CogInfoCom), p. pp. 655-659, 2012. Citado na página 39.

CURRAN, E. A.; STOKES, M. J. Learning to control brain activity: a review of the production and control of EEG components for driving brain-computer interface (BCI) systems. Brain and cognition, Elsevier, v. 51, n. 3, p. 326-336, 2003. Citado na página 147.

DEMARCHI, A.; FARÇONI, L.; PINTO, A.; LANG, R.; ROMERO, R.; SILVA, I. Modelling a solenoid's valve movement. In: SPRINGER. Robot World Cup. [S.1.], 2017. p. 290-301. Citado na página 127.

DORNHEGE, G. Toward brain-computer interfacing. [S.1.]: MIT press, 2007. Citado na página 145.

DUDA, R. O.; HART, P. E.; STORK, D. G. Pattern recognition, second edition. 2001. WileyInterscience. Citado na página 158.

D’ABREU, J. V. V.; BASTOS, B. L. Robótica pedagógica: Uma reflexão sobre a apropriação de professores da escola elza maria pellegrini de aguiar. Anais dos Workshops do Congresso Brasileiro de Informática na Educação, Campinas, SP, Brasil, 2013. Citado na página 36.

D'ABREU, J. V. V.; LOURENÇO, M. Núcleo de informática aplicada à educação (nied)-30 anos de atuação (1983-2013). In: Anais dos Workshops do Congresso Brasileiro de Informática na Educação. [S.1.: s.n.], 2013. v. 1, n. 1. Citado na página 36.

EDWARDS, A.; EDWARDS, C.; SPENCE, P. R.; HARRIS, C.; GAMBINO, A. Robots in the classroom: Differences in students' perceptions of credibility and learning between "teacher as robot" and "robot as teacher". Computers in Human Behavior, Elsevier, 2016. Citado na página 41.

EHRLICH, S.; WYKOWSKA, A.; RAMIREZ-AMARO, K.; CHENG, G. When to engage in interaction - and how? eeg-based enhancement of robots ability to sense social signals in hri. 2014 14th IEEE-RAS International Conference on Humanoid Robots (Humanoids) 18-20 November - Madrid, Spain, Munchen, Germany, 2014. Citado na página 44.

EOW, Y. L.; BAKI, R. Form one students' engagement with computer games and its effect on their academic achievement in a malaysian secondary school. Computers \& Education, Elsevier, v. 53, n. 4, p. 1082-1091, 2009. Citado na página 48.

FATOURECHI, M.; BASHASHATI, A.; WARD, R. K.; BIRCH, G. E. EMG and EOG artifacts in brain computer interface systems: A survey. Clinical neurophysiology, Elsevier, v. 118, n. 3, p. 480-494, 2007. Citado na página 149.

FENWICK, I.; RICE, M. Reliability of continuos measurement copy-test- methods. Journal of Advertising Research, Journal of Advertising Research, v. 507, n. 28, p. 15422-1529, 1991. Citado na página 38.

FERREZ, P. W.; MILLAN, J. d. R. You are wrong!- - automatic detection of interaction errors from brain waves. In: . [S.1.: s.n.], 2005. p. 1413-1418. Citado na página 51.

FERREZ, P. W.; MILLÁN, J. d. R. Error-related eeg potentials generated during simulated brain-computer interaction. IEEE transactions on biomedical engineering, IEEE, v. 55, n. 3 , p. 923-929, 2008. Citado na página 52. 
FRASER, N. M.; GILBERT, G. N. Simulating speech systems. Computer Speech \& Language, Elsevier, v. 5, n. 1, p. 81-99, 1991. Citado nas páginas 40 e 41.

FREEMAN, W. J. Mass action in the nervous system. 1. ed. [S.1.]: Academic Press, 1975. Hardcover. ISBN 0122671503. Citado na página 152.

Origin, structure, and role of background eeg activity. part 1. analytic amplitude. Clinical Neurophysiology, Elsevier, v. 115, n. 9, p. 2077-2088, 2004. Citado na página 109.

FREEMAN, W. J.; HOLMES, M. D.; BURKE, B. C.; VANHATALO, S. Spatial spectra of scalp eeg and emg from awake humans. Clinical Neurophysiology, Elsevier, v. 114, n. 6, p. 1053-1068, 2003. Citado na página 109.

FREEMAN, W. J.; YAO, Y.; BURKE, B. Central pattern generating and recognizing in olfactory bulb: a correlation learning rule. Neural Networks, Elsevier, v. 1, n. 4, p. 277-288, 1988. Citado na página 152 .

FRIEDMAN, J. H. On bias, variance, 0/1-loss, and the curse-of-dimensionality. Data mining and knowledge discovery, Springer, v. 1, n. 1, p. 55-77, 1997. Citado na página 159.

GÁCSI, M.; KIS, A.; FARAGÓ, T.; JANIAK, M.; MUSZYŃSKI, R.; MIKLÓSI, Á. Humans attribute emotions to a robot that shows simple behavioural patterns borrowed from dog behaviour. Computers in Human Behavior, Elsevier, v. 59, p. 411-419, 2016. Citado na página 25.

GHAEMMAGHAMI, M. P. Tracking of Humans in Video Stream Using LSTM Recurrent Neural Network. 2017. Citado nas páginas 68 e 70.

GHANI, F.; JILANI, M.; RAGHAV, M.; FAROOQ, O.; KHAN, Y. U. Elbow movement detection using brain computer interface. In: IEEE. Computing Technology and Information Management (ICCM), 2012 8th International Conference on. [S.1.], 2012. v. 2, p. 736-740. Citado na página 44.

GOH, S. K.; TRAN, N. P.; PHAM, D.-T.; ALAM, S.; IZZETOGLU, K.; DUONG, V. Construction of air traffic controller's decision network using error-related potential. In: SPRINGER. International Conference on Human-Computer Interaction. [S.1.], 2019. p. 384-393. Citado na página 55.

GOODRICH, M. A.; SCHULTZ, A. C. Human-robot interaction: a survey. Foundations and trends in human-computer interaction, Now Publishers Inc., v. 1, n. 3, p. 203-275, 2007. Citado nas páginas 25 e 26.

GRAIMANN, B.; ALLISON, B.; PFURTSCHELLER, G. Brain-computer interfaces: A gentle introduction. 2011. Citado na página 27.

GREEN, A.; HUTTENRAUCH, H.; EKLUNDH, K. S. Applying the wizard-of-oz framework to cooperative service discovery and configuration. In: IEEE. Robot and Human Interactive Communication, 2004. ROMAN 2004. 13th IEEE International Workshop on. [S.1.], 2004. p. 575-580. Citado na página 41.

HACKMAN, M. Z.; WALKER, K. B. Instructional communication in the televised classroom: The effects of system design and teacher immediacy on student learning and satisfaction. Communication Education, Taylor \& Francis, v. 39, n. 3, p. 196-206, 1990. Citado na página 42. 
HASELSTEINER, E.; PFURTSCHELLER, G. Using time-dependent neural networks for eeg classification. IEEE transactions on rehabilitation engineering, IEEE, v. 8, n. 4, p. 457-463, 2000. Citado na página 157.

HAYKIN, S. Redes Neurais: Principios e Prática. [S.1.]: Bookman, 2008. Citado nas páginas 65,66 e 67.

HOCHREITER, S.; SCHMIDHUBER, J. Long short-term memory. Neural computation, MIT Press, v. 9, n. 8, p. 1735-1780, 1997. Citado na página 69.

HOSNI, S. M.; GADALLAH, M. E.; BAHGAT, S. F.; ABDELWAHAB, M. S. Classification of eeg signals using different feature extraction techniques for mental-task bci. In: IEEE. Computer Engineering \& Systems, 2007. ICCES'07. International Conference on. [S.1.], 2007. p. 220 226. Citado na página 151.

HOWARD, A. G.; ZHU, M.; CHEN, B.; KALENICHENKO, D.; WANG, W.; WEYAND, T.; ANDREETTO, M.; ADAM, H. Mobilenets: Efficient convolutional neural networks for mobile vision applications. arXiv preprint arXiv:1704.04861, 2017. Citado na página 82.

HWANG, H.-J.; IM, C.-H.; PARK, S.-A. Evaluation of feature extraction methods for motor imagery-based bcis in terms of robustness to slight changes of electrode locations. In: IEEE. Brain-Computer Interface (BCI), 2013 International Winter Workshop on. [S.1.], 2013. p. 76-78. Citado na página 45.

HYVÄRINEN, A.; OJA, E. Independent component analysis: algorithms and applications. Neural networks, Elsevier, v. 13, n. 4, p. 411-430, 2000. Citado na página 149.

JAIN, A. K.; DUIN, R. P. W.; MAO, J. Statistical pattern recognition: A review. IEEE Transactions on pattern analysis and machine intelligence, IEEE, v. 22, n. 1, p. 4-37, 2000. Citado nas páginas 157 e 158.

JANSEN, B. R.; LOUWERSE, J.; STRAATEMEIER, M.; VEN, S. H. Van der; KLINKENBERG, S.; MAAS, H. L. Van der. The influence of experiencing success in math on math anxiety, perceived math competence, and math performance. Learning and Individual Differences, Elsevier, v. 24, p. 190-197, 2013. Citado na página 49.

JASPER, H. Ten-twenty electrode system of the international federation. Electroenceph. Clin. Neurophysiol, 10:371-375, 1958. Citado na página 145.

JIMENEZ, C. O. S.; MESA, H. G. A.; REBOLLEDO-MENDEZ, G.; FREITAS, S. de. Classification of cognitive states of attention and relaxation using supervised learning algorithms. In: IEEE. 2011 IEEE International Games Innovation Conference (IGIC). [S.1.], 2011. p. 31-34. Citado na página 152.

JIMENEZ, L. F.; ANDUJAR, M.; GILBERT, J. Reader engagement. EDUCATION2012 Disponível em: https://parasol.tamu.edu/dreu2012/Jimenez/ReaderEngagement.pdf, New Jersey, United States, 2012. Citado na página 47.

JINGWEI, L.; YIN, C.; WEIDONG, Z. Deep learning eeg response representation for brain computer interface. In: IEEE. 2015 34th Chinese Control Conference (CCC). [S.1.], 2015. p. 3518-3523. Citado na página 120.

JONES, M. T. Artificial Intelligence: A Systems Approach: A Systems Approach. [S.1.]: Jones \& Bartlett Learning, 2015. Citado na página 25. 
JUNCO, R. The relationship between frequency of facebook use, participation in facebook activities, and student engagement. Computers \& Education, Elsevier, v. 58, n. 1, p. 162-171, 2012. Citado na página 48.

KANDEL, E. R.; SCHWARTZ, J. H.; JESSELL, T. M. Fundamentos da Neurociencia e do Comportamento. Guanabara Koogan. 1997. Citado na página 65.

KANOH, S.; MIYAMOTO, K.; YOSHINOBU, T. A p300-based bci system for controlling computer cursor movement. In: IEEE. 2011 Annual International Conference of the IEEE Engineering in Medicine and Biology Society. [S.1.], 2011. p. 6405-6408. Citado na página 42.

KELLEY, J. F. An iterative design methodology for user-friendly natural language office information applications. ACM Transactions on Information Systems (TOIS), ACM, v. 2, n. 1, p. 26-41, 1984. Citado nas páginas 25 e 40.

An iterative design methodology for user-friendly natural language office information applications. ACM Transactions on Information Systems, v. 2, n. 1, p. 26-41, 1984. Citado na página 41.

KEROUS, B.; SKOLA, F.; LIAROKAPIS, F. Eeg-based bci and video games: a progress report. Virtual Reality, v. 22, n. 2, p. 119-135, Jun 2018. ISSN 1434-9957. Disponível em: $<$ https://doi.org/10.1007/s10055-017-0328-x>. Citado na página 54.

KIM, J. Y.; BAE, J. H. A study on serious game technology based on bci for adhd treatment. Advanced Science and Technology Letters, p. 208-211, 2014. Citado na página 50.

KIMBERLEE, J.; KING, M.; HELLERSTETH, S.; WIREN, A.; MULLIGAN, H. Feasibility of using a humanoid robot enhancing attention and social skills in adolescents with autism spectrum disorder. International Journal of Rehabilitation Research, 2013. Citado na página 40.

KLEM, G. H.; LÜDERS, H. O.; JASPER, H. H.; ELGER, C. The ten-twenty electrode system of the international federation. the international federation of clinical neurophysiology. Electroencephalography and clinical neurophysiology. Supplement, v. 52, p. 3-6, 1999. Citado na página 100.

KOENEMANN, J.; BENNEWITZ, M. Whole-body imitation of human motions with a nao humanoid. In: IEEE. Human-Robot Interaction (HRI), 2012 7th ACM/IEEE International Conference on. [S.1.], 2012. p. 425-425. Citado na página 37.

KOZMA, R.; AGHAZARIAN, H.; HUNTSBERGER, T.; TUNSTEL, E.; FREEMAN, W. J. Computational aspects of cognition and consciousness in intelligent devices. IEEE Computational Intelligence Magazine, IEEE, v. 2, n. 3, p. 53-64, 2007. Citado nas páginas 152 e 153.

KREPKI, R.; BLANKERTZ, B.; CURIO, G.; MÜLLER, K.-R. The berlin brain-computer interface (BBCI)-towards a new communication channel for online control in gaming applications. Multimedia Tools and Applications, Springer, v. 33, n. 1, p. 73-90, 2007. Citado na página 27.

KUMAR, A.; PIROGOVA, E.; FANG, J. Q. Classification of error-related potentials using linear discriminant analysis. In: IEEE. 2018 IEEE-EMBS Conference on Biomedical Engineering and Sciences (IECBES). [S.1.], 2018. p. 18-21. Citado na página 54. 
LALOR, E. C.; KELLY, S. P.; FINUCANE, C.; BURKE, R.; SMITH, R.; REILLY, R. B.; MCDARBY, G. Steady-state vep-based brain-computer interface control in an immersive $3 \mathrm{~d}$ gaming environment. EURASIP journal on applied signal processing, Hindawi Publishing Corp., v. 2005, p. 3156-3164, 2005. Citado na página 151.

LAMTI, H. A.; KHELIFA, M. M. B.; GORCE, P.; ALIMI, A. M. The use of brain and thought in service of handicap assistance: Wheelchair navigation. In: 2013 International Conference on Individual and Collective Behaviors in Robotics (ICBR). [S.1.: s.n.], 2013. Citado na página 44.

LECUN, Y.; BOTTOU, L.; BENGIO, Y.; HAFFNER, P. et al. Gradient-based learning applied to document recognition. Proceedings of the IEEE, Taipei, Taiwan, v. 86, n. 11, p. 2278-2324, 1998. Citado na página 71.

LEE, H.; CHOI, S. PCA+ HMM + SVM for EEG pattern classification. In: IEEE. Signal Processing and Its Applications, 2003. Proceedings. Seventh International Symposium on. [S.1.], 2003. v. 1, p. 541-544. Citado na página 158.

LEE, P. J.; CHIN, S. W. Early childhood educator assistant with brain computer interface. 2014 International Conference on Software Intelligence Technologies and Applications. 4-6 December - Hsinchu, Taiwan, Hsinchu, Taiwan, 2014. Citado nas páginas 47 e 148.

LEITE, I.; MARTINHO, C.; PAIVA, A. Social robots for long-term interaction: A survey. International Journal of Social Robotics, v. 5, n. 2, p. 291-308, Apr 2013. ISSN 1875-4805. Disponível em: <https://doi.org/10.1007/s12369-013-0178-y>. Citado na página 26.

LENT, R. Cem bilhões de neurônios? conceitos fundamentais de neurociência-2a edição. Brasil: Editora Atheneu, 2001. Citado na página 143.

LI, J.; CICHOCKI, A. Deep learning of multifractal attributes from motor imagery induced eeg. In: SPRINGER. International Conference on Neural Information Processing. [S.1.], 2014. p. 503-510. Citado na página 120.

LIM, C. G.; LEE, T. S.; GUAN, C.; FUNG, D. S. S.; ZHAO, Y.; TENG, S. S. W.; ZHANG, H.; KRISHNAN, K. R. R. A brain-computer interface based attention training program for treating attention deficit hyperactivity disorder. PloS one, Public Library of Science, v. 7, n. 10, p. e46692, 2012. Citado nas páginas 50 e 148.

LOTTE, F.; CONGEDO, M.; LÉCUYER, A.; LAMARCHE, F.; ARNALDI, B. A review of classification algorithms for eeg-based brain-computer interfaces. Journal of neural engineering, IOP Publishing, v. 4, n. 2, p. R1, 2007. Citado na página 159.

LOURENÇO, Y. M.; TELLES, M. L. F. A.; PINTO, A. H. M.; ROMERO, R. A. F. Uma análise quantitativa e qualitativa de aprendizado a longo a prazo de crianças em idade pré-escolar. 2018. Citado na página 127.

LUCK, S. J. An introduction to the event-related potential technique. [S.1.]: Cambridge, MA The MIT Press, 2014. Citado na página 147.

LUGER, G. F. Artificial Intelligence - Structures and Strategies for Complex Problem Solving. [S.1.]: Pearson Education, 2008. Citado na página 25. 
LUXBURG, U.; SCHOLKOPF, B. Statistical Learning Theory: Models, Concepts, and Results. 2008. E-print, arxiv.org. URL http://arxiv.org/abs/0810.4752. Citado nas páginas 154, 155 e 156.

MACHADO, A. Neuroanatomia Funcional (2.Ed. ed.). Rio de Janeiro: Atheneu. 2000. Citado na página 65.

MAHAJAN, R.; MORSHED, B. I. Unsupervised eye blink artifact denoising of eeg data with modified multiscale sample entropy, kurtosis, and wavelet-ica. IEEE journal of Biomedical and Health Informatics, IEEE, v. 19, n. 1, p. 158-165, 2014. Citado na página 112.

MAKEIG, S.; BELL, A. J.; JUNG, T.-P.; SEJNOWSKI, T. J. Independent component analysis of electroencephalographic data. In: Advances in neural information processing systems. [S.1.: s.n.], 1996. p. 145-151. Citado na página 111.

MALIK, A. S.; FAWZY, S. M.; OSMAN, D. A.; KHAIRUDDIN, R. N. H. R. Effect of movie clips on human brain. 4th International Conference on Intelligent and Advanced Systems (ICIAS) - 12-14 June - Kuala Lumpur, Malaysia, Kuala Lumpur, Malaysia, 2012. Citado na página 47.

MARCHESI, M.; RICCO, B. Bravo: A brain virtual operator for education exploiting braincomputer interfaces. CHI 2013 Extended Abstracts - April 27 - May 2 - Paris, France, Paris, France, 2013. Citado nas páginas 48 e 148.

MEINZER, M. C.; PETTIT, J. W.; WAXMONSKY, J. G.; GNAGY, E.; MOLINA, B. S.; PELHAM, W. E. Does childhood attention-deficit/hyperactivity disorder (adhd) predict levels of depressive symptoms during emerging adulthood? Journal of abnormal child psychology, Springer, v. 44, n. 4, p. 787-797, 2016. Citado na página 50.

MILEKOVIC, T.; BALL, T.; SCHULZE-BONHAGE, A.; AERTSEN, A.; MEHRING, C. Errorrelated electrocorticographic activity in humans during continuous movements. Journal of neural engineering, IOP Publishing, v. 9, n. 2, p. 026007, 2012. Citado na página 99.

MORALES, J. M.; STASI, L. L. D.; DÍAZ-PIEDRA, C.; MORILLAS, C.; ROMERO, S. Realtime monitoring of biomedical signals to improve road safety. In: ROJAS, I.; JOYA, G.; CATALA, A. (Ed.). Advances in Computational Intelligence. Cham: Springer International Publishing, 2015. p. 89-97. ISBN 978-3-319-19258-1. Citado na página 46.

Nakayama, K.; Inagaki, K. A brain computer interface based on neural network with efficient pre-processing. In: 2006 International Symposium on Intelligent Signal Processing and Communications. [S.1.: s.n.], 2006. p. 673-676. Citado na página 28.

NEUMANN, N.; KUBLER, A. Training locked-in patients: a challenge for the use of braincomputer interfaces. IEEE Transactions on Neural Systems and Rehabilitation Engineering, IEEE, v. 11, n. 2, p. 169-172, 2003. Citado na página 45.

NIEDERMEYER, E. Electroencephalography: basic principles, clinical applications, and related fields. 2005. Chapter The normal EEG of the waking adult. Lippincott Williams \& Wilkins, ISBN 0781751268. Citado na página 146.

NIEUWENHUIS, S.; RIDDERINKHOF, K. R.; BLOM, J.; BAND, G. P.; KOK, A. Error-related brain potentials are differentially related to awareness of response errors: evidence from an antisaccade task. Psychophysiology, Cambridge University Press, v. 38, n. 5, p. 752-760, 2001. Citado na página 51. 
NOIRHOMME, Q.; KITNEY, R. I.; MACQ, B. Single-trial eeg source reconstruction for braincomputer interface. IEEE Transactions on Biomedical Engineering, IEEE, v. 55, n. 5, p. 1592-1601, 2008. Citado na página 150.

OBERMAIER, B.; GUGER, C.; NEUPER, C.; PFURTSCHELLER, G. Hidden markov models for online classification of single trial eeg data. Pattern recognition letters, Elsevier, v. 22, n. 12, p. 1299-1309, 2001. Citado na página 152.

OLIVEIRA, J.; FARÇONI, L.; PINTO, A.; LANG, R.; SILVA, I.; ROMERO, R. A review on locomotion systems for robocup rescue league robots. In: SPRINGER. Robot World Cup. [S.l.], 2017. p. 265-276. Citado na página 127.

OLIVEIRA, R. Tecnologia na Aula de Matemática: Robótica na Educação. 2007. Tese Departamento de Matemática e Engenharia, Universidade de Madeira, Minas Gerais, p.39-45. Citado na página 26.

PENNY, W. D.; ROBERTS, S. J. Eeg-based communication via dynamic neural network models. In: IEEE. Neural Networks, 1999. IJCNN'99. International Joint Conference on. [S.1.], 1999. v. 5, p. 3586-3590. Citado na página 157.

PERRENOUD, P. Construir competências é virar as costas aos saberes. Pátio. Revista Pedagógica, v. 11, p. 15-19, 1999. Citado na página 36.

PFURTSCHELlER, G.; BRUNNER, C.; SCHLÖGL, A.; SILVA, F. L. D. Mu rhythm (de) synchronization and eeg single-trial classification of different motor imagery tasks. Neuroimage, Elsevier, v. 31, n. 1, p. 153-159, 2006. Citado na página 45.

PFURTSCHELLER, G.; FLOTZINGER, D.; KALCHER, J. Brain-computer interface-a new communication device for handicapped persons. Journal of Microcomputer Applications, Elsevier, v. 16, n. 3, p. 293-299, 1993. Citado nas páginas 28, 151 e 158.

PFURTSCHELLER, G.; NEUPER, C. Motor imagery and direct brain-computer communication. Proceedings of the IEEE, IEEE, v. 89, n. 7, p. 1123-1134, 2001. Citado na página 146.

PFURTSCHELlER, G.; NEUPER, C.; FLOTZINGER, D.; PREGENZER, M. Eeg-based discrimination between imagination of right and left hand movement. Electroencephalography and clinical Neurophysiology, Elsevier, v. 103, n. 6, p. 642-651, 1997. Citado nas páginas 145 e 157.

PIAZENTIN, D. R. de M.; ROSA, J. L. G. Motor imagery classification for brain-computer interfaces through a chaotic neural network. In: IEEE. 2014 International Joint Conference on Neural Networks (IJCNN). [S.1.], 2014. p. 4103-4108. Citado nas páginas 152 e 153.

PINTO, A.; NARDARI, G.; MIJAM, M.; MORYA, E.; ROMERO, R. A serious game to build a database for errp signal recognition. In: SPRINGER. International Work-Conference on Artificial Neural Networks. [S.1.], 2019. p. 186-197. Citado na página 127.

PINTO, A. H.; OLIVEIRA, L. O. de; MENEGHETTI, R. C.; ROMERO, R. A.; BENICASA, A. X. Attention based object recogniton applied to a humanoid robot. In: IEEE. Robotics: SBR-LARS Robotics Symposium and Robocontrol (SBR LARS Robocontrol), 2014 Joint Conference on. [S.1.], 2014. p. 136-141. Citado na página 80. 
PINTO, A. H.; TOZADORE, D. C.; ROMERO, R. A. A question game for children aiming the geometrical figures learning by using a humanoid robot. In: IEEE. 2015 12th Latin American Robotics Symposium and 2015 3rd Brazilian Symposium on Robotics (LARS-SBR). [S.1.], 2015. p. 228-233. Citado nas páginas 26, 75 e 127.

PINTO, A. H. M.; BATISTA, M. R.; TOZADORE, D. C.; LANG, R. G.; TRIDICO, S. F.; ROSA, J. L. G.; ROMERO, R. A. F. Robótica humanoide no grupo biocom/lar da usp de são carlos. 2015. Citado na página 127.

PINTO, A. H. M.; MIJAN, M. A. M.; NARDARI, G. V.; ROMERO, R. A. F. Comparing features extraction and classification methods to recognize errp signals. In: IEEE. 2018 Latin American Robotic Symposium, 2018 Brazilian Symposium on Robotics (SBR) and 2018 Workshop on Robotics in Education (WRE). [S.1.], 2018. p. 1-7. Citado na página 127.

PINTO, A. H. M.; Ranieri, C. M.; Nardari, G. V.; Tozadore, D. C.; Romero, R. A. F. Users perception variance in emotional embodied robots for domestic tasks. p. 476-482, Nov 2018. Citado nas páginas 83 e 126.

PLAZA, P.; SANCRISTOBAL, E.; FERNANDEZ, G.; CASTRO, M.; PÉREZ, C. Collaborative robotic educational tool based on programmable logic and arduino. In: IEEE. 2016 Technologies Applied to Electronics Teaching (TAEE). [S.1.], 2016. p. 1-8. Citado na página 31.

POT, E.; MONCEAUX, J.; GELIN, R.; MAISONNIER, B. Choregraphe: a graphical tool for humanoid robot programming. In: IEEE. Robot and Human Interactive Communication, 2009. RO-MAN 2009. The 18th IEEE International Symposium on. [S.1.], 2009. p. 46-51. Citado na página 97.

PRENSKY, M. Computer games and learning: Digital game-based learning. Handbook of computer game studies. [S.1.]: Cambridge, CA: MIT Press, 2005. Citado nas páginas 36 e 48.

PRIMI, C.; BUSDRAGHI, C.; TOMASETTO, C.; MORSANYI, K.; CHIESI, F. Measuring math anxiety in italian college and high school students: validity, reliability and gender invariance of the abbreviated math anxiety scale (amas). Learning and Individual Differences, Elsevier, v. 34, p. 51-56, 2014. Citado na página 49.

PUTTEN, M. J. van; HOFMEIJER, J.; RUIJTER, B. J.; TJEPKEMA-CLOOSTERMANS, M. C. Deep learning for outcome prediction of postanoxic coma. In: EMBEC \& NBC 2017. [S.1.]: Springer, 2017. p. 506-509. Citado na página 120.

QIN, J.; LI, Y.; CICHOCKI, A. ICA and committee machine-based algorithm for cursor control in a BCI system. In: SPRINGER. International Symposium on Neural Networks. [S.1.], 2005. p. 973-978. Citado na página 158.

RABBITT, S. M.; KAZDIN, A. E.; SCASSELLATI, B. Integrating socially assistive robotics into mental healthcare interventions: Applications and recommendations for expanded use. Clinical psychology review, Elsevier, v. 35, p. 35-46, 2015. Citado na página 30.

RABINER, L. R. A tutorial on hidden markov models and selected applications in speech recognition. Proceedings of the IEEE, IEEE, v. 77, n. 2, p. 257-286, 1989. Citado nas páginas 152 e 157.

RAKOTOMAMONJY, A.; GUIGUE, V.; MALLET, G.; ALVARADO, V. Ensemble of svms for improving brain computer interface p300 speller performances. In: SPRINGER. International conference on artificial neural networks. [S.1.], 2005. p. 45-50. Citado na página 158. 
RANIERI, C. M.; NARDARI, G. V.; PINTO, A. H. M.; TOZADORE, D. C.; ROMERO, R. A. F. Lara: A robotic framework for human-robot interaction on indoor environments. In: IEEE. 2018 Latin American Robotic Symposium, 2018 Brazilian Symposium on Robotics (SBR) and 2018 Workshop on Robotics in Education (WRE). [S.1.], 2018. p. 376-382. Citado na página 127.

REBOLLEDO-MENDEZ, G.; FREITAS, S. de; ROJANO-CACERES, J. R.; GARCIA-GAONA, A. R. An empirical examination of the relation between attention and motivation in computerbased education: a modeling approach. In: FLAIRS Conference. [S.1.: s.n.], 2010. Citado nas páginas 47 e 48.

REBSAMEN, B.; BURDET, E.; GUAN, C.; ZHANG, H.; TEO, C. L.; ZENG, Q.; LAUGIER, C.; JR, M. H. A. Controlling a wheelchair indoors using thought. 2007. IEEE Intelligent Systems, 22(2):18-24. Citado na página 27.

RIBEIRO, E. S. L.-L.; MANCHO, R. A. Incremental construction of lstm recurrent neural network. 2002. Citado nas páginas 68 e 69.

RIEK, L. D. Wizard of oz studies in hri: a systematic review and new reporting guidelines. Journal of Human-Robot Interaction, v. 1, n. 1, 2012. Citado na página 40.

RIOS-MARTINEZ, J.; SPALANZANI, A.; LAUGIER, C. From proxemics theory to sociallyaware navigation: a survey. International Journal of Social Robotics, Springer, v. 7, n. 2, p. 137-153, 2015. Citado na página 26.

ROBINS, B.; DICKERSON, P.; STRIBLING, P.; DAUTENHAHN, K. Robot-mediated joint attention in children with autism: A case study in robot-human interaction. Interaction studies, John Benjamins Publishing Company, v. 5, n. 2, p. 161-198, 2004. Citado na página 31.

ROCHA, R. H. S. Reconhecimento de Objetos por Redes Neurais Convolutivas. Tese (Doutorado) - PUC-Rio, 2015. Citado nas páginas 72 e 73.

ROMERO, R. A. F.; RANIERI, C.; PINTO, A.; TOZADORE, D. Uma introdução à interação humano-robô para cuidados com idosos. Medicina, v. 50, p. 19-23, 2017. Citado na página 127.

ROSA, J. L. G.; PIAZENTIN, D. R. M. A new cognitive filtering approach based on freeman k3 neural network. Applied Intelligence, v. 45, n. 2, p. 363-382, 2016. Citado na página 153.

SABOURIN, J. L.; LESTER, J. C. Affect and engagement in game-basedlearning environments. IEEE Transactions on Affective Computing, IEEE, v. 5, n. 1, p. 45-56, 2014. Citado na página 49.

SAJDA, P.; GERSON, A.; MULLER, K.-R.; BLANKERTZ, B.; PARRA, L. A data analysis competition to evaluate machine learning algorithms for use in brain-computer interfaces. IEEE Transactions on neural systems and rehabilitation engineering, IEEE, v. 11, n. 2, p. 184-185, 2003. Citado na página 27.

SAK, H.; SENIOR, A.; BEAUFAYS, F. Long short-term memory recurrent neural network architectures for large scale acoustic modeling. In: Fifteenth annual conference of the international speech communication association. [S.1.: s.n.], 2014. Citado na página 70.

SANEI, S.; CHAMBERS, J. A. Eeg signal processing. 2007. Chichester: John Wiley \& Sons. Citado na página 145. 
SATAKE, S.; KANDA, T.; GLAS, D. F.; IMAI, M.; ISHIGURO, H.; HAGITA, N. How to approach humans?-strategies for social robots to initiate interaction. In: IEEE. Human-Robot Interaction (HRI), 2009 4th ACM/IEEE International Conference on. [S.1.], 2009. p. 109116. Citado na página 30.

SCHALK, G.; MCFARLAND, D. J.; HINTERBERGER, T.; BIRBAUMER, N.; WOLPAW, J. R. Bci2000: a general-purpose brain-computer interface (bci) system. IEEE Transactions on biomedical engineering, IEEE, v. 51, n. 6, p. 1034-1043, 2004. Citado nas páginas 42 e 43.

SCHOLKOPF, B.; SMOLA, A. Learning with Kernels. 2002. MIT Press, Cambridge, M. Citado na página 155.

SHAMSUDDIN, S.; YUSSOF, H.; ISMAIL, L.; HANAPIAH, F. A.; MOHAMED, S.; PIAH, H. A.; ZAHARI, N. I. Initial response of autistic children in human-robot interaction therapy with humanoid robot nao. International Colloquium on Signal Processing and its Applications, p. pp. 188-193, 2012. Citado na página 40.

SOBOTTA, J. Atlas da anatomia humana. 2006. 22. ed. Rio de Janeiro: Guanabara Koogan. Citado na página 145 .

SPÜLER, M.; NIETHAMMER, C. Error-related potentials during continuous feedback: using eeg to detect errors of different type and severity. Frontiers in human neuroscience, Frontiers, v. 9, p. 155, 2015. Citado nas páginas 52, 87, 99, 112 e 117.

STANKOVIĆ, R. S.; FALKOWSKI, B. J. The haar wavelet transform: its status and achievements. Computers \& Electrical Engineering, Elsevier, v. 29, n. 1, p. 25-44, 2003. Citado na página 60 .

STEINFELD, A.; JENKINS, O. C.; SCASSELLATI, B. The oz of wizard: simulating the human for interaction research. In: IEEE. Human-Robot Interaction (HRI), 2009 4th ACM/IEEE International Conference on. [S.1.], 2009. p. 101-107. Citado na página 41.

SUAY, H. B.; CHERNOVA, S. Humanoid robot control using depth camera. In: IEEE. 2011 6th ACM/IEEE International Conference on Human-Robot Interaction (HRI). [S.1.], 2011. p. 401-401. Citado na página 37.

SZEGEDY, C.; IOFFE, S.; VANHOUCKE, V.; ALEMI, A. A. Inception-v4, inception-resnet and the impact of residual connections on learning. In: AAAI. [S.1.: s.n.], 2017. p. 4278-4284. Citado na página 82.

TANAKA, F.; CICOUREL, A.; MOVELLAN, J. R. Socialization between toddlers and robots at an early childhood education center. Proceedings of the National Academy of Sciences, National Acad Sciences, v. 104, n. 46, p. 17954-17958, 2007. Citado nas páginas 38 e 81.

TANAKA, F.; GHOSH, M. The implementation of care-receiving robot at an english learning school for children. In: IEEE. Human-Robot Interaction (HRI), 2011 6th ACM/IEEE International Conference on. [S.1.], 2011. p. 265-266. Citado nas páginas 17, 38 e 39.

TAPUS, A.; PECA, A.; ALY, A.; POP, C.; JISA, L.; PINTEA, S.; RUSU, A. S.; DAVID, D. O. Children with autism social engagement in interaction with NAO, an imitative robot - a series of single case experiments. Interaction Studies, John Benjamins Publishing Company, vol. 13(3), p. 315-347, 2012. Citado na página 39. 
TELLES, M. L. F. A.; PINTO, A. H. M.; ROMERO, R. A. F. Um estudo de interação a longo prazo com aulas de matemática usando robôs. 2019. Citado na página 127.

THOMAZ, S.; AGLAÉ, A.; FERNANDES, C.; PITTA, R.; AZEVEDO, S.; BURLAMAQUI, A.; SILVA, A.; GONÇALVES, L. M. Roboeduc: a pedagogical tool to support educational robotics. In: IEEE. 2009 39th IEEE Frontiers in Education Conference. [S.1.], 2009. p. 1-6. Citado na página 36.

TOZADORE, D.; PINTO, A.; ROMERO, R.; TROVATO, G. Wizard of oz vs autonomous: children's perception changes according to robot's operation condition. In: IEEE. 2017 26th IEEE International Symposium on Robot and Human Interactive Communication (ROMAN). [S.1.], 2017. p. 664-669. Citado nas páginas 79 e 126.

TOZADORE, D.; Pinto, A.; Valentini, J.; Camargo, M.; Zavarizz, R.; Rodrigues, V.; Vedrameto, F.; Romero, R. Project r-castle: Robotic-cognitive adaptive system for teaching and learning. IEEE Transactions on Cognitive and Developmental Systems, p. 1-1, 2019. Citado nas páginas 78, 79 e 127.

TOZADORE, D. C.; PINTO, A. H.; RANIERI, C. M.; BATISTA, M. R.; ROMERO, R. A. Tablets and humanoid robots as engaging platforms for teaching languages. In: IEEE. 2017 Latin American Robotics Symposium (LARS) and 2017 Brazilian Symposium on Robotics (SBR). [S.1.], 2017. p. 1-6. Citado nas páginas 78 e 126.

TOZADORE, D. C.; PINTO, A. H. M.; ROMERO, R. A. F. Variation in a humanoid robot behavior to analyse interaction quality in pedagogical sessions with children. submitted to LARS, 2016. Citado nas páginas 26, 80 e 126.

TRIDICO, S. F.; PINTO, A. H. M. de; ROMERO, R. A. F. Reconhecimento de figuras geométricas 3d utilizando redes neurais em um robô humanoide para aplicação na educação. 2016. Citado na página 127.

VAPNIK, V.; GUYON, I.; HASTIE, T. Support vector machines. 1995. Citado na página 154. VELTROP, T. 2012. Disponível em: http://taylor.veltrop.com/. Citado na página 37.

VERKIJIKA, S. F.; WET, L. D. Using a brain-computer interface (bci) in reducing math anxiety: Evidence from south africa. Computers \& Education, Elsevier, v. 81, p. 113-122, 2015. Citado nas páginas 49 e 148 .

VERNER, I. M.; POLISHUK, A.; KLEIN, Y.; CUPERMAN, D.; MIR, R.; WERTHEIM, I. A learning excellence program in a science museum as a pathway into robotics. International Journal of Engineering Education, v. 28, n. 3, p. 523, 2012. Citado na página 39.

VIDAL, J. J. Toward direct brain-computer communication. 1973. Annu. Rev. Biophys. Bioeng., vol. 2, pp. 157-180. Citado na página 27.

Vonesch, C.; Blu, T.; Unser, M. Generalized daubechies wavelet families. IEEE Transactions on Signal Processing, v. 55, n. 9, p. 4415-4429, Sep. 2007. Citado na página 62.

VYGOTSKY, L. S. Pensamento e linguagem. 1993. Martins Fontes, São Paulo. Citado na página 35.

WALTER, W. G. An imitation of life. Scientific American, v. 182, p. 42 - 45, 19501950. Citado na página 30. 
WEISS, A. Validation of an evaluation framework for human-robot interaction: the impact of usability, social acceptance, user experience, and societal impact on collaboration with humanoid robots. [S.1.]: na, 2010. Citado na página 41.

WILSON, N. R.; SARMA, D.; WANDER, J. D.; WEAVER, K. E.; OJEMANN, J. G.; RAO, R. P. Cortical topography of error-related high-frequency potentials during erroneous control in a continuous control brain-computer interface. Frontiers in neuroscience, Frontiers, v. 13, p. 502, 2019. Citado na página 55 .

WOLF, S.; BAHLS, T.; CHALON, M.; FRIEDL, W.; GREBENSTEIN, M.; HÖPPNER, H.; KÜHNE, M.; LAKATOS, D.; MANSFELD, N.; ÖZPARPUCU, M. C. et al. Soft robotics with variable stiffness actuators: Tough robots for soft human robot interaction. In: Soft Robotics. [S.1.]: Springer, 2015. p. 231-254. Citado na página 25.

WOLPAW, J. R.; BIRBAUMER, N.; MCFARLAND, D. J.; PFURTSCHELLER, G.; VAUGHAN, T. M. Brain-computer interfaces for communication and control. Clinical neurophysiology, Elsevier, v. 113, n. 6, p. 767-791, 2002. Citado na página 157.

YASUI, Y. A brainwave signal measurement and data processing technique for daily life applications. Journal of physiological anthropology, Japan Society of Physiological Anthropology, v. 28, n. 3, p. 145-150, 2009. Citado na página 48.

YILDIRIM, N.; VAROL, A. Developing educational game software which measures attention and meditation with brainwaves: Matching mind math. In: Joint International Conference on Engineering Education \& International Conference on Information Technology, Cape Town. [S.1.: s.n.], 2013. Citado nas páginas 48 e 148.

YOUSEFI, R.; SERESHKEH, A. R.; CHAU, T. Exploiting error-related potentials in cognitive task based bci. Biomedical Physics \& Engineering Express, IOP Publishing, v. 5, n. 1, p. 015023, 2018. Citado na página 54.

ZEYL, T.; YIN, E.; KEIGHTLEY, M.; CHAU, T. Improving bit rate in an auditory bci: Exploiting error-related potentials. Brain-computer interfaces, Taylor \& Francis, v. 3, n. 2, p. 75-87, 2016. Citado na página 53.

Partially supervised p300 speller adaptation for eventual stimulus timing optimization: target confidence is superior to error-related potential score as an uncertain label. Journal of neural engineering, IOP Publishing, v. 13, n. 2, p. 026008, 2016. Citado na página 53.

ZUHER, F.; ROMERO, R. Whole-body imitation and recognition of human motions through a humanoid robot. In: SBR/LARS-Simpósio Brasileiro de Robótica/Latin American Robotics Symposium. [S.1.: s.n.], 2012. p. 190-195. Citado na página 37. 
APÊNDICE

\section{A}

\section{INFORMAÇÕES ADICIONAIS}

\section{A.1 Anatomia do Cérebro}

Este apêndice destina-se áqueles que não são da área de neurologia e não estão familiarizados com informações sobre a anatomia cerebral. Todo o material aqui descrito foi inspirado em Lent (2001), e ilustra alguns detalhes do cérebro, como sua divisão por lóbulos e a localização dos córtex que são importantes para este projeto de Doutorado.

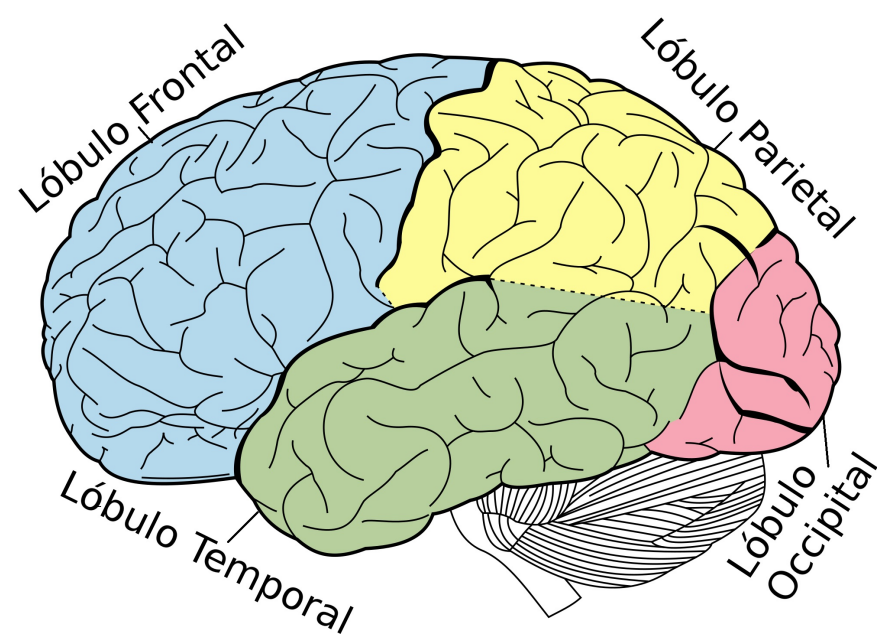

Figura 41 - Separação dos lóbulos cerebraiss Adaptada de uma imagem em domínio público ${ }^{1}$.

O Sistema Nervoso Central (SNC) reúne todas as estruturas neurais situadas dentro do crânio e da coluna vertebral. Anatomicamente, pode-se dividir o SNC em grandes partes que obedecem uma hierarquia de complexidade, e a primeira sub-divisão é em encéfalo e medula espinhal. A medula, de forma cilíndrica ou tubular, é a parte que continua do encéfalo para o interior da coluna vertebral e apresenta funções motoras, principalmente controle imediato do

1 Disponível em: https://upload.wikimedia.org/wikipedia/commons/thumb/0/0e/Lobes_of_the_brain_NL.svg/ . 
corpo. O encéfalo, parte que está contida no interior da caixa craniana, tem um forma irregular e apresenta diversas subdivisões e funções, sendo mais complexo do que a medula espinhal. $\mathrm{O}$ encéfalo pode ser dividido em três partes: o cérebro, o cerebelo e o tronco encefálico.

O cerebelo é um cérebro em miniatura, que tem dois hemisférios não separados e o tronco encefálico é uma estrutura em forma de haste que se esconde por debaixo do cerebelo e, no seu inferior, continua com a medula espinhal. Um dos órgãos mais importantes do ser humano, e o mais complexo, o cérebro é a parte mais desenvolvida do encéfalo, é regido por centenas de milhares de sinais elétricos a cada instante, e é responsável pela coordenação motora, pela memória, pela fala, pelo controle de todo o corpo e por processar toda informação vinda do meio ambiente.

O córtex cerebral é um tecido fino constituído pelas células neuroglias, uma espécie de cola neural, e pelos neurônios. O córtex é dividido em áreas chamadas lóbulos, e cada lóbulo tem uma função em particular. As letras utilizadas no sistema 10-20 de posicionamento dos eletrodos do EEG seguem os nomes dos módulos. A divisão dos lóbulos é mostrada na Figura 41, mas não se trata de uma divisão exata, mas sim como algo mais didático. A priori, o todo o cérebro trabalha para execução de qualquer tarefa, porém algumas informações específicas, e interessante para esta pesquisa, ativa o córtex em uma determinada região, sendo um bom local para posicionamento do eletrodo.

Localizado na parte da frente do cérebro (região da testa), o lóbulo frontal inclui o córtex motor e o córtex frontal e é responsável pelo planejamento de ações e movimentos. Por esse motivo, os trabalhos de imagética motora utilizam muito os eletrodos "F", e principalmente o equipamento MindWave tem apenas um eletrodo, localizado na posição Fp1. Um trauma nesta área pode causar fraqueza muscular e até paralisia, já que o córtex motor é responsável pela movimentação voluntária e trabalha de forma espelhada (o córtex do hemisfério esquerdo controla o lado direito do corpo). Já o córtex pré-motor, fica mais ativo quando se imagina um movimento, sem executá-lo. O pensamento abstrato e criativo acontece no córtex frontal, cuja atividade aumenta quando um indivíduo se depara com uma tarefa difícil que envolva uma sequência de ações a serem executadas.

Na região superior do cérebro temos o lóbulo parietal, que é subdividido em anterior e posterior. $\mathrm{O}$ anterior, de tamanho maior, é chamado de córtex somatossensorial, e é o que possibilita as sensações, como calor, paladar e tato, por exemplo. A zona posterior é responsável por analisar as informações recebidas pela anterior, permitindo ao indivíduo fazer associações, como reconhecer sabores e se localizar no espaço. Nas laterais, na região acima das orelhas, encontra-se o lóbulo temporal, responsável principalmente por processar informações auditivas. A informação é recebida por uma área auditiva primária e tratada por uma área auditiva secundária, que se comunica com outras partes do cérebro, para ativar conhecimento, memórias, entre outros. Analogamente, o lóbulo occipital é responsável pelo córtex visual que também tem subdivisões, processando a informação na área visual primária e interpretando na área visual secundária, que 
se comunica com as demais regiões do cérebro.

\section{A.2 Obtendo o sinal cerebral}

A partir desta seção, serão discutidos todos os conceitos das arquiteturas BCI encontradas na literatura e suas aplicações. Serão demonstradas técnicas e equipamentos abordadas nas principais etapas do processamento do sinal, desde a sua obtenção até a classificação final do sistema em outras pesquisas disponíveis na literatura.

\section{A.3 Obtendo o EEG}

As atividades elétricas do cérebro são resultado dos impulsos nervosos emitidos pelos neurônios, o que indica a atividade do córtex cerebral (SOBOTTA, 2006). Os grupos de neurônios são excitados, por exemplo, durante a ocorrência de um estímulo nervoso, gerando essa atividade elétrica, o que pode ser medido pela Eletroencefalografia (SANEI; CHAMBERS, 2007). Usado como exame na medicina, os potenciais elétricos podem ser plotados em um gráfico, e médicos podem reconhecer atividades anormais (como picos de atividade não esperados) e reconhecer síndromes epilépticas, morte encefálica, estado de coma, entre outros. Como visto no Capítulo 2, sistemas BCI que utilizam o EEG como entrada de sinal, se bem calibrados, podem diagnosticar doenças, perceber a probabilidade de uma convulsão epiléptica eminente, reconhecer intenção do movimento (imagética motora) e até transcrever algo que o usuário queira falar.

Um dos grandes problemas com o EEG é justamente a interpretação desse sinal coletado, porque ocorrem componentes não localizados espacialmente, além da grande quantidade de ruído. Os ritmos sensório-motores, classificados pelas ondas $\mu$ e $\beta$ são alguns dos casos de componentes bem localizados (PFURTSCHELLER et al., 1997), sendo que as ondas $\mu$ ficam na faixa $8 \mathrm{~Hz}-13 \mathrm{~Hz}$, enquanto as ondas $\beta$ se situam na faixa entre $13 \mathrm{~Hz}$ e $30 \mathrm{~Hz}$ (DORNHEGE, 2007). Os movimentos, ou mesmo a intenção de movimentar, gera os chamados Event Related Desychronization (ERD) e os Event Related Sychronization (ERS). Pela sua boa localização, no caso, o córtex central, o planejamento do movimento (ou ativação) gera ERD enquanto a desativação (ou não-ativação) gera ERS, criando modulações na amplitude do sinal que geralmente é fraco, na casa dos microvolts.

A partir do sinal, é possível reconhecer os padrões da atividade cerebral associados a algum evento. As pessoas dispostas a utilizar essa tecnologia precisam passar por um processo de treinamento, fazendo exercícios mentais para criar os padrões a serem reconhecidos. Porém, fatores como a idade e sexo influenciam no sinal do EEG, fazendo com que uma atividade elétrica seja normal em crianças, mas anormal em adultos. O local onde os eletrodos são colocados também podem gerar diferentes leituras, o que atrapalha estudos comparativos. O sistema mais comum utilizado na literatura é o sistema 10-20, proposto por Jasper (1958). Os eletrodos são 
posicionados de forma a permitir uma cobertura o mais uniforme possível do escalpo. A Figura 42 mostra o posicionamento dos eletrodos neste sistema, onde as letras indicam a posição de cada eletrodo: P para Parietal, F para Frontal, T para Temporal, C para Central, O para Occipital. Índices ímpares são para o hemisfério esquerdo, pares para o hemisfério direito e o índice z são os eletrodos posicionados na linha central. O nome 10-20 deriva da distância total entre os pares de eletrodos, que variam entre $10 \%$ e $20 \%$.

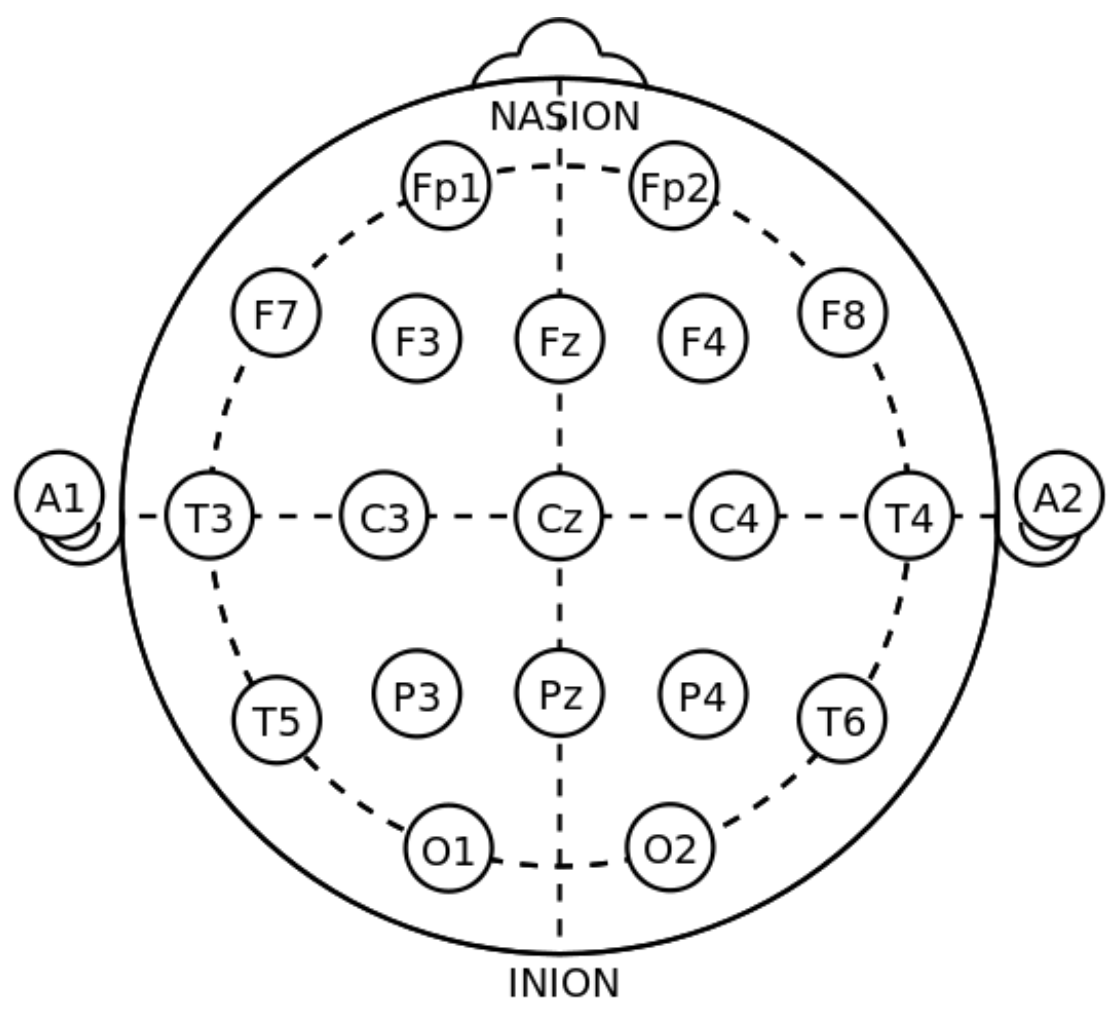

Figura 42 - Sistema internacional de posicionamento dos eletrodos 10-20. Imagem em domínio público²

Apesar de algumas diferenças, algumas frequências foram mapeadas e são definidas na literatura ${ }^{3}$. Muitos dos trabalhos com BCI para educação se baseiam nessa classificação (NIEDERMEYER, 2005; PFURTSCHELLER; NEUPER, 2001):

- Delta $(\delta)(1-4 \mathrm{~Hz}$ e amplitudes entre $20-400 \mu V)$ São ondas geralmente de alta amplitude, encontradas em adultos durante o estágio de sono e anestesia profundos ou em crianças como menos de um ano. Em adultos despertos, pode indicar doenças no cérebro

- Theta $(\theta)(4-7 \mathrm{~Hz}$ amplitudes entre 5-100 $\mu \mathrm{V})$ Encontrada no estágio de sonolência em crianças pequenas (2-5 anos). Mais evidente nas derivações parietais-temporais

2 Disponível em: https://upload.wikimedia.org/wikipedia/commons/thumb/7/70/21_electrodes_of_International_1020_system_for_EEG.svg/537px21_electrodes_of_International_1020_system_for_EEG.svg.png .

3 Algumas informações, como a variação da frequência $\alpha$ (até $12 \mathrm{ou} 13 \mathrm{~Hz}$ ) e a presença ou não da frequência $\mu$ podem variar de acordo com o foco do trabalho pesquisado. 
- Alpha $(\alpha)(8-13 \mathrm{~Hz}$ amplitudes entre 2-10 $\mu \mathrm{V})$ Ligadas à região Occipital, quando o usuário está com os olhos fechados ou em um estado de relaxamento

- Mu $(\mu)(8-13 \mathrm{~Hz})$ Estão localizadas no córtex motor e sensório-motor, sendo comum durante os movimentos do usuário. Melhores observadas com o Alpha bloqueado e nas derivações frontais-parietais.

- Beta $(\beta)(14-30 \mathrm{~Hz}$ amplitudes entre 1-5 $\mu \mathrm{V})$ Ondas também afetadas pelo movimento, são observáveis em usuários despertos, conscientes e geralmente mostram engajamento em alguma atividade

- Gamma $(\gamma)$ (Acima de 30Hz) Frequência associada a várias funções cognitivas e motoras, atingindo normalmente uma frequência máxima que varia entre 80 e $100 \mathrm{~Hz}$.

Esses sinais se combinam em um ou muitos padrões de atividades cerebrais, sendo possível associar os comandos a esses padrões emergentes. Muitos deles foram estudados, e são considerados relativamente fáceis de se identificar, respentando-se as particularidades de cada indivíduo. Os sinais são divididos em duas categorias (CURRAN; STOKES, 2003):

- Sinais evocados - são sinais gerados automaticamente pelo indivíduo, quando submetido a algum tipo de estímulo externo. Um dos mais conhecidos e utilizados na literatura é o P300. Inicialmente chamados de Evoked Potentials (EP), o termo é considerado antigo, sendo atualmente chamado de Event-Related Potential (ERP) (LUCK, 2014);

- Sinais espontâneos - são sinais que acontecem sem a interferência de estímulos externos.

Os sinais sensório-motores, importantes para o estudo da imagética motora, encontramse na categoria dos sinais espontâneos. Com um processo de imaginação de movimentos (ou também por um longo processo de aprendizagem conhecido como Condicionamento Operante um sistema pode perceber a intenção de movimentos e acionar um braço mecânico, por exemplo, para executar a ação por alguém que tenha perdido um membro do corpo. Apesar do foco deste trabalho ser nos potenciais espontâneos, é importante conhecer a influência dos sinais evocados, já que devem ser filtrados nas etapas de pré-processamento do sinal.

\section{A.4 Dispositivos comerciais para captação do sinal EEG}

\section{A.4.1 NeuroSky MindWave}

Este dispositivo consiste apenas de um eletrodo, posicionado na testa, acima dos olhos (correspondendo a posição FP1 do sistema 10-20), um plug para orelha, correspondendo à referência e para o cálculo da diferença de potencial elétrico e ao terra e conexão bluetooth 
wireless com o computador. Tem como saída ondas puras entre 3 e $100 \mathrm{~Hz}$, com uma taxa de amostragem de $512 \mathrm{~Hz}$. Porém, também é possível obter o espectro de potência e informações de atenção e meditação, utilizando o software proprietário eSense. Recomenda-se o seu uso apenas em regiões cuja rede elétrica é de $60 \mathrm{~Hz}$, como no Brasil. O sistema foi utilizado em muitos trabalhos com BCI aplicada a educação por ser leve $(90 \mathrm{~g})$ e ter uma aparência mais amigável, apresentado na figura 43 (MARCHESI; RICCO, 2013; YILDIRIM; VAROL, 2013; LIM et al., 2012)

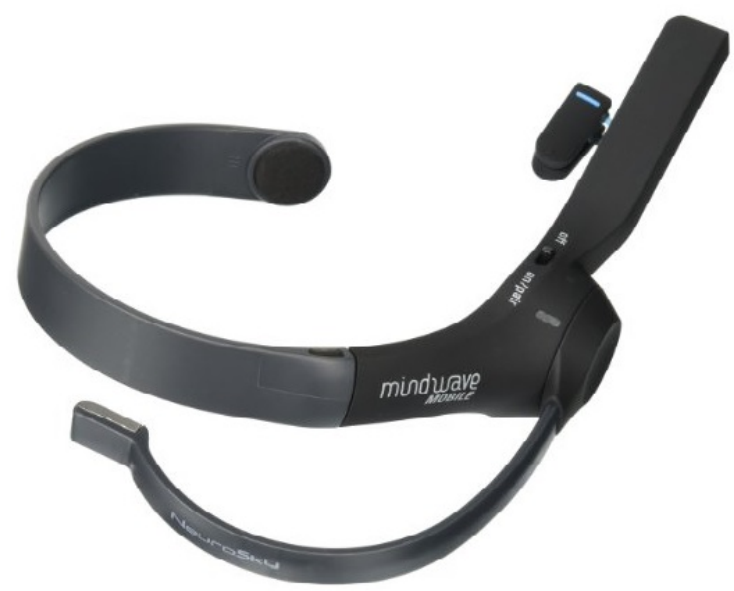

Figura 43 - Headset NeuroSky MindWave. Fonte: Site da NeuroSky ${ }^{4}$.

\section{A.4.2 EMOTIV Epoc}

Dividido em 2 categorias, temos o headset da EMOTIV como outra alternativa para obtenção do EEG. A versão Insight contém 5 eletrodos e mais 2 referenciais, referentes às posições AF3, AF4, T7, T8 e Pz, com taxa de amostragem de 128Hz. Essa versão é indicada para verificação de desempenho e aptidão cerebral, monitorando a saúde cognitiva e o bem-estar. Nas pesquisas com educação é mais comum a utilização da versão EPOC+ (Figura 44)(ANDUJAR et al., 2011; LEE; CHIN, 2014; VERKIJIKA; WET, 2015), que utizada 14 canais e 2 referências nas posições AF3, AF4, F3, F4, FC5, FC6, F7, F8 T7, T8, P7, P8, O1 e O2. Ele tem uma amostragem interna de $2048 \mathrm{~Hz}$, mas é filtrado e amostrado em 128 ou $256 \mathrm{~Hz}$. Utiliza conexão bluetooth e uma bateria de Li-poly ${ }^{5}$ de $680 \mathrm{mAh}$, possibilitando 12 horas de autonomia. O dispositivo é capaz de detectar algumas ações (piscar, levantamento de sobrancelha, aperto dos dentes, risos) e também alguns estados emocionais, como excitação (instantânea e a longo prazo, frustração, engajamento, meditação, interesse e afinidade).

4 Disponível em: http://store.neurosky.com/ .

5 Baterias "seca" de lítio. 


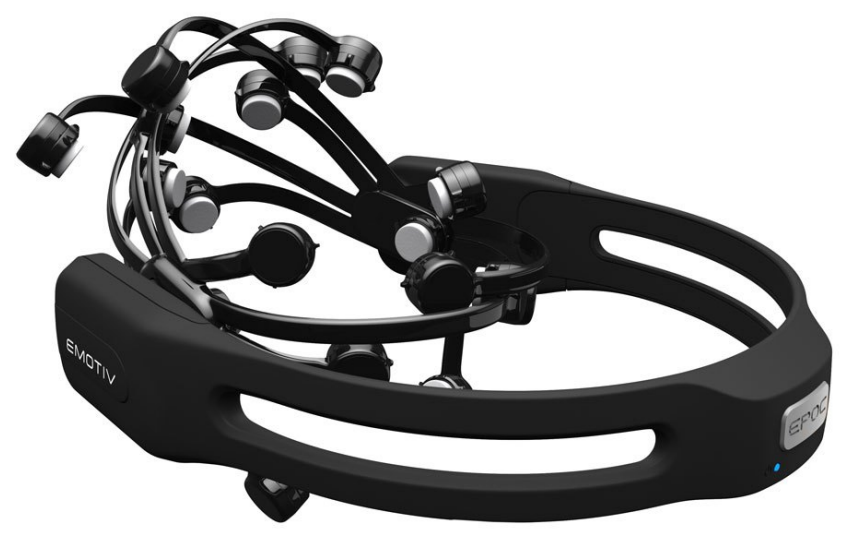

Figura 44 - Headset EMOTIV Epoc. Fonte: Site da EMOTIV ${ }^{6}$.

Disponível gratuitamente, o EMOTIV Control Panel oferece informações como o status da conexão dos eletrodos, monitorar e gravar algumas expressões faciais e praticar comandos mentais. Além disso é possível acompanhar alguns estados emocionais, porém não é possível modificar o extrator de características ou a filtragem do sinal. Para obter o sinal puro e permitir ajustes nos algoritmos é necessário utilizar o software proprietário Pure EEG Raw, que é pago no regime de assinatura mensal ou anual.

\section{A.5 Pré processamento}

Devido à grande quantidade de dados gerada pelos canais da eletroencefalografia, existe muita dificuldade para se conseguir separar e classificar características do sinal. Diversas outras atividades elétricas podem acabar gerando ruídos nos sinais captados, principalmente a atividade muscular, por ter como característica uma amplitude maior (FATOURECHI et al., 2007). Para fazer a "limpeza" desse sinal, retirando os ruídos ou artefatos ${ }^{7}$, é necessário levar em consideração as características mais importantes a serem extraídas, como informações temporais, de amplitude e frequência.

Existem muitos filtros que podem ser utilizados para fazer a limpeza do sinal. Dentre os mais utilizados destacam-se os filtros temporais, como Filtros Digitais de Duração Finita (Finite Impulse Response (FIR)) e infinita (Infinite Impulse Response (IIR)) e os filtros espaciais como a Separação Cega de Fontes (Blind Source Separation (BSS)), principalmente com a Análise dos Componentes Independentes (Independent Component Analysis (ICA)), que é um dos métodos mais conhecidos de BSS (HYVÄRINEN; OJA, 2000), ou Padões Espaciais Comuns (Common Spatial Patterns (CSP)).

6 Disponível em: https://www.emotiv.com/ .

7 Potenciais elétrico indesejados que contaminam o sinal. 


\section{A.5.1 Filtros Temporais}

Os filtros temporais, como passa-baixa e passa-banda, para limitar o sinal na faixa onde se encontra o comportamento desejado. Por exemplo, para os casos sensório-motores, filtros passa-banda entre 8 e $30 \mathrm{~Hz}$ são utilizados para a separação das ondas $\mu$ e $\beta$. Os filtros temporais separam as frequências da zona de interesse do sistema BCI. Como os trabalhos de educação utilizando BCI focam na comparação das frequências $\alpha$ e $\beta$ para comparação dos níveis de atenção, a utilização dos filtros temporais é muito comum.

\section{A.5.2 Filtros Espaciais}

A ponderação da contribuição de cada eletrodo ajuda a separar as informações necessárias para se isolar o sinal neurofisiológico desejado. Sabendo-se previamente a região de interesse, a forma mais simples de realizar essa filtragem é ignorar o sinal vindo dos demais eletrodos. Por exemplo, sabendo-se que os eletrodos $\mathrm{C} 3$ e $\mathrm{C} 4$ se referem respectivamente ao córtex motor esquerdo e direito, pode-se enfatizar essa informação (caso o sistema seja de imagética motora) ou ignorá-la, diminuindo a quantidade de ruído para o sinal final. Porém, apenas esse tipo de abordagem não é suficiente para a maioria das aplicações de BCI, que necessitam de um tratamento mais complexo do sinal. O filtro ICA, mais comum para esta tarefa, está melhor descrito no Capítulo 4.

\section{A.5.3 Outras Soluções}

Aparecendo com menos frequência na literatura, outros filtros são utilizados para o pré-processamento. Alguns deles são as soluções inversas que determinam a atividade modelando o conjunto de potenciais elétricos de dipolos espalhados por todo cérebro. Essas soluções costumam ser utilizadas tanto no pré-processamento (com resultados promissores nos trabalhos de Noirhomme, Kitney e Macq (2008)) ou na fase de extração de características, como será discutido na próxima Seção. Entre outras opções, também aparecem as redes neurais, porém os testes realizados com essa abordagem se mostraram muito problemáticos para serem utilizados na extração de características, pois a rede tem dificuldade para convergir (BOGACZ; MARKOWSKA-KACZMAR; KOZIK, 1999).

\section{A.6 Extração de Características}

Mesmo com o pré-processamento, ainda há muita informação para ser tratada pelo sistema, fazendo necessária uma fase de extração de informações relevantes para a tarefa proposta. Apenas a partir de uma boa extração dessas características é possível uma boa classificação da informação obtida, refletindo adequadamente o estado mental do usuário. A escolha correta dos algoritmos de pré-processamento e de extração de características é mais importante para uma boa 
resposta do sistema e causa mais impacto na aplicação final do que a definição do classificador (PFURTSCHELLER; FLOTZINGER; KALCHER, 1993). Existem três grupos principais de extração de características: métodos temporais, de frequência e híbridos.

- Métodos temporais A partir das variações do sinal no tempo, estes métodos conseguem descrever o comportamento neurofisiológico, como no caso do ERD. Existem muitos métodos para serem utilizados, dos quais destacam-se os modelos de amplitude do sinal, os parâmetros Hjorth e os parâmetros auto-regressivos (AR);

- Métodos de frequência: Conjuntos de ondas (ou ritmos) diferentes compõe o resultado da captura do EEG. Os sinais cognitivos e evocados alteram, respectivamente, a amplitude e a oscilação desses sinais, fazendo com que a extração das características no domínio de frequência seja uma técnica adequada. Para tal, a literatura mostra duas abordagens muito comuns: Potência Espectral e Densidade de Potência Espectral;

- Métodos hídridos: Esses métodos são os mais utilizados em BCI, porém, devido às características específicas de alguns sinais neurofisiológicos, alguns autores abordam métodos híbridos de tempo e frequência para a fase de extração de características. Nesses casos são utilizadas, por exemplo, a Transformada rápida de Fourier (Fast Fourier Transform (FFT)) e as transformadas ondaleta (wavelets), indicadas para quando é necessário informações da variação de frequência no domínio do tempo.

Os métodos de frequência retornam bons resultados para a imagética motora (PFURTSCHELlER; FLOTZINGER; KALCHER, 1993) e a Densidade de Potência Espectral (Power Spectral Density (PSD)) é, segundo Lalor et al. (2005), o extrator mais utilizado em sistemas BCI aplicados a jogos eletrônicos. Entretanto, o trabalho de Hosni et al. (2007) chega à conclusão de que os parâmetros AR superam a classificação dos demais modelos, tendo uma acurácia de 70\% na média, contra $56 \%$ da melhor perfomace entre os modelos baseados em frequência.

\section{A.7 Classificadores}

Com as características do sinal separadas, o próximo passo é classificar esses conjuntos, traduzindo um sinal desconhecido em uma informação ou em um comando a ser executado pelo sistema. Tanto algoritmos supervisionados como não-supervisionados podem ser utilizados, porém os supervisionados são amplamente utilizados na literatura, sendo considerados a melhor forma de se abordar essa tarefa. Algoritmos supervisionados utilizam conjuntos de treinamento já classificados (ou seja, um conjunto de exemplos) para encontrar uma função que melhor generalize esses dados, usando normalmente a margem do erro para adaptar essa função. A escolha de uma função que consiga separar os dados e de uma base de treinamento que represente bem o espaço de dados da tarefa são importantes para uma boa classificação das características extraídas. 
Na literatura, algoritimos clássicos de classificação são os mais utilizados para a BCI, que são as Redes Neurais (Artificial Neural Network (ANN)), Máquinas de Vetores de Suporte (Support Vector Machines (SVM)), Modelos de Markov (Hidden Markov Model (HMM)) e o k-Vizinhos mais Próximos (k-Nearest Neighbors (kNN)). Uma técnica não muito comum, mas que é encontrada na literatura com bons resultados (PIAZENTIN; ROSA, 2014) são os Conjuntos K de Freeman (Freeman k-Sets).

O Hidden Markov Model é um autômato finito probabilístico, em que cada estado corresponde a probabilidade de se encontra um determinado vetor de características. Nos sistemas BCI, essa probabilidade é representada por modelos de misturas Gaussianas (OBERMAIER et al., 2001). Esses modelos são adequados à classificação de séries temporais (RABINER, 1989), mas são escassos

O k-Nearest Neighbors É um algoritmo bastante simples, com a premissa de que instancias suficientemente próximas são consideradas como sendo da mesma classe. Para cada instância, procura-se nos k vizinhos mais próximos e a classificação é feita de acordo com as classes desse vizinhos visitados. Várias métricas podem ser utilizadas para se determinar a distância entre um ponto e outro, mas a mais utilizada é a distância euclidiana. Em alguns testes preliminares, o $\mathrm{kNN}$ teve melhor desempenho (com $k=10$ ) se comparado a abordagens como a LDA, Naive Bayes e árvore de decisão C 4.5 (JIMENEZ et al., 2011).

\section{A.7.1 Conjuntos $K$ de Freeman}

As redes neurais clássicas, como o modelo perceptron, são a representação matemática de um neurônio que corresponde à atividade microscópica do cérebro (KOZMA et al., 2007). Os conjuntos $\mathrm{K}$ de Freeman formam uma hierarquia de modelos que representam a atividade mesoscópica do cérebro, ou seja, representam regiões com milhares de neurônios. A partir a observação do bulbo olfatório, Freeman desenvolveu a teoria dos conjuntos-K, onde os conjuntos de neurônios interagem e se alteram, gerando a cognição (FREEMAN; YAO; BURKE, 1988).

Durante a inalação de um odor, cada neurônio no bulbo olfatório participa na cognição desse odor, percebendo o número de receptores especializados que captaram esse estímulo e a distribuição espacial para se conhecer o tipo de odor. Utilizando BCI invasiva, Freeman (1975) verifica a inspiração de odores familiares ou não, observando a excitação no cérebro com o aumento da amplitude das ondas e a inibição da informação representada pelas quedas. A escolha do bulbo olfatório se justifica por ser mais primitivo e isolado dos demais córtices.

A modelagem matemática dos Conjuntos-K de Freeman é feita com base em uma série de suposições:

- A atividade macroscópica é distribuida de forma contínua no espaço;

- Tempo e distância macroscópica é muito maior que no caso dos neurônios individuais; 
- As populações podem ser descritas por meio de equações diferenciais ordinárias (EDO);

- A média de atividade do neurônio é consistente com a média da sua vizinhança.

Os conjuntos são organizados em uma hierarquia, onde o conjunto de um nível é uma combinação de conjuntos de níveis abaixo. Esses conjuntos, ou níveis, são denominados $K O, K I, K I I$ e assim por diante. Apesar de já ter-se definido, em nível teórico, até o conjunto $K V I$, experimentalmente só foi utilizado até o conjunto $K I V$.

O KO, primeiro nível da hierarquia, representa um conjunto que varia entre $10^{3}$ e $10^{8}$ neurônios, sendo geralmente usado $10^{4}$ (KOZMA et al., 2007). Esse conjunto possui uma fonte de entrada e um tipo de saída (excitatório ou inibitório) e eles não são interagentes. Até que seja perturbado, o ponto atrator que governa o KO se mantém em equilíbrio. As dinâmicas do KO são descritas por uma EDO linear de segunda ordem:

$$
F(t)=(a * b) \ddot{P}(t)+(a+b) \dot{P}(t)+P(t)
$$

onde $a$ e $b$ são constantes de tempo, $P(t)$ denota a ativação do nó como função do tempo e $F(t)$ é uma função não-linear.

O segundo passo na hierarquia é o conjunto $K I$, que representa duas unidades $K O$ conectadas com uma forma de interação, ou seja, um feedback de mesmo sinal, gerando o $K I_{i}$ quando os $K O$ são inibitórios ou o $K I_{e}$ quando são excitatórios. Com a junção de dois $K I$ ou de quatro $K O$ totalmente conectados temos um $K I I$. Existem três tipos de conjuntos $K I I$, classificados de acordo com sua polaridade e sua trajetória de ativação: atrator positivo, negativo ou zero. Os conjuntos KII são configurados para reagir conforme o comportamento biológico. Suas conexões têm peso fixo, e por isso suas características não variam muito dentro da mesma região do cérebro.

Para aplicações em tarefas de aprendizado de máquina, o KIII é o primeiro nível com possibilidade de aplicação (PIAZENTIN; ROSA, 2014; ROSA; PIAZENTIN, 2016). Seguindo a hierarquia, o $K I I I$ é formado por pelo menos três camadas de $K I I$, os padrões encontrados podem ser chamados de sinais neurais e são relacionados às entradas recebidas pela rede. Essa montagem do KIII pode ser relacionada à um sistema sensorial completo, mas é esperado que seu comportamento seja semelhante ao sistema olfativo. A equação para o conjunto KIII é descrita por:

$$
\frac{1}{a b}\left[\frac{d^{2} v_{i}(t)}{d^{2}(t)}+(a+b) \frac{d v_{i}(t)}{d t}+a b v_{i}(t)\right]=\sum_{j \neq 1}^{N}\left[W_{i j} \times Q\left(v_{j}(t), q\right)\right]+I_{i}(t)
$$


onde $v_{i}$ é a ativação da i-ésima população de neurônios, $N$ é o número de populações no conjunto, $I$ é o estímulo de entrada externo, $W$ é o vetor de pesos representando a força da conexão entre as populações $i$ e $j, t$ é o tempo e $Q($.) é a função de conversão modo onda-pulso.

\section{A.7.1.1 Aprendizado do KIII}

O modelo KIII apresenta algumas vantagens em relação aos demais modelos apresentados:

- Produz memória robusta com poucos exemplos de treinamento;

- A capacidade de codificação de uma rede é exponencialmente maior;

- Podem recuperar os dados armazenados rapidamente.

Porém, a grande quantidade de EDO para serem computadas aumenta muito o custo computacional do modelo.

O treinamento do KIII ocorre de forma não-supervisionada, utilizando a regra do aprendizado hebbiano para o ajuste do peso das conexões. Sempre que dois neurônios são ativados ao mesmo tempo, as conexões são fortalecidas, fazendo com que os neurônios tenham conexões mais fortes dentro da sua população. Além disso, temos um processo de habituação, introduzindo uma situação de esquecimento na rede, reduzindo alguns pesos de conexões fracas. Isso permite uma menor sensibilidade aos ruídos, uma vez que eventualmente a conexão criada pelo mesmo será esquecida pela rede. O processo de habituação diminui lentamente o peso, a menos que a conexão seja reforçada por um estímulo externo, e tem uma taxa menor do que a do aprendizado.

\section{A.7.2 SVM}

Outro método muito utilizado para pesquisas com aprendizado de máquina é o método das Máquinas de Vetores de Suporte Support Vector Machines (SVM) que também consiste em encontrar uma função que generalize o conjunto de treinamento para predizer exemplos nunca vistos antes. Este método é utilizado em várias pesquisas, como reconhecimento de padrões (VAPNIK; GUYON; HASTIE, 1995), reconhecimento de objetos (BLANZ et al., 1996), identificação de fala, detecção de face, categorização de texto, entre outros. O desempenho das SVM se comparam aos classificadores clássicos da literatura.

O modelo SVM se baseia na Teoria do Aprendizado Estatístico Statistical Learning Theory (SLT), e, considerando a existência de alguns pressupostos, garente a aprendizagem em algoritmos supervisionados (LUXBURG; SCHOLKOPF, 2008). Isso significa que o algoritmo irá encontrar uma boa função de generalização para o problema, classificando exemplos desconhecidos com um custo (ou erro) baixo. Alguns desses pressupostos são: nenhum conhecimento prévio da distribuição de probabilidade do problema, o conjunto de dados amostrado de forma 
independente nessa distribuição e o fato da distribuição ser estacionária (ou seja, não vai mudar de comportamento ao longo do tempo).

Para problemas do mundo real, é impossível calcular diretamente o melhor classificador (chamado de "classificador Bayes") (LUXBURG; SCHOLKOPF, 2008), então não é possível saber o risco real de uma determinada função escolhida. Assim o foco do SLT é minimizar o chamado risco empírico, proporcionando uma garantia sobre a confiabilidade das aproximações necessárias. Uma série de conveniências e métodos matemáticos são empregados para alcançar esta solução, como a lei dos grandes números, convergência uniforme, união de limites, o coeficiente de ruptura e a dimensão VC (em homenagem a Vapnik e Chervonenkis). Todos os métodos, pressupostos e provas da SLT são discutidos em Luxburg e Scholkopf (2008).

A diferença principal da SVM é a preocupação com o espaço de dados. Assim como a MLP, a SVM utiliza funções lineares, mas faz um mapeamento do espaço de dados, aplicando as funções neste novo espaço mapeado, fazendo com que, ao voltar os dados para o espaço original, ela possa se comportar como uma função não-linear. Esta função de mapeamento é chamado de Kernel. É importante para entender o espaço de entrada e a distribuição dos dados para encontrar o melhor kernel que irá classificar com menor risco. Outra diferença importante é a margem. Uma vez que os dados são separados por um hiperplano (considerando funções lineares na dimensão 3D) a margem é a menor distância entre os exemplos do conjunto de treinamento usados para convergir e este hiperplano. Quanto melhor otimizada for essa margem, maior a probabilidade do algoritmo responder corretamente um exemplo desconhecido. Uma discussão mais aprofundada deste assunto pode ser encontrada em Scholkopf e Smola (2002).

Equacionando para o caso mais simples, com dados bi-dimensionais linearmente separáveis. Seja $H_{1}: \mathbf{x}_{i} * \mathbf{w}+b=1, \mathbf{w}$ um hiperplano, $|b| /|| \mathbf{w}||$ a distância perpendicular do hiperplano à sua origem, e $\|\mathbf{w}\|$ a norma Euclideana do $\mathbf{w}$, os pontos $x$ que pertencem ao hiperplano satisfazem $\mathbf{w} * \mathbf{x}+b=0$. Considerando um hiperplano para cada classe $\left(H_{1}\right.$ e $\left.H_{2}\right)$ pode-se notar que eles são paralelos (possuem a mesma norma) sem quaisquer pontos entre eles. Assim, para maximizar a margem, ou seja, achar a melhor margem, é preciso minimizar $\|\mathbf{w}\|^{2}$, sujeito à seguinte desigualdade:

$$
y_{i}\left(x_{i} * \mathbf{w}+b\right)-1 \geq 0 \forall i
$$

o que representa a combinação de margem separada para cada classe. Pontos de treinamento que pertencem a um dos hiperplanos $H_{1}$ e $H_{2}$, cuja remoção pode alterar a solução encontrada são chamados de vetor de suporte ( support vector), mostrado na Figura 45 para esse caso. Uma equação com desigualdade significa uma função com restrições. Para se encontrar uma solução para esse tipo de problema é necessário usar a função lagrangiana. respeitando as condições Karush-Kuhn-Tucker (KKT). Isto satisfaz qualquer problema de restrição de otimização (convexa ou não) e são condições necessárias e suficientes para convergência de uma SVM (LUXBURG; 


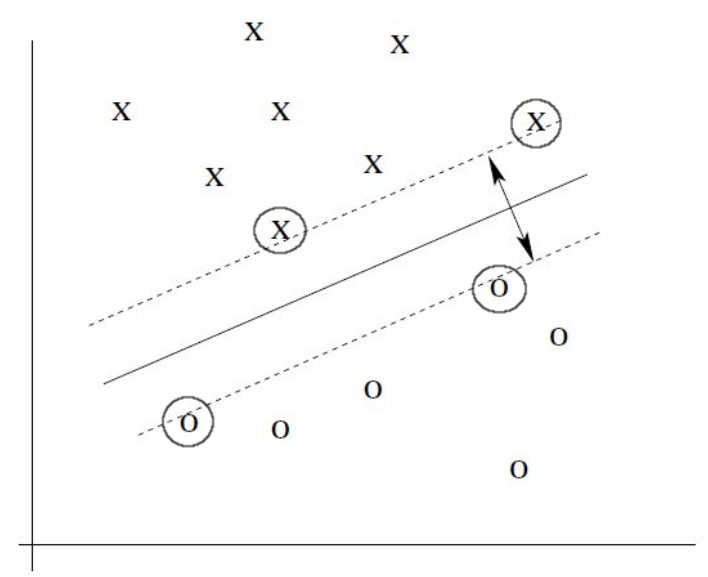

Figura 45 - Os vetores de suporte num caso de separação linear e o hiperplano separador.

Fonte: Adaptada de Luxburg e Scholkopf (2008).

SCHOLKOPF, 2008).

\section{A.7.2.1 SVM Multiclasse}

Utilizado normalmente para classificação binária, existem formas de adaptar o método SVM para classificação de multiplas classes. Uma adaptação é a utilização de ensembles, utilizando diversos classificadores SVM e combinando os seus resultados. Algumas das estratégias para combinação de resultados utilizadas com a SVM são o "one-against-one"e one-against-all". No primeiro caso, os classificadores combinados em um comitê e treinados para cada par de classe, escolhendo-se a classe predominante (ou a que teve um erro menor). Na segunda abordagem, os classificadores são treinados para uma classe e comparados a todas as outras. Para exemplificar, considerando-se que exista 3 classes: A, B e C.

- O classificador 1, treinado para a classe A, reconhece A ou desconhecido

- O classificador 2, treinado para a classe B, reconhece B ou desconhecido

- O classificador 3, treinado para a classe $\mathrm{C}$, reconhece $\mathrm{C}$ ou desconhecido

Um novo exemplo, da classe C, apresentado para os três classificadores, será classificado como:

- Desconhecido pelo classificador 1

- Desconhecido pelo classificador 2

- Classe C pelo classificador 3 


\section{A.8 Construindo um sistema $\mathrm{BCl}$}

Para a extração de características, é necessário considerar que o sinal vindo do EEG tem uma grande quatidade de ruído vindo da forma como se obtém os dados, além de existirem muitos outliers. A atividade neurofisiológica também está relacionada a variações específicas do sinal do EEG, de acordo com o tempo, o que torna um problema de alta dimensionalidade e não-estacionaridade, onde se é necessário analisar os vários canais de gravação (eletrodos) e vários segmentos de tempo para concatenar o vetor de características.

Os padrões da maioria das atividades cerebrais são relacionados a variações de tempo particulares e bem definidas do EEG (WOLPAW et al., 2002), fazendo com que o tempo seja uma variável a ser considerada durante a extração de características. Algumas abordagens consideradas na literatura são as seguintes:

- Concatenação de segmentos de tempos diferentes: Consiste na extração em vários momentos diferentes e a sua concatenação em um único vetor para classifica-lo (PFURTSCHELLER et al., 1997);

- Combinação de classificação em momentos diferentes: Consiste na combinação da extração e classificação feitas em vários momentos diferentes (HASELSTEINER; PFURTSCHELLER, 2000);

- Classificação dinâmica: Consiste na criação de uma sequência temporal de vetores de características, com base nas extrações feitas durante vários períodos de tempo. Esse vetor pode ser rotulado por um classificador dinâmico (PENNY; ROBERTS, 1999).

Como dito, os algoritmos supervisionados são mais populares e apresentam uma melhor acurácia para as aplicações BCI. Então, para se escolher o melhor algoritmo a ser usado para cada tipo de aplicação, é necessário considerar a taxonomia dos classificadores, o problema da dimensionalidade e o conflito Bias-Variância (Bias-Variance trade off).

\section{A.8.1 Os maiores problemas em classificação de $B C / s$}

Os algoritmos para classificação podem ser descritos de acordo com algumas características. Algoritmos estáticos, como as MLPs, não conseguem trabalhar com informações temporais. Para tal, são mais indicados algoritmos dinâmicos, como o HMM (RABINER, 1989). Algoritmos instáveis são consideravelmente afetados por pequenas variações no conjunto de treinamento e outro problema comum é o overtraining (BREIMAN et al., 1998), que afeta a classificação de algoritmos não regulares, devido ao problema de outliers (JAIN; DUIN; MAO, 2000).

Problema de dimensionalidade (curse-of-dimensionality): a quantidade de informação necessária para se classificar o sinal cresce exponencialmente com a dimensionalidade do vetor de características (JAIN; DUIN; MAO, 2000). Isso afeta também a importância de um bom 
conjunto de treinamento, pois se o seu tamanho for pequeno, comparado a quantidade de vetores de características, o classificador tem uma chance maior de rotular de forma errada. É necessário utilizar um número bem maior de exemplos de treinamento para resolver este problema, o que pode não ser possível para todas as tarefas de sistemas BCI, devido às particularidades do sinal.

Problema Bias-Variância (Bias-Variance and estimation-approximation trade off): a redução de erros em modelos matemáticos deve considerar dois pontos particulares: o bias aplicado e a variância dos dados. A SLT, mencionada na Seção A.7.2, define dois tipos de erro na definição das funções que generalizam um problema: $O$ erro de aproximação e o erro de estimação. Ao se escolher um algoritmo, embutimos um bias, assumindo que o problema pode ser resolvido com funções lineares ortogonais (como na MLP) ou polinomiais (como o caso de alguns kernels de SVM). Uma vez embutido esse bias, existe um erro de estimação, entre a melhor função no espaço do algoritmo escolhido e a melhor função no espaço de todas as funções possíveis. Dentro desse espaço de possíveis funções dado pelo algoritmo escolhido está o erro de aproximação para a melhor função dentro deste espaço, que é chamado de variância.

Para a melhor classificação, ambos bias e variância devem ter valores baixos. Entretanto, os algoritmos atuais têm uma disparidade natural, onde classificadores estáveis tendem a ter um bias baixo, com uma variância alta (BREIMAN et al., 1998), ou seja, as soluções aceitam uma gama maior de funções, tornando difícil encontrar a melhor dentro desse espaço. Como dito, a não-estacionaridade dos sinais do EEG e a variação entre os sinais obtidos em diferentes sessões geram um problema de variabilidade nos sistemas BCI; uma manobra que mostra resultados na literatura é a combinação de classificadores. Três maneiras diferentes de classificar essa combinação são:

- Boosting: Consiste em ter vários classificadores em cascata, como cada um focado nos erros do algoritmo anterior (DUDA; HART; STORK, 2001). Apesar de ser possível construir um classificador forte por meio de vários outros, o que impediria o overtraining, essa técnica é muito sensível a erros, não obtendo muito sucesso em sistemas BCI (JAIN; DUIN; MAO, 2000);

- Voting: Vários classificadores são utilizados, cada um rotulando uma classe ao vetor de características. A classe final será a que for escolhida pela maioria dos classificadores. Por ser simples e eficiente, é a combinação mais encontrada na literatura. Um exemplo é utilizando-se Learning Vector Quantization Neural Network (LVQNN) (PFURTSCHELLER; FLOTZINGER; KALCHER, 1993), MLP (QIN; LI; CICHOCKI, 2005) e SVM (LEE; CHOI, 2003);

- Stacking: Utiliza uma pilha de classificadores, onde a entrada do nível mais alto (ou Level-1 Classifier) é a resposta obtida no nível anterior (Level-O Classifier). Na abordagem de Rakotomamonjy et al. (2005) o primeiro nível utilizava classificadores HMM e o segundo nível utilizava SVM. 
Tabela 12 - Uma comparação dos algoritmos mais utilizados em BCI. Adaptado de (LOTTE et al., 2007)

\begin{tabular}{|c|c|c|c|c|c|c|c|c|c|c|}
\hline & Linear & $\begin{array}{l}\text { Não } \\
\text { Linear }\end{array}$ & $\begin{array}{l}\text { Gene- } \\
\text { rativa }\end{array}$ & $\begin{array}{c}\text { Discri } \\
\text { minante }\end{array}$ & Dinâmica & Estática & $\begin{array}{l}\text { Regu- } \\
\text { larizada }\end{array}$ & Estável & $\begin{array}{l}\text { Ins- } \\
\text { tável }\end{array}$ & $\begin{array}{c}\text { Robusta } \\
\text { à alta } \\
\text { Dimensão }\end{array}$ \\
\hline FLDA & $\mathrm{X}$ & & & $X$ & & $\mathrm{X}$ & & $\mathrm{X}$ & & \\
\hline RFLDA & $\mathrm{X}$ & & & $\mathrm{X}$ & & $\mathrm{X}$ & $\mathrm{X}$ & $\mathrm{X}$ & & \\
\hline $\begin{array}{c}\text { SVM } \\
\text { linear }\end{array}$ & $\mathrm{X}$ & & & $\mathrm{X}$ & & $\mathrm{X}$ & $X$ & $\mathrm{X}$ & & $\mathrm{X}$ \\
\hline $\begin{array}{l}\text { RBF } \\
\text { SVM }\end{array}$ & & $\mathrm{X}$ & & $\mathrm{X}$ & & $\mathrm{X}$ & $\mathrm{X}$ & $\mathrm{X}$ & & $\mathrm{X}$ \\
\hline MLP & & $\mathrm{X}$ & & $\mathrm{X}$ & & $\mathrm{X}$ & & & & \\
\hline $\begin{array}{l}\text { BLR } \\
\text { NN }\end{array}$ & & $\mathrm{X}$ & & $\mathrm{X}$ & & $\mathrm{X}$ & & & & \\
\hline ALN NN & & $X$ & & $\mathrm{X}$ & & $\mathrm{X}$ & & & & \\
\hline TDNN & & $\mathrm{X}$ & & $\mathrm{X}$ & $\mathrm{X}$ & & & & & \\
\hline FIRNN & & $X$ & & $X$ & $X$ & & & & & \\
\hline GDNN & & $\mathrm{X}$ & & $\mathrm{X}$ & $X$ & & & & & \\
\hline $\begin{array}{c}\mathrm{NN} \\
\text { Gaussiana }\end{array}$ & & $\mathrm{X}$ & & $\mathrm{X}$ & & $\mathrm{X}$ & & & $\mathrm{X}$ & \\
\hline LVQ NN & & $\mathrm{X}$ & & $X$ & & $\mathrm{X}$ & & & $\mathrm{X}$ & \\
\hline $\begin{array}{l}\text { Percep- } \\
\text { tron }\end{array}$ & $\mathrm{X}$ & & & $\mathrm{X}$ & & $\mathrm{X}$ & & $\mathrm{X}$ & & \\
\hline RBF-NN & & $\mathrm{X}$ & & $\mathrm{X}$ & & $\mathrm{X}$ & & & $\mathrm{X}$ & \\
\hline PeGNC & & $\mathrm{X}$ & & $\mathrm{X}$ & & $\mathrm{X}$ & $\mathrm{X}$ & & $\mathrm{X}$ & \\
\hline $\begin{array}{l}\text { fuzzy } \\
\text { artmap } \\
\text { NN }\end{array}$ & & $\mathrm{X}$ & & $\mathrm{X}$ & & & $\mathrm{X}$ & & $X$ & \\
\hline HMM & & $\mathrm{X}$ & $\mathrm{X}$ & & $\mathrm{X}$ & & & & $\mathrm{X}$ & \\
\hline IOHMM & & $\mathrm{X}$ & & $\mathrm{X}$ & $X$ & & & & $\mathrm{X}$ & \\
\hline $\begin{array}{c}\text { Bayes } \\
\text { Quadrático }\end{array}$ & & $\mathrm{X}$ & $\mathrm{X}$ & & & $\mathrm{X}$ & & & $X$ & \\
\hline $\begin{array}{c}\text { Rede } \\
\text { Gráfica } \\
\text { de Bayes } \\
\end{array}$ & & $\mathrm{X}$ & $\mathrm{X}$ & & & $\mathrm{X}$ & & & $\mathrm{X}$ & \\
\hline k-NN & & $X$ & & $\mathrm{X}$ & & $\mathrm{X}$ & & & $\mathrm{X}$ & \\
\hline $\begin{array}{c}\text { Distância } \\
\text { Mahalanobis }\end{array}$ & & $\mathrm{X}$ & & $\mathrm{X}$ & & $\mathrm{X}$ & & & $\mathrm{X}$ & \\
\hline
\end{tabular}

A combinação de classificadores diminuiu a variância e, consequentemente, o erro de classificação (BREIMAN et al., 1998; FRIEDMAN, 1997), sendo considerado o melhor modelo para o problema da não-estacionaridade. Uma classificação de alguns algoritmos, segundo sua taxonomia, é mostrado na Tabela 12, proveniente de uma revisão feita por Lotte et al. (2007). De acordo com as características do sistema, os algoritimos foram classificados de acordo com sua performance. Problemas de ruído, outliers e alta dimensionalidade foram melhor resolvidos pela SVM. Algoritmos dinâmicos devem ser utilizados no caso de experimentos síncronos e a LDA foi a que melhor rotulou corretamente classes em pequenos grupos de testes. 


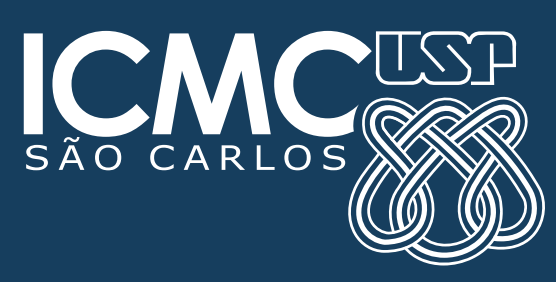

